\title{
Divinatory Conventions in Late Shang China
}

A Diachronic and Contextual Analysis of Oracle-Bone Qi 其 and Related Issues (1995)

\author{
David N. Keightley
}

\section{ABSTRACT}

To use the Shang oracle-bone inscriptions as historical documents for the writing of Shang history, it is essential that we understand the conventions that produced them. Such understanding involves, to a significant degree, an understanding of how the Shang word gi functioned.

Parts I-III of this study demonstrate, by focusing on the evolving usage of the Shi-, Li-, Chu-, and subsequent diviner groups, that $q i$ was deictic rather than modal. Part IV applies that understanding to the contextual analysis of a large number of positive-negative charge-pairs (and some prognostications) of the Bin-diviner group, in order both to defend the deictic interpretation of $q i$ and to explore the conventions that governed its use in this special environment.

These conventions were: (1) The Bin-group diviners generally placed the charge about whose outcome they were most immediately concerned (usually a matter of hope, but sometimes of fear) on the right side of the shell. (2) Whichever charge of a charge-pair contained the $q i$ was the retest that the diviner cracked second. (3) When one member of a charge-pair was abbreviated, it was the charge in the more complete form of the inscription unit that was divined first. (4) Favorable and non-contingent prognostications (together with verifications) were appended to, or incised on the same right or left side of the shell as, the desired charge. (5) When $q i$ was present in both charges of a charge-pair, no diviner's name was likely to be recorded in the preface. Baldly stated, these conventions may seem of minor importance, but. considered in context, they permit coherent and consistent translations of the inscriptions, either in pairs or in groups of pairs.

A number of prominent cases in which the Bin-group diviners consistently did not observe one or more of these conventions is explored. These cases reveal the degree to which the use of $q_{i}$, in particular, was contextdependent. The rules of Shang divination were not, in fact, inflexible. Some scenario-specific considerations, not perhaps recoverable by modern scholars, appear to have influenced the placement of inscriptions and the use of $q i$ on particular occasions. It is hoped, however, that the conventions, when either honored or breached, provide a clearer understanding than has yet been available of the divinatory procedures adopted by the various diviner groups.

The study ends with some reflections on the rationale that underlay these aspects of Shang divinatory practice. 


\section{CONTENTS}

INTRODUCTION

I. THE MEANING AND FUNCTION OF QI 其 . . . . . . . . . 5 Deictic $Q i \ldots \ldots \ldots \ldots$ Nominalizing, Anaphoric $Q i \ldots \ldots \ldots$ Qi as Optional (1): Not a Necessary Marker of Subordination . . 10 Qi as Optional (2): Not a Marker of the Future ........ 11 Simple and Complex Charges .............. 15 Complete or Incomplete Charges? . . . . . . . . . . 20

II. QI 其 AND THE GAO 告 RITUAL-REPORTS: A DIACHRONIC ANALYSIS . 22 Abbreviations ................ . . 22

Gao Ritual-Reports in Bin 賓-Group Charges . . . . . . . . 23

The Absence of Qi Markers . . . . . . . . . . 28

Qi Linked to the Complexity of the Charge ....... . 32

Qi in Shi 自-Group Charges about Gao Ritual-Reports . . . . 35

Deictic $Q i$ in Other Shi-Group Charges (1) . . . . . . . 36 Shi-, Bin-, and Li-Group Charges About Attack ....... 41 Deictic $Q i$ in Other Shi-Group Charges (2) . . . . . . 43 $Q i$ in Li-Group Charges (Periods I-II) About Gao Ritual-Reports . 46 Qi in Period II Charges About Gao Ritual-Reports . . . . . . . 51 Qi in Period III-IV Charges About Gao Ritual-Reports . . . . 53 Gao Ritual-Reports in Period V............ . 54 
III. QI IN THE LI 䇥-GROUP INSCRIPTIONS . . . . . . . . . . . . . 55

Li-group Charge-Pairs . . . . . . . . . . . . . . . 55

Qi in Simple (or Not So Simple?) Li-Group Charges . . . . . . .62

$Q i$ in Complex Li-Group Charges: (1) Initial Considerations . . .65

Qi: Etymological Speculations . . . . . . . . . . . 71

Qi in Complex Li-Group Charges: (2) Optional . . . . . . . . 73

$Q i$ in Complex Li-Group Charges: (3) Hunting Charges . . . . . .80

Exclamatory Charges and Ambiguities . . . . . . . . . . .85

Unpaired Hunting Inscriptions, Periods III-V . . . . . . . . . .88

IV. DIVINATORY CONVENTIONS IN BIN-GROUP CHARGE-PAIRS . . . . . . .91

$Q i$ in Bin-Group Charge-Pairs .. . . . . . . . . . . . 91

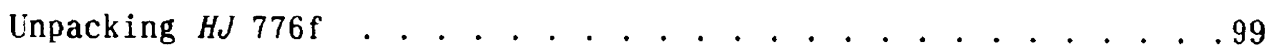

Qi Marked the Core . . . . . . . . . . . . . . . 105

CONVENTION NO. 1 (INITIAL FORMULATION): RIGHT AND LEFT

PLACEMENT . . . . . . . . . . . . . . . . . . . . 112

CONVENTIONS NO. 2: RIGHT-LEFT SEQUENCE AND RETESTS . . . . . . 115

Testing the Retest Hypothesis . . . . . . . . . . . 118

Qi in Both Charges ..................... 119

To what Did "This" Refer? . . . . . . . . . . . . . 120

This and That ...................... . 124

An Abundance of Qis . . . . . . . . . . . . . . . . 126

$Q i$ in a Series of Same-Topic Divinations . . . . . . . . 131

Qi as a Mark of Exasperation? . . . . . . . . . . . . . 133

$Q i$ in the Right-Side, or Primary, Charge . . . . . . . . 137

CONVENTION NO. 1 (REVISED): FINAL DESIRE AND IMMEDIATE CONCERN .142 Inconstancy of Right and Left Placement . . . . . . . . . . . . 147 
Summary to Date . . . . . . . . . . . . . . . . 151

CONVENTION NO. 3: SEQUENCE AND ABBREVIATION . . . . . . . . 152

CONVENTION NO. 4: PLACEMENT OF PROGNOSTICATIONS (AND

VERIFICATIONS) . . . . . . . . . . . . . . . . 153

Exceptions to, and Refinement of, Convention No. 4 . . . . 158

CONVENTION NO. 5: DIVINERLESS INSCRIPTIONS . . . . . . . . 163

QI AND THE DIVINATORY CONVENTIONS . . . . . . . . . . . 165

A Final Test. . . . . . . . . . . . . . . . . . . 165

Qi 其 Usage, Charge-Pairs, and Early Diviner-Groups . . . . . 170

The $Q i$ 其 - Wu 勿 Opposition . . . . . . . . . . . . 171

Qi in Prognostications (1): Simple . . . . . . . . . . . 175

Qi in Prognostications (2): Time-Specific . . . . . . . . 177

Qi in Prognostications (3): Multi-Part, Contingent . . . . . 180

$Q i$ 其 and $Y o u$ 出. . . . . . . . . . . . . . . . 182

Qi as Context-Dependent

V. CONCLUSIONS . . . . . . . . . . . . . . . . . . . . 187

The Bone Inscriptions: A Rationale . . . . . . . . . . 189

Postscript: The Origins of Modal $Q i$. . . . . . . . . . . 192

APPENDIX A: RETESTS ON SCAPULAS . . . . . . . . . . . . 193

APPENDIX B: QI AS A MARK OF QUOTATION IN LATER TEXTS . . . . . 199

SYMBOLS USED . . . . . . . . . . . . . . . . . . 208

TABLES . . . . . . . . . . . . . . . . . . . 210

FIGURES . . . . . . . . . . . . . . . . . . . 212

WORKS CITED ......................... 227

FINDING LIST OF INSCRIPTIONS CITED . . . . . . . . . . . . . 235 
It is the first responsibility of historians--though not their last--to assess their sources and to make their critical methods and conclusions about those sources available to other scholars.

\section{INTRODUCTION}

I invoke the above credo, with which I introduced an earlier study of Shang historiography, 1 to justify the present account of Shang divinatory conventions. Because the oracle-bone inscriptions provide such a narrow, although deep, view of certain aspects of Shang elite life, it is essential that we understand the nature of those sources--the forms that shaped the record and the biases that colored it--if we are to use them to write accurate history. The conventions of Late Shang divination are not an antiquarian topic.

It has become increasingly clear that we cannot fully understand those conventions unless we have some sense of how $q i$--a word that may have appeared in more Shang divination charges than any other--functioned; ${ }^{2}$ nor can we fully

1. Keightley 1978:xiii.

2. There is a wealth of previous scholarship on $q i$ that I cannot hope to address in detail here. See, e.g., in addition to the already cited works of Nivison and Takashima: Kwok-ching Chow 1982:158-70; Ikeda 1964, commentary to Houbian 2.9.13; Serruys 1974:25-36;1981:342-49; 1986:204-22; 
understand how $q i$ functioned unless we have some sense of how certain conventions worked. ${ }^{3}$ The argument in this extensive study advances, accordingly, on two interrelated fronts--that of $q i$ on the one hand and the conventions on the other. The study is so constructed that readers who wish to start with my analysis of the conventions (in Part IV), and then move back to my analysis of $g i$ (in Parts I, II, and III) may do so without, I hope, undue difficulty. I have done my best to ease the reader's way by providing a large number of cross-references and a finding list of the 174 oracle-bones whose inscriptions I have translated (on page 232). It is not entirely inappropriate that the study can be read rather like an oracle-bone itself-with one example (or charge) being judged in the context of, and with reference to, other examples, with one 'lucky (or unlucky) crack' and auspicious (or inauspicious) interpretation in one section being used to evaluate other arguments elsewhere.

Takashima, who has continued to refine his pioneering 1970 paper as at 1973 (in particular, "Appendix I: The Modal Particle U," pp. 267-305); 1984:68; 1990:39-40; 1991:680-81; Yu Xingwu 1979: Zhao Cheng 1988:295-961. Djamouri (1987:364-427) and Takashima (1994p:480-538) provide good resumés of the recent work. I would pay particular tribute to the writings, published and unpublished, of David Nivison, Paul L-M Serruys, and Ken-ichi Takashima. I have also benefited greatly from the thoughtful critiques of Derek Herforth, E.G. Pulleyblank, Edward G. Shaughnessy, and Paul L-M Serruys. None of these colleagues, of course, is responsible for my errors of understanding. I continue to look forward to their instruction.

3. I have discussed elsewhere numerous other divinatory conventions that, although historiographically significant, do not bear directly on the problem of $q i ;$ e.g., the use of subcharges and contracts (Keightley 1991: 8-28); the rule of coherence (Keightley 1991:43-49); the work schedules of, and the interaction between, the diviner groups (Keightley 1991:65-85); the validating role of display inscriptions (Keightley 1975:13-17; 1991:248); the diviners' commitment to the keeping of records that were historically accurate (Keightley 1994a); the general evolution of divinatory practice (Keightley 1991:315-27); the storage and disposal of the oracle-bones (Keightley 1974:71-81). 
Part I provides a brief account of my understanding of how qi--deictic rather than modal--worked in the inscriptions. On the assumption that it will be useful to see how the word operated in one divinatory context over time, Part II starts with the evolving role of $q i$ in charges about gao 告 ritualreports to the ancestors.

Part III assumes that it may be a mistake to base our initial understanding of $q i$ upon its behavior in the positive-negative charge-pairs of the Bin 而-diviner group of period I. By privileging, in particular, the attested oracle-bones excavated from pit YH 127--with their preference for plastrons rather than scapulas, and for balanced positive and negative charge-pairs ${ }^{4}-$ we perhaps have been (forgive the levity) 'barking up the wrong qi.' We may have succumbed to the archival fallacy, treating what I now believe to have been the exceptionally formalized and elaborate usages of the Bin-group diviners as basic, and neglecting to appreciate the less dramatic but more enduring usages represented by their contemporaries, the Shi f $^{-}$ (period I) and Li 歷-group (periods I and II) diviners and their successors. Part III, accordingly, turns to the way in which the Li-group diviners of periods I and II used $g i$ in a variety of charges. I select the Li-group inscriptions because it was their routine use of what I have earlier called "executive $q i^{n 5--a}$ seemingly "strengthening" rather than "weakening" modal--

4. See, in particular, the invaluable analyses of Paul L-M Serruys (1974, etc.) and Ken-ichi Takashima (1973, etc.) who have devoted assiduous attention to the Bingbian corpus excavated in YH 127.

5. See Keightley 1994; cf. Nivison (1994:5 ms): "There is no doubt that Shang gi sometimes expresses determined intent to act in the future." Takashima has referred to this usage as that of "assertive' $q i^{n}(1994 p: 483)$. For examples of inscriptions in which $I$ would have earlier assigned this strong modal function to the $q i$ in the head clause see, e.g., $[64],[65],[66]$, $[96],[100],[103],[106],[110]$, etc. below. 
presented a challenge to the modal view encouraged by the Bin-group charge pairs. That the Li-group diviners used charge-pairs far less frequently than the Bin-group suggests, however, that their use of $q i$ might not have involved the modal distinctions that some scholars have seen in the Bin-group's use of gi. I hope that readers who join me in observing the usage of the other diviner-groups will come to accept that conclusion too.

Part IV explores the conventions that the Shang diviners and engravers employed, with particular attention to the role of $q i$ and its function in the Bin-group charge-pairs; it explores, in particular, the way that deictic $g i$ functioned anaphorically in this specialized environment. The demonstration that the deictic interpretation of $q i$ works for all Shang cases provides us with a unitary explanation of the word. 


\section{THE MEANING AND FUNCTION OF $Q I$ 其}

Deictic $Q i$

Although I started as a strong supporter of "modal $q i, " 6$ the study that follows represents my move to the deictic camp. I had suggested three years ago, and I now believe more firmly, that $q i$ was "a mark of...specificity" that served as an "adverbial demonstrative" that delimited the action it qualified, providing, in charge-pairs, the sense of "in this case, at this time."7 Nivison (letter of 22 February 1992), I discover, had originally explored the possibility that $q i$ "picks out individual objects or situations" in a 1971 manuscript, "A New Analysis of Modal $\mathrm{Ch}^{\prime} \mathrm{i}$ 其, And a Suggestion for a New Theory of the Archaic Chinese Demonstrative and Indefinite Substitutes," 18 July 1971, but he did not distribute the paper. In his response to my 1992 paper, Nivison (1992:7) also proposed that $g i$ in the inscriptions "was thought of as a demonstrative." My thinking has been stimulated by Nivison's probings

6. E.g., Keightley 1978, 1988, 1993. Cf. Takashima 1994p:481: who notes that the modal $q i$ interpretation "has met with universal acceptance, though the precise modality the word was meant to express has remained in dispute."

7. Keightley 1992:19-21. See n. 198 below. I first outlined my "delimiting" argument in a letter of 3 May 1992, to William Boltz and Ken-ichi Takashima, versions of which went to William H. Baxter ( 3 May), Father J.A. Lefeuvre (13 June), Nivison (10 July) and E.G. Pulleyblank (13 July 1992) respectively. I am grateful to Pulleyblank for his response of $27 \mathrm{July}$ 1992 . 
and I am in sympathy with his more recent proposal that $q i$ meant "something like 'here-now." 8

As Herforth has argued in his recent study of conditionals, there is no reason for thinking that 0ld Chinese $g i$ was in any sense modal.9 Building upon his analysis--and that of Nivison and Takashima (see below)--I now propose that, in complex charges, oracle-bone $q i$ demoted "an independent clause to dependent status within a superordinate structuren ; that this demotion was a purely syntactic process; and that, the subordination we impute to such cases "derives from the semantic relation construed as holding between" the two clauses.10 Simply put, deictic $q i$, meaning "this," served to focus on a clause as "in this case" or "this verbing," and thus permitted the clause, so delimited or demoted, to be construed as an "as to this case."

Evidence that Shang $q i$ served as a deictic can be found, first of all, in the following set of Li-group inscriptions:

[1A] 今日不雨

"Today it will not rain." 11

[1C] 其雨

"In this case it will rain."

8. Letter of 26 April 1995.

9. Herforth $1994: 188, \mathrm{n} .82$; see too, 284, n.25.

10. Herforth 1994: 177, 179, 189, n.82, 197. Herforth writes: "Comrie (with Haiman) has remarked on the tendency for 'apodosis particles' to be anaphoric in origin and thus analyzable as resumptive proforms $(1986: 88) . "$ Oracle-bone $q i$, in my view, fits that general model. Cf. too Cikoski (1978:91; cf. 82): "a nucleus peripheralized by $g$ 'iug [ $g i$ 其] functions as topic to a sentence, in particular the special kind of topic I call a 'time-phrase,' which is typically translated into English as either an "if...then..." clause or a "When...then..." clause depending on context."

11. This charge was divined and inscribed twice; I do not reproduce [1B] here. 
[1D] 茲不雨

"In this case it will not rain." (I. Li?)12 (HJ 33909)

One cannot be certain that the shift to $z i$ 㰦 in [1D] did not introduce a new semantic shift to these charges, such as "Here, it will not rain"(?), but the probability is strong that the deictic $q i$ of [1C] and the $z i$ of [1D] were being used interchangeably on this bone, that they shared the same anaphoric function. The affinity between the two words is also suggested by comparing the two Bin-group charge pairs $[2 \mathrm{AB}]$ and $[3 \mathrm{AB}]$ :

[2A]辛西貞:䐨卜:乙丑其雨不隹我禍

Crack-making on xinyou (day 58), Que divined: "Yichou (day 2) its raining will not be ominous for us."

[2B] 真: 乙丑其雨住我禍 L」へ

Divined: "Yichou its raining will be ominous for us." (I. Bin) $(\text { HJ } 6943=\text { Bingbian 306.6-7 })^{13}$

[3A] 貞:茲雨不隹我祜

Divined: "This raining will not be ominous for us."

[3B] 甲申卜爭賁:茲雨佳我祜

Crack-making on jiashen (day 21), Zheng divined: "This raining will be ominous for us." (I. Bin) (HJ 12883 = Yibian 4742)

One senses that, just as the the 弦 of [1D] was equivalent to the 其 of [1C], the 茲 of $[3 \mathrm{AB}]$ was equivalent to the 其 of $[2 \mathrm{AB}]$. That 其 and 弦 belonged to

12. In this draft of my study I have not yet taken the time to refine my Ligroup datings; a "?" after the Li-group label indicates that the decision about whether the inscription is $\mathrm{Li} 1$ (period I) or $\mathrm{Li} 2$ (period II) remains to be made.

13. For the meaning of the symbols in the right margin, see p. 208. For a further discussion of the charges on this plastron, see [170A-D] below. 
the same Shijing rime group further supports the view that their meanings and functions would have been been close.

Nominalizing, Anaphoric $Q i$

Deictic $g i$ frequently functioned to nominalize the verb phrase in which it appeared, and, in many cases, provided anaphoric reference to a related divinatory topic. In reaching this understanding, I have benefitted from and am in substantial agreement with the arguments of both Nivison and Takashima. Nivison has concluded, in part, that $q i$ was
a verbal adjective amounting to "the" (which would indicate definite existence or occurrence). Before a noun it might amount to "the ... in question," and even "his ...," etc; and before a verb it would in its "adjective" phase convert the verb into a verbal noun, "the ...-ing." Before a verb-phrase or sentence it could thus create a noun phrase: "the fact that ...," or simply "that...."14

Takashima, responding in part to Nivison's views, has concluded that $q i$ "is used as a pronoun having anaphoric reference." He substantially agrees with Nivison that:

$q i$ has a nominalizing effect, entailing a quasi "that" clause which functions like "subject zhi [之] verb ye [也]" in classical Chinese. In fact, zhi in the OBI [oracle-bone inscriptions] is also pronominal, meaning "this, that," and its later development into a genitive marker parallels the case of $q i$. The only difference is that in this stage of the OBL [oracle-bone language], $q i$ is already genitive-pronominal.15

Referring back to Nivison, ${ }^{16}$ Takashima quotes examples in Shangshu and Shijing "where $g i$ occurs between two nouns, the first noun (often a topic) followed by

14. Nivison 1992:10-11; also quoted by Takashima 1994:13 ms.

15. Takashima $1994: 10,17 \mathrm{~ms}$.

16. Nivison 1992a:4. 
what should be analyzed not as a modal particle but as a genitivized anaphoric-pronoun $q i . "$ And he concludes that "if the above analysis of the genitive-pronominal $g i$ in the Shangshu and Shijing holds true, it is reasonable to assume that it also had a similar function" in earlier stages of the language. ${ }^{17}$ At the same time, Takashima (1994a:9 ms.) has maintained his view--denied by Nivison--that Shang $q i$ acted modally, proposing that $q i$ was highly flexible in its working and as a result not fully knowable: ${ }^{18}$

17. Takashima 1994:15-16 ms.; see too Takashima 1984-85:255-57). Nivison $(1991: 15)$, as Takashima notes (1994:16 ms.), had earlier drawn attention to the appearance of $q i$ in a Western Zhou bronze inscription (the Diao Sheng gui 渭生毁; Shirakawa 1962-，29:633) where it apparently served as zhi 之: 朕宗君其休, "my ancestral lord's grace." And Takashima approves, as do I, Nivison's parenthetical comment: "Compare 'John his book," for 'John's book,' in earlier English," and proceeds to list five more western Zhou bronze inscriptions in which $q i$ was used genitive-pronominally. Herforth (letter of 19 August 1993, p. 8) even suggests that $g i$ in a Western Zhou bronze formula like, 衛其子 $=$ 榇 $=$ 永保用 (found on the Qiu Wei gui 惑衛段; translation at Shaughnessy 1991:85-87)--which Takashima would evidently treat as modal--was not preverbal, and that, this phrase, where $q i$ occurred between nouns, must have meant something like "Wei his progeny." (For another instance of this pattern, see 大其子 =孫 =永保用 on the Da ding 大鼎; translation at Shaughnessy 1991:277-79.) See too note 41 below. The use of $q i$ as a genitive, acting like $z h i$, can also be found in Shu, "Kang gao": 朕其弟小子封, "My younger brother, the young child Feng" (Yang Shuda 1986:144).

18. E.g.. Takashima (1994:1): " $q i$ functions as a kind of adverbial particle, conveying a variety of modal as well as aspectual meanings."

the ultimate answer may be that we cannot assign any uniform meaning to $q i$, neither "perhaps, maybe, might" (Takashima 1970,1973 , etc.) nor "definitely, certainly" (Nivison $1992: 6) \ldots$ The feelings [these terms] express are subjective qualifications by the speaker. They admit of an element of doubt, shifting along a continuum between "possible" at one end and "certain" at the other, the exact position determined largely by context, if indeed it is determinable.

While I agree that we may never be able to determine why $g i$ was recorded in some charges and not in others (see "IV. Conclusions" on page 187 below), I do not, for reasons presented below, find this 'agnostic' account satisfactory. It may be that noted that Qiu Xigui (1982:175) also refers to $q i$ as a modal auxiliary. 
I now believe that in the simple charges of the Li 歷-group diviners (periods I-II), gi was a deictic, serving as a demonstrative marker (adverbial or adjectival) that focused the hearer's (or reader's) attention on the word or word phrase it governed. Such focus served to both call attention to and to delimit the word or clause to which it was applied, thus demoting it to dependent status, and, in so doing, frequently permitting the modern hearer (or reader) to construe that clause as a conditional, temporal, etc. ${ }^{19} Q i$ acted this way because it served as a marker of anaphoric reference, permitting the clause it governed to be construed as a nominalized phrase. Thus, 其告 in both simple and complex charges could, depending on context, mean, if $q i$ were acting as an adverbial demonstrative, "(We) will in this case make ritual-report" (as in [60B] and [62]); and, in complex charges, if $q i$ were acting as a nominalizing adjectival demonstrative that demoted the clause from independent to dependent status, 20 it could also mean, "as to this/his/its/the reporting" (as in [33], [60A] (tr. uncertain), [64] [65], [66], [67], etc. See, too, the discussion of simple and complex charges on pp. 15-20 below.).

Qi as Optional (1): Not a Necessary Marker of Subordination As will be stressed below (page 73), and as Kwok-ching Chow and Takashima, in particular, have pointed out, $q i$ was not a necessary marker of

19. Cf. Herforth $1994: 15, \mathrm{n} .16$, who in seeking to define the nature of conditionals, writes "we have described $P$ [the protasis of a conditional] as "restricting the assertion of " $Q$ " " [the apodosis of a conditional].... $P$ in fact functions as a restriction, broadly defined, on whatever illocutionary act is represented by Q--assertion, question, command, etc."

20. See too the discussion on $p .184$ below on how the meaning of the phrase 乙丑其雨 varied with context. In what follows I adopt much of my terminology, including the word "demoted," from Herforth 1994. 
the conditional or other subordinated forms. ${ }^{21}$ The diachronic analys is presented below indicates, however, that the diviners in later periods increasingly introduced $g i$ to formally mark clauses that, in the earlier periods, were of ten recorded without $q i$, and that, with or without $q i$, we must read as conditionals (or other forms of delimitation), on the basis of our understanding of semantic coherence and divinatory context.22 The use of $g i$, particularly in the early periods, was optional.

Qi as Optional (2): Not a Marker of the Future

Because oracular $q i$ only appears in sentences that refer to future events it evidently found future-directed environments congenial.23 It could certainly appear in charges that referred unequivocally to the future, as in the following Shi-Li group charge-pair:

[4A]乙未ト:其雨丁.不.四月

21. Kwok-ching Chow 1982:158-70; Takashima 1990:39-40; cf. 1991:680-81. (See too Nivison [1992:12-13] who characterizes the view of $q i$ as a conditional marker as "dead wrong.") Their arguments are entirely congruent with those of Herforth who consistently notes the optional nature of conditional markers in 0ld Chinese (e.g., 1994:11, 134, 197, 249, 255). Particularly striking is his observation that 77 percent of the conditional constructions in Mengzi "carry no marking whatsoever" on the protas is (p. 253).

22. Herforth makes a similar argument for the construal of conditionals and other subordinates in 0ld Chinese; he notes that early written Chinese "sentences we interpret as (formally marked) English conditionals are, in many cases, not marked as such" (1994:11; see too pp. 72, 141).

23. Djamouri (1987:373) concludes that $q i$ was an auxiliary that expressed futurity. Nivison (1992:10) noted that "The reference of $q i$ is always future in the oracles." He subsequently (1994:5-6 ms) cited one instance ( $H J$ 13399f) in which he found $q i$ in a verification, thus having past reference; I find it difficult to translate the entire verification with any certainty, however. For one case in which the $q i$ in a charge might have served to delimit a past event, see $n .97$ below. 
Crack-making on yiwei (day 32 ): "The raining (will be) on the ding-day (i.e., dingyou, day 34)."24 (Verification:) It did not (rain). Fourth moon.

[4B]乙未卜:翌丁不其雨.允不

Crack-making on yiwei: "On the next ding-day it will not in this case rain." (Verification:) It really did not (rain).

(I. Shi-Li) (TN 4513+4518)

I see no evidence, however, that $q i$ itself necessarily referred to the future or was needed to express the future. Thus, it was entirely possible to have a charge of future reference that contained no $q i$, as in:

[5]丙戌卜:丁亥王陷摧.允摇三百又四十八

Crack-making on bingxu (day 23): "On dinghai (day 24) the king will trap and catch (game)." (Verification:) (We) really did catch 348. (I. Li?) (HJ 33371)

In this case, the ganzhi day dates make it clear that the charge referred to a future event, on the next day, even though no $q i$ was present.25 $Q i$ in such contexts, as in the case of conditional constructions (page 10 above), was optional and its presence or absence had no evident bearing on the "futurity" of the charge.

Similar conclusions can be drawn from the appearance or absence of $g i$ in Bin-group prognostications:

[6A] 壬宙卜賓員:今十月雨 $R L^{2}$

Crack-making on renyin (day 39), Bin divined: "(In the) present tenth moon it will rain."
[6B] 貞:今十月不其雨

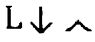

24. For why $I$ read $[4 \mathrm{~A}]$ as a quasi-隹 construction, *其雨隹丁, see p. 37 below.

25. For similar charges about hunts on coming days, without the $q i$, see, e.g., $T N 663,664$. See too $[81 \mathrm{AB}]$ below, about rain. 
Divined: "(In the) present tenth moon, it will not in this case rain." (HJ 809f = Bingbian 523.5-6)

[6C] 王固日:吉·其雨隹庚其隹辛雨引吉

The king read the cracks and said: "Auspicious. This raining will be on a geng-day (i.e., gengxu [day 47]); this being a $x$ in-day raining (i.e., xinhai [day 48]), will be extensively auspicious." (I. Bin) ( $H J$ 809b = Bingbian 524.4)

The $q i$ might be present, as in [6C].26 or the $q i$ might be absent, as in $[7 \mathrm{C}]:^{27}$

[7A] 戊戌卜䐨貞:自今于壬宙[雨] $R d{ }^{2}$

Crack-making on wuxu (day 35), Que divined: "From today down to renyin (day 39 ), [it will rain]."

[7B] 貞: 自今于壬[宙不其]雨 L Lへ

Divined: "From today down to ren(yin it will not in this case] rain." (I. Bin) (HJ 12311f = Bingbian 255.1-2)

[7C] 王固日:庚雨

The king read the cracks and said: "On the geng-day (i.e., gengzi [day 37]), it will rain." (I Bin) (HJ 12311b = Bingbian 256)

In some cases, one prognostication might contain a $q i$, as in $[8 \mathrm{~B}]$, while another prognostication, about the same topic and on the same plastron, might not, as in $[8 \mathrm{C}]$ :

[8A][癸]末ト爭貞:雨

Crack-making on [gui/wei (day 20), Zheng divined: "It will rain."

[8B] 王固日:雨隹其不延.甲午允雨

R J

26. For another complex prognostication about rainfall that included a $q i$, see [56B].

27. For another prognostication about the weather on the next day, with no use of $q i$, see [166A] below. 
The king read the cracks and said: "It will rain, only, 28 in this case, it will not be prolonged." (Verification:) On jiawu (day 31 ) it really did rain.

[8C]王固日:口于辛雨

The king read the cracks and said: "... on the $x$ in-day (i.e., xinmao [day 28]) it will rain." (I. Bin) (HJ $14161 \mathrm{~b}=$ Bingbian $255.3-5 \lcm{29}$

The prognostications necessarily referred to the future and needed no marker to signal this.30 It is not unexpected, in view of the discussion below (see page 32 ) that the $q i$ was absent in simple prognostications like [7C] and [8C], and was present in complex prognostications like [6C], [8B], and [56B]. It was present because of the complexity of the prognosticatory utterance, not because the text was about the future.

That $q i$ rarely if ever appeared in verifications (see note 23 above) was not, I believe, because verifications were about the past (so that the absence of $q i$ would further confirm that $q i$ served to mark the future), but because verifications were not complex. A prognostication might contain more than one verb, but the clauses were independent, providing only a sequential narrative

28. Derek Herforth (comments of 19 August 1993) has suggested that wei, placed before the $q i$, cannot be a copula here, but must mean "it is only that". Cf. Nivison's translation of the same prognostication (1994T:10): "It will rain. It's just that it will not be prolonged." If one assumes that the 其 of the prognostication, [8B], was a nominalizing anaphoric reference back to the 雨 of the charge, $[8 \mathrm{~A}]$, then one can read the prognostication as *雨隹其雨不延, *"It will rain, only the raining (divined about) will not be prolonged."

29. For further discussion of the inscriptions on this plastron, see [168A-D] below.

30. I no longer believe, as I had argued earlier (Keightley 1991:34-43, $193-96,456-57 ; 1992)$, that some prognostications, because they contained

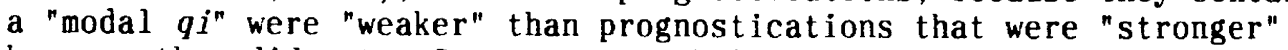
because they did not. See too p. 59 below. 
of events, as in [59]: 乙霛不雨, "On the $y i$-day it was foggy; it did not rain."

Simple and Complex Charges

Because the distinction between these two kinds of charges plays a significant role in my analysis of Shang $g i$, my understanding of which Shang charges were simple and which were complex merits some explanation. The basic distinction, of course, involves the number of main verbs in a particular charge. A one-verb charge was a simple charge, a two-or-more-verb charge was complex. Thus, [24] and [25B], with their one main verb, 告, were simple; and [25B], with its two main verbs, 稱 and 告, and [28], with its two main verbs, 令 and 告, were complex.

But some caution is necessary. On the face of it, a charge like [9] 丙申下:告于父丁牛一

Crack-making on bingshen (day 33): * "Make report to Father Ding, bovids, one." (II. Li 2) (HJ 32031)

would be read as a simple charge, for it has only one main verb, 告. But the difficulty comes with how to integrate the 4 - at the end of the charge into the rest of the charge to its left. Kwok-ching Chow translates the charge as "We should make an announcement to Father Ding (with) an ox," and as a result of extensive analysis of Shang and Zhou texts argues that the ox, the objectvictim, must be understood as linked to the ritual-sacrifice verb, 告, by a co-verb like $y i$ 以, thus *告于父丁以牛一. ${ }^{31}$ He presents $y i$ in such contexts

31. One can think of alternative interpretations, such as *告于父丁牛斗一, *"The bovid reported to Father Ding should be one," but these receive no support in the oracle-bone or classical corpus. 
as a co-verb "with a strong verbal sense" and is prepared to supply the Shang equivalent, yong 用, in such contexts, so that he would read

[10]貞: 䄇年于大甲十䒠祖乙十宰

Divined: *Pray for harvest to Da Jia, ten lao, (to) Ancestor Yi, ten lao." (I. Bin) (HJ 672f = Bingbian 147.24)

as *䄇年于大甲用十羍祖乙用十宰, and would evidently translate as "We should pray for a (good) harvest to Da Jia (by USING) ten lao, and to Zu Yi (by USING) ten lao," or "In praying for a (good) harvest to Da Jia, we should USE ten 1 ao."32

There is no doubt that Chow's analysis is correct. A whole series of Bin-, Li-, and He- diviner-group inscriptions reveal the role that yong might play in charges of this sort. For example: 33

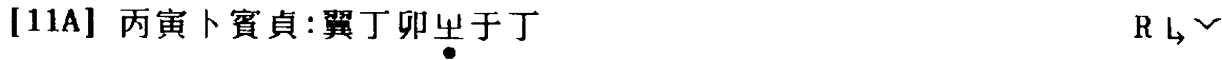
Crack-making on bingyin (day 3), Bin divined: "On the next day, dingmao (day 4), make of fering to (Father?) Ding."34

[11B] 貞:勿出于丁.五月 L」

Divined: "Do not make offering to Ding."

32. Kwok-ching Chow 1982:200-02 (see too Zhou Guozheng 1983, which I have not yet consulted). To achieve consistency with my own translations, I revise Chow's terminology and romanization in minor ways. In my translations below, for sake of analytical clarity, I also translate 用 literally, as "use," but with the understanding that it meant "use in sacrifice $\rightarrow$ sacrifice."

33. Chow (p. 204) also cites Yicun 449, 于兄丁製用牛, "When performing an exorcism to Brother Ding, we should use an ox," as another charge involving a ritual-sacrifice verb in which a yong 用 was present. Unfortunately, I cannot locate the inscription in Heji, the Yicun rubbing is illegible, and Shang Chengzuo 商承祚's commentary gives a slightly different reading: 于兄丁口集用牛. Nevertheless, the inscription provides further, if uncertain, support for the argument below.

34. On the identity of these Ding ancestors, see the discussion at Shaughnessy 1982-83:10, n.14. This plastron, though belonging to the Bin-group, was probably divined in period IIa, the reign of $\mathrm{Zu}$ Geng. 
[11C]丁未ト賓員:今日出于丁.六月

Crack-making on dingwei (day 44), Bin divined: "Today make offering to Ding." Sixth moon.

[11D]丁未ト䆵員:出于丁䒠用

Crack-making on dingwei, Bin divined: "In making of fering to Ding, a lao should be used." 35

[11E]丁巳ト賓冒：出于丁用二牛

R $\rightarrow$

Crack-making on dingsi (day 54), Bin divined: "In making offering to Ding, use two bovids."

[11F] 貞:勿出.六月

Divined: "Do not make offering." Sixth moon.

[11G] 丁巳卜賓貞：出于丁䒠出牛.六月Ｒ R

Crack-making on dingsi, Bin divined: "In making of fering to Ding, (use) a lao and a bovid."

[11H] 丁巳卜賓貞:崩于丁一牛.六月Ｒムへ

Crack-making on dingsi, Bin divined: "In making of fering to Ding, (use) a bovid." Sixth moon. (IIa. Bin) ( $H J 339=$ Jiabian

$2124.1-2,6-7,11-14)^{36}$

It is evident that the 用 attached to the object-victims at the right of [11D\&E] referred to their "use" in the 4 -offering proposed at the left. One can see, accordingly, that a 用 would have been understood in [11G\&H]

*出于丁用.... And there is a presumption, as Chow has argued, that whenever an object victim was recorded at the end of charges about type A ritualsacrifice verbs, but without an operational verb, a verb such as 用 must be supplied. For example:

35. I treat [11D] as a quasi-卋 construction: *出于丁宙宰用; for the full form see [14] below.

36. The Jiabian and Heji rubbings of this plastron are not clear at all points: I have followed the handcopy provided by Dong Zuobin 1931, fig. 1 , and $\mathrm{Qu}$ Wanli's commentary to Jiabian 2124 . 
[12]丁丑卜：出兄丁羊由昌用.五月

L L

Crack-making on dingchou (day 14): "In making of fering to Brother Ding (of) a sheep, it should be today that we (use it $=$ ) sacrifice it." Fifth moon. (I. Shi-Bin) ( $H J$ 20007)

Once again, it is evident that the 4 -offering was to be executed with the 用 method of sacrifice. A Shi-Li transitional charge leads to the same conclusion:

[13]辛卯卜:甲午禬禾上甲三牛用 Ra

Crack-making on xinmao (day 28): "On jiawu (day 31), in praying for grain (to) Shang Jia (P1), three bovids should be used."37 (I. Shi-Li) (HJ $33309=$ Jimbun 2982)

The three bovids used in the harvest prayer were to be dispatched with the 用; it is precisely charges like [13] that permit us to insert 用 into the analogous $[10]$ above. The same pattern may be observed in period III:

[14]其又大乙專五牢用

"In making offering to Da Yi (K1), it should be five lao that we use." (III. He) ( $H J$ 27090)

True to pattern, the 又-offering was performed by 用-ing the animal victims.

Not only does Chow present the yi 以 that he supplies as a co-verb that "still maintains a strong verbal sense" in classical Chinese, but he argues that "the relationship between the type A verbs [such as gao 告] and the ovs" being "rather loose, it takes another verb (i.e., USE) to conjoin them."38 Concurring in his analysis, I accordingly treat [9] 告于父丁牛一 as a complex

37. By analogy with [12] and [14] (and by analogy with my understanding of [11D]), I treat [13] as a quasi-來 construction: *...市三牛用, *n...it should be three bovids that are used."

38. Kwok-ching Chow $1982: 202,208$. 
charge, supplying the second main verb in what we might refer to as a "quasi用" construction, "In making ritual-report to Father Ding, (use) bovids, one." And, most importantly, I see no difference in meaning between that charge, recorded without a $q i$, and another $\mathrm{Li}$-group charge, recorded with a $q i,[64]$ 其告于口牛一, "In making ritual-report to the sun (or to Ding?), 39 (offer) bovids, one."

This "lack of difference" lies at the core of my belated rejection of the modal interpretation of $g i$. Thus, I see no difference in meaning or structure between [92A], with a $g i$, 壬子賁:其䄇禾于河燎三羍沈三图羍, "On renzi divined:) "In praying for grain to the River, make burn-sacrifice of three lao, ritually-drown three, and yi-sacrifice a lao," on the one hand, and [15], without a $q i$ :

[15]甲子卜爭貞: 裙年于唯燎六牛

Crack-making on jiazi (day 1), Zheng divined: "In praying for harvest to Kui, make burn-sacrifice of six bovids." (I. Bin) (HJ $10076=$ Jiabian 3512.2 )

The $g i$, as we have repeatedly seen, was optional; the Bin diviners of [15] were less likely to insert it than the Li diviners of [92A]. Chow, by contrast, translates these two charges differently. He treats the $q i$ of [92A] as a modal, and translates, "If we perhaps pray for harvest to the River...." And he translates [15] non-modally: "In praying for harvest..." I, by contrast, believe that both charges should be translated non-modally, and that the head clause was demoted in both cases, that the demotion is determined by syntax, and that the use of the $q i$ to mark that demotion was a conventional option more employed by some diviner-groups than others.

39. See n. 57 above. 
In conclusion, accordingly, I believe that there are a large number of "hidden" verbs or ritual-sacrifice, such as 用, 以, or even 4 , that we must understand as being present in many charges about the offering of victims in cult. The diviners (or engravers) frequently omitted such words in their records because they were so standard, representing conventions that were so commonly accepted, that their presence was unnecessary.

Complete or Incomplete Charges?

The question of whether a charge is simple or complex is further complicated by the question of how complete a record the engravers have left of us of the charges that were presumably uttered by the diviners. It is generally agreed that some charges were radically abbreviated, so that even what, to the modern reader, would seem the most significant and strategic elements of a charge could, on occasion, be omitted from the record (see, e.g., [136B] below). That proviso aside, however, modern scholars have generally accepted the unstated assumption that most Shang charges were complete sentences. W'ith the charges conceived as formal statements, wishes, prayers, addressed to the spirits (e.g., [83A] "We will receive millet harvest") this assumption is entirely plausible. That many charges, such as $[18 \mathrm{AB}],[31],[50 \mathrm{AB}],[83 \mathrm{AB}],[137]$, etc., can be translated as full sentences has encouraged us to treat the shorter charges in the same way, so that a solitary $y u$ 雨, for example (as in [141A]), is translated "It will rain."

The possibility exists, however, that in routine and simple charges of the sort represented by $[141 \mathrm{~A}-\mathrm{N}]$, the charges were merely incomplete or exclamatory, either called out in this abbreviated form as the diviner formed the cracks: "Raining!, "Not this raining!," "This raining!, "Not this 
raining!," and so on, or recorded in this abbreviated form, as the engraver adopted a form of Shang shorthand. The use and recording of such putative exclamations would accord well with the theory that, in some divinations at least, the diviner cried out particular "subcharges," one for each crack, the contents of the subcharges only being deducible from the wording of certain prognostications .40

Such an interpretation of certain charges would accord well with Herforth's suggestion, arrived at on the basis of non-Shang linguistic considerations, that "Clauses marked by morphemes whose original function was to subordinate or embed can break loose of their 'matrices' or main clauses to become strongly assertive exclamations, etc. because they carry with them the typical force of such dependent elements."11

These considerations bear significantly on the way that I interpret the role of $q i$ in a significant number of inscriptions below (see the crossreferences in note 40 above).

40. Keightley 1991:8-16. For a discussion of charges that lend themselves to this exclamatory interpretation, see e.g., nn. 82, 207, 247, 253, 256, $259,280,304,317$, below.

41. Herforth, letter of 19 August 1993, p. 11. He cites as an example, Lunyu 17.21: 宰我出.子日:予之不仁也, "Zaiwo went out. The Master said, 'How' unfeeling the fellow is!" "予之不仁也, Herforth suggests, "is clearly an independent clause construed as an exclamation." For the way in which Shang $g i$ 其 might function much like $z h i$ 之 in later texts, see the opinions of Nivison and Takashima on p. 8 above. 


\section{I. $Q T$ 其 AND THE GAO 告 RITUAL-REPORTS: A DIACHRONIC ANALYSIS}

Charges about gao ritual-reports made to the ancestors are to be found in the inscriptions of the first four periods, but mainly in periods I and II. In period I, whether paired or not, the charges were generally recorded without any use of $q i$. In the subsequent periods, the record-keepers inserted $q i$ more frequently but the use of the word remained entirely optional. ${ }^{42}$ Kwok-ching Chow has identified gao as what he calls a "type A verb." "Type A verbs represent major cult activities requiring the accompaniment of other cult activities represented by the type B verbs, which can be placed either in front or after the type A verbs."43

\section{Abbreviations}

In discussing the various grammatical formulas that the engravers of these ritual-reports recorded, I employ the following abbreviations. I base them upon the terms employed by Chow in his own extensive analysis of the various sentence structures found with gao and other type A verbs.44

42. I take as my basic sample the ritual-report inscriptions at Y247.1-55.1, with the proviso that most of the charges there dated to period IV should be assigned to the Li-group inscriptions of periods I-II (see, e.g., the summary of the arguments at Keightley 1990:56-59).

43. Kwok-ching Chow 1982: iii, 190-205.

44. Kwok-ching Chow 1982:190. 
$\mathrm{OB}$

OG

OV

OT

RS object-beneficiary: the recipient of the ritual-sacrifice activity, e.g., a deceased ancestor

the goal or cause of an RS activity, e.g., for a good harvest.

object-victim: the animals, the things being sacrificed

object-topic of the ritual report

ritual-sacrifice verb

Gao Ritual-Reports in Bin 賓-group Charges

In divining about ritual reports, the Bin-group diviners rarely used $q i$ to modify the gao in their simple charges, which, particularly on scapulas, they couched in the form of unpaired charges, as in [16A-E]:

[16A] 丙辰卜靔貞:出于唐

Crack-making on bingchen (day 53), Que divined: "Make offering to Tang."

[16B] 貞:于河告

Divined: "To the River Power make ritual-report."

[16C] 員:生于大甲

Divined: "Make offering to Da Jia."

[16D] 員:告古方于上甲

Divined: "Make ritual-report about the Gongfang to Shang Jia."

[16E] 貞:于唐告

Divined: "To Tang make ritual-report." (I. Bin) (YC 546f) 
They did employ charge-pairs, not of the form *告/不其告 (see page 30 below), but of the form 告/勿告, as in:45

[17A] 貟:告于唐

Divined: "Make ritual-report to Tang (K1)."

[17B] 勿告于唐

"Do not make ritual-report to Tang."

[17C] 告于大甲

"Make ritual-report (to) Da Jia (K3)

[17D] 勿告于大甲

"Do not make ritual-report to Da Jia." (I. Bin) (HJ 6250; Y248.2, partial)

[18A] 癸末卜靔貞:告于娰己䅖姚庚

$\operatorname{RA} \vee$

Crack-making on guiwei (day 20), Que divined: "Make ritual-report to Mother Ji and Mother Geng."

[18B]貞: 勿告于轧已暨㛨庚

L Цへ

Divined: "Do not make ritual-report to Mother Ji and Mother Geng." (I. Bin) $\left(H J 1248 \mathrm{f}[=\text { Bingbian 392.3-4]; Y247.2 })^{46}\right.$

Given the fragmentation of the shells and bones it is not always easy to tell if the positive ritual-report charges we have on some fragments were paired with the prohibitory negative charges found on others, though it seems likely that in many cases this was so. ${ }^{47}$ But, whether paired or not, the positive

45. See too [36AB] below and $H J 667 \mathrm{f}, 938 \mathrm{f}, 947 \mathrm{f}, 1167 \mathrm{f}, 1168 \mathrm{~b}, 1169,1582 \mathrm{f}$, $1727 \mathrm{f}, 1728,1860,2467,6583$, etc. at Y247.1-48.2. The pair was also occasionally of the form 告/弲告, as in $H J$ 938f (= Bingbian 305.3-4); Y247.1.

46. For other inscriptions on this plastron, see [152AB] below.

47. See, e.g., n. 49 below and the inscriptions on $H J 938 \mathrm{f}, 1582 \mathrm{f}$ and $1584 \mathrm{~B}$, 1726 and $1727 \mathrm{f}$, etc. It may be noted that of the 95 charges under the heading "告祖先" at Y247.1-48.2, the gao appears to have been governed by 
and negative charges that remain to us lack the $q i$, with the standard positive formulations being of the form 告 于 $O B$ as in [17A\&C] and [18A], and the negatives governed by 勿 as in $[17 \mathrm{~B} \& \mathrm{D}]$ and $[18 \mathrm{~B}] .48$

The order of the elements in the basic form, 告 于 $O B$, could be reversed, to give the formulation 于 $O B$ 告, as in:

[19]賁:于唐告

Divined: "To Tang (K1) make ritual-report." (I. Bin) (HJ6148) $\square$

It is a nice question whether the reversal in phrase order had semantic value. On the assumption that the core of a charge was placed to the right, it would be tempting to argue that in the case of [17A] the concern was whether or not the ritual-report should be made to Tang, whereas in [19] the concern was whether or not it should be a ritual-report (as opposed to some other ritual) that was made to Tang. But I find it more probable that in such cases the diviner, or engraver, was simply 'saying the same thing a different way.' That both patterns, 告于 $O B([20 A])$ and 于 $O B$ 告 $([20 B \& C])$, might appear on the same plastron, encourages this more relaxed view of the matter:

[20A] 勿告于中丁

"Do not make ritual-report to Zhong Ding (K9)."

[20B] 勿于大戊告

"Do not, to Da Wu (K7), make ritual-report."

[20C] 勿于大甲告

L L へ(?)

a negative in some 24 cases. This suggests that about half (i.e., 48 cases) of the period I charges about ritual-reports would have been divined as members of charge-pairs.

48. See too $H J 183,667 \mathrm{f}, 1584 \mathrm{~B}, 1586,1722,1726$, etc. 
"Do not, to Da Jia (K3), make ritual-report."49 (I. Bin) (HJ $13646 f)$

The structure of the charges could be rendered more complex by the inclusion of an object-topic, the content of the report. In such cases, the formula might be 告 OT 于 OB, as in the next two charges:50

[21] 口未ト爭貞:告王目于祖丁

Crack-making on /ding?]wei (day 44?), Zheng divined: "Make ritual-report about the king's (sick) eyes to Ancestor Ding (K15)." (I. Bin) (HJ 13626)

[22] 癸已ト爭貞:告土方于上甲

Crack-making on guisi (day 30), Zheng divined: "Make ritual-report (about) the Tufang to Shang Jia (P1)." (I. Bin) (HJ 6385f; Y250.2)

Or, as in $[19]$, the recipient might be placed before the gao verb, to give the formula 于 $O B$ 告 OT, as in the next two charges:51

[23]貞:于黃尹告吕方

Divined: "To Huang Yin make ritual-report (about) the Gongfang." (I. Bin) ( $H J 6146)$

[24]壬申卜殸賁:于唐告吕方

Crack-making on renshen (day 9), Que divined: "To Tang make ritual-report (about) the Gongfang." (1. Bin) (HJ 6301)

49. I tentatively assume that these charges were divined in the ascending order of the ancestors, starting with the most junior, Zhong Ding (in [20A]) and ending with the most senior, Da Jia (in [20C]). I also believe that the three charges, all of which appear on the left half of a plastron, would have been balanced by positive charges on the missing right half; see n. 47 above.

50. See too $H J 1956,6384$.

51. For another instance of this formula, see $H J 6144$ (scapula). 
Once again, it is hard to determine if the reversal of phrase order altered the meaning of the charge.52 That, however, both patterns, 告 OT 于 $O B([25 A])$ and $O T$ 告 于 $O B([25 B])$, could appear on the same bone suggests that, in this case at least, diviners or engravers were not wedded to one pattern to the exclusion of the other and that the choice of wording may have been a matter of whim as much as a matter of divinatory strategy:53

[25A] 貞:告古方于上甲

Divined: "Make ritual-report (about) the Gongfang to Shang Jia (P1)."

[25B] 貞: 沚首武栲冊告于大甲

Divined: "As to Zhi Guo calling out the orders, make ritual-report to Da Jia (K3)." (I. Bin) (HJ 6134)

The object-beneficiary could likewise be placed before the verb when the charge was couched in the negative, to give the sequence 勿于 $O B$ 告 $O T$ :

[26]員:勿于父乙告疾身

Divined: "Do not to Father Yi (K20) make ritual-report (about) the sick stomach." (I. Bin) ( $H J$ 13670)

The Bin-diviners might also prepose the topic to the front of the charge to give the formula $O T$ 告 于 $O B$, as in:

[27A] 貞: 小疾勿告于祖乙

Divined: "As to the minor sickness, do not make ritual-report to Ancestor Yi (K12)."

[27B] 告于祖乙

52. Kwok-ching Chow (1982:199-200) demonstrates, in his discussion of charges containing gao, significant syntactic differences in the way objectvictims appear with one type of word order, and object-goals appear with another, but he does not address the question of what we might call varying divinatory intent. 53. For Li-group inscriptions that raise the same problem, compare [60A\&B]
with $[60 \mathrm{C}]$. 
"Make ritual-report to Ancestor Yi." (I. Bin) ( $H J 6120 \mathrm{f}$ )

[28] 貞:令军伐東土告于祖乙于丁.八月

Divined: "As to ordering Qin to attack the Eastern Lands, make ritual report (of this) to Ancestor $\mathrm{Yi}$ (K12) and to (Ancestor?) Ding (K15?)." Eighth moon. (I. Bin) (HJ 7084)

The lack of $q i$ as deictic marker in these Bin-group charges about ritual-reports, together with the considerable variability of word order, suggests to me that the Bin-group diviners were dealing with standard semantic units, involving object-topics, object-beneficiaries, and the like, whose meaning and function in the ritual-report charges was sufficiently conventional that markers were not needed and word order, within reason, was not significant.54

The Absence of Qi Markers

Despite the complex nature of the charge of [28], it should be noted that--by contrast, say, with numerous Li-group charges (e.g., [60AB] to [64], [66], [67], etc.)--the diviners (or engravers) of this Bin-group charge provided no overt marker, such as a nominalizing $q i$, to break the charge into its constituent clauses or to specify their hierarchical relationship. Similarly, the Bin-group diviners did not provide the following short, although complex, charge, $[29 \mathrm{~A}]$, with a $q i$ :

[29A] 貞:出于祖乙告

Divined: "In making offering to Ancestor Yi (K12), make ritualreport."

[29B] 員: 䄇戌于祖乙

54. I return to this point on 81 below. 

Divined: "Pray (about) Yue to Ancestor Yi." (I. Bin) ( $H J$
6610f)

The second charge, [29B], was simple and required no marker, but it would have been entirely possible--as contemporary and later diviners were to do--to insert a gi marker into [29A], thus *出于祖乙其告 or *其出于祖乙告. 55

For a more striking example of a complex, Bin-group charge furnished with no markers, consider:

[30]己酉卜賓貞: 坐來告方显于寻裸刖告于口

Crack-making on jiyou (day 46), Bin divined: "(Someone) having come to report that the Fang are invading at Xun,56 in making the libation and cutting-sacrifice (we) will make ritual report to the sun (?)."57 (I. Bin) (HJ 6672)

55. See, for example, Bin-group: [31]; Chu 出-group: [75], [76]; He-group: [80]; Li-group: $[64],[65],[67],[68]$, etc.

56. Many scholars read the oracle-bone graphs 足 and 品 in military contexts as 征. Others, however, distinguish between (1) 趿 (one foot beneath the phonetic) as 征 and (2) 品 (two feet beneath the phonetic) as some other word, such as we $i$ 圍, "surround, besiege." See KJS 3288, 3289. I distinguish the two words in English by translating 趿 (which I transcribe as 征) as "attack" and 品 (which I transcribe with the oracle-bone form, 罚) as "invade." For one important distinction in their use, see p. 41
below.

57. For the reading of oracle-bone $D$ (normally read as $x i$ 夕 or yue 月) as yue 刖, see Kwok-ching Chow 1982:322. Most scholars read oracle-bone as ding 丁, so that they. would translate [30] (and [63], [64], and [75]) in terms of a report to a Ding ancestor. On the face of it, it seems unlikely that the Shang would have performed a ritual report to a Ding ancestor on a ji-day (as in [30] and [63]) or a gui-day (as in [64] and [75]), rather than on a ding-day. A variety of considerations have led me to conclude that oracle-bone $\square$ should be read as an abbreviated form of oracle-bone $\boxminus$, and thus as modern $r i$ 日, "sun"; see Keightley (in preparation). Given the present study's interest in ritual reports, I cannot help calling attention to the Shi-group inscription, HJ 20240 (Y253.2): 丙子貝: 啨乎告日. I am uncertain as to the correct transcription of some of these characters and thus uncertain about the charge's precise meaning. There is no doubt however that the last two words 告日, "make ritual-report (to) the sun," are carved on the plastron. One possible translation, following Nivison 1977 in reading the $\frac{h}{g}$ graph as a loan for 克, would be "Divined on bingzi (day 13): 'On the ding-day (i.e., dingchou [day 14]), (we) can cal] out to make ritual-report (to) 
The absence of $q i$ in the Bin-diviner group charges about the gao ritualreport can be correlated with several features. First, because gao was a verb of controllable action, i.e., a verb whose execution was determined by the Shang king and his staff rather than by the religious Powers, it was governed, as we have seen, with the negative wu 勿 rather than bu 不.58 And wu was rarely, if ever, followed by $q i .59$ Because the Bin-group diviners (or, indeed, any other diviner-group) did not employ the verb phrase *不告, we do not find the verb phrase *不其告.

Second, most of the Bin-group charges were simple rather than complex. They were usually of the form, 'Make ritual-report about OT (object-topic) to OB (object-beneficiary). Unlike the Li-group diviners (see, e.g., [68], [69], [70], etc., below) they rarely linked the ritual-report to the of fering of cult or to any other outcome or result. The complex structure of [30], OT RS 告于 $\mathrm{OB}$, with no $g i$, was rare. As was the form represented by $[31]$, 其告于 OB RS: 60

the sun." Whether in [30] and similar charges we read $\square$ as $\theta$ or $丁$, in any event, does not bear on the presence or absence of $q i$ in the inscriptions discussed in this study.

58. See, e.g., Takashima 1990:21: "When the *p-type negatives (不 and 弗) are used, the subject is always non-human whose power is beyond the control of the living." See Keightley 1978:70, n.63, for a summary of the previous scholarship of Serruys and Takashima; see too n. ??? below.

59. Because I believe (p. 34 below) that 勿 functioned as a marker, like 其, that indicated a demoted clause--as in [34] and [36A]--the combination 勿其 would have been redundant. Wu might, in a negative charge-pai $r$, be contrasted with $q i$ in the positive member of the charge-pair, but such cases were relatively rare (see, page 171 below and the discussion of [157AB] and related texts) and none involved charges about ritual-reports.

60. The only other examples of Bin-group inscriptions that link the making or ritual-reports to the offering of cult are $H J 116 \mathrm{~A}(\mathrm{Y} 247.2)$ and, probably, $H J 1800$ (Y247.2); neither charge employed $q i$. $H J$ 19923, again without $g i$, links a sacrifice to the making of a ritual report, but it should be dated to the Shi 色-diviner group, not the Bin. 
[31] 貞:其出告于母丙紫

Divined: "When offering a ritual-report to Mother Bing, perform an exorcism."61 (1. Bin) (HJ 2525b; Y248.1)

Equally rare in the Bin-group charges was the form 其 RS 告 于 OB OV:

[32]癸丑卜史員:其过? 鼓告于唐 $\square$ 牛

Crack-making on guichou (day 50), Shi divined: "In offering(?) the drum ritual and making ritual-report to Tang (K1), (offer) ... cow."62 (I. Bin) ( $H J$ 1291)

And equally rare, again, was the form 其告 OT 于 $0 \mathrm{~B} \ldots$.

[33]丙辰卜賓貞:其告蝗于上甲不隹 $\square$ 隹

Crack-making on bingchen (day 53), Bin divined: "In reporting the locusts (?) to Shang Jia it will not be ... be ..."63 (I. Bin) ( $H J$ 9628)

Bin-group charges about ritual-reports, in short, rarely placed $q i$ in the head position (see page 49 below); [31], [32], and [33] were exceptional.

Similarly, because they were simple, few if any of the Bin-group charges about ritual-reports were linked to the assistance or hostility of the Powers.

61. It is possible that the charge of [31] should be translated as a conditional, "If (we) offer a ritual report to Mother Bing. (we) will perform an exorcism." On the assumption, however, that the core of the charge--the issue that the diviner wished to resolve or approve--was placed to the right, I believe that in this case, the emphasis was on whether or not the exorcism should be performed, not on whether or not the ritual-report should be made; hence I prefer not to translate the subordinated clause, 其坐告, as a conditional.

62. Because the $q i$ appears at the head of the charge, I treat the two clauses that follow it as both within its domain and as coordinate. I am unhappy with the translation of niu 牛 as "bovid." I have experimented with "cow(s), cattle, ox(en)," but the uncertainty of the osteological evidence precludes such specific designations (see Keightley 1978:6-7, nn.17-20).

63. Yany scholars read the oracle-bone graph that I have transcribed as huang 蝗 as qiu 秋 (KJS 1578); here I follow the reading of Akatsuka 1977:501; Chow Kwok-ching 1982:200, in his translation of Cuibian $88 \quad(=H J 28206$ (Y695.2), evidently concurs. 
None of the charges ended with object-goal clauses like*受(生)又, * (we) will receive assistance (in this case)" or *亡害, * "there will be no harm." They were rarely of the form *'If we make ritual-report about or to $0 B$, we will receive assistance (in this case), or, *'If we make ritual-report... there will be no harm).'64

Qi Linked to the Complexity of the Charge

That most of the Bin-group ritual-report charges were simple, and that few of them, except for complex charges like [31], [32], and [33], contained a $q i$, permits the hypothesis that the presence of $q i$ was linked to, though not of course required by, the complexity of the charge.65

A group of uncharacteristically complex charges from period I, with $q i$ in the body of the charge, supports this hypothesis:

[34]乙酉卜靔貞:古方還?王其[征]勿告于祖乙

Crack-making on yiyou (day 22), Que divined: "(As to the Gongfang's returning, [about] the king's in this case [attacking] do not make ritual-report to Ancestor $Y i=$ ) The Gongfang having

64. Chow Kwok-ching $(1982: 200,331, \mathrm{n} .7)$ found only one charge of the form 告 于 $O B$ OG; this was Nanbe $i$ "Ming" 79, treated below as [35A\&B]. For another rare, Bin-group exception, see $H J$ 3957: 貞:王告沚酋若, "Divined: "If the king makes ritual-report (about) Zhi Guo, there will be approval." For a period-III example, see [80] below.

65. For other complex Bin-group charges with $q i$, see $[50 \mathrm{~B}],[127 \mathrm{~A}],[147 \mathrm{~A}]$, $[157 \mathrm{~A}],[159 \mathrm{~A}],[170 \mathrm{CD}],[172]$, and [174]. Takashima (1994a:501-02) has resisted such a linkage. He argues that "(a) Since there are many complex sentences in which no $g i$ is observed, $q i$ should not be construed as introducing subordinate clauses. (b) Since there are many simple sentences in which $q i$ is observed, it should not be taken as a subordinate marker." The evidence, in my view, does not require the conclusions that he reaches; it certainly permits the view that $q i$ could have served as an optional marker of subordination, particularly in view of the frequency with which such markers were omitted in 0ld Chinese (see $n$. 21 above). 
returned, do not make ritual-report to [Ancestor] Yi (K12) (about) the king's [attacking]."66 (I. Bin) (HJ 6345; Y248.1)67 (about)

[35A] 乙靔貞:古方摆? 率伐不王其征告于祖乙旬又

[Crack-making on yiyou (day 22), ] Que divined: "(As to the Gong fang returning [to] Shuai, $\mathrm{Fa}$, and $\mathrm{Bu}$, the king's attacking being reported to Ancestor $Y i$, there will be no assistance $=$ ) The Gongfang having returned (to) Shuai, $\mathrm{Fa}$, and $\mathrm{Bu}, 68$ if (we) make ritual-report to Ancestor $\mathrm{Yi}_{\mathrm{i}}$ (K12) about the king's attacking, there will be no assistance."

[35B] Ø靔負:吕方退?率伐不王告于祖乙其征匂又.七月

[Crack-making on yiyou,] Que divined: "(As to the Gongfang returning.... etc. $\Rightarrow$ ) The Gongfang having returned (to) Shuai, Fa, and $\mathrm{Bu}$, if the king reports to Ancestor Yi his attacking, there will be no assistance." (I. Bin) (HJ 6347 [ = Nanbei "Ming" 79]; Y248.1)

The record-keepers, as the hypothesis linking complexity to the use of $q i$ predicts, inserted $q i$ in all three complex charges. It is as if the greater complexity of the charges encouraged them to be more explicit about recording their structure. The engravers appear to have inserted the $q i$ as a caesura (see note 143 above) to indicate the pause required in reading the charge. Thus, using Herforth's terminology to analyze [35A], the charge may be divided into prebase 2 (西方退? 率伐不), prebase 1 (王其征告于祖乙)--which may itself be divided into its own prebase (王其征) and base (告于祖乙)--and base

66. I supply the graphs in square brackets on the basis of [35A\&B] below.

67. Similar charges were evidently divined on the scapula $H J 6344[=$ Xubian $3.4 .2]$ and 6346.

68. My translation of 率伐不 as places names is tentative. For the opinion that each word, taken separately, could serve as a place name, see entries at KJS 1567 (for 率), 1007 (for 伐, but the form of the graph differed from that used in [35]), and 1383 (for 不, and adding Zhang Bingquan's commentary to Bingbian 1, pp. 13-14). Kwok-ching Chow (1982:331), by contrast, offered (for Nanbei "Ming" 79): "The Hu (?) statelet came back and subsequently attacked Bu...." 
(包又).69 The deictic $q i$ in the clause, 王其征, served as an anaphoric reference back to the returning Gongfang, conveying the sense "(in this case $=)$," while serving to nominalize the clause itself. Given the complexity of the charges, [35A\&B], one might well expect that more than one $q i$ might have been added to mark its various components. And this was precisely the strategy that the Li-group and later diviners adopted, as in [77], [80], [69] and $[70]$ below.

The following charge-pair also supports the hypothesis that there was a positive correlation between the use of $q i$ and the complexity of the charge:

[36A] 貞: 古方還勿告于祖乙

Divined: "As to the Gonfang's returning, do not make ritual-report to Ancestor Yi (K12)."

[36B] 員: 告吕方于祖乙

Divined: "Report the Gongfang('s returning) to Ancestor Yi." (I. Bin) (HJ 6349)

Itself a clause marker, ${ }^{70}$ the prohibitive 勿 in [36A] removed the need for 其 as a clause marker. In [36B], by contrast, one can see that the diviner could--by comparison with Li-group $([60 \mathrm{~B}],[62],[68]$, etc.) and Chu-group ([75]，[76]，[77]) charges--have recorded*百方還其告于祖乙, *"As to the Gongfang's returning (we) will in this case make-ritual report to Ancestor $\mathrm{Yi}^{n}$; he avoided doing so, however, by transposing the topic, so that whereas [36A] was of the form OT 告于 OB, [36B] was of the form 告 OT 于 OB. The

69. For this terminology, see Herforth 1994:97, 120-21: "Prebase constituents are first and foremost identified by the caesurae attested in reading practice between each of them.... The second general diagnostic of the $P B$ [prebase position] involves anaphora."

70. For the way wu might demote the initial clause in a complex charge, see p. 174 below. 
transposal, together with the omission of the verb 退, converted the complex charge of [36A] into the simple charge of [36B] by avoiding the embedded clause, 而方退. And thus the need to add 其 as a marker was eliminated.

Qi in Shi 自-Group Charges about Gao Ritual-Reports

The situation in the Shi-group charges (period I) about ritual-reports was similar to that in the roughly contemporary Bin- and Li-groups. ${ }^{71}$ That is, $q i$ was generally not recorded, even in complex charges where its presence would have served to mark the charge's structure. ${ }^{72}$ Two examples, the first simple, the second complex, will suffice:

[37]乙丑卜:王于唐告

Crack-making on yichou (day 2): "The king, to Tang (K1), will make ritual-report." (I. Shi) (HJ 19824)

[38] 口卯卜:王告父辛大甲盟酶三十口

Crack-making on ...mao: "When the king makes ritual-report to Father Xin (K19) and Da Jia (K3), (he) will sacrifice-in-blood covenant and cut up thirty [victims]." (I. Shi) (HJ 19923)

The simple charge, [37], was close in form those of Bin-group charges like [19] and [20B\&C]. I would suggest that a $g i$ could have been inserted in [38] so that it read *王其告父辛大甲盟酰三十口 with no change in meaning ( $\mathrm{cf}$. the Li-group charges $[60 \mathrm{~A} \& \mathrm{~B}])$.

71. Shi-diviner group charges may be found at $H J$ 19724-21525. See Keightley and Lefeuvre 1991:499-509.

72. I know of only one complex Shi-group charge about ritual-reports that may have employed qi: 壬子卜 : 又其歸婦亡. 大吉 (HJ 22067= Bingbian 610.2). Unfortunately, I cannot translate it. 
Deictic $Q i$ in Other Shi 自-Group Charges (1)

So few Shi-group charges involved 告 ritual-reports that, to understand how this diviner-group employed $q i$, it will be of value to consider a few more Shi-group charges about other topics. ${ }^{73}$ As with the charges of the Bindiviner group, most of the Shi-group complex charges were not marked with $q i$. For example:

[39]辛亥員:雀執亘受又

On xinhai (day 48) divined: "As to Que's manacling Xuan, he will receive assistance." (I. Shi) (HJ 20384)

[40A]甲申ト:㵖婦鼠㛨己二牝牡.十二月

Crack-making on jiashen (day 21): "In making exorcism (for) Lady Shu (to) Mother Ji, (use) two bovids and a bull." Twelfth moon.

[40B]一牛一羊製婦鼠㛨已

"(Use) one bovid and one sheep in making exorcism (for) Lady Shu (to) Mother Ji."

[40C]一牛整婦鼠姚己

"(Use) one bovid in making exorcism (for) Lady Shu (to) Mother Ji." (I. Shi) ( $H J$ 19987)

I can provide no exact parallels to [39], largely because this is the only instance I have found of a charge about "manacling" that ended with the words "receive assistance." One can imagine, however, in terms of the argument so far, that a fuller form of the charge could have been *往其執亘受又. [40A] could have been inscribed as * 其集妇鼠妮已二牝牡 with no change in meaning (compare, for example, [31], [32], [73], etc.). The three charges [40AB\&C] are also instructive for the flexibility with which the elements in the

73. For other Shi-group charges about ritual reports, none of which contained a $q i$, see $H J 20240$ (referred to in $\mathrm{n} .57$ above), 20534, 20576f, 20577, 21641 . 
charges were ordered. [40A] was of the form: RS OB OV; [40B\&C] were of the form: OV RS OB. Once again, I have no sense that any significant distinction in meaning or emphasis was intended by the changed order. Rather. I sense that the Shi-diviners were free to cobble the elements of their charges together in a number of ways. A particularly notable example of their casual approach is provided by:

[41]庚宙卜王貞:用豕母庚今日

Crack-making on gengyin (day 27), the king divined: "Use a pig (to) Mother Geng today." (I. Shi) (HJ 20706b)

A more standard, "refined" ordering would have been*今日于母庚用家 or

*今日用家于母庚. One can find similar casualness in two loosely related Shigroup charges that both used a $q i$ :

[42A]乙巳卜:今日方其至.不

Crack-making on yisi (day 42): "Today the Fang will in this case arrive." (Verification: They did not (arrive).

[42B] 丙午卜：方其品今日

Crack-making on bingwu (day 43): "The Fang will in this case invade today." (I. Shi) (HJ 20410)

It is conceivable that these two charges could be read as "quasi-也" (or "quasi-隹") constructions, 74 thus: [42A]*今日方其至也, *"Today will be the Fang's arriving" (or, *隹今日方其至, *"It will be today, the Fang's arriving") and [42B]*方其星今日也 (or *方其品隹今日), *nThe Fang's invading will be today." When a time phrase like jinri 今日 appears at the end of a charge, in fact, I am prepared to treat it as a clause, "will be today" that requires a noun phrase before it. Thus [41] can be understood as *(其)用豕母庚今日也,

74. Cf. the comments of Takashima about the nominalizing effect of $g i$ on page 8 above; see too [48AB] and, for the use of we $i$ 隹, [4A] and [49C]. 
*"The using of a pig (to) Mother Geng will be today."75 Support for this reading can be found in the Chu-group divination in which jinri clearly served as the predicate for a dependent nominalized phrase qualified by $q i:{ }^{76}$

[43]丙子卜大貝:其菻四子東今日.四月 L? L

Crack-making on bingzi (day 13), Da divined: "The burnt-offering (to) the four sons should be today." 77 (II. Chu) (HJ 23541)

It may also be noted that we only find the phrases 方其至 (as in [42A]) and 方不至 (as in [44]) in charges about the arrival of the Fang:

[44]辛酉卜王貞:方不至.今八月 R?

Crack-making on xinyou (day 58), the king divined: "The Fang will not arrive." In the present eighth moon. (I. Shi) (HJ 20480)

The Shang never recorded *方其不至. "The Fang's not arriving," presumably because such a counterfactual in a complex charge--unlike the simple apotropaic forecast 方不至, "The Fang will not arrive" of [44]--was not an appropriate topic for divination.

When the Shi-group diviners used loosely-structured positive-negative charge-pairs to divine about enemy attacks they could, on occasion, insert a referential $g i$ into both charges, as in:

[45A] 辛西卜:七月大方不其來畧 R L

Crack-making on xinyou (day 58): "In the seventh moon, the Greater Fang will not in this case come to invade."

[45B] 丙子卜：小方不其品

R

75. Cf. [12], which ends "…击今日用; see too [48AB] and [49C].

76. For similar constructions see [49A] and [55A] below.

77. On the four sons, see Kaizuka and Itô's commentary to Jimbun 1269 and 1270 . 
Crack-making on bingzi (day 13): "The Lesser Fang will not in this case invade." (I. Shi) $H J$ 20475)

The Shi-group diviners would also insert a referential $q i$ in both charges in their imperfect charge-pairs about rain, ${ }^{78}$ as in [46A\&B] and [47C\&E]:

[46A] 癸西卜:自今至丁丑其雨. 不 L? \& 2

Crack-making on guiyou (day 10): "From today down to dingchou (day 14) it will in this case rain." (Verification:) It did not (rain).

[46B] 自今至丁井不其雨.允不

"From today down to dingchou it will not in this case rain." (Verification:) It really did not (rain). (I. Shi) (HJ 21052)

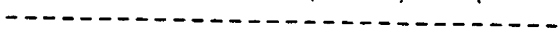

[47A] 戊寅卜:于癸舞雨.不

Crack-making on wuyin (day 15): "If (we) dance on the gui-day (i.e., guiwei [day 20]), it will rain."

[47B]乙未ト:于丁出舞

Crack-making on yiwei (day 32): "On the ding-day (i.e., dingyou [day 34]), (we) will go out and dance."

[47C]乙未卜:翌丁不其雨.允不

La

Crack-making on yiwei: "On the next ding-day it will not in this case rain." (Verification:) It really did not (rain).

[47D]乙末ト:丙舞

Rd

Crack-making on yiwei: "On the bing-day (i.e., bingshen [day 33]) (we) will dance."

[47E]乙未卜:其雨.不.四月

R L

Crack-making on yiwei: "It will in this case rain."

(Verification:) It did not (rain). (I. Shi) (HJ 20398)

It may be noted that the engraver did not insert a clause-marker $q i$ in the complex charge $[47 \mathrm{~A}]$, though, in light of later practice, he might have been

78. For the definition of "imperfect" charge-pairs, see page 209 below. 
expected to do so: *于癸舞其雨. I assume that the 其雨's in [47C\&E] referred back to the 雨 in $[47 \mathrm{~A}]$, so that [47C] meant 'On the next ding-day there will not be the "rain" that we have been divining about earlier" and [47E] meant "There will be the "rain" that we have been divining about earlier."79 It is also possible that [47D\&E] were differently abbreviated versions of charge analogous in form to $[47 \mathrm{~A}]$, so that the diviner understood both [47D] and [47E] to be *于丙舞其雨: * "If (or when) (we) dance on the bing-day, it will in this case rain."

One finds the similar "free use" of $q i$ on both sides of an imperfect charge-pair in:

[48A]壬申[ト小自真:方其品今日[夕]

[Crack-making] on renshen (day 9), Shi divined: "The Fang's invading will be today [or tonight]."

[48B] 癸酉卜追具:方其品今日夕 $\mathrm{L} \downarrow$ Crack-making on guiyou (day 10), Shi divined: "The Fang's invading will be today or tonight."80 (I. Shi) (HJ 20408= Zhuixin 498)

The use of the nominalizing $q i$ in Shi-group charges about the Fang was, indeed, common: 81

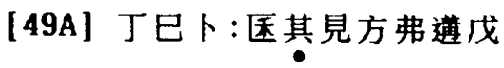
R? ل Crack-making on dingsi (day 54): "He's encountering the Fang will not (meet with $=$ ) be on the wu-day (i.e., wuwu [day 55])."

[49B] 丁民ト:翌其品 R? L

79. For a fuller discussion of how referential $q i$ functioned in charge-pairs, see the discussion of conventions 1-4 starting on page 112 below.

80. For this translation of [48AB], using the quasi-隹 or quasi-也 construction, see p. 37 above.

81. See too, e.g., $H J 20414,20419,20420$, etc, at MZ448.1-2. 
Crack-making on dingsi: "On the next day (i.e., wuwu) (the Fang) will in this case invade." 82

[49C] 庚申卜：方其睡今日.不品 R? L

Crack-making on gengshen (day 57): "The Fang's invading will be today." (Verification:) (They) did not invade. (I. Shi) (HJ $20413=$ Zhuihe 385$)^{83}$

Shi-, Bin-, and Li-Group Charges About Attack

It is of interest that while the Shi-group diviners divined about the Fang invading, and usually did so (as in [49A-C]) by delimiting the possibility in a demoted clause, 方其品, the same diviners never divined about the Shang attacking (征) the Fang.84 And when the Bin-group diviners did so, the possibility was only placed in a dependent clause when it formed the topic of some other action, as in [34] and [35A\&B] above. When the Shang attacking was the main topic of concern, the topic of the independent clause, we never find *其征方. The form was always 征方, as in:85

[50A] [己]酉卜真:王征吕方下上若受我又一月Ｒ」レ

Crack-making on (jilyou (day 46), divined: "(As to the king's attacking $=)$ If the king attacks the Gonfgang, the Lower and Upper Spirits will approve and will confer assistance on us." First moon.

82. The possibility that this charge was recorded as an incomplete sentence-whose full form would have been something like*翌日隹其品, *"The next day will be their invading, " or *隹翌日其品, * "It will be the next day, their invading" (cf. the discussion of [55AB] below)--or as an exclamation (see p. 16 above) - $*$ 翌日其品. "The next day, their invading!"--cannot be
excluded.

83. I tentatively places these inscriptions on the right side of the plastron on the basis of the pattern nos. 78,81 , and 85 presented at Yan Yiping
$1978: 1073,1076,1080$.

84. See the inscription sample at Y311.1 and Y304.1

85. For comparable examples of Bin-group charges about attacks on various Fang groups, see, e.g., $H J 6314,6315,6316,6317,6320$, etc. at MZ156.2. 
[50B] 員:勿征吕方下上弗若不我其受又

L Lへ

Divined: "Do not attack the Gongfang, (for) the Lower and Upper Spirits will not approve and will not confer assistance upon us in this case."86 (I. Bin) (HJ 6322)

The $g i$ in the apodosis of $[50 \mathrm{~B}]$ referred back to the attack on the Gong fang that had been divined, in positive terms, in $[50 \mathrm{~A}] .87$ when the charges were simple, and when the kind of assistance was already specified in the charge, the referential $q i$ was, we would expect, omitted:

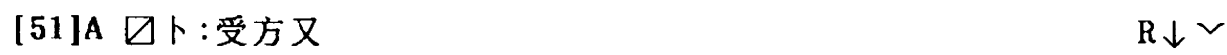

Crack-making on ...: "(We) will receive (Fang assistance =) assistance against the Fang."

[51B] Øト:弗受方 [又]

Crack-making on ...: "(We) will not receive [assistance] against the Fang." (1. Shi) (HJ 20616)

Other Bin-group charges sought divinatory validation of the subject of the Shang attack, as in:

[52]乙卯卜殸貞:王由土方征

Crack-making on yimao (day 52), Que divined: "It should be the Tufang that the king attacks." (I. Bin) (HJ 6442)

And when such charges were paired, no $g i$ was recorded to demote the attack to the status of a dependent clause:

[53A] 丙辰卜富貞:王來周方征

Crack-making on bingchen (day 53), Bin divined: "It should be the Zhoufang whom the king attacks."

[53B] 員:王勿佳周方征 <二告〉 L」

86. See the discussion, on page 172 below, of how the wu 勿 of $\{50 \mathrm{~B}\}$ functioned.

87. For a fuller discussion of how referential gi functioned in charge-pairs, see the discussion of conventions 1-4 starting on page 112 below. 
Divined: "It should not be the Zhoufang whom the king attacks." (I. Bin) ( $H J 6657 \mathrm{f})$

Li-group charges about Shang attacks on enemy Fang were similarly direct. They too made no use of $q i$, precisely because, as in the comparable cases above, they did not demote their clauses in a way that would have required $q i$ 's presence:

[54A] 庚戌:重疾令住

On gengxu (day 47) (divined): "It should be Ji whom (the king) orders to penetrate (the enemy)."

[54B] 庚戊:禹王自征刀方

On gengxu (divined): "It should be the king himself who attacks the Daofang."

[54C]王勿征令

"The king should not attack (or) order (Ji to penetrate)."

[54D] 辛亥貞:王征刀方

On xinhai (day 48) divined: "The king will attack the Daofang." (I? Li?) (HJ 33035)

Deictic $Q i$ in Other Shi-Group Charges (2)

Other Shi-group inscriptions also support the view that $q i$ acted as a deictic. As a demonstrative adverb it might focus on a verb or verb phrase by nominalizing it, as in [55AB]:

[55A] 庚[辰]卜夕:隹辛已其雨. [允]小雨 R? LV

Crack-making on geng[chen] (day 17), Shao (divined): "It will be on xinsi (day 18), this raining." (Verification:) There [really] was a small rain.

[55B] 庚辰卜夕:今夕其雨. 允小雨 $R ? \bigsqcup$ ム

Crack-making on gengchen, Shao (divined): "(It will be) this evening, this rain." (Verification:) There really was a small rain. (I. Shi) ( $H J$ 20912) 
In translating as I do, I assume that we may supply in [55B] the 集 that had been used in [55A], thus: *隹今夕其雨. That the 隹辛巳其雨 of [55A] should be read as "It will be on xinsi, this raining," is supported by the prognostications, $[6 \mathrm{C}]$ and $[56 \mathrm{~B}]$, on the following two Bin-group plastrons (the first group of inscriptions repeated from page 12):

[6A] 壬宙卜賓員:今十月雨 $\operatorname{R} L^{2}$ Crack-making on renyin (day 39), Bin divined: "(In the) present tenth moon it will rain."

[6B] 貝:今十月不其雨 $L \downarrow \wedge$

Divined: "(In the) present tenth moon, it will not in this case rain." $(H J 809 \mathrm{f}=$ Bingbian 523.5-6)

[6C]王固日:吉.其雨隹庚其隹辛雨引吉

The king read the cracks and said: "Auspicious. This raining will be on a geng-day (i.e., gengxu [day 47]); this being a $x$ in-day raining (i.e., xinhai [day 48]), will be extensively auspicious." (I. Bin) ( $H J 809 \mathrm{~b}=$ Bingbian 524.4)

[56A]己卯卜殸具:不其雨

$\operatorname{Rd} \approx$

Crack-making on jimao (day 16), Que divined: "It will not in this case rain."

[56B] 己卯卜靔員:雨.王固:其雨隹壬.壬午允雨 L

Crack-making on jimao, Que divined: "It will rain." The king read the cracks: "This raining will be on the ren-day." (Verification:) On renwu (day 19) it really did rain." (1. Bin) $($ HJ $902 \mathrm{f}=$ Bingbian 235.1-2)

In the case of $[6 \mathrm{C}]$ (and [56B]), the deictic reading of $q i$, as given above, is much preferable to the modal (and not entirely coherent) reading of, * It may rain and it will be a geng-day." I would also note that, in accordance with convention no. 4 (page 153 below), [56a] may be understood as a retest of 
[56B], with the deictic $q i$ of [56A] referring back to the rain divined about in $[56 \mathrm{~B}] .88$

As a demonstrative adjective, $q i$ as used by the Shi-group diviners might, on one occasion, have specified and delimited a noun, as in [57]:

[57]丙午卜：其生月雨.癸丑允雨

Crack-making on bingwu (day 43): "In this moon aborning it will rain."89 (Verification:) On guichou (day 50) it really did rain." (I. Shi) (HJ 20470)

But the translation is uncertain. The charge could equally be construed as "(As to this borning of the moon $\Rightarrow$ ) When this moon is born, it will rain."9o

88. For retests, see conventions nos. 2 and 3 , and the discussion on p. 115 below.

89. The oracle-bone character that I read as 其 is written in a slightly irregular manner. Shima Kunio (S489.1 for Ye 2.37.5) and the Y editors both read it as $q i$. The $J G W B$ editors, moreover, read a similar graph on Jing $j$ in 3000 as $g i(0577)$.

90. David Nivison (1994T:9) has also of fered the following translation as evidence that oracular $q i$ could qualify a noun ( $I$ revise the wording of his original translation in ways that have no bearing on his argument): $Y C$ 1846: 庚宙卜王:余燎于其配, "Crack-making on gengyin (day 27), the king (divined): 'I [should] make a burnt offering to my/his/their [deceased] consort(s)'" (I. Shi) (Yingcang 1864; Y1041.2). The charge might accept such a construction, but there is no certainty that Nivison has translated it correctly. First, most scholars think that the graph read as pei 配 refers to some kind of cult; nobody has proposed that it be read as "consort" (see KJS 1711). Second, the liao burnt-offering was rarely offered to lower-ranking human spirits. (See Mizuno Hiroshi 1960:69. Chen Mengjia 1956 is said to list eight kinds of recipients [but I don't yet have the reference].) A quick scan of the inscriptions at $Y 555 \mathrm{ff}$. suggests that Iiao was offered to high ancestors (and one high ancestress?), but it was usually offered to Nature Powers like the River, the Mountain, the Eastern Mother, and the cardinal directions. An offering to "the consort(?), " though not out of the question, would have been unusual. Third, that 余配 appears in $H J 5007$, 辛西卜王貞: $\square$ 余配, suggests that in this charge the pei served as a verb in the phrase; thus, "I will perform the pei-ritual." For YC 1864 this would suggest a translation of something like "I will perform a burnt offering at the performing of the pei-ritual." Some version of Nivison's translation may be correct. But the case is so rare, and its meaning so uncertain, that 
That, in the Shi-group, as in the Bin-group (see page 25 above) inscriptions, $q i$ often carried little or no semantic weight is strongly suggested by a comparison of the following two charges:

[58]壬午ト: 自今日至甲申日其雨.一月

Crack-making on renwu (day 19): "From today down to the jiashen day (day 21) it will in this case rain." First moon. (I. Shi) $H J$ 20924)

[59]辛丑卜追:自今至于乙巳日雨.乙籍不雨

Crack-making on xinchou (day 38), Shi (divined): "From today down to the yisi day (day 42 ), it will rain." (Verification:) On the yi-day it was foggy; it did not rain." (I. Shi) (HJ 20923)

The presence of $q i$ in [58] and its absence in [59] appears to have lent no special force to either charge. I suspect, once again, that [58] may have been a retest, divined second, 91 so that the "in this case" referred to the rain in the missing primary charge that, similar in form to [59], would have been divined without the $q i$. It may also be remarked--to anticipate the argument below (convention No. 5 on page 163)--that, as in [45AB], [46AB], $[47 \mathrm{CE}],[48 \mathrm{AB}]$, and $[49 \mathrm{ABC}]$, above, the $q i$ was present in the charge whose preface recorded no diviner's name.

$Q i$ in Li-Group Charges (Periods I-II) About Gao Ritual-Reports

Continuing the investigation of how the various diviner groups treated the ritual-report charges, we find that the practice of the Li-diviners resembled, but with some important distinctions, that of the other early

it does not, unfortunately for my argument here, carry the conclusive force that Nivison assigns it.

91. For "retests," see conventions nos. 2 and 3 , and the discussion on $p .115$ below. 
diviner groups, Bin and Shi, considered above. In simple charges, paired or unpaired, as we have seen (page 23), the Bin-group diviners generally employed no $q i$ at all, as in $[16 \mathrm{BD} \& \mathrm{E}]-[27 \mathrm{AB}]$; in the case of complex charges about ritual-reports, they sometimes did not use $g i$ (as in [29A] and [30]) and sometimes did (as in $[31]-[35 \mathrm{AB}]$ ).

The Li-group diviners also formulated their simple charges without $g i$ (as in $[60 \mathrm{C}]$ and $[61])$ :

[60A]己未員:王其告其比亞候

On jiwe $i$ (day 56) divined: "The king's making ritual-report (will be) about joining with Ya Hou."92

[60B] 庚申員:王其告于大示

On gengshen (day 57) divined: "The king's making ritual-report (will be) to the Great Ancestors."93 (OR, as exclamatory: "The king's making ritual-report to the Great Ancestors!"g4

[60C] 庚申員:王于父丁告

On gengshen divined: "The king will make ritual-report to Father Ding." (I. Li?) ( $H J$ 32807)

[61] 乙貞:來[乙]亥告自上甲

On ... divined: "The making of the ritual-report on the coming lyi-Jhai (day 12) (will be to the ancestors) from Shang Jia (on down). (I. Li?) ( $H J 32338)$

92. I treat [60A\&B] (and [61] and [62]) as quasi-隹 constructions: *(王)(其)告焦....; but see too the discussion on p. 85 below. I do not know the identity of Ya Hou in $[60 \mathrm{~A}]$.

93. Although here proposing to treat [60B] as a quasi-隹 construction, *王其告焦于大示, I must admit that I can find no charges in which the combination 住于 (or 重于) appeared.

94. For the possibility that some charges were exclamatory, see the discussion on pp. 16 and 62 . 
But the Li-diviners might also use a nominalizing $g i$ in the head position of simple charges like $[60 \mathrm{~B}]$ and $[62]$ :

[62] 丁尸具:其告自上甲

Divined on dingsi (day 54): "The ritual-reporting (will be to the ancestors) from Shang Jia (on down)." (I. Li?) (HJ 32336) $\triangle$

I have found no Bin-group charges about ritual-reports that employed $q i$ in this way.

In complex charges, the Li-group diviners might, rarely, employ no $q i$, as in [63] and [105] (cf. the Bin-group cases, [28], [29AB], and [30]):

[63]己巳卜:告于ロ一牛

Crack making on jisi (day 6): "In making ritual-report to the sun, (offer) one bovid." (I. Li?) (HJ 32650)

Complex Li-group charges with one $q i$, generally in the head position, include [64] to [68]:

[64] 癸酉卜:其告于口牛-..

Crack-making on guiyou (day 10): "In making ritual-report to the sun, (offer) bovids, one." (I. Li?) (HJ 32649)

[65] 癸酉:其告于父乙一牛

On guiyou (day 10): "In making ritual-report to Father Yi, (offer) one bovid." (I or II. Li 1 or 2) (HJ 32724)

[66] 庚宙卜:其告亞隺往于ロ今庚

Crack-making on gengyin (day 27): "Making ritual-report of Ya Qin's going to (Father?) Ding will be on the present geng-day." 95

95. The meaning of the charge is uncertain (see the Shiwen for TN 9). Ding might have been a place name, in which case the report, made to unnamed ancestors, would have been 'Ya Qin is going to Ding.' On the other hand, if Ding were the name of an ancestor llike the Father Ding who received a 
(I. Li?) (TN 580)

[67]辛巳卜:其告水入于上甲祝大乙牛

Crack-making on xinsi (day 18): "In ritually-reporting the entry of the floods to Shang Jia, in this case make invocation to $\mathrm{Da} Y \mathrm{Y}$ (with) a bovid."96 (I. Li?) ( $H J$ 33347)

[68]辛巳買：日音其告于父丁

Divined on xinsi (day 18): "As to the day offering of food, the ritual-reportng will be to Father Ding." (I. Li?) (HJ 33710)

The custom that placed $q i$ at the head of complex ritual-report charges, as in [64] to [67], was far more commonly used by the Li-group diviners than by the Bin-group (for whose relatively rare cases see [31], [32], and [33]).

The Li-group diviners (or engravers) also inserted two qis in some of their more complex charges, as in [60A], [69], and [70]:

ritual-report in [105]), then the report might have been 'Ya Qin is going.' And if wang 往 were the name of a ritual, then the report would have been 'Ya Qin is performing the wang- ritual,' with the problem still unresolved for the modern reader of whether the Ding was the recipient of the wang-ritual (on a geng-day? see below) or of the gao-report. The charge of [66], in any event, can, in accordance with the discussion of the charges ending in jinri on page 37 above, be construed as a "quasi-隹" construction: *其告亞草往于丁隹今庚 or *其告亞率往于丁車今庚. For the possibility that oracle-bone $\square$ should be read not as $\mathrm{J}$ but as $\theta$, so that the charge would have meant "Making ritual-report of Ya Qin's going to the sun will be on the present geng-day, " see n. 57 above; such a reading would, as noted, at least avoid the awkwardness of a geng-day ritual to a Ding-day ancestor.

96. I construe [67], by adding a second $q i$ to mark what I take to be the second dependent clause, as *其告水入于上甲其祝大乙牛. For similar patterns see [70] and [???]. If we were to treat that complex charge as a quasi-焦 construction, *其告水入于上甲隹其祝大乙牛, we could translate, *"The reporting of the entry of the floods to Shang Jia will be (the making of the invocation $=)$ at the time of making the invocation to Da Yi with a bovid." 
[69]丁未貞:王其令望乘瞵其告于祖乙一牛父丁一[牛]

On dingwei (day 44) divined: "As to the king's ordering Wang Cheng to return,97 in making ritual-report (of this) to Ancestor Yi (use) one bovid, to Father Ding (use) one [bovid]."98 (I. Li?) ( $H J$ 32896)

[70] 丁卯貞:其告于父丁其狩一牛

Divined on dingmao (day 4): "When making ritual-report to Father Ding (as to $=$ ) about the hunting, (offer) one bovid." 99 (I. Li?) ( HJ 32680)

I have found no Bin-group charges about ritual-reports that employed two gi's in this way.

I draw at least three conclusions from the evidence presented so far. First, that patterns of $q i$ usage were generally similar in all the early

97. I see no way to assess the precise nature of the "demotion" of the head clause of [69]. I exclude "If the king orders Wang Cheng..." on the grounds that since the main assertion concerned the offering of victims, the ordering of Wang Cheng was no longer at issue. I suspect, in fact, that the ordering had already taken place and that the king was now determining how best to report to his ancestors what he had done: "The king, having ordered Wang Cheng to return,..." In this instance, gi would have been linked to a past event.

98. Serruys (1974:51) translated the charge of [69] $(=$ Cuibian $506=$ Hebian 334) as follow's (I convert Wade-Giles to pinyin): "The "The king, if he commands Wang Cheng to return, and when making an announcement to $\mathrm{Zu} \mathrm{Yi}$ (about it), there be one ox, and to Fu Ding also there be one ox (offered in sacrifice)"; Takashima (1994a:497) offered: "The king shall order Wang Cheng to return (and that he) shall make the announcement ritual to $\mathrm{Zu} \mathrm{Yi}$ (with the offering of) one ox...."

99. Serruys (1974:51) translated the charge of [70] as "One might on the other hand $(g i)$ make an announcement to Father Ding, that when going on a hunt there be one ox (offered in sacrifice)"; Takashima (1994a:496), thinking--mistakenly, in my view; the Li-group diviners rarely if ever used charge-pairs in divining ritual reports (and many other topics; see p. 55 below)--that [70] was a member of a charge-pair, and assigning a different value to the graph I have transcribed as 狩, tentatively of fered "... [The king] shall make the announcement ritual to Fu Ding (that he) keep (>set aside for sacrificial use?) one ox." 
diviner groups from periods I to III. Second, that the insertion of $q i$ was frequently optional. Third, that the Li-group diviners employed $q i$ with rather greater frequency than the Bin-group had done, routinely placing the word at the head of their complex charges of controllable action, to indicate that, "in this case," they were delimiting and nominalizing the phrase in question.

$Q i$ in Period II Charges About Gao Ritual-Reports

We find that, as Shang divinatory practices evolved, some period-II complex charges were still recorded without $q i$, as in:

[71] 甲子卜即賁: 告于丁酰亡害

Crack-making on jiazi (day 1), Ji divined: "If (or when) making ritual-report to (an ancestor named) Ding, 100 (we) perform the you-cutting sacrifice, there will be no harm." (II. Chu) (HJ 23065; Y248.2)

Such unmarked complex charges, however--which could have been recorded as *其告于...101--were increasingly rare.

Divinatory conventions had, in fact, evolved considerably by period II. In terms of the concerns of this study, the Chu-group diviners made far less use of charge-pairs than their Bin-group predecessors had done, and they made greater use of complex charges about ritual-reports. A few were unmarked, as in:

[72]已酉卜即貞:告于母辛南辰(?).十月

100. On the identity of this ancestor, see n. 34 above.

101. See, e.g., the Li-group charges $[60 \mathrm{AB}],[62],[64],[65], \mid 66], \mid 67]$, $\{70\}$. 
Crack-making on jiyou (day 46), Ji divined: "In making ritualreport to Mother Xin, it should be the chen-ritual (that we offer)."102 (II. Chu) (HJ 23419 [= Qianbian 5.48.1]; Y248.2) $\square$ ?

Qi, however, was used more consistently as a clause marker than it had been in earlier periods. Thus, one period II pattern in the complex charges that linked ritual-reports to cult was 其 OT 告于 OB (OV):

[73]辛亥卜出員:其鼓告于唐九牛.一月

Crack-making on $x$ inha $i$ (day 48), Chu divined: "(As to the drumming- and yong-ritual ritual-reporting.... =) In making ritual-report to Tang (K1) about the drumming- and yong-rituals, (use) nine bovids." First moon. (II. Chu) (HJ 22749; Y248.2) o

[74]辛酉卜出貞:其困?新坶?陟告于祖乙

Crack-making on xịnyou (day 58), Chu divined: "If/When (we) stop at (?) Xinyu and of fer the ascending-ritual, make ritual-report to Ancestor Yi (K12)." (II. Chu) (HJ 22912; Y248.2) Q?

The object-topic might also precede the $q i$ rather than follow it, to give the pattern: OT 其 告 $\mathrm{OB}$ OV:

[75]癸酉卜即員:上甲升歲其告口一牛

Crack-making on guiyou (day 10), Ji divined: "At Shang Jia's presentation of the cut-up (victims), in making ritual-report to the sun, (use) one bovid."103 (II. Chu) (HJ 22676; Y248.2) D

In a still more complex pattern, the $g i$ still preceded the gao verb, OT 于 $\mathrm{OB}_{1}$ 其告 于 $\mathrm{OB}_{2} \mathrm{OV}$, as in:

102. There is little agreement on the word or meaning for what I have provisionally translated as "the chen-ritual"; see KJS 0328. Akatsuka (1977:55), in addition, offers the reading of nou 耘.

103. Similar charge patterns were employed by the Li-group diviners; see [64] and $[63]$. 
[76] 口否于唐其告于ロ一牛

"... as to offering the Xie-ritual to Tang (K1), in reporting to the sun,104 (use) one bovid." (II. Chu) (HJ 22755; Y248.2) @

And on occasion, the period-II diviners would employ two $q i$ markers in particularly complex charges, such as:

[77]己巳】貞:䴖不既妰其亦奏自上甲其告于口.十一月

[Crack-making on] jisi (day 6) ... divined: "As to Long, Bu, Ji, and Zuo's (?) likewise making offering (to the ancestors) from Shang Jia (on down), in this case make ritual-report to the sun." Eleventh moon. (II. Chu) (HJ 22680 l = Haiwai $2.9(\mathrm{~S} 242.4)=7 \mathrm{~W}$ 41 = Oumei 38 ]; Y248.2)

Whatever the precise meaning of the first clause of this long charge, there can be little doubt that the two gis served as markers, dividing the charge into a series of clauses in which the clauses to the left set the domain for those to the right.

$Q i$ in Period III-IV Charges About Gao Ritual-Reports

Charges about ritual-reports are not numerous in periods III-IV, but in the small sample available we find that the engravers continued to use $q i$ in complex charges to demote the dependent clause, as in:

[78]其告娰辛禹昆

"In making ritual-report (to) Mother $X i n$, it should be a swine (that we use)." (III. Nameless, Royal) ( $H J$ 27557; Y248.2)

\section{[79]其告于高祖王亥?三牛}

In making ritual-report (to) High Ancestor Wang Hai, (use) three bovids." (IV. Nameless, Royal) ( $H J$ 30447; Y248.2)

104. For the reading of oracle-bone $\square$ as $\theta$ rather than $丁$, see $n 57$ above. 
As a marker $q i$ might also appear twice in a complex charge, as in,

[80] 其王田其告妮辛王受又

"As to the king's hunting, (in making ritual-report of it =) if/when he makes ritual-report of it (to) Mother Xin, the king will receive assistance." (III. Nameless, Royal) (HJ 27558; Y804.1)

Gao Ritual-Reports in Period V

The last two Shang rulers, Di Yi 帝乙 and Di Xin 帝辛, ceased divining about ritual-reports to their ancestors. The few reports about which they did divine were for the most part secular in nature, as the king, for example, contemplated making a report to the Great Settlement Shang (告于大邑商),105 or an officer made a report to the king.106 No charges, accordingly, permit us to extend the investigation of $q i$ and gao ritual-reports into period $v$.

105. As in $H J 36511$ (= Jiabian 2416), the longest inscription unit (some sixty-six characters long) that remains to us; for a tentative translation, see Keightley 1991:240.

106. As in $H J 37392$. 


\section{I I $Q$ QI 其 I N THE LI 歴-GROUP I NSCR I PT I ONS}

The Li-diviner group inscriptions, which may be found at $H J$ 31969-35342, and which were mainly excavated in Xiaotun South, employed, as we have begun to suspect, a rather different set of divinatory conventions from those of the Bin-group diviners (whose inscriptions were mainly excavated in Xiaotun North). It is, accordingly, instructive to study the use of $g i$ in this less thoroughly explored context. Most of the inscriptions discussed in this section are from the Li-group. These diviners generally employed scapulas rather than turtle shells,107 and, by contrast with the Bin-group, made little use of positive-negative charge-pairs about actions controllable by the Shang, preferring to offer only one charge per topic. The Li-group preference for scapulas can be correlated with the reduced use of charge-pairs; scapulas lack the central median line and right-left symmetry of plastrons that was suited to the Bin-diviners' contrasting placement of positive-negative charge-pairs.

\section{Li-group Charge-Pairs}

We do find a good number of Li-group charge-pairs about rainfall, 108 but it is evident, for a number of reasons, that the diviners did not have their heart in formulating the kind of pairing emphasized by the Bin-group diviners.

107. Keightley 1991:525.

108. Sample at MZ760.2-66.1. 
First, they sometimes preferred to divine about choice of days--rather than use the positive-negative form of the perfect Bin-group charge-pairsiog--as they moved up the scapula:

[81A] 甲戌卜:乙亥雨.允雨

Crack-making on jiaxu (day 11): "On yihai (day 12) it will rain." (Verification:) It really did rain.

[81B] 甲戌卜:丙子雨

Crack-making on jiaxu: "On bingzi (day 13) it will rain." (I. Li?) ( $H J$ 33779)

Second, when the Li-group diviners did offer charge-pairs about rainfall, the two charges were not given equal weight; one of the preface-and-charge units was usually a much abbreviated version of the other, as in [82B\&C] and [82D\&E] below. Compare, for example, the Bin-group charge-pair, [56AB], with

[82A] 辛巳ト:今日雨

Crack-making on xinsi (day 18): "Today it will rain."

[82B] 壬午ト:今日雨.允雨

Crack-making on renwu (day 19): "Today it will rain." (Verification:) It really did rain.

[82C] 不雨 $\leftarrow$ 个

"It will not rain."

[82D] 癸末ト:今日雨

42

Crack-making on guwei (day 20): "Today it will rain."

[82E] 不雨

$\downarrow \wedge$

"It will not rain." (I. Li 1) (TN 100)

$\triangle$

109. For the definition of perfect and imperfect charge-pairs, see p. 208 below; for examples of perfect charge-pairs, see, e.g., [56AB] and [83AB]; for a full discussion of Bin-group pairs, see pp. $91 \mathrm{ff}$. below) 
In the Bin-group charge-pair, [56A\&B], the preface was fully recorded in both charges, the content of both charges was in positive-negative contrast (不其雨/雨), and the charges were placed on the right and left sides of the shell, with the inscriptions frequently "balanced calligraphically," that is, with the characters running in opposite directions on either side of the shell.110 By contrast, the Li-group charge, [82A], was not balanced with any negative charge; the positive charges, [82B\&D], "Today it will rain," were balanced with the negative charges [82C\&E], but those charges lacked any divinatory preface and any reference to "today."111 They were so perfunctory, in fact, that we cannot even be certain that they were not recorded as verifications, *"It did not rain," rather than as alternative charges. And the charges forming the pairs were, by contrast to Bin-group practice, not written to "run against" one another (see the arrows in the right margin for [82B\&C] [82D\&E]; see too the arrows for [84A\&B]).

Third, the most common Li-group charge-pair about rain--again with the two units not given equal weight--appears to have been 不雨/其雨 "It will not rain"/"It will in this case rain." 112 we rarely, if ever, find the standard pairing used by the Bin-group diviner, as in [56A\&B]: 不其雨/雨.113 Why the Li-group diviners routinely placed the $q i$ in the positive charge, 其雨 rather than in the negative charge, 不雨, is not entirely clear.

110. Keightley $1988: 374$.

111. For a similar Li-group pattern of abbreviation, see the charges on $T N$ $1063,2106,2282$, and 2604 .

112. See, e.g., HJ 33787, 33788, 33798, 33799, 33800, 33801, TN 2126, etc. 113. ANY EXAMPLES OF LI GROUP?? 
Given (1) the irregularity with which diviners placed their charges on scapulas, 114 and (2) the fragmentary nature of many of the Li-group scapulas, it is not always easy to determine which of the two charges in such pairs was divined first, but, on the assumption, which generally holds, that the diviners moved up the bone as they made their cracks, I have the sense that the 不雨 charges were divined before the 其雨 charges.115 This is what one would expect if the $g i$ in the second charge, "It will in this case rain," were indeed referring back to the "this case," the "rain" of the first charge's "It will rain." 116

At first, it might seem strange that the primary concern--because divined in the initial charge of the pair (see convention no. 2 on page 115 below)--of the Li-group diviners would have been to have no rain (不雨) rather than to have rain (其雨), but it does appear that the Li-group diviners were generally more concerned about bringing undesired weather to an end than with praying for desired weather. ${ }^{17}$ Thus, while these diviners performed their share of divinations about praying for rain (袢雨), 118 it is striking that they also divined the bulk of all Shang charges (unpaired) about pacifying the wind

114. For an introduction to the various placement patterns, see Keightley 1978:52. Yan Yiping (1978:983-1059) illustrated 56 layouts found on scapulas; unfortunately for our purposes, he did not indicate the sequence in which he thought the inscriptions had been divined.

115. See, e.g., HJ 33788, 33798, 33799, 33802, 33805, 33806, 33808, 33811, TN 784,3126 .

116. On the referential function of $q i$ in charge-pairs, see pp. 124 below.

117. I make much use of the terms "primary charge" and "secondary charge" in analyzing charge-pairs below. By the primary charge I mean the charge of immediate concern that was usually divined first and was usually divined on the right side of the shell.

118. See the inscriptions at Y564.2-65.1. 
(穤風) or pacifying the rain (卌雨). There is, by contrast, only one Bingroup divination for each topic.119 The Li-group preference for 不雨 rather than 不其雨 charges may thus be explained on the grounds that, given their special concerns, they divined the "no rain" charge first.120 The referential $q i$ thus appeared, in accordance with convention no. 2 , in the charge they divined second.

It is also of interest that, on the few occasions when one does detect the possible existence of a Li-group charge-pair, gi was not used in the way that the Bin-diviner group would have used it. The Bin-group charge-pairs about receiving harvest, for example, such as (see fig. 1),

[83A]【丙]辰卜靔貝:我受黍年 $\langle 1\rangle\langle 2\rangle\langle 3\rangle\langle 4\rangle\langle 5\rangle \quad \mathrm{R}$ L Crack-making on (bing-Jchen (day 53), Que divined: "We will receive millet harvest."

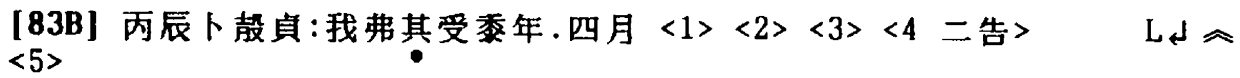
Crack-making on bingchen (day 53), Que divined: "We will not in this case receive millet harvest."121 Fourth moon. (I. Bin, 1) ( $H J 9950 \mathrm{f}=$ Bingbian 8.1-2; Y536.2)

provide evidence for treating charges containing $q i$ as "weaker" than those that do not.122 Thus, we always find, in Bin-group charge-pairs, 我不(or

119. See the inscriptions at Y1032.1-2. Of the 19 charges about "pacifying the wind," 12 may be dated to the Li-group; of the 9 charges about "pacifying the rain," 6 may be dated to the Li-group.

120. Similarly, on TN 784 the diviner appears to have divined the 不延雨, "not prolong the rain," before the 其延雨, "in this case prolong the rain."

121. For a fuller discussion of the translation of [???9950a]B] see p. 105 below. 
弗)其受㯟年; ${ }^{23}$ we never find *我不(or 弗)受黍年, without the $q i$. The contrast was always between the supposedly "strong," desired charge, 我受年年, divined first, without the $q i$, and the supposedly "weak," undesired charge, 我弗(or 不)其受㯟年, divined second, with the $q i$.

By contrast, the Li-group diviners, who used the word he (which, to distinguish the two words, I translate as "grain") rather than nian 年 ("harvest") in such contexts,124 never seem to have recorded the negative, undesired charge *我不其受禾 in their charge-pairs; they always omitted the $q i$, as in:

[84A] 辛亥貞:受禾 $L^{2}$

Divined on xinhai (day 48 ): "(We) will receive grain."

[84B] 不受禾 $\rightarrow \wedge$

"(We) will not receive grain." (I. Li?) (HJ 33261)

Since most of the negative grain charges of the form 不受禾 were recorded on scapulas that are now badly fragmented,125 it is of ten not easy to tell whether they were paired with positive charges of the form 受禾, as seems to have been true in the case of $[84 A \& B] .{ }^{126}$ That, as in this case, one inscription was written directly above the other, as the diviner moved up the

122. But see my disavowal of this understanding in $n$. 30 above and the further discussion of $[83 \mathrm{AB}]$ on page 111 .

123. In period I charge-pairs containing the formula "not receive millet harvest" 不 outnumbered 弗 by about two to one; I count thirteen cases of 不 and seven cases of 弗 at Y536.1-37.1. Cf. Zhu Qixiang 1990:61, who notes that, in period I, the phrase 不受 was common, 弗受 was rare.

124. Xie Ji 1982:100; Ji Xiaojun 1991:35.

125 See, e.g., HJ 33244, 33256, 33259, 33262-68 at MZ745.2-46.1.

126. For other Li-group charge pairs about receiving grain, see TN 423,646, 1063,2106 , and 2282 (all at Y252.2). 
bone--starting, it may be noted in light of the discussion about the "no rain" charges being divined first (page 58 above), with the the more complete unit containing the desire charge, 辛亥員:受禾--might suggest the hypothesis that the $q i$ might have been omitted because the relation between the two charges, so juxtaposed on the bone, was clear; there would have been no need for a referential $q i$ to appear in the second, undesired charge. But this can hardly be satisfactory since it fails to explain why the Li-group diviners did insert a $g i$ in their second, undesired charges about rainfall.

We may note, however, that the Li-diviners avoided qualifying the receiving of divine gifts--whether grain or assistance--with a $q i$. Whereas Bin- and Chu-group charges about warfare ended with the incantation, 受出又. "(We) will receive assistance in this case," those of the Li-group ended with only 受又, "(We) will receive assistance," a phrase that omitted the 4.127 If we accept the view that you in such contexts was a referential demonstrative, ${ }^{28}$ then we have a second case in which the Li-group diviners found such referencing superfluous. That is, they made no use of the formulas *不其受禾 and *受生又. Given their conception of charges and the way they placed them on the bone, the Li-group diviners evidently found the deictic $q i$ less necessary in charge-pairs than the Bin-group diviners did. The underlying message of the charge pairs was frequently similar in both groups, but their formulation was frequently different. This conclusion is all the

127. Xie Ji 1982:100. Compare, e.g., the Li-group divination, HJ 31976 (Y958.1), on a scapula fragment, 甲辰貝: 䔀以眾的伐召方受又, "Divined on jiachen (day 41): 'If Qin takes the zhong and penetratingly attacks the Shaofang, (we) will receive assistance," with the Bin-group divination, $H J 6226$ (Y154.2), also on a scapula fragment, 庚申卜爭員:呼伐工方受出又, "Crack-making on gengshen (day 57), Zheng divined: "If (we) call out (to) at tack the Gongfang, (we) will receive assistance in this case."

128. As argued by Nivison 1977; see too Keightley 1978:78, n.85. 
more striking when we recall that the Li-group diviners, in their unpaired charges, appear to have made fuller use than the Bin-group did of the deictic qi (see page 51 above and the discussion below).

Qi in Simple (or Not So Simple?) Li-Group Charges

In the (what appear to be) simple charges of the Li-group diviners, the use of $q i$, to express delimitation ("in this case," "now, "as to this..."), was optional. It is often hard to determine if or how its presence affected the meaning of the charge. I have proposed one solution in my above translations of the Li-group charges [60B] 王其告于大示 and [60C] 王于父丁告, and [61] 告自上甲 and [62] 其告自上甲, but as I have indicated in note 93 there are no analogous cases to support my use of the quasi-隹 construction for and $[60 \mathrm{~B}]$, *王其告隹于大示, and [62]*其告隹自上甲。 Alternatively one might treat the charges with $q i$ as incomplete, exclamatory sentences (see p. 16 above): [60B] 王其告于大示, "The king's ritual-reporting to the Great Ancestors!," and [62] 其告自上甲, “"The ritual-reporting (to the ancestors) from Shang Jia (on down)!" If these solutions are rejected then it is not easy to see how deictic $q i$ adds meaning to [60B] and [62] or why it was omitted in $[60 \mathrm{C}]$ and $[61]$.

I have observed, however, that in unpaired Li-group charges, the $q i$ was more likely to be present when the charge was the first one on that particular topic divined on that particular day (and, of course, on that particular bone), thus emphasizing the sense of will "in this case, now." Thus, [60B], the first charge divined on gengshen about making a ritual-report, contained a $g i ;[60 \mathrm{C}]$, the second charge on that topic, did not. A similar pattern may be observed in the case of [85A\&B] and [85CD\&E] below; the first charge of the 
day contained the $q i$; the second and third did not.129 As we shall see below (page 116), this tendency was directly opposed to the preference of the Bingroup diviners for inserting $g i$ in what was often the second charge of a charge-pair. As convention no. 2 states: "The charge without the $q i$ was divined first, and the charge with the $q i$ was divined, as a retest, second."

The difficulty involved in assessing the function of $q i$ in the unpaired, simple charges of the Li-group is further illustrated by the following five charges that move up a scapula fragment:

[85A]壬[辰卜]:其[出?]小禘

[Crack-making on] ren-(chen] (day 29): "As to the Lesser Di ritual-sacrifice (to the) [Wu Power (?)]....130

[85B] 壬辰卜:製于土

Crack-making on renchen: "Perform an Exorcism to the Tu Power." [85C] 癸巳卜：其禘于出

Crack-making on guisi (day 30): "Performing the Di-ritual to the wu Power."

[85D] 癸巳卜 : 製于土

Crack-making on guisi: "Perform an Exorcism to the Tu Power."

[85E] 癸巳卜:又于亞家虫一姜三牛

129. For additional inscriptions that support this hypothetical convention, see, e.g., $H J 32336,33283$, and the discussion of [85A\&C] and [90AC\&I] below. For a case that appears to contradict it, see, e.g., HJ 32335 .

130. I tentatively supply the $\Psi$ in $[85 \mathrm{~A}]$ on the grounds that the phrase, 王禘, "Perform Di-ritual (to the) Wu Power, " appeared in several other $\mathrm{Li-group} \mathrm{inscriptions} \mathrm{(e.g.,} \mathrm{[86]} \mathrm{and} H J 33159,34074,34158$ (Y421.2-22.1). It is possible, accordingly, to expect *出小斾 in [85A] (as a variation of the 小帝于巫 found in [87]), although I have found no occurrences of it elsewhere. Because it is impossible to tell if 衽 was the last graph in this fragmentary inscription, the translation is particularly tentative. For Xiao $\mathrm{Di}$ 小䭒 as the name of a ritual, offered, as in the case of [87] below, to the Wu Power or Powers, see the commentary to Jimbun 2298 . 
Crack-making on guisi: "In making of fering to Yashi, of fer (?) one Qiang and three bovids." 131 (I. Li) (HJ $32012=$ Zhixu 91)

Although the precise meaning of some of these charges is uncertain, their general thrust is clear. The Li-group diviners were considering a series of offerings to various High Powers over the course of a two-day period. In two of the ostensibly simple charges, [85A\&C], the RS verb was preceded by a 其; in the three other cases, including the complex charge, [85E], it was not. Should we assume that the $q i$ was casually omitted in these three charges and that its presence or absence made no semantic difference and that, as I have suggested earlier, the use of $q i$ was, at least in certain cases, optional? Or should we assume that the diviner inserted the $q i$ to mark [85A\&C] in some way, perhaps because, as suggested on page 62 , these were the first charges on the general topic of cult to the High Powers divined on their respective days? Or should we assume that $[85 \mathrm{C}]$, for example, was of the quasi-隹 form, *其帝隹于王, *"The performing of the Di-ritual will be to the Wu Power," an assumption, of course, that would convert such charges from simple to complex? Or should we assume that these two charges were incomplete or exclamatory, as I have indicated in my translations above? And even if we accept either of these last two hypotheses, we are left with the puzzle: why did the diviner treat $[85 \mathrm{~A} \& \mathrm{C}]$ and not treat [85BD\&E] in this way? I do not have a ready answer.132 For the present I incline toward what one might call the "incomplete sentence" solution, assuming that the deictic $q i$ delimited a head clause and that the charge itself was abbreviated (from complex to simple)

131. I do not know the identity of Yashi nor the meaning of the word transcribed as 虫.

132. Those who would treat the $q i$ in these charges as modal probably have no ready answer to these questions either; consider, e.g. Takashima's "all purposen $^{n}$ explanation quoted in $\mathrm{n} .18$ above. 
because the conventions of divination were sufficiently well-known (and also perhaps because the conventions or record-keeping were sufficiently inconsistent) that the full record was unnecessary. In this view, rather than translate [85C], 其帝于王, as a quasi-隹 construction, I take it as: "As to performing the Di-ritual to the Wu Power...."

Support for this understanding comes from the following Li-group charges that had not--except for the standard omission of the yong 用 (see page 16 above)--been abbreviated:

[86] 庚戌卜：王帝一羊一豕

Crack-making on gengxu (day 47): "In performing the Di-ritual to the Wu Power(s), (use) one sheep, one pig." (II. Li 2) (HJ 33291 = Ninghu 1.76)

[87] 癸亥員:今日小帝于巫豕一犬

On guihai (day 60) divined: "Today in performing the Lesser Diritual to the Wu Power(s), (use) a pig, one dog." (II. Li 2) (HJ $34155=$ Jimbun 2298)

In these cases, the diviner (and engraver) had supplied the $0 \mathrm{~V}$ that was missing or omitted in [85A\&C]. Thus, [86] and [87] provide some grounds for treating [85A\&C] as incomplete records of standard divinatory units.

$Q i$ in Complex Li-Group Charges: (1) Initial Considerations

That the presence of $q i$ was frequently optional in simple Bin- and Ligroup charges has been noted (see pages 11,62 above). Its similar variability in the complex charges of the Li-group also rewards analysis. 
The way in which the $q i$ could shift from the first clause to the second--and the difficulties involved in understanding why--are well illustrated in the following two charges on the same scapula fragment:

[88A] 癸亥貞:其䄇禾自上甲

Divined on guihai (day 60): "The praying for grain (will be to the ancestors) from Shang Jia (on down)."

[88B] 戊辰員: 裱禾自上甲其燎

Divined on wuchen (day 5): "In praying for grain (to the ancestors) from Shang Jia (on down), in this case make burnsacrifice."133 (I. Li?) ( $H J$ 33209)

Since a five-day interval (Western count) separated [88B] from [88A],134 and since one charge involved a burn-sacrifice and the other did not, it is not clear that they need be regarded as variant treatments of the same ritual scenario. But, assuming that there was a topical link between the two, and that the offering of a burn-sacrifice had not been omitted from the wording of [88A], I would propose that the main assertion, placed to the right, of [88A] had been concerned with specifying the recipient of the prayer for grain, whereas the main assertion, placed to the right, of [88B] was concerned with specifying whether or not it was the burn-sacrifice that should be offered,

133. Chow identifies liao 燎 as a type B ritual-sacrifice verb; these verbs do not take an object-goal and really 'take' the object-victims as patients; "they represent a specific method of sacrificing victims" (Kwok-ching Chow 1982:205, 208).

134. Since [88A] was placed above [88B] on the scapula, it is possible that it was divined after it; if so, the charges would have been separated by fifty-five days. My sense, is however, that the placement of the inscriptions on this bone was irregular and that the closer interval proposed in the translation is more plausible. 
now that this particular kind of grain prayer to a particular group of ancestors had been decided on.135

These two charges permit us to make a distinction between two syntactical patterns: [88A] 其 RS OG 于 $\mathrm{OB}, 136$ and [88B] $\mathrm{RS}_{1} \mathrm{OG}$ 自 $\mathrm{OB}$ 其 $\mathrm{RS}_{2}$. In cases like [88A], in which no OV or second RS was specified, I treat the charge as a quasi-隹 construction: 其 RS OG (隹) 于 $O B$, in which the 其 in the head position at the left, nominalized the delimited topic: 'The ritual-sacrifice for a particular goal (will be) to a particular object-beneficiary.' When the charge, such as $[88 \mathrm{~B}]$, ended with a second ritual-sacrifce, then there was no need to supply the 隹; the first clause was delimited by its head position, and the 其, which was placed to the right, served to delimit the main assertion.

The diviner could, in theory, have used two $q$ is in a charge like [88B]: *其裱禾自上甲其燎, to yield precisely the translation already provided above. Such a Li-group pattern can indeed be found in [89B], 其 $\mathrm{RS}_{1}$ OG 自 OB 其 $\mathrm{RS}_{2}$ : [89A] 弜已(=祀?)

"Do not sacrifice (?)."137

[89B] 其裱于上甲其祝

"In praying to Shang Jia, in this case "offer an invocation." (I. Li?) (HJ 32654)

135. For these distinctions in emphasis, see too the discussion of [115] on page 86 below.

136. The diviner used 自 rather than 于 in the case of [88AB] because the $O B$ was the group of ancestors "from (自) Shang Jia (on down)." Had only one $O B$ been specified, the f would have been present.

137. Lian Shaoming (letter of 10 June 1995) has remarked on the frequent opposition in charge-pairs between 其 in the positive charge and 弲巳 in the negative. 
The correctness of these interpretations is supported by a consideration of the ritual-announcement charges on a large Li-group scapula fragment:

[90A] 丁卯貞：出以羌其用自上甲砄至于父丁 L」

On dingmao (day 4) divined: "As to the Qiang that Cha brought in, in using them to (the ancestors) from Shang Jia (K1) (on down), cut them up (and offering their blood to the ancestors) down to Father Ding (K21). ${ }^{n 138}$

[90B] 丁卯貞: 以差于父丁 L」

On dingmao divined: "(Sacrifice) the Qiang (that Cha) brought in (duwn?) to Father Ding."

[90C] 辛末是:其裱禾于高祖

On xinwei (day 8) divined: "The praying for grain (will be) to the High Ancesturs."

[90D]辛未貞:裙禾于高祖燎五十牛

On xirwci divined: "In praying for grain to the High Ancesters, buri sacrifice fifty bovids."

[O0E]辛去貝:于河潇禾

$\mathrm{L}$

On rinci divined: "To the River pray for graiii."

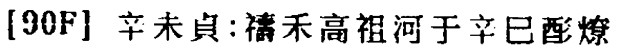

On xinwei divined: "In praying for grain (tu) the High Ancestor River, on xinsi (day 18) perform the you-cutting sacrifice and burn-sacrifiec." 139

[30G] 辛末賁: 裙禾于河燎三牢沈三牛图审

On xinwei divined: "In praying for grain to the River, burnsacrifice three lao, ritually-drown three bovids, and $y i$-sacrifice a lav."

[90H] 辛未貝:裱禾于岳(?)

$C \downarrow$

138. For the meaning of oracle-bone $\pi$, see Keightley 1991:451; see too KJS 4855,5518 .

139. I follow the reading of Li Yanung in his commentary to Zhixu 2, who treats the final two characters, 醇, as part of the charge. The $M Z$ editurs, by contrast, treat the two characters as part of a separate charge; this is pussible. 
On xinwei divined: "Pray for grain to the Mountain."

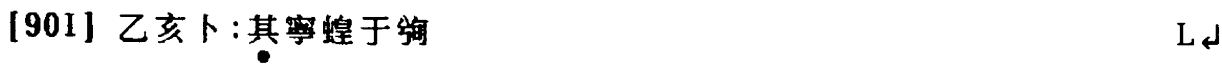

On yihai (day 12) made cracks: "The (ritual for) pacifying the locusts (will be) to Xun (?)."140 (II. Li 2) (HJ 32028)

It may be noted first of all that the engravers recorded a $q i$ in three of the charges: $[90 \mathrm{~A}],[90 \mathrm{C}]$, and $[90 \mathrm{I}]$. In each case, following the Li-group custom, the $q i$ was used in the charge that appears to have been divined first about that particular topic. In the case of [90A] the inscription unit was recorded below its imperfect pair, [90B], which was abbreviated, a strong sign that [90B] was indeed divined second (see convention no. 3 on page 152 below). In the case of $[90 \mathrm{C}]$ my ordering of the charges is tendentious. I have no certain method for determining the sequence in which the $x i n w e i$-day charges about praying for grain were divined. The sequence proposed above follows a rational plan: First, in $[90 \mathrm{C}]$, the diviners proposed that the prayer would be made to the High Ancestors in general. Next, in [90D], they provided more details about the prayer by proposing the offering of fifty bovids. They then singled out one of the High Ancestors, the River Power (referred to as Gao Zu He 高祖河 in [90F])--first, in [90E], proposing the River as recipient; then, in $[90 \mathrm{~F}]$ and $[90 \mathrm{G}]$, specifying the kind of cult that was to be offered; and finally, in $[90 \mathrm{H}]$, proposing that the prayer be offered to the Mountain Power (another High Power). Finally, the diviner turned to an entirely new topic-and, because this was the first charge about that topic on the new day, yihai, the engraver employed the nominalizing, topicalizing, deictic $q i$.

140. For the reading of "locusts," see n. 62 above. For Xun(?), who in this case appears to have been a predynastic ancestor, see KJS 0595, supplemented by Akatsuka 1977:159, 207. 
A comparison of this sequence of charges with those on the previous scapula suggests that the diviner of [88A\&B] had followed a similar rationale: he first, in [88A], proposed a prayer for grain to the ancestors from Shang Jia on down; he next, in $[88 \mathrm{~B}]$, became more precise, specifying the kind of sacrifice, a burn-sacrifice, that was planned. That this would have been an entirely natural progression is indicated not only by [90DF\&G], which link grain prayers to burn-sacrifices, but by a whole series of other Li-group charges that record the same linkage.141

Finally it may be noted that the syntax distinctions proposed for [88AB] above (page 67), continued to function. The complex charges [90ADF\&G] were of the form similar to that seen in $[88 \mathrm{~B}]$, i.e., OV (其) $\mathrm{RS}_{1}$ 于 $\mathrm{OB}$ 其 $\mathrm{RS} 2$; they involved no quasi-隹 construction (and only one of them, [90A], contained the optional qi). The other two charges, [90C\&I] (both with qi), were of the form similar to that of $[88 \mathrm{~A}]$, 其 RS OG 于 OB, and may, as predicted, best be understood as quasi-隹 constructions.

These charges indicate the degree to which the $q i$ was a deletable option; it was present in [90AC\&I], but absent in the other charges on the scapula. Compare too $[91 \mathrm{AB}]$ with $[92 \mathrm{AB}]$ :

[91A]壬申貞:裱禾于河燎三牛沈三牛 $\mathbf{R} L^{2}$

On renshen (day 9) divined: "In praying for grain to the River, burn-sacrifice three bovids and ritually-drown three bovids."

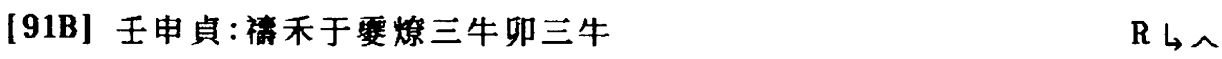

On renshen divined: "In praying for grain to Nao (a High Power), burn-sacrifice three bovids and split open three bovids." (II. Li 2?) ( $H J$ 33277)

141. See, $H J 30439,33276,33277,33280,33282,33283,33293$, and other cases at Y523.1-2. 
[92A] 千子具:其䄇禾于河燎三宰就三图羍

On renzi (day 49) divined:) "In praying for grain to the River, burn-sacrifice three lao, ritually-drown three, and $y i$-sacrifice a
lao."

[92B] 壬子貝:其裙禾于河燎三羍沈五

On renzi divined:) "In praying for grain to the River, burnsacrifice three lao, ritually-drown five." (II. Li2?) (HJ 33282)

The charges are remarkably similar, yet in [91AB] the diviners (or engravers) employed no $g i$ while in [92AB] they did. I see no evident change in meaning; the only difference was that the divining staff in the second case felt the need to insert the delimiting, nominalizing marker. In such contexts, deictic $q i$ was frequently used, frequently not used.142 The demotion was indicated by the syntax of the charge, whether the $q i$ were present or not.

\section{Qi: Etymological Speculations}

I have already noted above (page 8) that 其 and 茲 belonged to the same Shijing rime group. Indeed, I think it possible that, in some contexts, the oracle-bone graph $U$, usually read as $q i$ 其, was used to write the word that was later written $s i$ 斯, which served in 0ld chinese as the adjective and pronoun $c i$ 此, "this" (the definition given by Erya), as the clause marker ze 則, and as the possessive pronoun $z h i 之 .{ }^{143}$ Graphically, the Eastern

142. Other Li-group charges about praying for grain in which $q i$ : (1) was used: $H J 33283,33293$ (see too the period II I cases: HJ 28269, 30439): (2) was not used: $H J 33284,33292,33293,33296$ (see too the period III case: $H J$
28271 ).

143. I take the meanings of $s i$ from Yang Shuda 1986:285-86. It may be noted that two of these words had meanings that would have been appropriate for a clause marker and caesura (see n. 69 above). The Shuowen defines $s i$ 斯 as $x i$ 析, "to split, divide." It defines $c i$ 此 as $z h i$ 止, "to stop." 
Zhou bronze form of 則 was evidently composed of 其 (the "winnowing basket," $\forall)$ placed on a stand, with an ax (?) element on the right.144 And etymologically, $g i$ 其 and $s i$ 斯 belonged to the same xiesheng series.145 Indeed, they were evidently part of the same word family, sharing phonetic, graphic, and semantic features. When oracle-bone $q i$ served as a sentence marker, separating two clauses, it can well be read as $s i$ or $z e .^{146}$

Herforth has proposed that "Functionally, [0ld Chinese] 則 is probably best treated as a resumptive anaphoric" and cites scholarship that remarks "on the tendency for 'apodosis particles' to be anaphoric in origin and thus analysable as resumptive proforms."147 Referring to Li Fang-kuei's phonetic

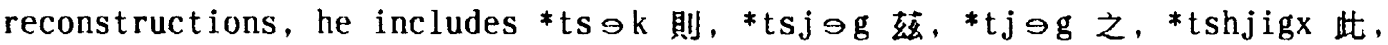
and ${ }^{*}$ sjig 斯 in his list of old Chinese words that shared the "syntactic function of appearing within the base to resume a prebase constituent."148 The oracle-bone evidence, together with the consideration that 其 and 則 belonged to the same xiesheng series ( $\mathrm{n}$. 144 above), suggests that ${ }^{*} \mathrm{gj} \ni \mathrm{g}$ 其 might also be included in this set, serving, to borrow Herforth's analysis once again, as "the base-internal resumption of a prebase phrase."

144. See the graph form at Gao Ming 1980:362.

145. Boltz 1994:92.

146. Consider, e.g., the role played by $q i$ in $[68],[69],[70],[75],[76]$, $[77],[80],[107 \mathrm{AB}]$, and $[174]$.

147. Herforth $1994: 273,274$. He cites Comrie (with Haima) $1986: 88$. Herforth (1994:274, n.18) also notes: "For general remarks on the broadly attested tendency to recruit deictics and demonstratives as clause connectives, see Hopper and Traugott $(1993: 178)$. Braunmuller (1978) is a detailed study of just this sort of recycling pattern in the history of Germanic." $Q i$ would certainly fit this pattern.

148. Herforth $1994: 274$. 


\section{Qi in Complex Li-Group Charges: (2) Optional}

As we have seen, the Li-group diviners frequently subordinated the background clause of a complex charge by placing it at the front of the charge. This was the clause that, in Herforth's terms, 'set the domain' or 'provides the setting of one sort or another (hypothetical, temporal, etc.).'149 Sometimes--1ike the diviners of other groups we have studied--they marked this backgrounded clause with a $q i$; of ten they did not. In either case, the initial clause can be translated as "As to...." or "When...." or "If..." It must be stressed once again, however, that context alone could also require the use of such subordinate translations.150 In complex charges where no $q i$ was provided, the context still requires that we demote the first clause in this way. Compare for example [65] and [64], both provided with an initial gi, and [63] and [93], both lacking the initial gi:

[93]庚宙員:射白以郑用自上甲重甲戊

On gengyin (day 27) divined: "The of fering to (the ancestors) from Shang Jia on down of the Qiang that Archer Cha brought in should be on jiaxu (day 11)." (I. Li) (HJ 32023)

In [93], the context indicates that everything before the hui 重 was delimited information. By contrast, what Herforth calls "the main assertion," i.e., the issue that the divination was intended to resolve, came at the end, "It should

149. Herforth (letter of 19 August 1993 and 20 September 1993, p. 7) who suggested that $g i$ might have marked "clauses containing 'backgrounded" propositions: those 'not at issue,' clauses which 'set the domain' or provide the setting of one sort or another (hypothetical, temporal, etc.)' for the main assertion (which, I hardly need say, comes at the end of the sentence in virtually all forms of Chinese)."

150. As Kwok-ching Chow (1982:158-70) and Takashima (1990:39-40; cf. 1991:680-81) have pointed out, it is the presence of two verbs, and not the $q i$ itself, that indicates a subordinate construction. This does not imply, however, that the $g i$ could not be used as an optional mark of such a construction, as in [96], [100], [101], [103], [110], [111] be] ow. 
be on jiaxu." One can imagine an alternate, fuller form of the charge that would read：＊射的以郑其用自上甲惠甲成， * As to the offering to Shang Jia of the Qiang that Archer Cha brought in, it should be on jiaxu." Compare, for example, this emended form of [93] with:

[94] 癸卯貞: 射耖以矧其用禹乙

Divined on guimao (day 40): "The sacrificing of the Qiang (prisoners) that Archer Cha brought in should be on the $y i$-day (i.e., yisi, day 42)." (I. Li?) (TN 9)

That $q i$ functioned as a resumptive anaphoric in the Li-diviner group inscriptions is well supported by comparing the following two charges on the same scapula:151

[95A]丁未貞:禹今夕醇·在父丁宗卜

On dingwei (day 44) divined: "It should be this evening that (we) perform the you-cutting sacrifice and the Exorcism." (Postface:) Cracked in the temple of Father Ding.

[95B] 癸丑賁:其大徨東甲子醇

On guichou (day 50) divined: "In performing the Great Exorcism, it should be on jiazi (day 1) that we perform the you-cutting sacrifice." (II. Li 2) ( $H J 32330)$

Although both charges were concerned with the day on which the Exorcism ritual was to be performed, they were structured differently. The Exorcism, which had appeared as the action of concern at the end of $[95 \mathrm{~A}]$, had, six days later, been placed in the dependent clause at the start of [95B], marked with a $q i$, which may have referred back to the Exorcism and you-cutting sacrifice of $[95 \mathrm{~A}]$, but which also served to delimit the action contemplated on a new day, "In performing the Great Exorcism in this case." (For the argument that

151. For another inscription on the same scapula, see [106] below. 
the Li-diviners frequently inserted an initial $q i$ when the charge was the first divined on a particular day, see page 62 above).

One can, in fact, find many complex charges that used the deliniting, subordinating $q i$ to mark the verb at the start of the opening clause, when that verb was not referring back to a previous clause containing another verb phrase (as it may have done in [94] and [106B]). Thus:

[96]庚午員:其酸高祖燎禹辛卯

Crack-making on gengwu (day 7): "In performing the you-cutting sacrifice to the High Ancestors, the burn-sacrifice should be on xinmao (day 28)."152 (I. Li) (HJ 32305)

In this case, by contrast with [93], the $q i$ had been used to mark the demoted clause ('As to the you-cutting sacrifice...'). It is evident, however, that the engravers treated the recording of the subordinating $q i$ as optional. It might be present, as in [94], [95B], and [96];153 it might be omitted, as in [93] (and [97], [98, and [104] below).154

Indeed, it is evident that, in contexts of this sort, the $q i$ and the hui could both be omitted, as in the next two examples:

[97]己酉卜:又于大乙乙卯

Crack-making on jiyou (day 46): "The offering to Da Yi (K1)

(should be) on yimao (day 52)." (I. Li) (HJ 32217)

152. It is striking that the offering in [93] was divined forty-four days in advance, and that the offering in [96] was divined twenty-one days in advance. For similar cases of long-range cult planning by the Li-group diviners, see....

153. The $g i$ is also present, e.g., in complex charges on $H J 32210$ (instructive to compare with 32211 ), 32287, 32302, 32313, 32330.

154. The $q i$ was also omitted in $H J 32211$ (cf. 32210), 32308, 32361, 32363, $32494,32667,32694,32699,33313$, and other complex charges about cult offering divined by the Li-diviner group. 
[98]乙亥卜:又十审十伐大甲申

Crack-making on yihai (day 12): "The offering of ten lao and ten dismembered victims (to) Da Jia (K3) should be on (jia)shen." (I. Li) ( $H J$ 32201)

I propose that the engraver had omitted both the 其 and the 重 in recording [97]. The fuller form of [97], by analogy with [96], would have been the "quasi-專" construction： *其又于大乙專乙卯 (see next paragraph), and I have translated [97] accordingly. Similarly, the fuller form of [98] would have been：；其又十牢十伐于大甲專甲申, leading to the translation given above. The form recorded by the engraver of [98] had been radically abbreviated, omitting the 其, 于, 禹, and 甲. 155 Once again (see pages 11, 62 above), the lesson to be learned from these examples is that the absence of words like $q i$ for $y u$ or hui) had no necessary semantic significance; their presence was optional.

The "quasi-專" interpretation of charges like [97] and [98] receives further support from the following divinations:

[99A]弲祝于妮辛

"Do not offer invocation to Mother Xin."

[99B]其祝轧辛禹翌日辛酸

"In offering invocation to Mother $X i n$, it should be on the next xin-day (that we) perform the you-cutting sacrifice."

[99C]柺翌日辛配

"Do not on the next $x$ in-day perform the you-cutting sacrifice." (II. Li 2) (TN 261)

155. So strong was the engraver's interest in abbreviating [98] that he evidently intended that the 甲 in the closing part of the charge, 大甲申， was to do double duty, serving as both the jia in the name of Da Jia and the $j i a$ in the day date, jiashen. For similar cases of one word used twice, see Yao Xiaosui 1985:114. 
The 其 at the head of [99B] served to demote and nominalize the initial verb phrase; the 重 further clarified the structure of the complex charge. Its presence, however, as we have seen in [97] and [98], was not obligatory.

Similarly, the presence of $q i$ in the opening clause of complex charges (see, e.g., [94], [96], and the inscriptions listed in note 153 above) could provide guidance as to how the charge was to be understood. For example, in cases like:

[100]甲午卜：其又升于觪祖一牢

Divined on jiawu: "In offering the sheng-sacrifice to the Progenitor Ancestors, (use) one lao." (II.

$\mathrm{Li} 2$ ) ( $H J$ 32316)

and :

\section{[101] 其又升父丁又伐王受又}

"If in offering the sheng-sacrifice (to) Father Ding he offers dismembered victims, the king will receive assistance."156 (II Li 2) ( $H J$ 32223)

the presence of the $q i$ indicates that the first part of the charge was to be delimited and prevents our translating [101] as: *"(We) will offer the sheng-sacrifice to Father Ding and offer dismembered victims and the king will receive assistance." It should be noted once again, however, that the complex structure of such charges would encourage us, $q i$ or no $q i$, to translate them in terms of subordinate clause(s) and a main clause.

156. I tentatively make the offering of dismembered victims the main point at issue that was to affect whether or the king would receive assistance. It is possible, however, that the subordinating $g i$ covered both activities: "In offering the sheng-sacrifice to Father Ding and in offering beheaded victims, the king will receive assistance." 
That $q i$ was generally deletable, regardless of the grammatical structure of the charges, suggests that a large number of inscriptions can be understood in the way just proposed. Consider, for example, the following four complex charges on a large scapula fragment:

[102A]己巳貞:庚午又于父丁牢

On jisi divined (day 6): "On gengwu (day 7), the of fering to Father Ding will be a lao."

[102B]己巳卜：王其逆執又(若)

Crack-making on jisi: "(As to the king's welcoming =) If the king welcomes the captives (for sacrifice), there will be (approval)."

[102C] 己巳貝:王其逆執又若

On $j$ is $i$ divined: "If the king welcomes the captives (for sacrifice), there will be approval."

[102D]已巳貞:王來逆又若

On jisi divined: "When the king returns from welcoming (the captives), there will be approval." (I. Li) (HJ 32185)

The presence of the $q i$ in $[102 \mathrm{~B} \& \mathrm{C}]$ encourages us to subordinate the initial clause ('As to the king welcoming the captives...'). But the structure of [102A\&D], even though lacking the $q i$, requires similar subordination ([102A]: 'As to the gengwu offering to Father Ding...'; [102D]: 'As to the king's returning from welcoming...').

The $g i$ was also optional in charges whose subordinating clauses specified the day of cult. The $g i$ might be present, as in:

[103]甲辰卜：乙巳其燎于岳大䒠小雨

Crack-making on jiachen (day 41): "On yisi (day 42), if we burnsacrifice to the Mountain Power a large lao, it will rain a little." (I. Li) ( $H J$ 33331) 
Or, the $q i$ might be omitted, as in the next two cases:157

[104]庚申員:今來甲子酷王大算于大甲燎六小羍卯九牛不遭雨

Crack-making on gengshen (day 57), divined: "If, in performing the you-cutting sacrifice on the coming jiazi (day 1), the king performs the Great Exorcism to Da Jia (K3), burn-sacrifices six small lao and splits open nine cattle, (we) will not encounter rain." (I. Li) ( $H J 32329 \mathrm{f})$

[105]己酉卜:召方來告于父丁

Crack-making on jiyou (day 46): "That the Shaofang are coming we will report to Father Ding." (I. Li) (HJ 33015)

In [104] it is evident that the backgrounded, subordinated topic for which the Shang did not wish to "encounter rain" must have been the various offerings recorded in the first part of the charge. So many conditions were recorded, in fact, that the engraver may have been puzzled where to put the subordinating $q i$ and thus omitted it entirely; but one can imagine a full form such as：*今來甲子酷王其大禦于大甲．.. Compare, for example,158

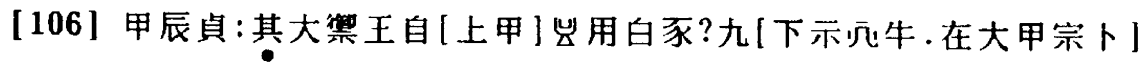

On jiachen (day 41) divined: "In performing the Great Exorcism (for the) king [(to the ancestors) from Shang Jia (on down)], sacrifice-in-blood-covenant (with the spirits) (?) white pigs (?), nine of them; [ ( to the) Lower Ancestors cut up (and of fer the blood of) (?) a bovid." (Postface:) Cracked in the temple of Da Jia (K3) (?). $]^{159}$ (II. Li 2) (HJ 32330; Y755.1, partial and in

157. For other Li-group charges in which a delimiting $q i$ could have served useful function but had been omitted, see $H J 33296,33305,33314,33317$, 33333 .

158. For another inscription on the same scapula, see [95AB] above.

159. I tentatively supply the missing characters in the charge of [106] on the basis of the parallels with the other inscriptions on the same bone. I supply the "In the temple of Da Jia" in the postface on the assumption (discussed at Keightley 1991:114-19) that in this sequence of divinations the Li-group diviners were returning to the same temple every ten days, as can be seen in the case of other inscriptions on $H J 32330$ and and $T N$ 
error)

In this case, by contrast with $[104]$, the engravers for the Li-diviners had placed the subordinating $q i$ at the start of a long string of conditions.

In [105] it is again evident that the subject of the ritual-report to Father Ding must have been the subordinated topic, the coming of the Shaofang. ${ }^{160}$ In this case, the diviner (or engraver) did not use a $q i$ to mark the subordinated sentence; he did not write*召方其來告于父丁. For a similar subject, but with the $g i$ recorded at the start of the charge, consider [66] above. It is evident, once again, that the use of $q i$ in such cases was optional.

Qi in Complex Li-Group Charges: (3) Hunting Charges

In complex charges in which $q i$ preceded the apodosis or main clause, i.e., the final clause, it served to mark it as the main assertion, as in $[107 \mathrm{AB}]:$

[107A]辛王强田其雨

"On the $x$ in-day, the king should not hunt, (for) it will in this case rain."

[107B] 壬王弜田其雨

"On the ren-day, the king should not hunt, for it will in this case rain." (I. Li?) (HJ 33533)

2707. That no other Jia temple except that of Da Jia is recorded in the present corpus of inscriptions supports my reconstruction.

160. Compare, e.g., 貞:告古方于上甲, "Divined: '(We will) report the Gongfang (going out?) to Shang Jia." (YC 546f). 
It is evident that a translation for [107A\&B] such as *"As to the king's not hunting, it will rain," would make no sense, and would also not do justice to the injunctive force of the 弲.

In a later period inscription, however, a hui further to the right than a $g i$ served to mark the main clause, removing the need for a second $q i$, as in [108A\&B]; we never find *其重 or *重其.

[108A] 甲辰卜狄具：王其田惠翌日乙亡災

Crack-making on jiachen (day 41), D divined: "The king's hunting (the king his hunting?) should be on the next day yi(si), day 42); there will be no disasters."

[108B]甲辰卜犾貞: 禹翌日戊亡災

Crack-making on jiachen, D divined: "(The hunting) should be on the next day wu(shen), day 45); there will be no disasters."

[108C]甲子卜狄貞：王其田亡災

Crack-making on jiazi (day 1), D Divined: "(As to the king's hunting $=$ ) If the king hunts, there will be no disasters." (IIIIV. He 3) ( HJ 30757)

In all such cases I assume that the apotropaic formula, 亡災, "there will be no disasters," was a standard semantic unit (see page 28 above), that frequently ended such charges as [108ABC] and needed no marker to delimit or emphasize its ultimate role in the divinatory process.

The Li-group diviners, in fact, devoted considerable attention to the royal hunts, and in this case we $f$ ind a suggestive distribution. When the initial verb phrase was 王往田, "the king goes to hunt," the Li-diviners never 
employed $q i^{161}$ their engravers never recorded *王其往田. Thus, the typical example was: 162

[109]辛巳卜：王往田亡企

Crack-making on $x$ insi (day 18): "If/When the king goes to hunt, there will be no harm." (I. Li) (HJ 33429)

But if the wang 往 were omitted, then it was replaced by $q i$ 其, as in, ${ }^{163}$

[110]辛巳卜貞:王其田亡

Crack-making on xinsi (day 18): "If/When the king hunts, there will be no harm." (I. Li) ( $H J 33444)$

In addition, the Li-group diviners never omitted the $q i$ in royal hunt charges that specified the place of hunt, as in, 164

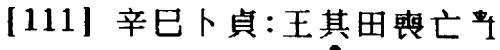

Crack-making on xinsi (day 18): "If/When the king hunts at Sang, there will be no harm." (I. Li) (HJ 33536)

We never find, for example, a Li-group charge of the form*王田嫊亡 1,165 even though such a charge would surely have been eminently decipherable to the Shang, as it is to modern readers, without or without the gi. This suggests

161. For a rare Bin-group charge that did employ the phrase 王其往田, see [174] below.

162. For other cases of 往田 without the $q i$ see $H J 33410,33413,33415,33416$, and other examples at MZ750.1-51.2.

163. For other cases of 王其田, see $H J 33441,33442,33443,33445$, and many other examples at MZ752.1-53.2.

164. For 'hunt at place-name' charges in which $⿴ 囗 十$ was invariably preceded by 其, see $H J 33529,33530,33531$, and numerous other inscriptions at $M 2$ $754.1-55.2$.

165. See the twenty-two 王其田霹亡 charges at Y518.2-19.1. Cf. the eighteen 王其田向亡 1 charges at Y750.2 and the eleven 王其田舌亡 1 charges at Y1029.1 
that the choice of words--其田 used when 往田 was not, and 其田 rather than 田 used when the place of hunt was divined--was deliberate. In these cases, the engraver was entirely consistent and the presence or absence of $q i$ was not optional.

I can provide no satisfactory explanation for these usage patterns. They provide one important indication, however, that, in certain contexts, the Ligroup diviners treated the presence or absence of $g i$ with considerable rigor (just as the Bin-group diviners treated $g i$ in their positive-negative charge pairs; see page 92 below). We find, for example, that the preferred formula 王其田 PN亡 ${ }_{1}$ (as in [111]) represented an extension of the preferred formula 王其田亡舟 (as in [110]) and that, just as we never find *王田PN亡 find *王田亡和, of wich it would have been a disallowed extension. Further, and not unexpectedly, just as we only find cases of 王往田亡 (as in [109]). we never find cases of *王往田PN亡*. Evidently, the use of the 往 before the 田 excluded the 其, but the addition of place-name after the 田 made the 其 mandatory and excluded the 往.

Whatever their meaning or function, it may be noted that the rigidity of these Li-group conventions about the hunt inscriptions had broken down by period $V$. Some of the hunt inscriptions preserved the 其, as in the formula 王其田PN亡災

[112] 丁口王卜貞:其田于叟往來亡災

On ding... the king made cracks and divined: "In hunting at Sang, going and returning there will be no disasters." (V. Huang) ( $H J$ 37595) 
But generally the $g i$ had been abandoned, 166 as in:

[113]辛卯卜賁:王田震往來亡災

On xinmao (day 28) made cracks and divined: "As to the king hunting at Sang, going and returning there will be no disasters." 167 (V. Huang) ( $H J 37660)$

This suggests, accordingly, that the Huang-group diviners found the rigid convention that the Li-group had observed less meaningful. Since, as is well known, the period $\mathrm{V}$ hunts had become rigorously scheduled, 168 one might relate the diminished use of $q i$ to the redundancy of adding "in this case, now" to a charge whose timing was set firmly in advance. This explanation receives some support from the consideration that the 王往田 formula of the Li-group diviners (as seen in [109]) had fallen into disuse by period V.169 Evidently, it had been displaced by 王田, without the $q i$ (as in [113]). Given the fixity of the schedule there was evidently no need to divine about the king "going to hunt," just as there was no need to divine about the king hunting "in this case." The schedule itself delimited the topic; there was little need of 其 or 往. 170

166. Thus, I find twenty period $\mathrm{V}$ charges about hunting at Sang with no $g i$, only two with $q i$ (Y519.1-2); sixteen period $V$ charges about hunting at $\mathrm{X}$ iang with no $q i$, only four with $q i$; nine period $\mathrm{V}$ charges about hunting at Yu with no $q i$, none with $g i(Y 1029.1-2)$. See too the discussion on $\mathrm{p}$. 90 below.

167. Five other charges on this scapula about hunting at other locations were all of similar form, lacking the $q i$. Three of them included a f before the place name.

168. Matsumaru 1963.

169. I note only one case of $\square$ 往于田 ( $H J 36760$ (a period III formula) in period V; see the inscriptions at Y320.1.

170. It may also be noted that, a comparison of [102D], also missing the $q i$, with the 王往田 formula, represented by [109], which always lacked the $q i$, suggests that $q i$ was likely to be omitted when two verbs were juxtaposed, such as the 來逆 of [102D] and the 往田 of [109]. Similarly, 


\section{Exclamatory Charges and Ambiguities}

The following two charges demonstrate a fruitful interpretive difficulty:

[114A]戊辰貝:其襍生于始庚始丙. 在祖乙宗卜

Divined on wuchen (day 5): "In this case pray for a (new) life to Mother Geng and Mother Bing." (Postface:) Cracked in the temple of $\mathrm{Zu} \mathrm{Yi}$.

\section{[114B]羊已貞:其䄇生于阵庚阵丙牡封白犬}

Divined on xinsi (day 18): "In praying for a (new) îfe to Mother Geng and Mother Bing, (use) a bull, a ram, and a white dog." (II. Li 2) ( $H J 34082 ; Y 5001.2$ )

The presence of the independent ciause, "(usej a buli, a ram, and a white dog," at the end of $[114 \mathrm{~B}]$ invites us to demote the initiai clause, as does the initial $q i$, to dependent status. This suggests that we might perform a similar demotion in the case of [114A] , on the understanding that the of had either been omitted (or at least deferred): * "In praying for a (new) life to Mother Geng and Yother Bing (we will use object-victims)." Such a formulation, in fact, could be read as an incomplete, exclamatory charge (see page 16 above): *"Praying for a (new) life to Mother Geng and Yother Bing!" The divinatory strategy wouid thus have been to first propose the prayer to the two ancestresses, with the understanding that the victims were to be specified later, and then, thirteen days later, to divine the prayer a second time, this time with the victims specified.171 I leave my translation of

we never find *其往省 or *其往來. It is possible to suppose that two verbs juxtaposed provided sufficient specificity; a $q i$ would, once again, have been superfiuous.

171. Wother Bing was the consort of $\mathrm{Da} Y \mathrm{Yi}$ (K1). On the assumption that Mother Geng was the consort of Ancestor Yi (K12), then the two Mothers would have been the consorts of Yi kings and it would have been appropriate 
[114A] in the clumsy "in this case" form; but I believe, once again, that in certain contexts Shang practice permitted the use of such incomplete, attention-seeking charges.

If, as we have frequently seen, the Li-diviners could use $q i$ on an optional basis, it is difficult to translate a number of charges with certainty. For example, do we translate thus:

[115]戊子卜:裱禾于示壬

Crack-making on wuzi (day 25): "Pray for grain to Shi Ren."172 (I. Li?) ( $H J$ 33317)

On the basis of the above discussion of [114A\&B], do we treat the charge as exclamatory: " "Praying for grain to Shi Ren!"? Had the charge for [115] been written *其裙禾于示壬, then I would, on the basis of the above discussion of [114A\&B], incline towards the exclamatory version. Since no $g i$ was present, however, I am prepared to treat the charge, which is a complete Chinese sentence, $R S O G$ 于 $O B$, as a simple sentence. But caution is still in order. Another Li-group charge reads:

[116]壬子卜:䄇禾[示]壬羍

Crack-making on renzi (day 49): "In praying for grain to [Shi] Ren, (use) a lao." (I. Li?) (HJ 33333)

Even though the head clause of [116] was not demoted with $q i$, the context requires that we so demote it. How then can we be sure that 1115] should not be similarly understood, as an incomplete precursor of [116]? The answer is, of course, that we cannot be sure. But in such cases I am prepared to assume

that the prayers for progeny be divined in a temple of the $\mathrm{Yi}$ ritual group, as specified in the postface to [114A].

172. The prayer to Shi Ren was presumably going to be offered on renchen (day 29), his name-day, four days in the future. 
that the Shang diviners and engravers were aware of such possible ambiguities and that, since they did not place a $q i$ at the head of $[115]$, we should, accordingly, treat it unambiguously, as a simple and complete sentence that can be construed as I have translated it above.

The Li-group diviners of ten used a series of short subcharges in which they divined a particular number of victims to be offered in sacrifice. Thus we find minimal charges like 五牛 and 十牛 (on $H J$ 33584; also 33585), or 三牛 and 五牛 (on HJ 33586). These evidently meant "(Use) five bovids," "(Use) ten bovids," and so on. The addition of a $q i$, however, as in 其三牢 ( $H J 33388$ ) or 其五牢 ( $H J$ 33587) introduces an uncertainty. One could take the $q i$ in such subcharges as adverbial: "In this case (use) three lao," or one could assume that the $q i$ was anaphoric and nominalizing, preceding an omitted verb of cult, so that the subcharge meant, "In performing the (R-S verb), (use) three lao." Because, as we have seen in charges [64], [66], [67], and [92AB], $q i$ at the start of a Li-group charge usually was delimiting in nature, I would prefer to assign it that role in these cases. The charge 其五牢, "In performing the ( $\mathrm{R}-\mathrm{S}$ verb), (use) five lao," accordingly, should be understood differently from the charge 五牛, "(offer) five bovids," The practical difference, of course, is small.

The following two charges on a scapula fragment indicate some of the further ambiguities involved in understanding the Li-group diviners use of qi:

[117A] 丁巳卜：其燎于河羍沉㢺

Crack-making on dingsi (day 54): "If/when we burn-sacrifice to the River Power, (use) a lao and ritually-drown a female sacrificial victim." 
[117B] 己末卜:其明羊十于西南

Crack-making on dingwei (day 56): *"In this case gang-sacrifice sheep, ten, to the Southwest." (I. Li) (HJ 32161)

Since the context indicates that the initial $q i$ of $[117 \mathrm{~A}]$, 其 $\mathrm{RV}_{1}$ 于 $O \mathrm{OB} O \mathrm{OV}_{1}$ $\mathrm{RV}_{2} \mathrm{OV}_{2}$, served to subordinate the initial clause, one would reasonably expect that the initial $g i$ of $[117 \mathrm{~B}]$, 其 $\mathrm{RV}$ OV 于 $\mathrm{OB}$, served a similar function. That the phrase specifying the object-beneficiary in [117A], 于河, has, in the form of 于西南, in [1178], been shifted from the middle of the charge to the end, encourages me to reorder [117B] as *其㡐于西南羊十, 其 RS 于 OB OV, so that the structure of the charge parallels that of [117A]. This would permit a retranslation of [117B] as: "In gang-sacrificing to the Southwest, (use) sheep, ten of them." Such manipulation suggests to me, once again, that $q i$ at the start of a Li-group charge served to mark the subordinate, nominalized clause rather than to indicate the delimited action of: "In this case..." What had at first appeared to be two different uses of $q i$ in similar charges, [117A\&B], turns out to have been only one.

Unpaired Hunting Inscriptions, Periods III-V

We may end this survey of Li-group practice in periods I and II by considering the fate of $q i$ in subsequent periods. The way in which $q i$ routinely demoted the initial clause is well illustrated by the following period III-IV charges about hunting:

[118] 戊子卜何貝:王其田往來亡災

Crack-making on wuzi (day 25), He divined: "(As to the king's hunting =) If/When the king hunts, going and coming back, he will have no disasters." (III) (HJ 28474; Y321.2) 


\section{[119]今日王其田渭日不雨}

"(As to the king's hunting tuday = ) If/when the king hunts today, the whole day it will not rain." (III-IV. He 3) (HJ 28520; Y215.1)

[120A]己巳卜狄貞:王其田車辛亡焱

Crack-making on jisi (day 6), D divined: "(The king's hunting should be on a xin-day; there will be no disasters."
[120B]己巳卜[犾]員:王其田禹壬 [亡災]
$R\left\llcorner へ^{2}\right.$

Crack-making on jisi (day 6), [D] divined: "The king's hunting should be on a ren-day; [there will be no disasters.]"

$$
\text { [120C]己巳卜犾貞：王其田車乙亡炎 L」へ }
$$

Crack-making on jisi (day 6), D divined: "The king's hunting shuuld be on an $y i$-day; there will be no disasters." (III-IV. He 3) $(\text { HJ } 27146=\text { Jiabian } 3914.10-12 ; Y 804 . \mathrm{i}, \mathrm{S} 428.3)^{173}$

Finaliy, it shoulu be noted that, whereas $y i$ had been present in the protasis of virtually every period II and II charge about hunting (as in $[118]-[120 \hat{A}-C])$, in periud $v$ the initial $q i$ had virtualiy vanished from the record. ${ }^{74}$ The basic period $V$ formulas, accordingiy, are represented by [12i] and [122], with the demotion of the head clause supplied by the context alone (ĉ́. [1i3]):

\section{[121]乙酉卜員:王画喪往來亡災}

Crack-making on yiyou (day 22): "If /wihen the king hunts at Sang, going and returning, there will be no disasters." (iv. Huang) (HJ $37367 ;$ Y8072)

173. I fulluw the transcriptions of [120A-C] given by Qu wall in his commentary to Jiabian 3914, by Shima (at S428.3), and the MZ editors. I an unable to see all the characters that they have seen, and I am nut confident that I have placed the inscriptions correctly on the shell.

174. The only late-period exceptions I have found are the three period $v$ charges on $H J 37793$ [Y809.2]：貴:王其田亡焱" if the king hunts, there will be no disasters." 
[122]辛亥卜是:今日王田害泪日不運雨

Crack-making on xinlal (day 48), divlned: "If/when today the king hunts at Hui, the whole day (he) will not encounter rains." (V. Huang) ( $H J 37728 ;$ Y809.2)

One can well see that [121] can be understood as an abbreviation of

*王其田叟往來亡災 (cf. [111] and [112]) and that [122] can be understood as an

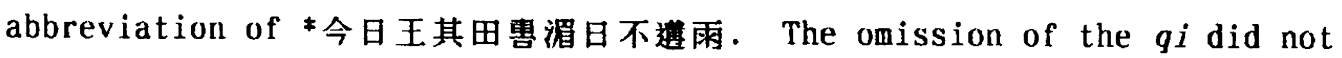
affect the meaning. Optional, as it had always been, it had increasingly fallen into disuse (see too the discussion on page 84 above). 


\section{DIVINATORY CONVENTIONS IN BIN-GROUP CHARGE-PAIRS}

\section{$Q i$ in Bin-Group Charge-Pairs}

In the reign of Wu Ding (ca. 1200-1181 B.C.), as is well known, the Bingroup diviners often presented their charges in the form of "perfect" (see page 209 below) positive-negalive charge-pairs (indicaled in this study by the symbols $\approx$ and $\approx$ ), one of which frequently contained $q i$ 其 (oracle-bone form ()). The question that many scholars have addressed is why did Wu Ding's diviners use $q i$ in numerous divination charges (like [1B]) and omit $q i$ in other charges ([1A]) that were similar or virtually identical? Any explanation of $g i$ will have to make consistent sense of the Bin-group examples provided below.

The Bin-group preference for placing $q i$ in one rather than the other of the charges that composed a charge-pair was strong and consistent, both in the general corpus and on particular bones. Of 55 period I charge-pairs involving rain in the Bingbian corpus (see Table 1), for example, 22 (40 percent) of the charge-pairs were of the form 其雨/不雨 and 17 (30.9 percent) were of the form 雨/不其雨. Thus, some 71 percent of these paired period I charges about rain observed the basic pattern: $q i$ in either the posilive charge (in modern Chinese, the zhengwen 正文), or the negative charge (the fanwen 反文), bui not in both. To lake a particular bone, the plastron that que used to divine $[145 \hat{A}-\dot{U}]$ now records, in ils fragmenlary staie, nine-plus charge pairs-- 
covering a period of twelve days (from dingmao [day 4] to wuyin [day 15])-that were all, without exception, of the form: 帝其令雨/帝不令雨, "Di will in this case order rain/Di not order rain." Such consistency in over nine instances, with $q i$ always present in the negative charges but never in the positive charges, is typical.

The conclusion that the Bin-group diviners did not use $q i$ randomly is further supported by many unpaired divinations involving cult in which the Bin-group diviners did not use $q i$ at all, as in [123AB] and [124A-X] below:

[123A]丁亥卜靔貞:翌庚宙出于大庚 $R L$

Crack-making on dinghai (day 24), Que divined: "On the next gengyin (day 27), (we) will make offering to Da Geng (K5)."

[123B] 具: 翌辛卯生于祖辛

Divined: "On the next xinmao (day 28), (we) will make offering to Ancestor Xin (K13)."

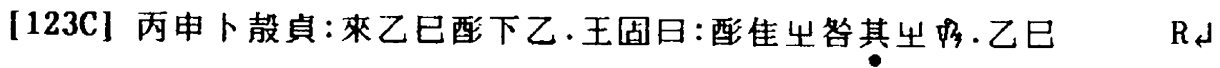
酰明雨伐既雨咸伐亦雨施卯鳥 (=修?)星 (=晴)

Crack-making on bingshen (day 33), Que divined: "On the coming yisi (day 42), perform the you-cutting sacrifice to Xia Yi (K12)." (Prognostication:) The king read the cracks and said: "When (we) perform the you-cutting sacrifice there will be occasion for calamities; in this case there will be thunder." (Verification:) On yisi (day 42), (we) performed the you-cutting sacrifice. At dawn it rained; at the dismembering sacrifice it stopped raining: ${ }^{175}$ when the dismembering sacrifice was all done, it likewise rained; when (we) displayed (the victims) and split them open, it suddenly (?) cleared."

[123D] 丙午卜爭貞: 來甲宙酛大甲

L L

175. Takashima (1984-85:294) translates differently; he takes $j i \quad y u$ 既雨 as "It was really (<already) raining," and thus in parallel with $y i$ yu 亦雨, "it was still (or likewise) raining." This is possible, but as Nivison has pointed out to me (letter of 15 November 1976), in Bingbian 209.3 (the second plastron in this set) the sequence fa $j i$ yu 伐既雨 is omitted as a unit so that it may also be considered as a unit in 207.3 . 
Crack-making on bingwu (day 43), Zheng divined: "On the coming jiayin (day 51), (we) will perform the you-cutting sacrifice (to) Da Jia (K3). (I. Bin) (HJ 11497f = Bingblan 207.1-4)

All four of the simple charges on the front of this plastron-fragment concerned the future offering of cult on a precise, predetermined schedule (1.e,. the offering to a Geng ancestor on a geng-day, to a Xin ancestor on a xin-day, etc.). None of the charges contained $g i$ and none were palred. One can see the same avoldance of $q 1$--and the use of imperfect charge-pairs--in a variety of related charges on another Bin-group plastron fragment. The 24 charges remaining to us, mainly divined by Que over a period of 14 days, contain 124 characters, not one of which was $q 1$ :

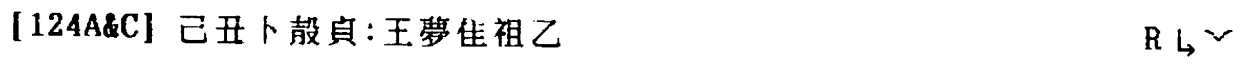

Crack-making on jichou (day 26), Que divined: "The king's dream is (due to?) Ancestor Yi (Ḱ12)."

[124B\&D] 貝:王贾不隹祖乙 Lง

Divined: "The King's drean is not (due to) Ancestor Yi."176

[124E]己丑卜靔貝：@吁于商丘。四月

$R \dot{L} \rightarrow$

Crack-making on jichou (day 26), Que divined: "Perform the ax-blow sacrifice at Shangqiu." Fourth moon.

[124F] 貝:勿笛釈于商丘 Lฝ

Divined: "Do not specifically perform the ax-blow sacrifice at Shangqiu."

[124G]翌辛卯出于祖辛 $R L^{\sim}$

"On the next xinmao (day 28), make offering to Ancestor Xin (K13)."

[124H]頁：出于祖辛三羍

Lง

176. The imperfect charge-pair $[124 \mathrm{AB}]$, engraved near the spine on the right and left hypoplastron, was repeated as [124CD] (not reproduced here), engraved near the edges of the right and left hyoplastron. 
Divined: "In making the offering to Ancestor XIn, (use) three lao." 177

[124I]翌辛坐于祖辛一牛

$R L^{2}$

"On the next $x$ in day (1.e., xinmao), in making the offering to Ancestor Xin, (use) one bovid."

[124J]一牛于祖辛 L」へ

"(Offer) one bovid to Ancestor Xin."

[124K]坐于祖辛羍

$R L^{2}$

"In making the offering Ancestor Xin, (use) a lao."

[124L]具:于祖辛出(宰?)

R」へ

Divined: "To Ancestor Xin offer (a lao?)."

[124M]坐于祖乙

"Yake offering to Ancestor Yi."

[124N] 壬辰卜靔：出于示壬羍

Lل

Crack-making on renchen (day 29), Que (divined): "In making the offering to Shi Ren (P5), (use) a lao."

[1240] 生于示壬二牛

"In making an offering to Sh1 Ren, (use) two bovids."

[124P] 甲午卜爭: 于河

$R L^{2}$

Crack-making on jiawu (day 31), Zheng (divined): (Make offering) to the River Power."

[124Q]甲午卜爭:勿于河

LA

Crack-making on Jlawu, Zheng (divined): "Do not (make offering) to the River Power."

[124R][甲]午[卜]敖[賁]:庋三舞

$R L^{2}$

[Crack-making on $j 1 a$ ] wu (day 31 ), Que [divined]: "(In offering)

captives, three of them, (use) dance."

[124S] [甲]午[ト]靔[賁]:勿[庋三舞] L」へ

177. For the understanding that a co-verb like yong 用 should be inserted in such complex charges, and that the charge itself is complex, see pp. 15. 
[Crack-making on Jla]wu, Que [divined]: "Do not, (in of fering)

[captives, three of them, (use) dance]."

[124T]壬宙卜靔賁:河害王

Crack-making on renyin (day 39), Que divined: "The River Power is harming the king."

[124U]壬宙卜䐨貝:河弗害王

L」た

Crack-making on renyin, Que divined: "The River Power is not harming the king."

[124V]壬宙卜靔貝:不雨佳茲商出作禍

$\operatorname{Rav}$

Crack-making on renyin, Que divined: "Its not raining means that this Shang (settlement) has (some Power) making something ominous (for it)."

[124W] 貝: 不雨不隹茲商出作禍

L Lへ

Divined: "Its not raining does not mean that this Shang (settlement) has (some Power) making something ominous (for $1 t$ )."

[124X]癸卯卜教: 翌甲辰生于上甲十牛

Crack-making on guimao (day 40), Que (divined): "In the next day, jiachen (41), of fering to Shang Jla (P1) (use) ten cattle." (I. Bin) $($ HJ $776 \mathrm{f}=$ Bingbian 203.1-24)

The marked absence of $g$ is on this plastron is worth comment. The assumption that the engraver had simply decided to omit the $g$ is--on the grounds, as we have seen, that their insertion was optional, is not, I thlnk justified, 178 Nor is it the case that the diviner Que, who with the exception of [124PQ], appears to have been the diviner of record for most of the charges, was a diviner who avolded using $g i$ in his charges. Indeed, it will be instructive to consider the kinds of charges, mainly charge-pairs, in which Que did use $g i$ and the kinds in which, as in $[124 \mathrm{~A}-0, \mathrm{R}-\mathrm{X}]$, he did not.

178. The writing style on $H J 6943(=$ Bingbian 211) and $11018 \mathrm{f}$ (= Bingbian 201), for example, is simflar to that used to record the inscriptions of $[124 \mathrm{~A}-\mathrm{X}]$; but the engraver of these plastrons recorded $q i$ five times on the first(divined by Que), and twice on the second (divined by Zheng and Que). 
Que employed $g i$ in, for example, the following inscriptions considered in this study; In most cases, as indicated, the charges (simple or complex) belonged to charge-pairs, on plastrons, that were perfect or imperfect: Rain (Complex charge) (Imperfect pair)

Shang at tack (Complex)

Shang attack (Complex)

Rain (Simple charge)

(Perfect pair)

Recelve harvest (Simple)

(Perfect pair)

$[140 \mathrm{~A}, \mathrm{~B}, \mathrm{C}]$

Rain (Simple)

(Perfect pair)

[145A, C, E, G, I , K, M, O,Q,R]

$$
\text { Di ordering rain (Simple) (Perfect pair) }
$$

[150B] Childbearing (Simple) (Perfect pair)

[153B] Childbearing (Simple) (Perfect pair)

[155B] Shang receiving assistance (Simple) (Perfect pair)

[164B] Someone bringing horses (Simple) (Perfect pair) Rain (Simple)

(Perfect pair)

$[170 \mathrm{C}]$

Rain (Complex)

(Imperfect pair)

This listing gives rise to three immediate observations: First, it further demonstrates that $q i$ frequently appeared in one element of a chargepair, whether perfect or imperfect. Second, there was no strong correlation in Bin-group charges between complex charges and $q 1$ usage (see the discussion on page 32 abovel; most of the cases that involved $q 1$ were simple charges.179 Third, Que tended to employ $g i$ in cases where the outcome was not entirely

179. The Bin-group charges translated in this study, of course, are not a representative sample of the group's $q i$ usage; the sample represents my own interest in particular kinds of cases. 
under Shang control, 1.e., cases--such as rainfall, campaigning, good harvests, someone's arrival, childbearing, assistance from the Powers--in which the king's decision to act could not determine the outcome.180

By contrast, the charges without $q 1$ over which Que presided, as exemplifled by $[124 \mathrm{~A}-0, \mathrm{R}-\mathrm{X}]$, were also members of charge pairs, but the pairs were, with one exception ([124TU]), imperfect rather than perfect. The charges were also nearly all simple rather than complex (the one exception, [124AB], is discussed on page 99 below). Third, the $[124 A-0, R-X]$ topics that Que divined on this plastron differed from those listed above in that they efther involved: (1) actions, like the offering of cult, that the king himself could or could not take without involving the cooperation of a second or third party; these were actions that we may refer to as "under Shang control";181 or: (2) "significance tests" about the meaning of events or to identify the Power responsible for producing them, as in Que's attempt to discover whether a dream or a fall of rain was or was not ominous or disastrous (as in [124AB\&VW]], or whether a particular Power was or was not harming the Shang (as in [124TU]).

In these simple charges of control or significance-testing, one might well suppose that there would have been no need to delimit the fanwen or zhengwen at the expense of its pair-mate. There would have been no need to formulate, as a variant of [124T], *河其害王, *"The River Power is in this case harming the king." This is because the information gained as a result of

180. Cf. Keightley $1988: 378$ on the kinds of lopics that were likely to paired or not paired.

181. For the distinction between controllable and uncontrollable actions, see Takashima $1973: 106,176,186-95 ; 1988: 115-16,118-19 ; 1990: 21$. See too n. 58 above. 
the divination--about whether the River Power was or was not harming the king--would not have been harmful but useful, since it would have permitted appropriate ritual action to then be taken. There would have been no need to restrict the import of one charge or the other.

It is true that one can find rare cases in which, by contrast to the situation in [124TU], one member of a Bin-group charge-pair about some Power cursing the Shang was marked with a $q i$, as in:

[125A] 娥其害王 $R L^{2}$

"E is in this case harming the king."182

[125B] 貝: 娥弗害王 L」

Divined: "E is not harming the king." (I. Bin) (HJ 1677f = Yibian $5313)^{183}$

But even in this case one can find the identical charge-palr without the gi, as in:

[126A] 員:娥害王 $R L^{2}$

Divined: "E is harming the king."

[126B] 娥弗害王 L」へ

"E is not harming the king." (I. Bin) (HJ $738 \mathrm{f}=$ Yibian 3429)

182. E was evidently a female Power, closely connected to the ancestresses of the royal house; see Akatsuka 1977:239-42. For additional views, see Allan 1991:189, n.125.

183. Since Que was recorded as the diviner on another charge on this plastron, it is likely that he was the diviner of [125AB]. In light of the discussion above, accordingly, it is of some interest that he employed no $g i$ in $[124 \mathrm{~T}]$ but did so, in a similar charge, [125A]. 
Such "identification" charges about various Powers causing or not causing harm were, In fact, almost invariably recorded without the $q i^{184}[125 \mathrm{~A}]$ was an exception. One could, of course, argue that the situations in [125AB] and [126AB] were subtly different, that the diviner of [125A] (not furnished with a prefatory 貝) had wished to delimit the charge, 娥其害王, in some way, and that the diviner of [126A], 娥害王 (furnished with a 貝)--like Que, the diviner of [124T], 河害王 (furnished with a rull 壬宙卜靔貝 preface)--had not. 185

Unpacking $H J$ 776f

It is instructive to explure some of the the twenty-four qi-less charges, $[124 \mathrm{~A}-\mathrm{X}]$, in more detail. With regard to the first charge-pair, [124AB] 王爱焦祖乙/王夢不隹祖乙, about the king's dream, such charges were only divined in period 1 , and, with only one exception, were never recorded with a qi. The one exception is:

[127A]壬午卜靔貝:王出夢其坐禍 $\mathrm{R} d \approx$

Crack-making on renxu (day 59), Que divined: "As to the king having a dream, in this case he will have something ominous."

[127B] Øト殸口王坐夢し禍

Crack-making on [renxu], Que [divined]: "As to the king having a dream, he will not have something ominous." (I. BIn) (HJ 17409 f)

If we lake the $g i$ in the complex charge [127A] as an anaphoric reference to the king, then we have a paratactic juxtaposition: 'The king's having a dream;

184. See, e.g., HJ 94, 2433, 6947f, 10299f, 14003f, 14488, 14707, etc. from the sample at $\mathrm{Y} 683.1 \mathrm{of}$.

185. For the argument that $q i$ was used more liberally when diviners were not recorded as being present, see convention no. 5, "Divinerless Inscriptions," on page 163 below. 
his having something ominous,' and it would be tempting to treat the charge as a quasi-隹 construction: *王出爱隹其生禍, *'The king's having a dream is/means his having something ominous.' I would argue that the $g i$ was required in this complex charge because it provided a resumptive agent for the 4 . Had the closing clause been 隹禍 rather than 4 祜, then the $q i$ would have been unnecessary, as in the next charge-pair:

[128A]王戌卜爭具:王夢隹禍 $R \downarrow \approx$

Crack-making on renxu (day 19), Zheng divined: "The king's dream is ominous."

[128B] 壬戌卜】王夢不隹禍

L L

Crack-making on renxu [Zheng divined:] "The king's dream is not ominous." (I. Bin) (HJ 17407f)

The contrast between $[127 \mathrm{AB}]$ and $[128 \mathrm{AB}]$, in ract, leads to the observation that the combination *其住 is never found in Shang divination charges. The combination is certainly found in prognostications--as in [6C], [150AC], $[153 \mathrm{~A}],[167]-$-where it meant "this being = It's being (the case that), "thus introducing the dependent clause in a conditional forecast. But in charges, the wei 隹 served as the copula that was equivalent to the French être, "to be, to mean," and as such, it was used in the main assertion of the charge to state that some event "was" ominous or "meant that" some Power was doing something (as in [124AB] and [128AB] above; see too [170CD], [172], and [173] below).186 Such charges of "neutral identification or explanation" were not delimited: the event meant something or it did not mean something; the diviner did not prefer one version of the charge over the other; there was no need to

186. For wei as the explanatory copula, see Takashima 1990 (espec. pp. 63-66); see too Keightley 1991:469. 
limit the positive or negative version of the utterance with an "in this cáse. ${ }^{1187}$

The other Shang verb of existence, you 4 , by contrast, which was equivalent to the French avoir, "have" (cf. Il $y$ a, "there is"), referred, in the main assertion, to the possible existence of something that would impinge on the Shang, and when that possibility was undesirable, then the you was frequentiy delimited with a $g i$, as in [127A], [155D], [146A], and [147A]. In short, there is no reason to think that the diviner or engraver of [124B\&D], 王夢不隹祖乙, had deliberalely omitled a $q i$; il was routine practice for charges about dreams that ended with 不住祖乙 (or some other ancestor) or with 不隹䙤 not to employ $g i$.

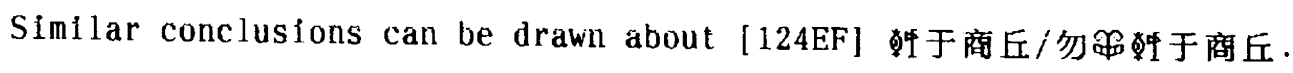
Such charges were only divined in period $I$ and they were never divined with a $q i .188$ The absence of the $g i$ on this plastron, accordingly, was entirely regular.

The varfous charges about offering animal sacrifice to Ancestor $X i n$, [124G-Y], were also generally recorded without $q i$ in period $I$, even when (as in $H J$ 1653) the charge was complex.189 In period II, $q 1$ was used, but rarely, in charges like:

[129A] 庚子卜行日貝:翌辛丑其又升成于祖辛 $\mathrm{R} \hookrightarrow$

187. Cf. Takashima $(1988-89: 50 ; 1989: 136)$ who notes that charge-pairs of the form 佳䙐/不住禍 have "equal informational value."

188. See the sample at Y939.2-40.1.

189. See the sample at Y1406.1-08.2. 
Crack-making on gengzi (day 37), Xing said and divined: "On the next day, xinchou (day 38), the offering of the presentation (will use) cut-up victims to Ancestor Xin (K13)."

[129B] 貞:翌辛丑其又祖辛羍>R L

Divined: On the next day, xinchou, the offering (to) Ancestor Xin (will use) a lao."

[129C]員: 翌辛丑祖辛歳物牛

Divined: "On the next day, xinchou, the cutting-sacrifice (to) Ancestor Xin (will use) a dappled bovid."190 (II. Chu) (HJ 23002)

The Li-group and period III diviners also inserted $q i$ at the head of charges about offering cult to Ancestor $X i n$, as in:191

[130] 庚申賁: 其告高祖裙以祖辛

On gengshen (day 57) divined: "In making ritual-report to the High Ancestors, pray (by means of $=$ ) by going through Ancestor Xin." (II. Li 2) ( $H J$ 32314)

[131] 其又祖辛王受又, 壣用

"If he makes offering to Ancestor $X i n$, the $k$ ing will receive assistance." This was used. (III) HJ 27251

There is no reason, in short, to $\mathrm{f}$ ind the $g i$-less charges [124G-Y] unusual; they conformed to Bin-group practice. That the Li-group and later diviners did tend to use $g i$ in such contexts us precisely what we would expect (see pages 49 and 51 above).

Similar conclusions can be drawn about [124NO], 出于示壬羍/出于示壬二牛. Bin-group and Chu-group charges about cult of ferings to Shi Ren were never

190. I read the three charges as quasi-隹 (or quasi-車) constructions: [129A] *...其又升隹藏于祖辛；[129B ${ }^{*}$...其又于祖辛隹羍; and [129C]

*于祖辛歲住物牛。

191. For similar period III cases, see $H J 27254,27503$. 
recorded with a $q i .192$ The Li-group diviners did on occasion employ $q i$ at the head of the charge, as in: 193

[132A] 癸亥真:其又升于示壬卯三牛

Divined on guihai (day 60): "In of fering the presentation to Shi Ren (P5), split open three bovids."

[132B] 癸亥員:其又升于示壬燎三小羍

Divined on guihai: "In offering the presentation to Shi Ren, burn-sacrifice three small lao." (II. Li2?) (HJ 32397)

Once again we see a pattern in which the Li-group diviners were more prepared to use $q i$ than their Bin-group (or later) colleagues ( $q i$ appears in rone of the period $V$ charges about cult to Shi Ren]. That [124N0] were recorded without $g i$ was entirely standard for Bin-group charges.

It is unnecessary to prolong the argument in detail. In the case of [124PQ], 于河/勿于河, no Bin-group analogues were recorded with $q i$. The Ligroup diviners, however, quite frequently inserted $q i$ at the head of charges about cult to the River Power, as in [92AB].194 In the case of [124RS] 尼三舞/勿[居三舞], the analysis is complicated both by the uncertainty of the translation I have offered and by my inability to translate the small number of other inscriptions in which the phrase 其居 does appear in the head position, perhaps, serving as a deictic.195 There are, however, no precise Bin-group analogues that employed $q i$. For the case of [124TU], 河害王/河弗害王, see the discussion of [125AB] above; despite this exception,

192. See the sample at Y1372.2-73.2.

193. See too the four Li-group charges with $g i$ at their head recorded on the scapula fragment $H J 33293$.

194. See tou $H J 33281,33283,33698,33699$, etc., at Y489.1.

195. E.g., HJ 16468 (I. Bin), 21548 (I. Zi), TN 1059 (I. Li). 
such simple Bin-group charges about curses were usually recorded without $q i$. With regard to [124VW], 不雨隹茲商出作禍/不雨不隹茲商坐作禍, there are, once again, no Bin- or other diviner-group analogs that employed $y i$ in seeking to determine the meaning of no rainfall. The phrase 其出作䙐 can be found in a Bin-group charge-pair:

[133A] 庚线卜内貝:王入于商亡作禍 R L ${ }^{-2}$

Crack-making on gengxu (day 47), Nei divined: "If/When the king enters into Shang, there will not be (sume Power) making something ominous."
[133B] 貞:王入于商其坐作䙤
L」へ

Divined: "If/When the king enters into Shang, there will in this case be (some Power) making something ominous." (I. Bin) (HJ $7772 \mathrm{f}=$ Bingbian 165.16-17)

But in this instance--which was not about delermining meaning but about determining outcomes (see the discussion on page 100 above), the use of $y i$ to delimit an undesired outcome, represented normal Bin-group practice. The absence of $g i$ in $[124 \mathrm{VW}]$, however, which was about meaning, was entirely standard.

Finally, similar conclusions can be drawn about the unpaired charge, [124X] 翌甲辰出于上甲十牛. There are few if any Bin-group and logues to this charge that employed $y i .196$ Wu Ding's engravers never recorded charges of the form *翌甲辰其出于上甲十牛, *"On the next day, jiachen (41), in this case make offering to Shang Jia (with) ten cattle." The king, in such Bin-group divinations (controllable) about offering cult, knew precisely when he wished to offer cult and to which Power he wished to offer it;197 the marking that $y i$

196. One possible exception is the fragmentary $H J 13548$.

197. The Li-group diviners, on uccasion, did employ $y i$ in the head position of complex charges about ritual sacrifice; see, e.g., [92AB], [96], [100], 
provided would evidently have been superfluous in such contexts, and so would the use of a positive-negative charge pair (see below).

\section{Qi Marked the Core}

If we return to the well-known charge-pair (fig. 1): [83A] 我受㯟年 and [83B] 我弗其受㯟年, there is little disagreement about how the positive charge, [83A], which in this case has no $q i$ in it, should be translated: "We will receive millet harvest." The negative charge, [83B], which does contain the $q i$, is where the interpretive difficulties lie. Takashima had earlier offered, "We shall not perhaps receive a (good) millet crop."198 Factoring in "the 'possibility' of not harvesting and the 'wish' that the situation not develop in that way," together with what he regards as "the prospective or anticipative aspect of $q i, "$ Takashima has now proposed, "We shall not perhaps be going to receive (= harvest) a millet crop."199

Given my new understanding of $q i$ as deictic rather than modal, I translate [83B], 我弗其受年, as "We will not in this case receive millet harvest." with the understanding that the "in this case" was anaphoric, a

[101], [103], etc. None of the charges, however, were members of perfect pairs; nor, unlike the Bin-group, did the Li-group employ the formula 翌干支... to start their ritual-sacrifice charges.

198. Takashima 1973:338. I had followed Takashima's reasoning (and that of Serruys) to propose "We will not perhaps receive millet harvest (Keightley 1978, fig. 8; see too Takashima 1973:267-305; Serruys 1974:25, 58$.$) I had also suggested, wrestling with q^{\prime}$ 's supposedly modal qualities. "We may not receive millet harvest" (Keightley 1988:367; $1992: 3$; in press, 33) and "We might not receive millet harvest" (Keightley 1993:12).

199. Takashima 1994a: ms., 21-22. 
the harvest divined to in the zhengwen, [83A]), 我受年.200 One could argue that the anaphoric-genitivizing role of $q i$ (see note 4 above) operated in such cases, so that [83B] could be translated as an exclamatory phrase, "Our not receiving the millet harvest!"201 I do not believe, however, that $q i$ played such a needlessly complicating role in simple, complete charges. 202

Support for the translation offered may be derived from two related observations about Shang divinatory syntax. First, when $q i$ appeared in only one charge of a simple charge-pair (i.e., a pair in which the charges did not involve complex sentences), the text that followed the $q i$ (受雪年 in the case of (83B]) was almost always an exact duplicate of the verb or verb phrase that we may regard as the core concern or "main assertion" of the paired charge that did not contain the $q i$ (i.e., 受霡年 in the case of [83A]). With the exception of one class of inscriptions, to be discussed in a moment, the text

200. I first proposed the translation, "in this case," for $q i$ in keightley 1992:20-35, under the rubric of "the delimiting $q i$." As I noted then, the delimiting role of $q i$ would be well suited to the "basket" that the oracle-bone graph $\&$ may have represented. (Shuowen took 其 to be the original form of $j i$ 箕, "winnowing basket." According to Karlgren [GSR, no. 952], no text examples support this etymology, but $j i$ 箕 does appear with this meaning in Liji; see Couvreur 1899, 2:789.) The word would have served to winnow out, separate out one group of words from others--" in this basket," "in this case," "at this time." This leads to the possibility that we should read $q i$ 其 as $q i$ 期 ...in the sense of "at this particular time." (Cf. the standard, dictionary meanings of $q i$ 期. "a period, fixed time, stipulated time, limit"; GSR no. 952k; Schuessler $1987: 472$ ).

201. For the possibility that some charges were exclamatory, see pages 20 and 62 above.

202. An exclamatory fanwen in such cases raises the question of how the zhengwen, lacking the $q i$, should be translated. Should [83A], 我受乘年, statement, "We will receive millet harvest"? Or should we impose the putative structure of the fanwen upon it, the exclamatory, "Our receiving millet harvest!"? 
that followed $g i$ in one charge of the pair duplicated the language at the core of the other charge in the pair.203 Thus, [83A/B] …受年 (core text) $/ \ldots$ 弗其'受㯟年' (negative + 其 + 'core text'); [141A/B] 雨 (core

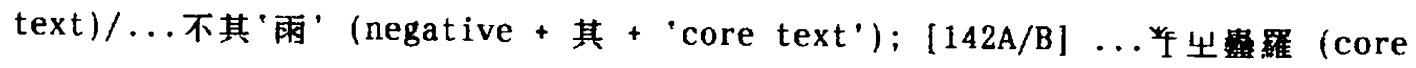
text) / ...弗其'毕出患羅' (negative + 其 + 'core text'); [164AB] …來白馬 (core text)/...不其“來白馬' (negative + 其 + 'core text'), etc. The core text was precisely the text that followed the $q i$, whether the $q i$ appeared, as in the great majority of cases (including those just quoted), in the fanwen, or, more rarely, in the zhengwen, as in $[154 \mathrm{AB}], \ldots$ 其 '疾骨' (其 + 'core text') /... 弗疾情 (negative + 'core text'). This usage was also observed in the apodosis of complex charges--the concluding clause of a conditional sentence, which indicated the consequences of the action (usually uncontrollable) contemplated in the protasis--as in [134AB] …受出又 (core text)/...弗其“受出又” (negative + 其 + 'core text'):204

[134A]辛酉卜靔貞:今告比望乘伐下危受出又 $\operatorname{Rd} \approx$

Crack-making on xinyou (day 58), Que Divined: "This season the king should join with wang Cheng to attack the Xiawei, (for) he will receive this assistance." 205

[134B]辛西卜琪貞: 今告王勿比望乘伐下危弗其受出又 $L L \approx$

Crack-making on xinyou, Que Divined: "This season the king should not (wu) join with Wang Cheng to attack the Xiawei, (for) he will

203. With two possible (and trivial) exceptions--[136B] and [151AB] (discussed in note 207 below)--and apart from the systematic exceptions discussed on page 109, this 'core-duplication' is true of every charge-pair presented in this study.

204. For the meaning of the symbols in the right margin, see page 208 below.

205. For an introduction to the scholarship on the word here translated as "season," see Keightley (in press), 31, n.22. 
not in this case "receive this assistance." (I. Bin) (HJ 6482f = Bingbian 12.1-2; Y107.1)206

It should be noted that even in long, simple-sentence charges the core text could be relatively short--and in such cases the $q i$ was likely to be found towards the right of the charge, as in [135B]:

[135A]壬宙卜殸貞:自今至于丙午雨 $\mathrm{R} L \approx$

Crack-making on renyin (day 39), Que divined: "From today down to bingwu (day 43), it will rain."

[135B]壬宙卜靔貞:自今至于丙午不其雨 L

Crack-making on renyin, Que divined: "From today down to bingwu, it will not in this case "rain." (I. Bin) (HJ $667 \mathrm{f}=$ Bingbian $155.5-6)$

In this instance, I assume that the core concern was whether, within the period from "today down to bingwu," it would rain or would not rain. On other occasions, however, the core could be considerably larger, so that the $q i$ appeared towards the left of the charge as in [151AB] (discussed more fully on page 157 below):

[151A]貞: 帝弗其及今四月令雨 $R \downarrow \wedge$

Divined: "Di will not, in this case "when it comes to the present fourth moon, order rain."

[151B] 戊子卜靔貞: 帝及[今?]四月令雨

206. I discussed the inscriptions on this plastron set at Keightley 1978:76-90. The use of "in this case" and "this assistance" is more confusing in English than it would have been in Shang Chinese. The $q i$ was an inter-charge reference to the topic divined in the other member of the charge-pair, [134A] (see the discussion on pp. 111 and 120 below); the you (see $\mathrm{n}$. 128 above) was an intra-charge reference to the alliance and attack specified earlier in the individual charge, either [134A or B]. 
Crack-making on wuzi (day 25), Que divined: "Di, when it comes to the present (?) fourth moon, will order rain." 207 (I) (HJ 14138; Y419.1, partial)

In this case, by contrast, the placement of the $q i$ to the left of [151A] indicates that the diviner's core concern was whether $\mathrm{Di}$, when it came to the present fourth moon, would or would not, order rain. The early placement of the $g i$ meant that the next six characters of the fanwen, 及今四月令雨, duplicated the core text found in the zhengwen.

The systematic exception to this convention that I referred to above was this: fanwen in which the negative wang 亡 rather than bu 不 appeared, did not obey the rule of core duplication, as can be seen in the following charge-pair (presented in full context on page 165 below):208

[155C]賁:的正化亡禍 <3> $R L^{2}$ Divined: "Zhi Hua of Cha will not have something ominous (happen
to him)."

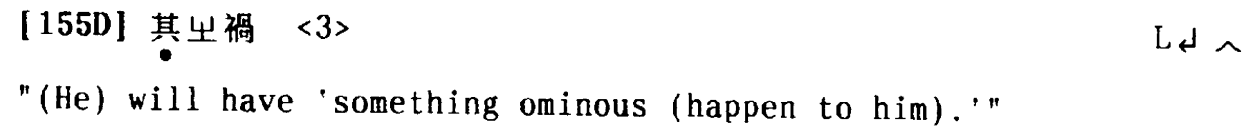

207. The $M Z$ editors do not see the $j$ in 今 in [151B]. Two considerations, however, suggest that it may have been present. First, [151B], with its preface, was the fuller of the two inscriptions forming this charge-pair; it would be anomalous to find that its charge was more abbreviated than the charge of the inscription without the preface. Second, examination of the rubbing suggests that a $j i n$, which would have fallen on the suture where the hyoplastron met the hypoplastron, might have been present, just below, and perhaps confused with the previous character, $j i$ 及. Indeed, if, in accordance with convention no. 3 (page 152 below), we conclude that [151B] was divined first, and that it was also recorded first (a topic, it is true, that I do not know how to addresss with certainty), then one can speculate that the care with which the scribe who recorded [151A] placed the jin below the suture join on the right, may have been his response to the difficulties he had encountered, on the suture line, when he had recorded [151B] on the left.

208. See too $[146 \mathrm{AB}],[155 \mathrm{CD}, \mathrm{IJ}]$. 


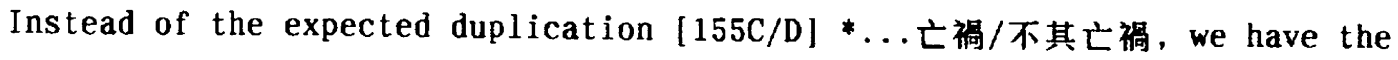
variation ...亡亡螎/其出禍. It is evident that when wang 亡 + Noun was involved in the fanwen the wang had to be balanced by a gi you 其坐 in the zhengwen. Presumably, the Shang wished to avoid, in this example, the redundant, double negative in *不其亡祜, * "not in this case "not have something ominous'"; they reduced this, quite naturally, to 其生螎.209

The second observation is that, when $g i$ was used in the fanwen of a charge-pair, the Shang word order was always Negative + 其 + Verb (as in [83B] 弗其受㯟年 and [56A] 不其雨) and never *其 + Neg + Verb (never *其弗受㯟年 and *其不雨). The pattern was so standard, in fact, that it was maintained even on the rare occasion when the engravers omitted the verb (or core text) entirely, as in:

[136A] 今夕雨 $\mathrm{R} \downarrow{ }^{2}$

"This evening, it will rain."

[136B] 今夕不其 L个へ

"This evening, it will not in this case ('rain')." (I. Bin) ( $H J$ $7352 \mathrm{f}=$ Bingbian $3.15-16)^{210}$

This placement, in charge-pairs, of the $q i$ before the verb or verb phrase rather than before the negative reminds us that it was only the core text that was governed by the $q i$; by placing the negative as they did, the Shang engravers made it clear that they were dealing with a case of, literally, "not this 'receiving millet harvest'" (弗其受年), "not this 'raining'" (不其雨)，

209. It may also be noted once again that it would also be possible to treat such charges as exclamations (see page 16 above): $[155 \mathrm{C}]$, "Zhi Hua of Cha's not having something ominous!," and [155D], "His having something ominous!"

210. For other inscriptions on this plastron, see [146AB] below. 
rather than *"this not receiving harvest" (*其弗受年) and *"this not raining" (*其不雨). The last formulation, 其不雨, in fact, which could be taken to mean "its not raining," should be understood as a subordinated clause that could mean, "if it not rain" $:^{211}$ such formulations are only found in prognostications, like $[150 \mathrm{~A} \& \mathrm{C}]$.

Since the demonstrative reference of $q_{i}$ in charge-pairs was consistently directed to the core text. I believe that we should understand a fanwen like [56A] 不其雨 as "not this 'raining," "with the "this 'raining'" referring to the 雨 of the zhengwen, $[56 \mathrm{~B}]$, so that [56A] meant not this raining divined about in the other member of the charge-pair.' Similarly, [83B], 我弗其受年, may be literally rendered as "We will not this 'receive millet harvest, " referring back to the 我受年 of $[83 \mathrm{~A}]$. I express how anaphoric $q i$ marked the core in this way by placing single quotes around the clause that it governed (thus dispensing with the "in this case").212 Hence, I would translate the charge [56A] 不其雨 as "It will not 'rain" and the charge-pair [83AB] (already presented on page 59 above) as follows:

[83A] [丙]展卜靔賁:我受黍年 $\langle 1\rangle\langle 2\rangle\langle 3\rangle\langle 4\rangle\langle 5\rangle \quad \mathrm{R} L \approx$

(Preface:) Crack-making on /bing-Jchen (day 53), Que divined:

(Charge:) "We will receive millet harvest."

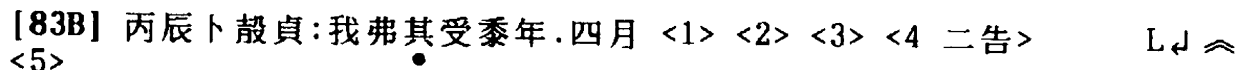

(Preface:) Crack-making on bingchen (day 53), Que divined:

(Charge: "We will not 'receive millet harvest.' (Postface:)

Fourth moon. (I. Bin, 1) (HJ $9950 \mathrm{f}=$ Bingbian 8.1-2; Y536.2) (I.

Bin, 1) (HJ 9950b = Bingbian 9; Y535.1)

211. David Nivison, conversation of 27 November 1994.

212. See too the discussion on page 183 below where it is suggested that $g i$ had the sense of "namely" in certain prognostications. 
The decision to use punctuation rather than words to convey the deictic sense of $g i$ in Bin-group charge-pairs has the virtue of suggesting the relatively light, though entirely real, semantic impact that $I$ believe the word had in Shang charges in general.213 $Q i$, in one member of a charge-pair, served to highlight, to focus attention on, the words that also appeared as the core of the other member of the charge-pair. Indeed, the translation could be lightened still further by replacing the single quotes with "the, "so that [83B] could be rendered "We will not receive the millet harvest," that is, the millet harvest referred to in $[83 \mathrm{~A}]$.

CONVENTION NO. 1 (INITIAL FORMLLATION): RIGHT AND LEFT PLACEMENT

Having established the way in which $I$ interpret $q i$ in Bin-group chargepairs, I next turn to a series of divinatory conventions, induced from the evidence, that the diviners and engravers appear to have observed. By situating $q i$ in its divinatory context, I hope to demonstrate more fully the ways in which the Shang employed the word.

Convention no. 1 states, as an initial hypothesis that when they cracked the turtle plastron to divine a pair of charges, the Shang diviners of period I generally placed the charge whose outcome they desired on the right of the shell, and the charge whose outcome they found undesirable (or less desirable) on the left.214 (For the revised formulation of convention no. 1, see page

213. For passages in later texts that may show $q i$ functioning to introduce a quotation, see Appendix $B$ on page 199 below.

214. Keightley 1978:51, n.124; Takashima 1988-89:15; 1989:10;1994:4, 11-12, ms.: 1994a:505. Nivison ???? The placement of inscriptions on scapulas, which lacked the clear central line of the plastromantic spine, was less rigorous (see Appendix A on page 193 below); there was a tendency to 
141 below.) That the form of the charge on the right should have been preferred in some way may, perhaps, be related to the general right-handedness of early Chinese culture. 215 It may also be related to what seems to have been a general human tendency to favor, in matters of divination, the right over the left.216 A representative example of the evidence that supports this assumption is the millet harvest divination, [83AB], presented above. The desirable outcome, the receiving of harvest, was divined in the charge, $[83 \mathrm{~A}]$, on the right of the shell; the undesirable outcome, the not receiving of harvest, was divined in the charge, [83B], on the left.217

observe the same convention, but charges forming a pair were frequently placed above and below rather than $r i g h t$ and left of each other (see, e.g., [A.1AB] [fig. 2 ] and [A.2A-G] [fig. 3] below); see too, Keightley
i $978: 38, n .45$.

215. Zhou Hongxiang (1969, "Preface," p. 4) has also suggested that the preference for the right may be related to the traditional Chinese preference for writing in columns that moved to the left--precisely the direction that was frequently, but by no means invariabiy, used to write the charges on the right. For inscriptions in this study whose columns did move from right to left, see, e.g., [140A\&F], [141G\&K], [56A], $[150 \mathrm{~A}],[153 \mathrm{~A}]$, and $[155 \mathrm{~A}]$. For inscriptions that violated this convention, see, e.g., $[83 \mathrm{~A}]$ and $[138 \mathrm{~A}]$.

216. Such "sector" distinctions occur in many divination systems. In ancient Mesopotamia, "one important principle of interpretation... is explicitly laid down in the handbook: "The right half refers to me, the left half to the enemy. This is the Roman distinction between the pars familiaris and the pars hostilis.... It means that an intrinsically good sign, if it occurred on the right, was favourable', if it occurred on the left, was 'unfavourable.' Similarly, a bad sign on the right was unfavourable, but one on the left was bad for the enemy and therefore "favourable" " (Gurney 1981:166-67).

217. The diviner of [83AB] also recorded the favorable (and thus desired) prognostication, [83C] 王固日: 吉受出年 $[(\mathrm{L})(\mathrm{j})]$ "The king read the cracks and said: "Auspicious; (we) will receive this harvest." " on the left of the plastron back, thus situating it immediately below the favorable charge, [83A], on the right of the plastron front; the desirability of the right side, in other words, inhered in the shell itself, and was thus present on the left side of the back. 
On occasion, the right and left placement of the desired and undesired charges might be displaced with reference to the central axis of the plastron, as in the following example (fig. 4):

[137A] 庚申卜古貞:王使人于䧅若.王固日:吉若

Crack-making on gengshen (day 57), Gu divined: "(If) the king sends men to $\mathrm{Yi}$, there will be approval." (Prognostication:) The king read the cracks and said: "Auspicious. (Some Power) will be approving."

\section{[137B] 貞:王勿使人于陝不若}

Divined: The king should not send men to $\mathrm{Yi}$, (for if he does, some Power) will not be approving." (I) (HJ $376 \mathrm{f}=$ Bingbian 96.25-26; Y133.1)

In this case, both charges were placed on the left side of the plastron's spine, with [137A], the desired charge that sought, and in the event, received, approval (in the prognostication), straddling the left hyoplastron and left hypoplastron, and with [137B], the undesired charge, being recorded at the bottom left of the left bridge. (For the modern names used to distinguished the parts of the plastron, see fig. 5.) Following convention no. 1 described above, however, the diviner had still placed the desired charge, [137A], considerably to the right of the undesired charge, [137B].

This Shang pattern of right/desirable and left/undesirable placement is too common to need further demonstration here.218 The convention is important to modern scholars since it generally provides one clue to determining which charge of a charge pair the Shang diviners preferred (i.e., [83A], 'receive millet harvest' rather than $[83 \mathrm{~B}]$, "not "receive millet harvest"'). It is, however, those cases in which the Shang did not observe the convention that

218. For other examples of this convention at work, see, e.g., $[2 A B],[3 A B]$, $[18],[138 \mathrm{AB}],[140 \mathrm{AB}],[141 \mathrm{AB}],[148 \mathrm{AB}],[149 \mathrm{AB}],[150 \mathrm{AB}],[153 \mathrm{AB}]$, $[142 \mathrm{AB}],[143 \mathrm{AB}],[144 \mathrm{AB}],[155 \mathrm{AB}, \mathrm{CD}, \mathrm{GH}]$. 
interest me.219 I now attempt to understand how such irregularities can be explained.

\section{CONVENTIONS NO. 2: RIGHT-LEFT SEQUENCE AND RETESTS}

On the plausible assumption that the diviners would first propose the charge that they desired (which, in obedience to convention no. 1, they would place on the right), before they proposed (on the left) the undesired charge that ran counter to their wishes, it has been proposed that the diviners cracked the (desired) charge on the right first, and cracked the undesired charge on the left second.220 The first charge cracked, which introduced the topic, can thus be characterized as "new information," the second (as already suggested by my use of single quotation marks above) as "old information," a "retest" of the first.221 It is plausible to assume, accordingly, that the

219. See, e.g., [2B\&D], [56AB], [140CD], [146AB], [147AB], [148CD], [154AB], [155EF\&IJ]. The large number of such irregular cases cited in this study does not represent their frequency in the entire corpus; they are assembled here in such here precisely because, as exceptions, they invite analysis.

220. My study of "subcharges" (e.g., Keightley 1991:8-14), which makes it possibie to associate particular subcharges with particular cracks, suggests that the diviners made crack number " 1 " on the right, followed by crack number " 1 " on the left, followed by crack number " 2 " on the right, crack number " 2 " on the left, and so on. They would not, at least in these cases, have cracked all the cracks associated with the charge on one side of the shell before turning to those cracks associated with the charge on the other side.

221. For the origins of this theory, see Takashima 1985:64, n.2, and Nivison to Keightley (letter of 22 January 1992): "I am assuming that the preferred alternative is the one thought of as being stated first (whichever was actually cracked first, if we can ever find that out)"; (letter of 24 January 1992): "Presumably the purpose of testing a paired charge was to get a confirmation of the result of the cracking on the primary charge.... (In fact, this reinforces my intuition that the primary charge is the favored alternative....)." See, too, Nivison 1992:13 (as cited by Takashima 1994:11-12 ms.), 1994, p. 4 ms.: " qi, being anaphoric, marks "old information," and the diviner simply (and 
grammatical anaphora, $q i$, "(in) this (case)" in the retest, referred back to the primary charge.222

In this view, the "old information" charges containing the $q i$ would have been divined second, and the "new information" charges without the $q i$ would have been divined first.223 we see this pattern in the case of [83AB], with the diviner proposing the new (and desired) information, without $q i$, in [83A], and proposing the old (and undesired) information, with $q i$, in [83B]. Such an explanation generally works wel] in cases like [56AB], [148AB], [149AB], and [150AB]. On the assumption that $q i$, "in this case," was used in a "retest" to refer back to the primary charge in the pair, convention no. 2 states that: The charge without the $q i$ was divined first, and the charge with the $q i$ was divined, as a retest, second. Qi may have been used as a marker in this way because the diviner, in reaching his judgments, needed to know which charge in the pair was the original test, which charge was the retest.

It should aiso be noted that it was this Bin-group convention of marking retests with the $q i$ that had led Serruys, and those of us who followed him, to

naturally) thinks of the alternative that he favors first." See too, Keightley 1992:23-26; Takashima 1994:11-12, 24, n.10 ms.

222. Qi played this role in Bin-group charge-pairs that involved actions not under human control; there is no $q i$ present, for example, in [137AB], which involved a decision about whether or the Shang king himself should do something. For $q i^{\circ} \mathrm{s}$ function in charge-pairs when it qualified actions under Shang control, see the discussion of [157AB], [159AB] and the subsequent inscriptions below (for Bin-group charge-pairs). The general absence of such charge-pairs in the inscriptions of other diviner groups has already been remarked (see, e.g., page 55 above).

223. See n. 221 above. As Takashima (1994:11, ms) has noted, the analys is depends upon which of the two sentences in a charge-pair was uttered first; the order in which the charges may have been engraved presumabiy has no bearing on our concerns. 
to associate $q i$ with the less desirable of two charges in a charge-pair.224 I had thus, earlier, taken the fact that we never find charges of the form * wo bu/fu shou shu nian *我不(弗)受䎑年 *"We will not receive millet harvest," but always find the $q i$ present--thus, wo bu/fu gi shou shu nian 我不(弗)其受䵒年 --as as an indicator that the $g i$ weakened the undesirable charge. I thus of fered *"We may $(q i)$ not receive millet harvest" as a translation for [83B], 我弗其受年. I now think, however, that this pattern of $q i$ distribution is better explained on the grounds that the desirable charge, 我受㯟年, was always the primary charge, and that the $q i$ served to mark the subsequent charge in the pair. As Nivison has noted,

Serruys' observation, accepted as a rule by Keightley, that $q i$ marks the less desired alternative in a duizhen pair may be accidentally right most of the time: normally the desired alternative is tested first; $q i$ in the alternative is thus acting on an idea already introduced, which is implicitly being referred back to as "old information." 225

I find these explanations generaily plausible, but will, as I proceed, suggest some revisions. I would stress, as Nivison has implied, that the implications of many of my conclusions about "strong" (i.e., desired) and "weak" (i.e., undesired) charges that were based upon the presence of the $q i$ in Bin-group charges, 226 are still generally true, if for the wrong reasons. All Shang charges were not created equal and the charge with a delimiting $q i$ is still likely, under the terms of conventions nos. 2 and 3 , to have been less desired.

224. E.g., Takashima 1973:267-305; Serruys 1974:25, 58. See too Keightley $1978: 51, \mathrm{n} .124,66, \mathrm{n} .41,80, \mathrm{n} .89$.

225. Nivison 1992:13.

226. As in, e.g., Keightley 1978, 1988, 1992. 
Testing the Retest Hypothesis

I start with a series of divinations about rainfall that challenge some of the proposals made above. My italicized commentary specifies the import of each charge as I understand it in light of the conventions proposed above. To clarify the analysis, I continue to "overtranslate" by using phrases like "in this case. 227

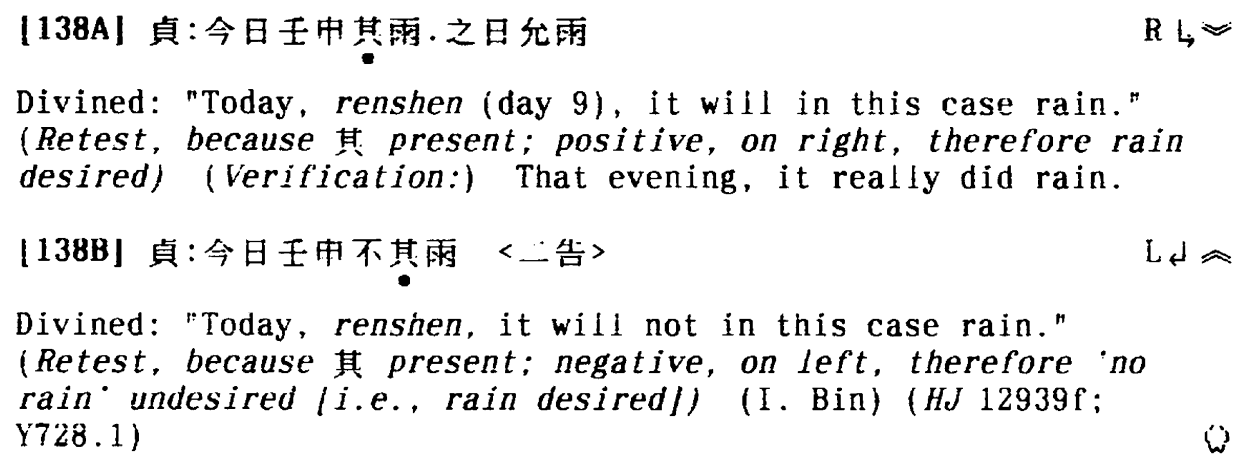

The er gao crack notation associated with [138B] and the verification in $[138 \mathrm{~A} \mid$ that records the fall of rain indicate that the unnamed diviner, who placed $[138 \mathrm{~A}]$ on the right side of the plastron, did indeed want rain (convention no. 1). That the diviner placed the charge, [138B] 今日壬用不其雨, on the left, undesired side of the sheil, indicates that 'no rain' was undesired, so that the force of such a charge, though couched in terms of something undesirable ('no rain'), was apparently weakened by its placement on the side of the shell reserved for undesired alternatives. In this view, the undesirability of an undesirable charge would apparently have been reduced, or at least restricted, by the diviner's placing the charge on the undesirable side of the shell, thus conveying the underlying message that the diviner did not want the future envisaged by this charge to be realized

227. For the view, advanced by Nivison, that $q i$ need not be translated in each case, see Keightley 1995:2. 
(compare the discussion of the pars familiaris, on the right, and pars hostilis, on the left, in note 216 above).228 To put the matter another way, the use of the $q i$ in the $[83 \mathrm{~B}]$, 我弗其受年, signalled that the auspicious crack-notation, er gao, was thought to apply to the core text, which had appared in the charge on the right side of the shell, and is presented in quotes in my translation: "We will not 'receive millet harvest."

\section{Qi in Both Charges}

The question, however, immediately arises: why did the diviner employ $q i$ in both charges, [138A] and [138B]?229 One plausible answer would be that both charges in this charge-pair were retests of an earlier charge or chargepair that either has not been preserved on this plastron (which is fragmentary) or that had been divined previously on another oracle-bone. In this case, in fact, it is possible to identify a charge, which may have been divined two days earlier, which refers to rain on renshen, and which might have served as the primary charge for which [138A] and [138B] would have been retests:

[139]庚午ト：壬申雨.壬申允雨

Crack-making on gengwu (day 7), divined: "On renshen (day 9), it will rain." (Primary charge, because qi not present; positive; rain desired) (Verification:) On renshen it really did rain. (I. Bin) (HJ 12908; Y16.1)

Given the recurring cycle of the ganzhi day dates, and the absence of any specifying month numbers on [138AB] and [139], we cannot, however, be sure that the rain of [139], divined on a scapula on day 7 , referred to the rain of

228. Yy argument here shares something in common with Takashima's discussion of placement and presupposition (1994:11 ms).

229. The same question may be asked of the charge-pairs listed in Table 1 , item (3), below (page 210). 
[138AB], divined on a plastron on day 9 , rather than to a different rain at a different time.230 And there would be little point in providing further examples of this kind of uncertain "backward reference" that involves more than one oracle bone. In most such instances, the linking of a retest divination, such as [138A] and [138B] (with qi), on one bone, to a primary divination, such as [139] (without gi), on another, will generally be plausible but unverifiable.231 In this case, moreover, we may note that the use of $q i$ in both charges of the pair appears to have been linked to the absence of a diviner's name attached to either charge (see "Divinerless Inscriptions," p. 163 below) .

To what Did "This" Refer?

The next two charge-pairs, [140AB and $\mathrm{CD}]$ inscribed on a single turtle plastron (fig. 6) suggest some revisions in our understanding of the meaning that we should assign to $q i$, and indicate, yet again, the difficulties involved in reaching any clear-cut solution:

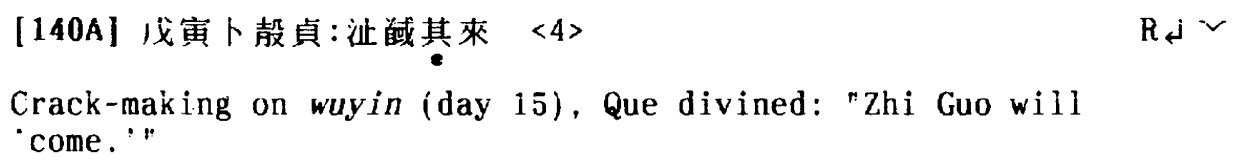

230. That the verification of [138A] recorded rain for the evening of renshen, and the verification of [139] also recorded rain for renshen, however, increases the probability that these divinations did record the same event and that the presence of $q i$ in both [138A] and [138B] could have referred back to a primary charge (or charges) on the same topic, 'rain on renshen.'

231. It would be possible to argue, for instance, that the three rainfall inscriptions, including 賁: 今乙卯允其雨, on the right carapace, $H J 1106 \mathrm{f}$ (Y738.1) might have been retests for the primary charge and verification, 辛亥卜承貞: 翌乙卯雨. 乙卯允雨, on the plastron, $(H J 6947 \mathrm{f}=$ Bingbian $304.1-2$; Y16.1). Because the placement of inscriptions on scapulas appears to have been less regular, and the conclusions to be drawn accordingly less clear, I discuss two such cases in Appendix A: "Retests on Scapulas," page 193 below. 
[140B]沚酽不其來 <4> L」へ

"Zhi Guo will not 'come.'"

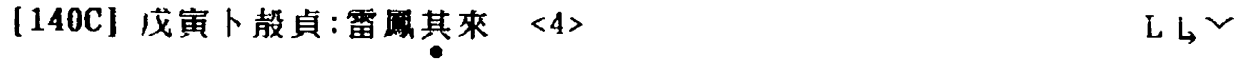

Crack-making on wuyin (day 15), Que divined: "Lei Feng wili

'come." "

[140D] 貞:鳳不其來 <4> R h

Divined: "Feng will not 'come." (I. Bin) (HJ 3947f = Bingbian $30.1-4$; Y915.1, partial)

[140E]王圆日:其出由庚其光戴至至 (L)( L)

The king read the cracks and said: "Guo's going out should be be on a geng-day (e.g., gengyin, day 17); as to (who will be first) (?), Guo will arrive." 232

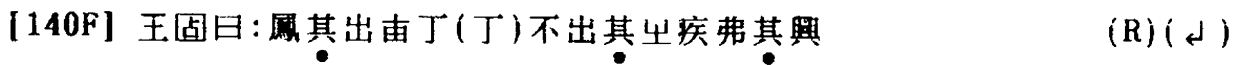

The king read the cracks and said: "Feng's going out should be on a ding day (e.g., dinghai [day 24]). (If, on the ding-day, )233 he does not go out, he will in this case be sick and will not in this case get better." (I. Bin) (HJ 3947b = Bingbian 31.1-2; Y915.1, partial [and in error])

Both prognostications, [140E\&F], are irregular in the sense that they

introduce considerations--Guo's "going out," who will arrive first, the shift

from the 來 of the charges to the 出 and 至 of the prognostications, Feng's

possible sickness--not referred to in the charges. Prognostications like

these support the view that the diviners offered a series of oral

232. I translate the prognostication, [140E], with uncertainty. I am also uncertain about my translation of [140F]. Serruys $(1981: 349)$ translates [140F] as follows: "Feng being expected to go out, we shall make it ( = decide upon) a ding-day. If on a ding-day he does not go out, as to Feng, anticipating he has (some) sickness, we shall not anticipate he will recover." Nivison (conversation of 13 January 1978) translated: "Feng will go out; it will be a ding-day. If (on the ding-day) he does not go out, Feng will have sickness; he will not recover"; see too Nivison $1978 \mathrm{f}: 7$.

233. The $T$ may be supplied from the prognostication on $H J 3945 \mathrm{~b}$, the second plastron in this set. See Zhang Bingquan's commentary to Bingbian 28, $\mathrm{p}$. 56 , discussion of Xucun 388 . 
"subcharges," frequently not recorded in the charges inscribed on the bone, as they made their pyromantic cracks (see page 21 above).

As fig. 6 indicates, the diviner Que (and his engraver) chose a crisscross placement of the inscriptions in these two pairs, [140AB] and [140CD].234 The presence of $g i$ in all four of the charges provides no clue as to which charges were primary, which secondary.235 On the assumption, however, that the king wanted Zhi Guo, one of his generals, to come back, we may assume that the primary charge (desired) was [140A] 沚䤋其來, divined--in accordance with convention no. 1--on the right edge of the right hyoplastron (the side of desirability) and followed by the counter-charge (undesired), [140B] 泟䤋不其來, divined on the left edge of the left hyoplastron (the side of undesirability); in this charge-pair, the "left-placement" weakening of the charge referred to above (page 118), is as we would expect. it is also of interest, given the use of $q i$ in both, that the two inscriptions of [140A\&B] did not (looking down at the plastron) run against each other ( $L j)$, rightto-left and left to right, but both ran in the same direction, right-to-ieft $(j)$ (see fig. 6).236

The second charge-pair, [140CD], was a mirror image of the first: on the assumption that the king also wanted Lei Feng (a figure about whom little is

234. The diviner presumably determined the location of the inscriptions by his choice of the hollows that he had cracked about Zhi Guo and Lei Feng. In this particular case, as in the other plastrons in the set that remain to us, only one crack per charge was made.

235. It is possible that all four charges, [140A-D], were referring back to a previous primary charge not divined on this plastron, but I have not been able to identify any candidates. See too, however, the discussion of emphasis on page 125 below.

236. A similar pattern was used in the case of [137AB]. 
knownj237 to come back--a conclusion supported by the solicitude for his welfare expressed in the prognostication $[140 \mathrm{~F}]-$-we may assume that the primary charge was $[140 \mathrm{C}]$ 雷国其來, divined--contrary to convention no, 1--on the left edge of the left hyoplastron (the side of undesirability) and followed by the undesired counter-charge, [140D] 風不其來, divined on the right edge of the right hyoplastron (the side of desirability). It is anomalous, in terms of convention no. 1 , and in terms of the placement of the desired charge [140A] on the right, to also find the undesired charge, [140D], on the right. If we accept the conclusions of the discussion on page 1 i 8 above, the placement on the right would have strengthened the surface force of the undesired charge, which suggests either that something may be wrong with our understanding of how convention no. 1 worked in such cases, or that we are misunderstanding the king's desires in the matter of Lei Feng. Once again, one wonders if the irregular placement of the charges was related in some way to the liberal use of $q$ is in all four charges (and in the prognostications, [140E\&F]). It may also be noted that the two inscriptions, [140C\&D] once again, did not run against each other $(L \downarrow)$, left-to-right and right-to-left, but in the same direction, left-to-right $(L L)$ (see fig. 6).

when we further consider the use of these $q_{i}$ 's, the assumption that [140A\&C] were the primary charges, divined before their complementary charges, [140C\&D], is rendered still more likely by the consideration that [140B\&D] were abbreviated versions of $[140 \mathrm{~A} \& \mathrm{C}]$ (convention no. 3 below, page 152). On the other hand, it will be evident that in this case the "fuller form first" rule of convention no. 3 stands in opposition to convention no. 1 , namely,

237. See the uninformative inscriptions at Y459.1 and 1104.1 and Zhang Bingquan's commentary to Bingbian 30 . 
that the Shang placed desirable charges on the right and placed less desirable (or undesirable) charges on the left.238 The Shang evidently wanted Lei Feng to come back, but in this case Que placed the fuller, primary, desirable charge, $[140 \mathrm{C}]$, on the left, not on the right.

The situation on this plastron is complicated yet again by the

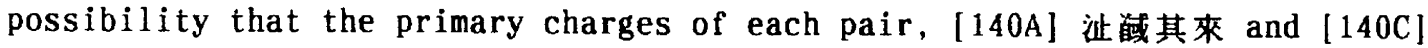
雷颯其來, and the subsequent charges of each pair, [140B] 泟首或不其來 and [140D] 風不其來, as Zhou Hongxiang has indicated in fig. 6,239 were also paired--by preface-date (in the case of [140A\&C], both divined on wuyin), position (situated symmetrically about the central spine), and by direction of writing $(L A$ for $[140 A \& C]$, and $\triangleleft L$ for $[140 B \& D])$. The possibility of this "secondary pairing" suggests not that Que was divining one topic ([140A], 'Zhi Guo wili come back') against the other ( $140 \mathrm{~B}\}^{\prime}$, 'Lei Feng will come back'), but that he had the topic of one charge-pair in mind as he divined the other, that he was aware, in short, that the charges about Guo Feng were embedded within a larger context that included the charges about Lei Feng, and vice versa.240 The complexity of reference involved may well have encouraged the unnamed diviner to specify and delimit each charge with an "in this case."

This and That

The larger divinatory context helps explain the liberal use of $q i$ in cases like $[140 A-D]$. "In this case" did not, in this new understanding,

238. See too $[6 \mathrm{AB}]$, where convention no. 3 is also violated.

239. Zhou Hongxiang 1969:175, fig. 27 .

240. For a further example of such 'secondary pairing,' see the discussion of [148A-D] on page 149 below. 
simply refer back to a previous divination, but also served to specify a particular divination in a cluster of similar divinations. Qi did not only (or invariably) mark retests; it could also emphasize the charge at hand. It is as if the diviner, each time that he proposed a charge with $q i$, were reiterating 'In this case, this is what I am divining about.'241 The distinction, to use modern chinese, would have been between $q i$ as the demonstrative pronoun meaning $b i$ 役, "that, that one over there" (cf. French celui-1aj) or the demonstrative pronoun meaning $c i$, 此, "this, this one here" icf. French celui-ci). In the "retest" view, Shang $g i$ as it functioned in these Bin-group charge pairs was a $b i$ 彼, referring to the previous, primary charge, "over there," on the other side of the shell (or perhaps on another shell). In my new proposal, $g i$ was a self-referential $c i$ 此, referring to the charge (usually secondary; see below) in which it appeared. The choice of interpretation, in other words, is between an extrovert demonstrative $q i$, referring to 'another charge out there, and an introvert demonstrative $q i$, referring to "this charge here.'

Redundant and inefficient as this new explanation for the lavish use of qis in $[140 \mathrm{~A}-\mathrm{D}]$ may seem to the stylistic purist--to adapt Gilbert and Sullivan's duet from "The Gondoliers," When every case is 'in this case," then no case can be special'--one can imagine that a diviner (or a member of his staff), appealing to the mantic Powers as he made each crack, might well have wished, by the formulaic, redundant $q i$, to emphasize that this was the particular charge, "in this case," to which he now sought a response--and not the particular charge (for which, to be sure, he might also have employed an "in this case") that he had divined just a moment ago. Indeed, to push the

241. Cf the discussion of $[146 B]$ below. 
argument to its logical conclusion, one can see that even in a perfect charge-pair like [83AB], the diviner might have wished to emphasize the distinction between the charges, not by using $q i$ (as bi 彼, celui-lä) to refer back to the first charge, "that "millet harvest" over there," but simply by using $q i$ to refer to, to isolate (as $c i$ 此, celui-ci), the charge now being divined, "this millet harvest being divined here."

Such an understanding in no way invalidates the view that $q i$ was likely to be used in retests; it merely provides a rather different view of what the $g i$ was referring to. $Q i$ in this view would have been self-referential, introvert rather than extrovert. If such a view has merit, then the decision to use gi sparingly (only once, for example, in simple Bin-group charge-pairs like $[83 \hat{A B}]$ ) or more abundantly (as in $[140 \hat{A}-D]$ above and $[141 \mathrm{~B}-\mathrm{N}]$ below [a series of seven charge-pairs with no diviner of record in three of the seven]) may well have depended upon his personal apprehension of each particular divinatory scenario, upon the amount of attention he wished to call to a particular charge or series of charges, upon, in short, his particular divinatory style (see too note 228 above).

\section{An Abundance of Qis}

If this hypothesis about the introvert, specifying function of $q i$ has merit, we would expect to find an abundance of $q$ is in those cases in which a number of charge-pairs bore on the same topic (or, as in the case of [140A-D], in which the charges composing those pairs might be related in more than one way). And this is precisely what we find. A normal complement of $q$ is in a perfect Bin-group charge-pair (represented, e.g., by $[56 \mathrm{AB}],[83 \mathrm{AB}],[146 \mathrm{AB}]$, $[147 \mathrm{AB}],[148 \mathrm{AB}, \mathrm{CD}]$, etc., and by Table 1, items [1] and [2]; page 210 below) 
would be one $g i$ per charge pair, i.e., one gi per every two charges divined. In the case of the four charges, $[140 \mathrm{~A}-\mathrm{D}]$, however, we do not $\mathrm{f}$ ind the expected two gis, but twice that number, four. Similarly, we do not find seven $q$ is in the seven charge-pairs of $[141 \mathrm{~A}-\mathrm{N}]$ below, but twelve, nearly double the normal complement. ${ }^{242}$ (Readers are warned that the discussion grows dense; consulting fig. 7 may help.)

[141A]乙未ト韋貞:雨 $<1><2><3>$

Crack-making on yiwei (day 32 ), wei divined: "It will rain."

(Primary charge; positive, on right, therefore rain desired)

[141B] 貞:不其雨 $[<1>]<2><3>$ L L 人

Divined: "It will not in this case 'rain." (Retest of [141A];

negative, on left, therefore, 'no rain' undesired li.e., rain desired J)

[141C] 丁西貞:其雨 $\langle 1\rangle\langle 2\rangle\langle 3\rangle \quad \mathrm{R} L \approx$

On dingyou (day 34 ), divined: "It will in this case rain."

(Retest of $[141 A B]$, two days later; positive, on right, therefore rain desired)

[141D] 丁西真:不其雨 $\langle 1\rangle\langle 2\rangle\langle 3\rangle$ L 小

On dingyou, divined: "It will not in this case "rain." (Reiest

of $[141 A B]$, two days later; negative, on left, therefore 'no

rain ${ }^{\circ}$ undesired (i.e., rain desired])

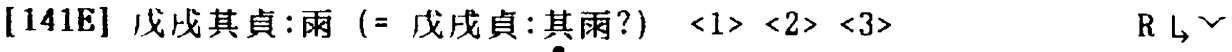

On wuxu (day 35) divined (?):243 "It will in this case 'rain."

242. Cf. $\{138 \mathrm{AB}\}--\mathrm{a}$ charge-pair with no diviner of record--where one $g i$ would have been expected, but two were present.

243. I assume that the Shang engraver erred in reversing the order of the 賁 and 其 in [141E]. The MZ editors, attempting to avoid the "error" transcribe several of the inscriptions on this plastron differently, but their alternative transcription results in a charge-pair with a highly unusual opposition: 雨/其雨 (cf. Table 1, entry [5a], page ??? below.) I suspect that the error in the Shang recording of [141E] may have been due to the diviner's inattention, suggesting that subordinates were in charge of recording some of these routine retests. Wei's name was not attached to $[141 \mathrm{EF}]$. That a significant number of inscriptions that contained 
(Retest of $[141 C D]$, one day later; positive, on right, therefore rain desired)

[141F] [不]其雨 $244<1>\langle 2\rangle\langle 3\rangle$ Ld?

"It will [not?] in this case 'rain." (Retest of [141CD], one day later; negative [?], on left, therefore 'no rain' undesired [?] [i.e., rain desired (?)])

[141G] 已酉卜韋貞:其雨 $<1><2><3>\mathrm{R}$ 小

Crack-making on jiyou (day 46), Wei divined: "It will in this case "rain." (Retest of $[141 E F]$, eleven days later; positive, on right, therefore rain desired)

[141H] 不其雨 $\langle 1>\langle 2\rangle\langle 3\rangle$

"It will not in this case "rain." (Retest of $[141 E F]$, eleven days later; negative, on left, therefore 'no rain' undesired [i.e., rain desired])

[141I] 庚伐卜韋:其雨 $<1><2><3>\quad R \bigsqcup$ Crack-making on gengxu (day 47), Wei (divined): "It will in this case 'rain.'" (Retest of [141GH], one day later; positive, on right, therefore rain desired)

[141J] 不其雨 $\langle 1\rangle\langle 2\rangle\langle 3\rangle$ Lلへ

"It will not in this case "rain." (Retest of [141GH], one day later: negative, on left, therefore 'no rain' undesired li.e., rain desired])

[141K] 辛亥卜韋:其[雨] $<1><2><3>\quad \mathrm{R}$ 小 ?

Crack-making on xinhai (day 48), wei (divined): "It will in this case [rain]." (Retest of [141IJ], one day later; positive, on right, therefore rain desired)

other kinds of errors did not record the name of any diviner, may be further evidence for thinking that conventions were less strictly observed (see "Divinerless Inscriptions," p. 163 below) when the diviner did not put his name to the record; see, e.g., Jiabian 476.1, 756.2, Bingbian 73.6 (taken from Keightley 1978:49, n.11), etc.

244. I supply the $b u$ 不 in $[141 \mathrm{~F}]$ on the assumption that it was recorded on the missing fragment at the middle-right section of the left hypoplastron; supplying the bu makes [141F] consistent with the other inscriptions in the series, $[141 \mathrm{~B}, \mathrm{D}, \mathrm{H}, \mathrm{J}, \mathrm{L}]$. If we do not supply the $b u$, then we again are faced with a virtually unique opposition, 雨/其雨 (see n. 243 above). 
[141L] [不其雨] <1><2><3> [L L 人]

["It will not in this case "rain." ] (Retest of $[1411 \mathrm{~J}]$, one day later; negative, on left, therefore 'no rain' undesired li.e., rain desired])

[141M] 壬子卜:其雨 $\langle 1><2><3>\quad \mathrm{R} L \approx$

Crack-making on renzi (day 49): "It will in this case "rain."

(Retest of [141N]; positive, on right, therefore rain desired)

[141N] 壬子卜:不雨 $<1>[<2>][<3>]$ L

Crack-making on renzi: "It will not rain." (New charge;

negative, on left, therefore 'no rain' undesired li.e., rain

desired]) (I. Bin) (HJ 11892f = Bingbian 527.1-13)

It is possible that, as I have suggested by my comments in italics, in this series of seven charge-pairs, the diviner wei (or his subordinates; see page 164 below) used $q i$ in both charges of the five charge-pairs, [141CD, EF, GH, IJ, KL], to indicate that both members of these charge-pairs were retests, referring back to the previous charge-pairs about rainfall, starting with the initial charge-pair, [141AB], in an extended chain of backward references ("in this case," bi 佊, celui-là).245 Whether or not that is true, it is evident that something about this particular scenario encouraged the diviner or his assistants to use $q i$ more frequently than mere reference to the primary charge would have required. In this case, it does not seem to have been, as I had once thought, ${ }^{246}$ the presence or the absence of the $q i$ that indicates whether

245. Thus, to follow out an analysis that has, by now, become tedious: on the assumption that wei placed the desired, primary charge on the right of the shell, it would appear from the charge lacking $q i,[141 \mathrm{~A}]$, that he did want it to rain. The placement of the charge with the qi, [141B], on the left, indicates that 'no rain' was not desired. And the presence of the $q i$ in that charge supports the view that the undesired charge was indeed divined second, referring back, as a retest, to [141A].

246. E.g., Keightley 1978, 1988, 1992. 
or not rain was desired; it seems, rather, to have been the placement of the charge on the right or left of the shell that served this function.

The diviner Wei appears to have applied convention no. 1 consistently, for, if we take the underlying force of his charges into account (see page 118 above), his consistent desire for rain, as indicated by my comments in italics, was communicated by the placement and wording of all fourteen charges, $[141 \mathrm{~A}-\mathrm{N}]$, on the shell. We may never know why, in each case, wei adopted the stratagem he did, but it appears that, in presenting such a series of charge-pairs that dealt repetitively with a single topic over an extended period of time, the diviner had several choices. He could, within the constraints provided by the conventions of the paired charges themselves: (1) put the primary charge, lacking $q i$ and desired ("it will rain') in its normal 'zone of desirability' on the right side of the shell (as in [141A]); (2) put the retests, containing $q i$, of the desired charge ( $\mathrm{it}$ will in this case "rain"') in the same 'zone of desirability' on the right (as in $[141 \mathrm{C}, \mathrm{E}, \mathrm{G}, \mathrm{I}, \mathrm{K}, \mathrm{N}] ;$ (3) put the, undesired charge, also containing qi, ('it will not in this case "rain", in the normal 'zone of undesirability' on the left side of the shell (as in $[141 \mathrm{~B}, \mathrm{D}, \mathrm{F}, \mathrm{H}, \mathrm{J}, \mathrm{L}] ;$ (4) put the undesired charge that lacked $g i$ ('it will not rain') in the 'zone of undesirability' on the left (as in $[141 \mathrm{~N}])$.

If it were primarily the right-left placement that expressed the intended force, then an undesired charge (but lacking gi), like [141N], "It will not rain," would have been rendered less potent, or would at least have been marked as less desirable, by being placed on the left, "undesirable," side of the shell. I do not think, however, that the "retest" explanation, invoking a 
resumptive $q \dot{i}(b i$ 彼, celui-là) works well in such cases (and, thus, perhaps in any cases?). Was Wei, for example, really treating [141G], divined on jiyou, as a retest, despite the fact that an interval of eleven days had elapsed since the last retest (if that is what it was), [141E] on wuxu? I suspect, rather, that wei or his staff used $g i$ so freely--in twelve of the fourteen charges on this plastron--because, in a group of so many similar divinations about rain, they wished to individuate each one. Considering that with three cracks per charge, a total of forty-two cracks were made, all on topics that were closely related, it is no surprise that some form of formulaic emphasis--redundant though it may seem to us--might have been called for. It is even possible that wei, the diviner, was getting exasperated (see page 134 below) at the need to keep divining about rain in this way (there are no verifications about any fall of rain on this shell), so that he kept insisting, "in this case...." in this case,..."

\section{$Q i$ in a Series of Same-Topic Divinations}

As we struggle to understand the rationale underlying the choice of words, we also need to consider why, after so many $q i s$, the engraver did not provide [141N], the last, and presumably undesired, charge in the series, with a $q i$ too. That [141N] 不雨, although placed on the left, lacked a $q i$ might indicate, in terms of the conventions discussed above, that it contained new information, i.e., an initial test, divined first; the resumptive $q i$-if it was resumptive (see previous paragraph)--would have been recorded in its pair, [1419] 其雨, on the right. On the other hand, if $q i$ were a self-referential demonstrative (i.e., $c i$ 此 rather than $b i$ 被; see page 126 above), the absence of $q i$ in what appears to have been the last charge of the series, might have 
indicated the diviner's desire not to specify this final 'no rain' charge, as if, in his exasperation, he had lost interest in specifying the undesired charge, [141N], that in accordance with convention no. 1, was placed on the left of the shell. In the case of [141MN], accordingly, the diviner (wei's name is not recorded) appears to have violated either convention no. 1 or no. 2: either he started his divination on the left (rather than on the right) with a charge about what he did not want $([141 \mathrm{~N}]$, 'no rain'), rather than one about what he did want ([141M], 'rain'), or he started with a charge on the right, [1419] that contained the $q i$ that we normaliy expect to find in the retest rather than in the primary charge. 247

Vyy own explanation is that the diviner did indeed mark [1411] with the $q i$ because he was stili concerned that the mantic Powers pay attention to this charge that, placed on the right, once more expressed his desire for rain; he did not mark [14iN] in this way because he was less anxious, after a long series of charges, to call this particular undesired charge, placed on the undesired side of the shell, to the attention of those Powers. In other words. I am proposing that, in an initial charge-pair like [141AB], qi was not normaliy used in the primary charge, [141A], because being primary, no emphasis would have been needed; in the charge that complemented the pair, [14iB], $q i$ was used to mark it off--"In the case of "this charge" "-from the primary charge. 248 After a series of charges, however, the diviner's use of

247. It is always possible, of course, that a change in the weather had changed the diviner's desire for rain, during the seventeen days that had elapsed between yiwei (day 32), the date when [14iAB] were divined, and renzi (day 49), the date when [141MN] were divined. The lack of any verification that confirmed the fall of rain renders this unlikely, but not out of the question.

248. That $q i$ was used in both the primary and secondary charges of $[140 \mathrm{AB}]$ and $[140 \mathrm{CD}] \mathrm{can}$, as we have seen in the discussion above, be expiained in 
$q i$ appears to have become more routine as he proposed a large number of charges, sometimes with a $q i$ present in each case (as in [141B-M]), desiring to individuate each of the charges so marked as it was cracked. The absence of $q i$ in a charge like [141N] at the end of a series, therefore, could have meant something quite different from its absence in the primary charge like [141A]; its absence, in fact, could have involved a de-emphasis of that particular, final charge. Indeed, since this entire series of fourteen rainfall charges started and ended with two charges [141A] and [141N], one positive, the other negative, that did not contain $q i$, one might also suppose that these two charges served to "frame" the other twelve, all of which did contain $q i$. It is not inconceivable that the diviner sought to complete a certain aesthetic or theological structure by ending the series, as he had started it, with an unmarked charge.

Qi as a Mark of Exasperation?

As i have suggested above, the seemingly redundant $q i$ in both charges of a charge-pair might also have been used when there is reason to think that the diviner involved in a series of charges about the same topic was becoming exasperated at the lack ô resolution. Consider, for example, the situation suggested by the following group of charges, [142A-C], [143A-C], [144A-C], that evidently concerned the same campaign:

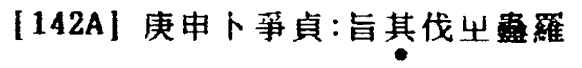

Crack-making on gengshen (day 57), Zheng divined: "Zhi will in this case 'attack Youguluo."

precisely these terms: given the cross-pairing of these two-pairs, and the similarity of subject matter, the diviner wished to individuate all the charges, including the primary ones, from the very start. 
[142B] 旨弗其伐出憲羅 一告

LAへ

"Zhi will not in this case attack Youguluo." (i. Binj $(\not H j b 0016 \mathrm{f}$

= Bingbian 141.11-12; Y1025.2)

[142C] 王固日:吉.我伐隹丁

The king read the cracks and said: "Auspicious. When we attack will be on a ding-day (e.g., dingmao [day 4])." (I. Bin) (HJ $6016 \mathrm{~b}=$ Bingbian 142.3; Y895.2))

Because [142A] was placed on the right, and because of the auspicious prognostication endorsing the attack, [1420] (placed on the back side of the piastron directly beneath, and thus linked to, $\{142 \mathrm{~A}\}$ and running, like [142A], away from the spine), I conclude that the Shang hoped that Zhi would indeed attack the enemy, why then did Zheng include a $q i$ in $[142 \mathrm{~A}]$, the desirable charge, as well as in [142B], the undesirable charge?

we may never be able to explain such anomalies with certainty, but we can at least propose scenarios that would explain their presence, the simpiest of which would be to assume that on one or more previous occasions Zhi had railed to attack Youguluo; the diviner, Zheng, accordingly was simpiy emphasizing, in $\{142 \mathrm{~A}\}$, the hope that "in this case," i.e., on this occasion (ci 此, celuici), Zhi would indeed (at last?) do so. The $g i$ in the negative charge, [142B], may either (as bi 彼, celui-1à) have referred back to the primary, more fuliy-recorded, divination unit, [142A], or it may have extended the reference still further back in time, reemphasizing the fact that ${ }^{\prime}$ in this case," i.e., once again, Zhi would fail to attack. That $q i$ appeared in both [142A\&B], however, encourages me in thinking that its role may have been self-referential, introvert rather than extrovert. It may not be entireiy fanciful to detect a note of exasperation in these retests and in the reiteration of the $q i s$, as $I$ did in the chain of rain divinations, $[141 \mathrm{~A}-\mathrm{N}]$, 
on page 131 above. Such exasperation--a form of extreme delimitation--would, it may be noted, well accord with the role of the "intentional" or "executive $q i^{\pi}$ discernible in the Li-group inscriptions (see note 5 above).

The plausibility of this emphatic interpretation of how $q i$ may have functioned in [142A\&B] is well supported by charge-pairs on two other plastrons that may have been divined about this same campaign against youguluo seven and five days earlier than $[142 \mathrm{~A}]$ :

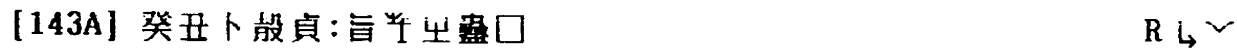

Crack-making on guichou (day 50), Que divined: "Zhi will strike Yougu [luo]."

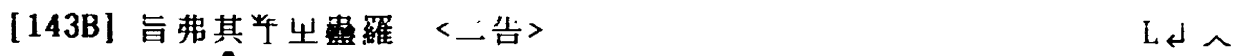

"Zhi will not 'strike Youguluo." (I. Bin) (HJ $5775 \mathrm{f} ; \mathrm{Y} 1025.2=$ Bingbian 83.3-4)

[143C] 王圆日: 芰隹庚不隹庚南丙的

The king read the cracks and said: "when we strike them it wili a geng-day (e.g.. gengshen [day 57]); if it is not a geng-day, it should be a bing-day (e.g., bingchen [day 53))."249 (I. Bin) (HJ $5775 \mathrm{~b} ; \mathrm{Y} 0000=$ Bingbian 84.2)

[144A]乙卯卜爭貞: 旨等羅

$R L^{2}$

Crack-making on yimao (day 52), Zheng divined: "Zhi will strike Luo."

[144B] 員:旨弗其学羅的人

Divined: "Zhi will not in this case 'strike Luo." (I. Bin) ( $H J$ $880 \mathrm{f}=$ Yibian 5395; Y1099.2)

[144C]王固日：吉等

The king read the cracks and said: "Auspicious. He will strike (Luo)." (I. Bin) (HJ 880b = Yibian 5396)

249. [143AB] and [144AB] might also be treated as exclamatory: "Zhi's stiriking Youguluo!," "Zhi's not striking Youguluo!," etc.; see page 16 above. 
These three sets of inscriptions, [142A-C], [143A-C], and [144A-C], permit us to establish the following scenario.250 Que divined about Zhi's striking the Youguluo on day 50; the king forecast that it would be on a geng-day (possibly day 57, seven days in the future), or, failing that, on a bing-day (possibly day 53, three days in the future) ([143AC]). Two days after the initial divination--and before either of the two gan days forecast had yet been reached--Zheng divined about Zhi's striking Luo and the king forecast, without specifying a day, that Zhi would do it ([144AC]). On day 57 , five days after that second divination (and after day 53 had already passed, presumably with Zhi having failed to attackj, Zheng again divined if Zhi would attack Youguluo; this time the king forecast that we would attack, on a ding-day (e.g., day 4, again seven days in the future) ([142AC]). Thus it is indeed piausibie to assume that the two charges, [142A\&B], were continuing and perhaps exasperated retests ('when will Zhi Guo attack?!') of earlier charges. The use of $q i$ in both $[1 \hat{4} 2 \mathrm{~A} \hat{\alpha} \mathrm{B}]$ may weil be explained in terms of the diviner's desire to emphasize the particularity of the [142A\&B] charges ('He wili attack this time, at least!'), which, in this understanding, would have been the third charge-pair in a seven-day period to address the same issue.

These inscriptions also suggest that $q i$ could play the role of both $b i$ 彼 and $c i$ 此. There would have been no need to employ $q i$ unless the chargeis) in which it appeared were part of a larger context of previous (primary) charges. That is, the emphasis on "this case, here" implies the existence of a "that case, there." The presence of the $q i$, in short, in a member of a charge-pair,

250. $H J 6827 \mathrm{f}$ also records a charge, divined on $x$ inyou (day 58 ), that seems to have been about the same campaign; the plastron is fragmentary, however, and the inscriptions remaining have no bearing on the discussion of $q i$. 
always implies the existence of another related charge or charges. That other charge, as we shail see in the case of $[56 \mathrm{AB}],[146 \mathrm{AB}]$, and [147AB], need not have been primary (i.e., of immediate concern). But its very existence, either primary or secondary, would, as it were, have been "in the air, "thus encouraging the diviner to insert the $q i$ in other charges in the group, both to individuate them and to acknowledge the existence of that larger context.

$Q i$ in the Right-Side, or Primary, Charge

"Violations" of convention, in which the diviner placed a $q i$ in the charge on the right side (or in the primary charge, i.e., the charge cracked first, even if on the left-side) rather than in the charge on the left-side (or in the secondary charge, even if on the right), are rare, but those that, in addition to [140A\&C] and [141CEGIK\&M], I have been able to identify repay scrutiny. The first two examples also involved rain (fig. 8):

[56A] 己卯卜敞貞:不其雨〈1><2><3> $\mathrm{R}\rfloor \approx$

Crack-making on jimao (day 16), Que divined: "It will not in this case "rain."

[56B] 己卯卜靔貞:雨.王固:其雨隹壬.壬午允雨 $\langle 1><2$ 二告 $><3>L d \approx$

Crack-making on jimao, Que divined: "It will rain."

(Prognostication:) The king read the cracks (and said): "The

"raining' will be on a ren-day." (Verification:) On renwu (day

$19)$, it really did rain." (I. Bin, 1) ( $H J 902 \mathrm{f}=$ Bingbian

235.1-2; Y16.2)

The presence of the $q i$ in $\{56 A\}$, 不其雨, would mean, in the "retest" $i b i$ 被, celà) view of such matters, that the charge, even though placed on the right. was old information and divined second, and that $[56 \mathrm{~B}]$, 雨, the charge without the $q i$, even though placed on the leît, was divined first and expressed the outcome that the Shang found desirable, namely that they wanted rain. That 
they desired rain is confirmed both by the attachment of the prognostication (of [56B]) to the charge desired (see convention no. 4, page 153 below) and by the presence of the er gao 二采 crack notation by crack number " 2 ," which indicates that the cracks predicted a fortunate result, i.e., that there would be rain, a conclusion confirmed by the [56B] wording of the prognostication, "The 'raining' will be on a ren-day," and by the verification, "On renwu, it really did rain." 251 Once again, therefore, we have a case in which the desired charge appears--as in the cases of [1400], [141N], and, below, [146B]--to have been placed on the left side of the shell, the side that was usuaily reserved for undesirable charges. In these cases, the diviners did not follow convention no. 1 .

The following nine charge-pairs on a fragmentary piastron show (fig. 9), in fact, that such "unconventional" piacement could, on occasion, be entireiy standard ( $I$ give up the clumsy, over-transiated "in this case" for $q i$ and "under-translate" by using oniy the single quotation marks):

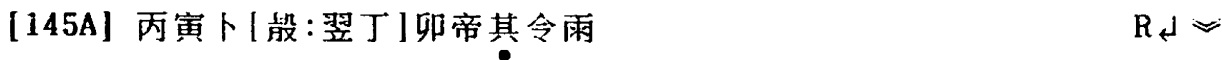
Crack-making on bingyin (day 3), [Que (divined): "On the next day, dinglmao (day 4), Di will order rain."

[145B] 丙宙卜[敖:翌丁]卯帝不[令]雨.允[不雨] L

Crack-making on bingyin, [Que] (divined): "On the [next day, ding]mao Di will not [order] rain." (Verification:) It really [did not rain]. ( $H J$ 14153Af)

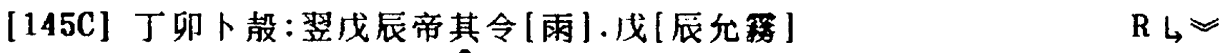

251. The fact that this plastron was cracked in the thirteenth month (approximately the modern January), which would have been among the driest months of the year (Keightley 1989) may be further reason for thinking that rain had indeed been desired by the diviner of [56AB]. If rain had not been desired, in what was normally a dry month, there would have been little reason to divine about rain at all. 
Crack-making on dingmao (day 4), Que (divined): "On the next day, wuchen (day 5), Di may will order [rain]." (Verification:) on wulchen it really was foggy.

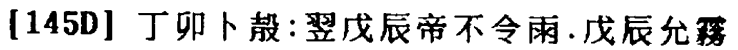

Crack-making on dingmao, Que (divined): "On the next day, wuchen (day 5), Di will not order rain." (Verification:) On wuchen it really was foggy.

[145E]戊[辰]卜殸: [翌]己巳[帝其]令雨 $R L \cong$ Crack-making on wu[chen] (day 5), Que (divined): "On [the next day], jisi (day 6), Di will ['] order rain[']."

[145F] 戊辰卜䐨: 翌己巳帝不令雨<1 二告>

Crack-making on wuchen, Que (divined): "On the next day, jisi, Di will not order rain."

[145G] 己巳[卜靔: 翌庚午帝其令雨]

[Crack-making] on jisi (day 6), [Que (divined): "On the next day, gengwu (day 7), Di will order rain." ]

[145H] 己[巳卜殸: 翌庚午帝不令雨]

[Crack-making] on $j i$ /si, Que (divined): "On the next day, gengwu, Di will not order rain." ]

[145I] 辛未卜[靔] : 翌壬[申]帝其 [ 令]雨

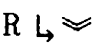
Crack-making on $x$ inwei (day 8), [Que] (divined): "On the next day, ren[shen] (day 9), Di will '[order] rain."

[145J]辛末卜[靔]:翌壬[申]帝不[令]雨.壬[申]軍

Crack-making on $[x i n]$ wei, [Que] (divined): "On the next day, ren[shen], Di will not [order] rain." (Verification:) on ren/shen], it was misty (but it did not rain).

[145K] 壬申 [ト䐨]: 翌癸[酉]帝其令雨

[Crack-making] on renshen (day 9), [Que] (divined): "On the next day, guilyou] (day 10), Di will order rain." <1 二告>

[145L] 壬申卜[靔]:翌癸酉帝不令雨

Crack-making on renshen, [Que] (divined): "On the next day, gui[you], Di will not order rain." 
[145M] 甲戊卜靔: 翌乙亥帝其令雨

R $L \cong$

Crack-making on jiaxu (day 11), Que (divined): "On the next day, yihai (day 12), Di will order rain."

[145N] 甲戌卜靔:翌乙亥帝不令雨

Crack-making on jiaxu, Que (divined): "On the next day, yihai, Di will not order rain."

[1450]乙亥卜靔: 翌丙子帝其令雨

R $4 \approx$

Crack-making on yihai (day 12), Que (divined): "On the next day, bingzi (day 13), Di will order rain."

[145P] 乙亥卜殸:翌丙子帝不令雨

Crack-making on yihai, Que (divined): "On the next day, bingzi, Di will not order rain."

[145Q] 丙子卜靔: 翌丁开帝其令雨

$R L \approx(?)$

Crack-making on bingzi (day 13), Que (divined): "On the next day, dingchou (day 14), Di will order rain." 252 (HJ 14153Bf =

Bingbian 529; Y149.i, partiaij

[145R] [丁丮卜靔]：翌[戊宙 j帝其[令雨 j

[Crack-making on dingchou (day 14), Que (divined)]: "On the next day, [wuyin (day 15)], Di will "[order rain]."

[145S] [丁开卜䐨]: 翌[戊寅帝]不[令雨]

[Crack-making on dingchou, Que (divined)]: "On the next day,

[wuyin, Di] will not [order rain]." (HJ 14153Af = Bingbian 529;

Y419.l, partial)

[145T] 己巳帝允令雨至于庚

( R L)

(Verification:) On jisi (day 6), Di really did order rain, which lasted down to the geng-day (i.e., gengwu [day 7]).

\section{[145U]龍}

"(Yake a clay?) dragon." (I. Bin) $(H J 14153 \mathrm{Bb}=$ Bingbian 530;

Y419.1, partial)

252. The other member of this charge-pair, *丙子卜靔:翌丁开帝不令雨, was presumably recorded on the left side of the plastron, but there is no trace of it on the fragments remaining. 
In each charge pair, the diviner consistently placed the deictic $q i$ 其 in the charge, "Di will order rain" " ([145ACEGIK, etc.]), on the right of the plastron. The placement of these charges on the right side (convention no. 1). would suggest that the Shang wanted it to rain. The wording of the verifications may also, though with no great certainty, be read to support that conclusion. That is, one verification, $[145 \mathrm{~B}]$, recorded that "It really [did not rain]." Two verifications, $[145 \mathrm{C}$ and $\mathrm{D}]$, indicate that "It really was foggy," indicating that it had not rained but it had almost rained. And one verification, [145T] records that "On $j i s i$, Di realiy did order rain, which lasted down to the geng-(i.e., the next) day." This was in response to the charge-pair [145EF] about rain "on the next day, jisi"; it had been carved aimost directly beneath (i.e. on the plastron back) the negative charge $[145 \mathrm{~F}]$, "On the next day, jisi, Di will not order rain."253 I suspect that had the rain been unwished, its fall would not have been recorded in such detail. Finally, if [145i] did referring to the making of a clay dragon, that ritual act would also suggest that rain was desired.254

On the other hand, the presence of the $g i$ in these charges on the right, suggests that they were divined second, as retests, and that, accordingly, the charges on the left, "Di will not order rain," were divined first and should have represented the Shang's real wish (conventions nos. 2 and 3 ). My account of the conventions so far, accordingly, does not fit this case satisfactorily.

253. On the placement of the verification, see n. 272 below.

254. On the zuo long 作能 ritual for making rain, see Qiu Xigui 1983-85:303-04. 
CONVENTION NO. 1 (REVISED) :

FINAL DESIRE AND IMMEDIATE CONCERN

These exceptions lead me to propose that my understanding of the conventions that governed Bin-group charge-pairs, particularly of convention no. 1 , is in need of revision. Either there was no regular rule for placing the divinations to right and left, so that, as in [56AB], [140CD], [145A-T]-all divined by Que--and, below, in $[146 \mathrm{AB}]$, the diviner reversed right-left fields at will, or the application of the rule involved a series of subconventions that conferred considerable flexibility, a ilexibility, in fact, that, in the absence of native informants, we may never be able to specify with certainty.

Given the fact that the diviners observed convention no. 1 as proposed (on page 112 above) in the vast majority of cases, I would still hope to discover an explanation that will account for the exceptions. I now propose, accordingly, as a working hypothesis, that convention no. 1 should be revised to state: When they cracked the turtle plastron to divine a pair of charges, the Bin-group diviners generally placed the charge about whose outcome they were most immediately concerned (not necessarily the one whose outcome they desired, although it frequently satisfied that description) on the right of the shell, and the charge of less immediate concern--but which expressed the larger, final desire or fear (and not necessarily, but frequently, was the charge whose outcome was undesired) as the contrastive context in which the primary charge had to be considered--on the left. One might summarize these distinctions in terms of whether, in any particular divinatory scenario, hope or fear was paramount. On some occasions the Bin-group diviner of charge- 
pairs placed the outcome he hoped would finally happen, unqualified by $q i$, on the right side of the shell; and he placed the outcome he feared would happen immediately, qualified by $q i$, on the left side of the shell. On other occasions, he placed the immediate outcome he feared would happen, qualified by $q i$, on the right side of the shell; and he placed the outcome he hoped would finally happen, unqualified by $q i$, on the left side of the shell.

what this means in the present case, [56AB], is that the diviner Que was immediately concerned, fearful, about its not raining, and he made that concern the topic of the charge [56A], 不其雨, placed on the right of the shell--a side that I would now redefine as a zone of immediate concern rather than as a zone of desirability--in which the $q i$ served primarily to emphasize the importance of his concern (as well, perhaps, as to delimit it): 'In this case ( $c i$ 此, ceci), it will not rain. That it wili not rain is what concerns me, what I fear, and I accordingly place that charge on the right side of the shell.' Had the diviner placed the 不其雨 on the lef $t$ side of the shell, as in $[135 \mathrm{~B}],[138 \mathrm{~B}]$, and $[141 \mathrm{BDHJL}]$, the presence of the $q i$ in the charge on the left side would have indicated that the outcome was undesired and that the topic was of secondary concern, and that, in these cases, as demonstrated by the positive charges, [135A], [138A] (with $q i$ ), and [141ACGIK] (the last four with $\left.g_{i}\right)$ on the right side, rain was desired and rain was the immediate, proximate concern (see in particular the discussion of [141] on page 129 above).

Similar analysis may be applied to the case of [151AB] below, in which [151A], the negative charge containing the $q i$, was placed on the right side of the shell: 帝弗其及今四月令雨, "Di will not in this case when it comes to the 
present fourth moon, order rain"; and [151B], 帝及[今?]四月令雨, the charge whose outcome was desired and which was presumably divined first, "Di, when it comes to the present (?) fourth moon, will order rain," was placed on the left. The final outcome desired, placed on the left with no $q i$, was that $D i$ would order rain; the proximate fear, that $D i$ would not order rain, was placed on the right, with the referential, delimiting $q i$.

whether the diviner actually cracked such proximate charges on the right side of the shell first is hard to determine. That, in the case of [56B], the prognostication was appended to the charge on the left suggests that that prognostication, "The "raining" will be on a ren-day," was the one that expressed the final outcome desired (convention no. 4, page 153 below). Even though this analysis makes immediate concern rather than final desire the criterion for right-left placement, it is still likely that, when an initial charge-pair in a series of charge-pairs was divined, the primary charge--now defined as the charge that expressed the final desire (as in [56B], [146B], and $[147 \mathrm{~B}])$ rather than the immediate concern (of $[56 \mathrm{~A}],[146 \mathrm{~A}]$, and [147A])--would have been divined without the $q i$, for it was still the charge that estabilished the context within which the secondary charge, even though it might have been divined first (like [56B], [146B], and [147B]), was treated. There, would accordingly, have been no need for the diviner to specify, "in this case ( $c i$ te $\operatorname{cec} i), "$ in the primary charge that expressed the final desire. But any charge after the first charge in such a series, or any charge that, although divined first, conveyed the immediate concern within the context of the larger desire--as in $[56 \mathrm{~B}],[146 \mathrm{~B}]$, and [147B] might well have included introvert $q i$. 
If we accept such an understanding, then it seems likely that $[56 \mathrm{~B}]$, 雨, expressing the final desire for rain, would, although on the left, have been divined first, and that [56A], 不其雨, expressing the immediate concern--i.e., the fear of 'no rain'--would, although on the right, have been divined second. Even though concern was immediate it was still situated, partly by the use of the referential $q i$, within a context of the diviner Que's larger desires. It is as if the right side (whether the outcome was desired or feared) was the foreground that got the spirits' attention; the left side established the background.

On the assumption that the diviners placed the charge of immediate concern on the right and the charge of final concern on the left, revised convention no. 2 (originally stated on page 116 above), following upon revised convention no. 1 (page 142) thus becomes: Whichever charge of a charge-pair contained the $q i$ was the one that was cracked second. Although we do not sufficiently understand the way in which the diviners actually read the cracks to pursue the matter any further, it is plausible to assume that it was important to them to know which charge of a pair was cracked first and which was cracked second; the presence of the $q i$ might have, in cases where $q i$ appeared in only one member of a charge-pair, provided this information.

Other examples support this new reading of the evidence. The next two involve something ominous:

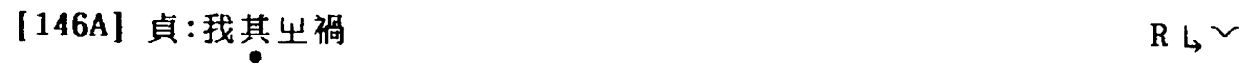

Divined: "We will in this case have something ominous." [146B] 貞:我亡禍 
Divined: "We will not have something ominous."255 (I. Bin) (HJ $7352 \mathrm{f}=$ Bingbian $3.11-12)^{256}$

I assume that in this instance, the Shang diviner's final desire was that he did not desire anything ominous (as in [146B]) but his immediate concern was that he feared it (as in [146A]). Accordingly, he divined the charge, [146A] "We will in this case have something ominous," on the right, because it was the charge that most concerned him. He balanced that with the apotropaic charge, [146B] "we will not have something ominous," which, because it was desirable, he cracked first; but which, because it did not represent the diviner's immediate concern (namely, that something bad might happen), he placed on the left of the shell.257

The second example, also about something ominous, leads to the same conclusion with even greater force:

[147A] 貞:酋往來其出禍 $R L^{2}$

Divined: "(For Zhi) Guo going and coming back, there will in this case be something ominous."

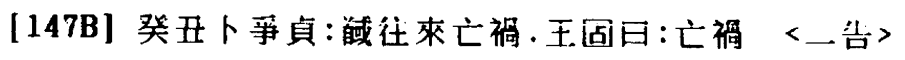
L」へ

Crack-making on guichou (day 50), Zheng divined: "(For Zhi) Guo going and coming back, there will be nothing ominous." The king read the cracks and said: "There will be nothing ominous."258 (I. Bin) $(H J 914 \mathrm{f}=$ Bingbian 32.26-27; Y914.2-15.1)

255. These charges might also be treated as exclamatory: "Our having something ominous!," "Our not having something ominous!"; see page 16 above.

256. For other inscriptions on this plastron, see [136AB] above.

257. Cf. the discussion of $[140 \mathrm{~A}-\mathrm{F}]$ on page 125 above.

258. These charges might also be treated as exclamatory: "(Zhi) Guo going and coming back's having something ominous!," "( Zhi) Guo going and coming back's not having something ominous!"; see page 16 above. 
The placement of [147A] on the right, despite its undesired content and the presence of the $g i$, suggests that it was the charge of immediate concern. The desired charge, [147B], whether or not it was divined first, expressed the final concern--because, as a statement of the larger context, it lacked the introvert, self-referential $q i$ and was placed on the left. It would be tempting to argue, on the grounds that Zhi Guo having trouble was the diviner's immediate concern, that $[147 \mathrm{~A}]$, on the right, was divined (or conceived) first, but this hypothesis is weakened when we consider that both the fuller form of the charge (see convention no. 3, page 152 below) and the prognostication attached to it (convention no. 4, page 153) were on the left, which, as in the case of $[56 \mathrm{~B}]$ above, indicates that the charge on the left was indeed the primary charge (expressing the final outcome desire), despite its placement.259

Inconstancy of Right and Left Placement

In another striking case, which further adds to the complexity of this discussion, we can observe the diviner reversing his left-right fields, as it were, in two charge-pairs about the same topic that were recorded on the same plastron (fig. 10):260

[148A]庚午卜爭貞:亘執 $\mathrm{R} L \approx$

Crack-making on gengwu (day 7), Zheng divined: "Xuan will be seized."

259. I can find no antecedent primary charges on other oracle bones for which [147A] could have served as a retest. The absence of any such charge in the remaining corpus is hardly conclusive, but it strengthens the view that $[147 \mathrm{~A}]$, the charge on the right, was divined second, as the pair of
$[147 \mathrm{~B}]$.

260. We have already seen a similar reversal in the case of [140A-D]. For two similar cases of reversal, on scapulas, see $[A .1]$ and $[A .2]$ in the
appendix. 
[148B] 庚午卜爭貞:亘不其執 Ld Crack-making on gengwu (day 7), Zheng divined: "Xuan will not "be seized."

[148C] 貞:亘不其執

$R L^{2}$

Divined: "Xuan will not be seized."

[148D]貞:亘執

L」へ

Divined: "Xuan will be seized."261 (I. Bin) (HJ 6947f = Bingbian $304.22-25 ; Y 850.2)$

The placement of these inscriptions about the central spine reveais considerable attention to symmetry; one may note, for example (fig. 10), how the oracle-bone form for Xuan's name was oriented one way, on the right side, and the other way, on the left. What is of interest, however, is the way in which the $q i$ changed sides. If we assume that the primary charge was [148A], 亘執, on the right, expressing the hope (and concern) that xuan (an enemy) would be seized, then the retest, [148B], 亘不其執, appeared, with the $q i$, on the left; this entirely standard placement accords well with convention no. 1 . The subsequent retests, however, reversed that normal order, placing [148D], 亘執, the desired primary charge, without the $q i$, on the left (the side usually reserved for undesirable charges), and $[148 \mathrm{C}]$, 亘不其執, the undesired retest, with $g i$, on the right (the side usually reserved for desirable charges). Since it is hardly likely that, in the interval between divining the full form and the short form, the diviner Zheng had changed his mind about what was desirable and undesirable, we once again (see page 142) have reason to think that the relationship between what the diviner wanted and where he placed the charge, to the right or left, was not inflexible.

261. These four charges might also be treated as exclamatory: "Xuan's being seized!," "Xuan's not being seized!," and so on; see page 16 above. 
One could, of course, argue that the reversal reflected a shifting of the diviner's concerns. The immediate concern $[148 \mathrm{~A}]$, that Xuan be caught, had now been replaced, in the zone of concern on the right, by the immediate concern of $[148 \mathrm{C}]$, the fear that Xuan not be caught. I see no way to test such an ad hoc explanation. Another reason for the reversal might be sought by invoking once again the concept of "secondary pairs" (page 124 above). That is, as the arrows supplied by Zhou Hongxiang in fig. 10 reveal, it is possible to treat [148A\&C] as a charge-pair (one initial charge, [148A], 亘執, positive and not containing $g i$, on the right; the other, retest charge, $[148 \mathrm{C}]$, 亘不其執, negative and containing $g i$, also on the right); and possible to treat [148B\&D] as a charge-pair (one, [148B], 亘不其乹, negative and containing $q i$, on the left, the other, retest charge, [148D], 亘乹, positive and not containing $g i$, on the left. ${ }^{262}$ It should be remarked that, had the diviner Zheng observed the convention of keeping all the desired, initial charges (without $q i$ ) on the right and all the undesired, retests (with $q i$ ) on the left, such secondary pairings would not have been possible. The added contextual richness that the actual placement of [148A-D] provided may help explain why the diviner "reversed fields" in this way. That a similar argument was used to account for the doubled used of $q i$ in [140A-D] above, suggests that such contextual considerations may not have been foreign to the Shang.

Takashima has addressed many of these problems, involving new and old information and the function of $q i$. He has commented, in particular, on [146AB] and the right-left placement of its charges:

262. Zhou Hongxiang 1969:28-29 notes the existence of these possible pairings. 
The only way that the demonstrative or pronominal interpretation of $g i$ can work is by assuming that the negative statement was made first, and that $q i$ in the positive statement refers to the nonoccurrence of the huo being divined about--a rather bizarre situation. 263

Takashima explains this 'bizarreness' by invoking the presupposition of the diviner who formulated such charges. He thus argues that, given the presence of $q i$ in $[146 \mathrm{~A}]$,

we can say that for the Shang the prospect of having misfortunes was a possibility. But it [(146A)] was inscribed on the "desirable R" side, so the presupposition of the diviner in this case must surely be one which denies it: "My (= diviner's) formulation of us having the possibility of misfortunes is to be rejected." 264

Whatever the merits of his appeai to presupposition and prospect--similar, in many ways, to my own appeal to immediate and final concerns--I would agree that we need to treat the Shang evidence flexibly.265 I am persuaded by the discussion above that what appear to be reversais of the normai divinatory conventions have to be understood in terms of the context of each particular situation, even though our attempts to discern the diviners particular appreciation of the situation in each instance have to remain speculative. Future research may indeed show that particular Bin-group diviners favored,

263. Takashima 1994:10, ms., quoting a 1992 manuscript.

264. Takashima 1994:11, ms.

265. While my categories of analysis differ from Takashima's, I agree that a variety of considerations--embracing desire, concern, placement, and larger context within a divinatory sequence--were present each time the diviner chose to use or not use $q i$. I would concur, for example, with Takashima's observation (1994:2 ms) that "we need to examine [the evidence] in a context greater than that in which [ $\left.q_{i}\right]$ is found, particularly the left or right placement of the inscription on the bone... and the contextual analysis of a charge that might indicate whether the content would or would not have been something the Shang really desired." 
adapted, or ignored particular conventions, or, indeed, developed their own characteristic solutions to the issues raised above, but that research still needs to be done. 266

\section{Summary to Date}

The situation, where Bin-group charge-pairs were concerned, seems to have been as follows. Generally, charges with desired outcomes were divined on the right side of the shell and were divined first (with no qi); charges with undesired outcomes were divined on the left side of the shell and were divined second (with gi present). On a number of plastrons, however, the Bin-group diviners did not observe these conventions, consistently placing the desired charge (without the $q i$ ) on the left and the undesired charge (with the $q i$ ) on the right (as in [56AB], and [151AB] below); or, placing the $q i$ in the desired charge on the right and not in the undesired charge on the left (as in $[145 \mathrm{AB}, \mathrm{CD}, \mathrm{EF}, \mathrm{GH}, \mathrm{IJ}, \mathrm{KL}, \mathrm{YN}, \mathrm{OP}, \mathrm{RS}])$; or, placing $q i$ in both members of a chargepair on both the right and left sides (as in $[138 \mathrm{AB}],[140 \mathrm{AB}, \mathrm{CD}]$, $[141 \mathrm{CD}, \mathrm{EF}, \mathrm{GH}, \mathrm{IJ}, \mathrm{KL}],[142 \mathrm{AB}]\}$.

I have been able to establish no correlation between the occurrence of these "irregularities" and either the placement of the inscriptions on the shell (see below), or the day-dates of the divinations. All one can state with any assurance is that the conventions of Shang divination were not inflexible and that some considerations, not perhaps recoverable by modern scholars, influenced the placement of inscriptions and the use of $q i$ on

266. Lian Shaoming (letter of 10 August 1994) writes that he intends to study the layout of the inscriptions; he notes that the topic that has been researched very little, but "I have discovered that the methods and conventions of various diviner groups were different." 
particular occasions. It is not out of the question, for example, that the diviners occasionally engaged in a form of divinatory "irony," in which--just as later Chinese would give their children unattractive names to mislead malicious spirits"67--they deliberately "misplaced" a charge or added a $q i$, so as to, as it were, obtain an "unbiased" response from the Powers, or trick the powers into misapprehending what the desired outcome really was. Such a possibility, involving the deliberate reversal of, or playing with, the standard conventions, would make it impossible to provide a comprehensive explanation of those conventions that would fit all cases.

I turn now to other divinatory conventions, and thus to other aspects of the divinatory context that we have not yet considered: the precise location of the inscription on the shell, the links between prognostications and charges, and the presence or absence of the diviner's name recorded in the divinatory preface. As with the discussion so far, we will find that the conventions proposed were generally, but not invariably, honored in the observance.

CONVENTION NO. 3: SEQUENCE AND ABBREVIATION

Convention no. 3 states that: when one member of a charge-pair was abbreviated, it was the charge in the fuller-form of the complete inscription unit (not necessarily just the fuller form of the charge) that was divined first. That is, the form that provided the most information was the one that was divined first. We have already seen this convention at work in the case

267. See, e.g., Smith $1899: 238-39$. 
of $[1 \mathrm{~B}], 268[2 \mathrm{~F}],[141 \mathrm{~B}]$, and $[147 \mathrm{~A}] .269$ What the convention means is that we should never find a charge pair of a form in which *賁:雨 appeared on the right and $\neq$ 干支iD貞:不其雨 appeared on the left. Thus, when oniy one $q i$ is present in a charge-pair, the normal pattern is represented by the pattern in which the fuller form of the inscription (without the $q i)$, as in $[6 A]$, was on the right, and the abbreviated form (with the $q i)$, as in $[6 \mathrm{~B}]$, was on the left:
[6A] 壬寅卜賓貞:今十月雨
$R L^{\sim}$

Crack-making on renyin (day 39), Bin divined: "(In the) present tenth moon it will rain."

[6B] 貞：今十月不其雨的 $\downarrow$ 人

Divined: "( In the) present tenth moon, it will not 'rain." (HJ $809 \mathrm{f}=$ Bingbian 523.5-6)

The existence of this convention is well supported. In most charge-pairs, as in the examples just cited, it was the inscription on the right that was complete, the one on the left that tended to be abbreviated.270

CONVENTION NO. 4: PROGNOSTICATIONS (AND VERIFICATIONS) APPENDED TO THE CHARGE WITH DESIRED OUTCOME

Convention no. 4 states that: When, in display inscriptions, an unambiguous or uncontingent prognostication 271 (and/or confirming

268. [1D] represents an exception to this convention.

269. Other instances of this convention can be found from Table 1, item [2], page 210 below.

270. Keightley 1978:52, n.130.

271. For ambiguous or continent prognostications, see the discussion on p. 161 below. 
verification) appeared on the same surface of the shell as the charges and was incised so that it formed a continuous unit with the charge, then the prognostication (and/or verification) was always appended to, or incised on the same right or left side as, the desired, not the undesired, charge. 272

we have already seen this convention at work in the case of [137A] (fig. $4)$, in which the engraver had appended the favorable prognostication to the desired charge, and in the case of [56AB], in which the prognostication was again attached to the desired charge, $[56 \mathrm{~B}]$, even though that charge was placed on the left of the shell. wu Ding's diviners also observed the convention in divinations about rainfall:

[149A] 癸巳卜争貞:今一月雨. 王固日: $\square$ 丙雨 $\mathrm{R} L \approx$

Crack-making on guisi (day 30), Zheng divined: "In the present first moon, it will rain." (Prognostication:) The king read the cracks and said: "...on the bing-day it will rain."

[149B] 癸巳卜争貞:今一月不其雨 Lレ

Crack-making on guisi, Zheng divined: "In the present first moon. it will not "rain."

[149C] 旬壬寅雨甲压亦雨

(Verification:) In the (next) ten-day week, on renyin (day 39), it rained; on jiachen (day 41 ), it also rained. (I. Bin) (*HJ $12487 \mathrm{f}$ $=$ Bingbian $368.1-3$ )

272. I deal only with prognostications in the discussion that follows. For verifications that observed this convention, see, e.g., [56B], [137A], $[138 \mathrm{~A}],[139],[150 \mathrm{~A}],[151 \mathrm{~B} \& \mathrm{C}],[154 \mathrm{~B}],[159 \mathrm{~A}],[163 \mathrm{~A}]$ In all these cases the verification confirmed the prognostication. It may be speculated, by contrast, that the verification, [145T], "On jisi, Di really did order rain, which lasted down to the geng-day," was placed on the back of the shell, below the undesired charge, [145F], "On the next day, jisi, Di will not order rain," precisely because the verification contradicted the charge. For possible exceptions to the convention involving prognostications, see [8D]. The verifications of [150A\&B] and [153A\&B] do not obey the convention because they were attached to ambiguous prognostications (see the discussion on page 161 below). 
The placement of [149A] on the right of the piastron, together with the use of $q i$ in [149B] on the left to indicate that the wish for 'no rain' had been divined second and was undesired, considered together with the verification, [149C] (written separately, and moving from left to right), that recorded considerable rainfall, all confirm that the engraver had appended the prognostication of [149A] to the charge that had initiated the king's desire for rain. 273

The Shang also observed convention no. 4 in divinations about childbirth: [150A]甲申卜靔貞:婦好婏嘉.王固日：其住丁婏茄其隹庚娩引吉. 三旬又一日甲宙婏允不嘉隹女 $\langle 1\rangle /\langle 1\rangle\langle 2\rangle /\langle 1\rangle\langle 2$ 长 $\rangle\langle 3\rangle\langle 4\rangle$ $\langle 5\rangle\langle 6\rangle$

Crack-making on jiashen (day 21), Que divined: "Lady Hao's childbearing will be good." (Prognostication:) The king read the cracks and said: "(This being $a=$ ) If it be a ding-day childbearing, it will be good; if it be a geng-(day) childbearing, there will be prolonged auspiciousness." (Verification:) (After) thirty-one days, on jiayin (day 51), she gave birth; it was not good; it was a girl.

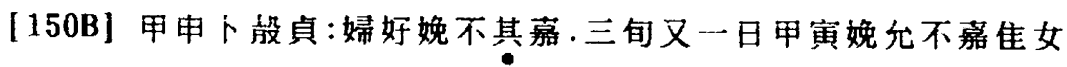
$\langle 1\rangle /\langle 1\rangle\langle 2\rangle /\langle 1$ 二告 $\rangle\langle 2\rangle\langle 3\rangle\langle 4\rangle\langle 5\rangle\langle[6]\rangle \quad \mathrm{L}$ L Crack-making on jiashen (day 21), Que divined: "Lady Hao's childbearing will not "be good." (Verification:) (After) thirty-one days, on jiayin (day 51), she gave birth; it really was not good; it was a girl. (I. Bin) (HJ 14002f = Bingbian 247.1-2; Y783.2; fig. 11)

[150C] 王固日:其隹丁婏募; 其庚引吉其隹壬戌不吉

(Prognostication:) The king read the cracks and said: "If it be a ding-(day) childbearing, it will be good; if it be a geng-day

(childbearing), there will be prolonged auspiciousness; if it be a

273. I continue to refer to the charges as desired and undesired even though, as we have seen (page 142), it is, on occasion, necessary to refer to them as the charges of immediate and final concern. In most cases the distinction makes little difference to the analysis. 
renxu (day 59) (childbearing) it will not be auspicious." (I. Bin) $(* H J 14002 \mathrm{~b}=\text { Bingbian 248.7 })^{274}$

The Shang presumably desired a "good" childbearing. The desired charge, the immediate concern, $[150 \mathrm{~A}]$, was, accordingly, placed on the right and was divined first (convention no. 1); the undesired charge, [150B], was placed on the left, was marked by qi--either as "old information" and was divined second. And, in accordance with convention no. 4, the prognostication was attached to the desired charge, [150A], on the right.275

In all the cases involving appended prognostications discussed so far, the record-keeper had abbreviated neither of the inscriptions containing the desired and undesired charge. The Shang also observed convention no. 4 in cases in which one of the inscriptions was abbreviated, as we have seen in [147AB], in which the undesired (and abbreviated) inscription, $[147 \mathrm{~A}]$, about Zhi Guo's return, was on the right, the desired (and unabbreviated) inscription, $\{147 \mathrm{~B}]$ was on the left, with the fortunate prognostication attached to it.

274. See the discussion of this plastron, as Bingbian 247.1-2 (S309.2), in Keightley: 1978b:7-10. For $q i$ we $i$ gan $j i$ 其隹干吉 as "(as for this being on a gan-day $\Rightarrow$ if it is on a gan day, it will be lucky," see Nivison 1992a:4 and the discussion at Takashima 1994:17 ms. where he treats $q i$ as having both modal and progressive force: 'It may turn out to be a gan-day (<lit. "may be going to be..." ) that is auspicious.'

275. Although the convention makes no mention of prognostications that were written on the reverse of a shell or bone, it is of interest (in light of $[153 \mathrm{~A}-\mathrm{C}]$ below) that the prognostication, $[150 \mathrm{C}]$, on the back of the shell, was recorded on the left surface of the back, running from the spine towards the left edge--so that, although it ran in the opposite direction, it was located directly beneath the favorable charge and its prognostication, [150A]. One can find similar "through the shell" linking in the case of the desired charge, [83A], and its favorable prognostication, $[83 \mathrm{C}]$. See too the discussion of the verification, $[145 \mathrm{~T}]$, at $\mathrm{n} .272$ above. 
Conventions no. 3 and 4 may also be observed in divinations about rain (fig. 12):

[151A] 貣: 帝弗其及今四月令雨 $\mathbf{R} \downarrow \wedge$

Divined: "Di will not, 'when it comes to the present fourth moon, order rain." "

[151B] 伐子ト䐨貞:帝及[今?]四月令雨

Crack-making on wuzi (day 25), Que divined: "Di, when it comes to the present (?) fourth moon,276 will order rain."

[151C] 王固日:丁雨不市辛

(Prognostication:) The king read the cracks and said: "On the ding day (e.g., dingyou [day 34 ]) it will rain; if not, it will be a xin-day (e.g., xinchou [day 38$]$ ) (that it rains)."

[151D] 旬丁酉允雨

(Verification:) "In the next ten-week, on dingyou (day 34), it really did rain. ${ }^{r}$ (I) $(* H J 14138$; Y419.1, partial)

In this case, the prognostication, [151C], was not directly appended to the full, desired charge, $[151 \mathrm{~B}]$, on the left (see fig. 12), but it was, nevertheless, recorded on the same, left side of the central spine as the desired charge; and so was the conîirming verification, [151D]. The case is of interest because the placement of the prognostication on the left side supports the conclusion that we have here yet another instance in which the diviner, Que in this case, divined the full and desired form of the inscription on the left, rather than the right, of the plastron, thus indicating (in the light of revised convention no. 1; see page 142) that the king's immediate fear, [151A], was that Di would not order rain in the fourth moon. That charge was divined on the right side (see convention no. 2 as

276. For whether or not the character $j$ in 今 was present in $[151 \mathrm{~B}]$, see $\mathrm{n} .207$ above. 
revised on page 145), against the background of his final hope, cracked on the left side, that $\mathrm{Di}$ would order rain in the fourth moon.

The convention that linked the prognostication to the desired, unabbreviated charge may also be observed in Bin-group charge-pairs about cult, as in:27i

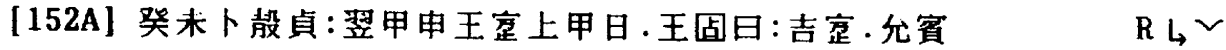
Crack-making on guiwei (day 20), Que divined: "On the next day, jiashen (day 21), the king should host Shang Jia (P1) and of fer the jia-day cult." (Prognostication:) The king read the cracks and said: "Auspicious. We should host (Shang Jia)." (Verification:) (We) really did host (Shang Jia).

[152B] 貞: 翌甲申王勿定上甲日 L」へ

Divined: "On the next day, jiashen (day 21), the king should not host Shang Jia and of fer the jia-day cult."278 (I. Bin) (HJ $1248 \mathrm{f}$ = Bingbian 392.1-2; Y768.2)

In this case, the inscriptions followed standard practice: the inscription containing the desired charge, [152A], was on the right, that containing the undesired charge (or, at least, the charge of no action), [152B], was on the left and abbreviated, and the favorable prognostication, [152A], was appended to the desired, unabbreviated charge on the right.

Exceptions to, and Refinement of, Convention No. 4

Convention no. 4 is confirmed in many cases but some instructive exceptions must be noted. ${ }^{279}$ we find in a charge-pair about childbearing, on

277. For other inscriptions on this plastron, see [18AB] above.

278. Abbreviated versions of the two inscriptions, [152AB], appear on the back of the plastron; they may be consulted as Bingbian 393.3-4.

279. For cases in which the Shang diviner did follow the convention, appending the prognostication to the desired charge, see n. 272 above. 
$H J 14034 \mathrm{f}$, that the abbreviated, undesired charge on the left,

貞: 子目婏不其嘉, "Zi Mu's childbearing will not be 'good," " was followed by a prognostication, also attached to it on the left, 王固日:隹壣[勿?]嘉.280

whatever the prognostication means, the fact remains that, contrary to convention no. 4, it was appended to the unfavorable and abbreviated charge. (For a possible explanation of why this was so, see page 161 below.) There is also at least one plastron on which prognostications were appended to both the desired and undesired charges. This repays study:

[153A]王宙卜涉貞:婦[好]婏嘉.王固日:其隹[成]申婏吉嘉

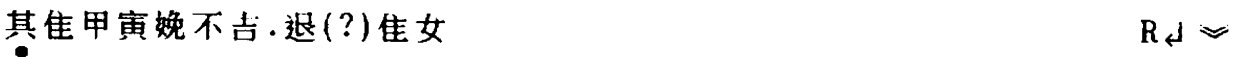

Crack-making on renyin (day 39), Que divined: "Lady [Hao's] childbearing wili be good." (Prognostication:) The king read the cracks and said: "If it be a /wulshen (day 45) childbearing, it will be auspicious and good. If it be a jiayin (day 51) childbearing, it will not be auspicious." (Verification:) It was delayed (?). It was a girl.

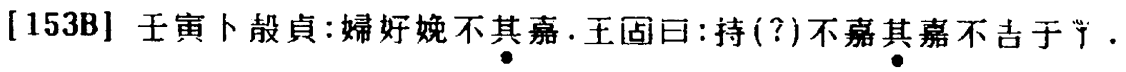

\section{若茲迺蓝}

Crack-making on renyin (day 39), Que divined: "Lady Hao's childbearing wili not "be good." "The king read the cracks and said: "She will hold (the baby) (?) and it will not be good. If it is good, it will not be auspicious...(?)..." (Verification:) It was like this and then (the baby?) died. (I. Bin) (HJ 14001f; Y783.2 = Yibian 4729.1-2; S309.2 (different at S140.1])

The prognostication of [153B] appears to mean that even if the birth were to be "good," that is, even if a boy were born, the outcome would not be auspicious, that is, the boy would not survive. A similar bifurcation that distinguished between the "good" and the "auspicious" is suggested by the

280. The presence of the $w u$ 㧅, as well as the meaning of the prognostication, is uncertain. Serruys (1981:352), translating the inscription as Yibian 3069 , offers: "The king prognosticating says: If it is this (place, time?) do not make (her) (= do not assume that she will) be fortunate." 
prognostication of [150A]: "If it be a ding-(day) that she give birth, it will be good; if it be a geng-day (that she give birth), there will be prolonged auspiciousness." In [153AB] below the birth was "not good" because a girl was born; apparently it was not "inauspicious" because the girl did not die.

On the assumption that the inscriptions on the two plastrons, [150A-C] and $[153 \mathrm{~A}-\mathrm{B}]$, refer to the same pregnancy--and there can be little doubt that this is so $281--t h e$ Shang king's strategy as prognosticator seems to have been to make a series of forecasts, some generalized only for certain gan days, some day-specific, for a series of days ranging up to thirty-days in the future. On day 21 (a jia day), he made auspicious forecasts about all the forthcoming ding and geng days, plus one day-specific forecast about day 59 (renxu). And on day 39 (renyin) he made an additional two forecasts about specific days, one auspicious for day 45 (wushen), one inauspicious for day 51 (jiayin). This means that for the nineteen days between day 39 (renyin), when the second divination was made, and day 59 (renxu), the day for which the last specific forecast had been made, the king's forecasts specified a total of five days: day 44 (a ding day)--good; day 45 (wushen)--auspicious and good; day 47 (a geng day)--extremely auspicious; day 51 (jiayin)--not auspicious; and day 59 (renxu)--not auspicious. No forecasts about births appear to have been made about the remaining fourteen days, though presumably

281. The following considerations support this conclusion: (1) Both plastrons were found in the same pit, YH 127. (2) Both charge-pairs, on days 21 and 38 , were divined by Que. (3) The calligraphy and "layout" of the characters on the two plastrons is virtually identical. (4) The forecasts about specific birth days on the two plastrons are not contradictory. (5) The bad and inauspicious forecast made on day 39 about day 51 of [153A] is confirmed by the inauspicious events recorded for day 51 by $[150 \mathrm{AB}]$. 
many, if not all, of these days may have been the subject of separate subcharges and crackings.

I dwell on the scenario in this way because it throws light on the considerable complexity (compared, say, to the evident yes-no simplicity of divinations about rain or harvest) of these childbirth divinations. The complexity is captured by the ambivalent, contingent nature of the prognostications themselves. The prognostication, $[150 \mathrm{C}]$, was "good," "prolonged auspiciousness," and "not auspicious"; the prognostication, [153A], was "auspicious and good" and "not auspicious"; and the prognostication, [153B], was "not good" and "if good, not auspicious." It is hardly a surprise, therefore, that convention no. 4 might not have applied in a situation of such complexity and that the king recorded two prognostications on each plastron. In the case of $[150 \mathrm{~A} \& \mathrm{C}]$, one prognostication, in $[150 \mathrm{~A}]$, was on the front and the other, $[150 \mathrm{C}]$, on the back of the shell, and both were appended to or associated with (by being on the back of the shell, but directly behind the charge on the front) the favorable charge. In the case of [153A\&B], both prognostications were on the front of the shell, and one was appended to the desired charge, one to the undesired charge. Given the fact that these prognostications were not forecasts of unmixed optimism, it is not surprising that they might equally well be attached to the undesired charge-an explanation that might also explain the anomalous placement of the prognostication of $H J 14034 \mathrm{f}$ (discussed on page 159 above), if it were a prognostication of misfortune.

We may, accordingly, refine convention no. 4 as follows: When, in display inscriptions, the prognostication appeared on the same surface of the sheli as 
the charge, was incised so that it formed a continuous unit with the charge, and involved only a forecast of good fortune unmixed with bad, then the prognostication was always appended to the desired charge and not to the undesired. Prognostications that foresaw an unfavorable outcome, in whole or in part, might be linked to the unfavorable charge.

Convention no 4 , confirmed in many cases, can help us assess the desirability of particular charges, as in the case of [151B\&C] discussed above (page 157), and in the following case:

[154A] 庚戌卜宣貞:王其疾骨 $<1$ 小告 $>2><3><4>\quad \mathrm{R} 4 \approx$ Crack-making on gengxu (day 47), Xuan divined: "The king will be sick in the bone."

[154B] 庚战卜宣員:王弗疾骨.王固日:勿疾 $\langle 1\rangle\langle 2\rangle\langle 3$ 上告 $>[<4>$ $<5>1$

Crack-making on gengxu (day 47), Xuan divined: "The king will not be sick in the bone." The king read the cracks and said: "Do not be sick."282 (I. Bin) ( HJ 709 $\mathrm{f}=$ Bingbian 334.2-3; Y834.2)

It is evident from the content of the charges and the presence of the $q i$ in [154A] that the initial desired charge--the charge of final concern--would have been $[154 \mathrm{~B}]$, placed on the left; it divined the hope that the king would not be sick. The presence of the favorable prognostication, appended to [154B] on the left, further confirms our understanding that, despite its placement on the left, this was the charge whose outcome was desired. Once again, therefore, we see that a diviner, Xuan in this case, did observe convention no. 1 (as revised) and convention no. 4.

282. These two charges might also be treated as exclamatory: "The king's being sick in the bone!." "The king's not being sick in the bone!": see page 16 above. 


\section{CONVENTION NO. 5: DIVINERLESS INSCRIPTIONS}

I assume that "perfect" Bin-group charge-pairs involved two charges in positive-negative opposition, in which one charge of the pair was qualified by $q i$ and the other was not, as in [56AB] and [83AB] above. of particular interest for this inquiry are the "imperfect" charge-pairs (see page 208), in which the two charges did not stand in positive-negative opposition, but were either both negative or both positive, or were presented so that both charges were either marked or unmarked by the presence of $q i$. when we look at such charge-pairs about rainfall, represented by items (3) and (6c) in Table 1 (page 210), we find that the imperfect cases--in which $q i$ either appeared in both the positive and the negative charge (Table 1, item [3]: 其雨/不其雨), as in $[141 \mathrm{CD}, \mathrm{EF}, \mathrm{GH}, \mathrm{IJ}, \mathrm{KL}]$, or in both positive charges (Table 1, item $[6 \mathrm{c}]$ : 其雨/其雨)--generaliy share the following feature: No diviner is recorded in either one or both of the two prefaces (if present) of such "imperfect" charge-pairs. This pattern is found in 49 of the 52 charge-pairs listed in Tabie 1 (i discuss the three exceptions below). The pattern, furthermore, is repeated in imperifect charge-pairs about other topics such as warfare, agricuiturai rituals, and the coming of trouble.z83 Thus, when $q i$ appeared in, for example, both the positive and negative charges of a charge-pair, no diviner (and usually, no preface) was recorded in the overwhelming majority of cases. And no diviner was ever recorded for both charges. Convention no. 5 states, accordingly: when $g i$ was present in both charges of a charge-pair, no diviner's name was likely to be recorded. Or, put the other way round, when

283. Warfare: [155GH], HJ 500f (Y625.1, partial $[=$ Yibian 3381$]), 6771 \mathrm{f}(=$ Bingbian 76.3-4), rituals: HJ 9599 (Y1106.1 [= Houbian 2.40.15]); trouble: $H J$ 721f (=Bingbian 47.7-8). In the body of this study, see [138AB] (rain). [140AB,CD] (somebody coming), [141CD,EF,GH, lJ, KL] (rain), $[142 \mathrm{AB}]$ (attack). 
both inscriptions in a charge-pair record the diviner's name, $g i$ was never present in both charges.

This raises the possibility that it was the diviner's role, as he uttered the charges, to supply the single, deictic $q i$ in one member of perfect charge-pairs, and that when the diviner, having initiated the primary chargepair, had no longer been present--or, more precisely, had no longer been recorded as being present--to formulate the subsequent pairs, his subordinates--uncertain of the links of reference or emphasis involved, lacking the authority to invoke such links or emphases, or merely content to indicate, with the $q i$, "more of the same"--had used the $q i$ more liberally on both sides of the abbreviated record. The disappearance of the diviner's name from the preface, like the disappearance of the preface itself, in cases of abbreviation, may merely have reflected the record-keepers' conventions, rather than the actual attention or inattention that the diviner was paying to the language of the charges. The fact, remains, however, that in an overwhelming majority of the pairs in which $g i$ appeared in both charges the inscriptions were recorded without a diviner's name. And one may also note that those inscriptions in which the right-left placement of the desiredundesired charges was reversed might also be divinerless in one or both members, as in the case of $[56 \mathrm{AB}],[146 \mathrm{AB}],[147 \mathrm{AB}]$, and $[148 \mathrm{CD}]$. There was likely to be more flexibility in the formal conventions, in short, when a diviner's name was not recorded in the preface to the charge. 


\section{QI AND THE DIVINATORY CONVENTIONS}

A Final Test

I end this extensive discussion of conventions about retests, placement, and the functions of $q i$ with a series of campaign divinations that has figured in other scholars' discussions of $q i$ and that can serve as a final test of the hypotheses advanced above (fig. 13):284

[155A]丁本卜靔貞:西正化受又<3>

$$
R_{a}=
$$

Crack-making on dingwei (day 44), Que divined: "Zhi Hua of Cha will receive assistance." (Desired; divined first; no referential

[155B] 丁禾卜能貞: 的正化弗其受又<3>

LLล

Crack-making on dingwei (day 44), Que divined: "Zhi Hua of Cha will not "receive assistance." (Undesired; divined second, as retest of $[155 \mathrm{~A}]$; referential 其; old information)

[155C]貞：的正化亡禍 <3>

Divined: "Zhi Hua of Cha will have nothing ominous (happen to him)." (Desired; divined first; no referential 其; new
information)

[155D] 其出禍 <3>

"He will have "something ominous (happen to him)." (Undesired; divined second, as retest of $[155 \mathrm{C}]$; referential 其; old
information)

[155E]貞：分其毕我史 <3>

Divined: "The (men of the) borders will 'strike our emissaries." (Undesired, but of immediate concern; divined second, as retest of $[155 F]$; referential 其; old information $)^{285}$

[155F]貞：方弗等我史 <3>

$$
\text { L」 }
$$

284. For earlier discussions of $[155 \mathrm{~A}-\mathrm{J}]$, as Bingbian 386 , see, e.g. . Nivison... Keight ley 1991:16-17; Takashima 1994:19, 28; 1994a: 28, 29
ms... CHECK ALL THESE.

285. Takashima (1994a:28 ms) offers for [155E]: "The Fang may be going to harm our emissaries. (Presupposition: No, the Fang will not be going to.)" 
Divined: "The (men of the) borders will not strike our information) 286 (Final desire; divined first; no referential 其; new

[155G]真:我史其等方 <3>

$\mathrm{R} L=$

Divined: "Our emissaries will 'strike the (men of the) borders." (Final desire; divined second, as retest of $[155 E F]$; referential

[155H] 貞:我史弗其等方 <3>

"Our emissaries will not 'strike the (men of the) borders. 288 (Undesired; divined second, as retest of $[155 E F]$; referential 其;

[155I]貞:我史亡其功〈3>

Divined: "Our emissaries will not have a successful attack."

(Undesired, but of immediate concern; divined second, as retest of $[155 \mathrm{~J}]$; referential 其; old information)

[155J] 貞:我史出功 $<3>$

Divined: "Our emissaries will have a successful attack."2so (Final desire; divined first) ( 1 . Bin) ( HJ $9472 \mathrm{f}=$ Bingbian $386.1-10 ;$ Yi20ิ9.2)

That the charges on another plastron, $H J 6771 \mathrm{fb}$, which evidently belonged to the same set the crack numbers on that plastron were all "2" rather than

286. Takashima (1994a:28 ms) offers for [155F]: "The Fang will not harm our emissaries. (Presupposition and the surface form match; no 其.)"

287. Takashima (1994a:28 ms) offers for [155G]: "Our emissaries shall be going to harm the Fang. (Presupposition: Yes, our emissaries will be.)"

288. For a possible prognostication to [155GH], see n. 291 below.

289. Takashima (1994a:28 ms i offers for [155H]: "Our emissaries will not be going to harm the Fang. (Presupposition: No, on the contrary, our emissaries will be.)"

290. Most scholars, following Ye Yusen, have read oracle-bone 古 in military contexts as gong 攻, "attack" (see the entries at KJS 05801; Takashima 1994:19). I find it more probable that the oracle-bone word should, in such contexts, like that of of $[155 \mathrm{IJ}]$, be understood as gong 功 (Keightley $1969: 18,25$, n.6; 1972:7) 
"3"), were, with one exception, 291 identically phrased and placed indicates that the choice of wording and placement in [155A-J] was not accidental. The initial divinations, [155A-D], may be explained in terms of the revised conventions proposed above. The desired charges (or the charges of immediate concern)，[155A] 先正化受又, and [155C] 自正化亡祜, were placed on the right (convention no. 1), were not marked by $q i$, and were presumably divined (if not uttered; see note 223) first, thus providing new information. The undesirable charges (or the charges of less immediate concern)，[155B] 的正化弗其受又 and [155D] 其坐禍, were presumably divined second; the $q i$ in these charges either referred (as a bi 诐, celui-làj back to the unmarked charges that had been divined $\hat{i}$ irst or served to specify (as a $c i$ 此, celui-ci) that these charges differed from their pairs.

In the case of the next charge-pair, [155EF], the placement was reversed: the desired charge, [155F] 方弗苂我出, divined first, and not marked by $q i$, was placed on the lefit rather than the right. Regular placement was resumed,

291. The charge-pair [155Ij] was not recorded on $H J 6771 \mathrm{f}$ (and is unlikely to have been present on the small section of the xiphiplastron that has been lost). On the other hand, two prognostications incised on $H J 6771 \mathrm{~b}$ were missing from $H J 9472 \mathrm{~b}$. The first reads (following the $\mathrm{MZ}$ transcription and that given for Bingbian 77.2): 王固日:吉隹其亡百(?).舌电其循(?). If this transcription is correct--the back of the plastron is rough and hard just their (i.e., our emissaries) last four characters have given rise having a successful attack." The interpretations. Serruys (1981: rise to radically different

"If we have food offering (ritual, ) , reading 言 (=歆) 甶其值 has of fered: anticipate to make a visitation (ins wall (make it $=$ ) assume to (1994:19) reading f直值, has (instead of an attack)." Takashima (that) $s$ /he is to 舍由其德, has countered with [the Fang]"; Nivison (1994T:10 ms.), reading cease), let us just make a showen they (the Fang) quiet down (she, assumption that the prognostication force." Whatever the meaning, on the we have an instance in which a charge-pair divined the charges, [155Ij], third plastron in the back of charges to which 
however, in the case of the charge-pair [155GH], with the desired charge, [155G] 我史其妓方, on the right, presumably divined first. But the order and placement were again reversed in the case of the charge-pair [155IJ]].

Why was $q i$ present in both [155G] and [155H]? And why did the diviner-or, because the diviner was unrecorded, the divining official--reverse the usual placement, putting the desired charges, [155F] and [155J] on the left rather than on the right? And why, in the case of [155E] and [155I], was the desired alternative, unmarked by $q i$, divined on the undesirable left rather than on the desirable right?

Clearly, one can invoke the diviner Que's own "ironic" choices (on divinatory "irony," see page 152 above) on this particular occasion as he practiced his pyromantic artistry--and I choose the word artistry deliberately, to emphasize my sense that Shang divination procedures were not simply bound by mechanical regulations. But such an explanation, by its nature, is untestable. One can, however, still invoke the absence of the diviner to account for the irregularities noted above. A diviner was recorded for none of the inscriptions, [155EF,GH,IJ], in which the conventional placement was reversed. Nor was a diviner recorded for the one charge-pair, [155GH], in which $q i$ appeared in both charges. Convention no. 5, therefore, which associates irregularities with the lack of a recorded diviner--well documented, as we have seen, in the case of rainfall and other divinations (page 163 above)--provides at least one explanation for the reversals and 'redundancies' of [155EF,GH,IJ]. Once again the absence of a diviner's name may be correlated with what appears to have been a more unconventional--or 
less assured?--use of $q i$ and a more unconventional right-left placement of the charges.

Indeed, one additional piece of evidence may involve the presence or absence of the diviners in the way that $g i$ was used. As $I$ have indicated, the charges and the way in which they used $q i$ were for the most part identical on HJ $6771 \mathrm{f}(=[156]$; all cracks numbered "2) and $H J 9472 \mathrm{f}(=[155 \mathrm{~A}-J]$; all cracks numbered " 3 "), as can be seen from the first two charges on $H J 6771 \mathrm{f}$ :

[156A] 丁未ト爭員:白正化受又 <2> R

Crack-making on dingwei (day 44), Zheng divined: "Zhi Hua of Cha will receive assistance." (Desired; divined first; no referential 其； new information)

[156B]丁未卜爭賁:的正化弗其受又 <2> L し

Crack-making on dingwei (day 44), Zheng divined: "Zhi Hua of Cha will not "receive assistance." (Undesired; divined second, as retest of $[155 \mathrm{~A}]$; referential 其; old information) (I. Bin) ( $\mathrm{HJ}$ $6771 \mathrm{f}=$ Bingbian 67.1-2)

There was, however, one suggestive difference. The diviner of [155AB] had been Que; the diviner of [156AB] had been Zheng. It was not unusual for the king to employ different diviners from the same diviner-group (in this case, Que and Zheng were both member of the Bin-group) to address the same topic. One may wonder, however, if the presence of the two diviners in the same set of inscriptions may, once again, have encouraged a more liberal use of $q i$ on the part of the record keepers of all the other charges on both plastrons for which no diviner was recorded. Since the "diviner-less" inscriptions on both the "Que plastron" and the "Zheng plastron" employed $q i$ in the same way, one must assume that some convention was at work. It was the one that I have labeled no. 5 (see page 163). In this instance, uncertain how the two different diviners might have wished to formulate the charges, their 
assistants might have sought to protect themselves against any accusations of carelessness, by putting in as many $q$ is as possible.

Qi 其 Usage, Charge-Pairs, and Early Diviner-Groups

As we have seen, in "retests" about activities not under the king's control the $q i$ would generally not appear in the primary charge fas in the case of $[83 \hat{A}])$, but would be inserted in the second or later charge (as in the case of $[83 \mathrm{~B}])$. I now believe it likely that this Bin-group convention represented an extension and refinement of earlier, more basic practice-evident in the Shi- and Li-group charges in which $q i$ had been used as anaphoric resumptive in single charges alone. Both of these diviner groups used charge-pairs relatively rarely and, when they did so, the linking of the inscription units was frequently so irregular as to make their status as pairs uncertain.292 And, furthermore, when these diviners did pair their charges, they frequently placed $g i$ in both members of the pair,293 or in neither member294--a practice that suggests not that they were injecting a modal flavor into their charges but that they were simply, as they elaborated single charges into charge-pairs, "doubling" their use of $q i$ just as they were "doubling" their use of the charge. In this view, the Bin-group's practice of pairing charges would have represented an imaginative, almost metaphysical experiment, that, given the general decline in the use of charge-pairs starting in period II, left little divinatory legacy. It was the singlecharge tradition of the Shi- and Li-groups, with its use of the deictic,

292. See, e.g.: Shi-group: $[42 \mathrm{AB}],[49 \mathrm{BC}]$; Li-group: [88AB], [89AB], [91AB].

293. See, e.g., See, e.g.: Shi-group: $[42 \mathrm{AB}],[46 \mathrm{AB}],[48 \mathrm{AB}],[55 \mathrm{AB}]$; Li-group $[92 \mathrm{AB}]$.

294. E.g., Shi-group: [51AB], [53AB]; Li-group: [82BC\&DE], [84AB], [91AB]. 
nominalizing $q i$, that remained standard throughout the period, from the Shigroup divinations of period I through the Huang-group divinations of period $V$.

The $Q i$ 其 - Wu 勿 Opposition

One more piece of evidence, however, needs to be considered before we can lay to rest the explanation that $q i$ was a modal particle that conferred a meaning like "should, ought." In a number of Bin-group charge-pairs about topics under Shang control, the presence of the imperative wu 勿, "do not, should not," in the negative charge has suggested that the $q i$ in the positive charge would have a similarly strong force. Thus it has been proposed that [157A] should be translated as *" (We) should ( $q i$ ) build a settlement, (for if we do) Di will not obstruct (but) will approve."295 I had long accepted this view of the matter, but I would now propose that there is no logical reason to assume that the $q i$ 其 of [157A] had to be equal and opposite in force to the $w u$ 勿 of $[157 \mathrm{~B}]$. The use of the prohibitive wu was, by contrast with the neutral negative $b u$ 不, sufficiently rare in charge-pairs to suggest that such pairs were special. In this view, the use of a prohibitive "do not, should not," in the [B] negative charge would have shifted the "center of gravity" of the pair from the normal, neutral position--represented by the model: [A] "Verb" and [B] "Not in this case verb"--towards a position that was biased in favor of not doing the verb: [A] "In this case, Verb" and [B] "Do not, wust not Verb." That the wu strengthened the negative charge, in other words, suggests that the diviner was not entirely neutral about proposing the positive one; the use of wu indicated that he would 'rather not Verb.'

295. Nivison and Takashima have cited this imperfect charge-pair, [157AB], to demonstrate the presence "of an intention" in a charge containing $q i$ when the $q i$ of the positive charge is balanced with $w u$ in the negative charge. See Nivison 1992:7; Takashima 1994:3, ms; 1994a:24 ms. 
Thus, I would translate the charge-pair in question as:

[157A]王子卜爭貞:我其作邑帝弗佐若.三月 R $\mathrm{R}$ 月

Crack-making on renzi (day 49), Zheng divined: "(As to our building $=$ ) If we build a settlement, Di will not obstruct (but) will approve." Third moon.

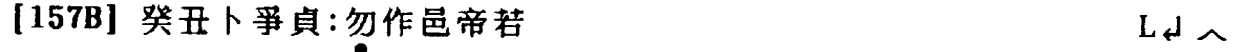

Crack-making on guichou (day 50), Zheng divined: "Do not build a settlement, (for) Di will approve (our not building it)." (I . Bin) $($ Heji $14206 \mathrm{f}=$ Bingbian 147.1-2; Y117.2-18.1)

The $q i$ evidently served to demote and nominalize the opening verb phrase of [157A].296 The $w^{\prime} u$ can be construed as serving the same purpose at the start of [157B]; 'As to (our) not building a settlement, Di will approve.' One sees the same construction in $[50 \mathrm{~B}]$, 勿征西方下上弗若..... As to not attacking the Gongfang, the Lower and Upper Spirits will not approve....297

It is of interest that the $w u / q i$ opposition was rarely used. I know of only one case in which it appears in a perfect charge-pair, in which the full preface appears in both members ([157AB] does not qualify):298

[158A] 庚宙卜賓員:今珪王其步伐夷 $R L シ$

296. The $g i$ of [157A] cannot have been referring to old information divined on this plastron, because it appears in the charge that was divined a day earlier than [157B], the charge that forms the other half of this imperfect pair. The existence, however, of $H J 13491$ (Y117.2), 壬子卜靔貞:我作㫕, "Crack-making on renzi (day 49), Que divined: 'We will build a settlement," "at least raises the possibility that it could have been the primary charge to which the $g i$ of [157A] referred back. That $H J$ 13491 was recorded on a scapula rather than a plastron, and that the diviner was Que rather than Zheng, does not, however, lend much support to this interpretation.

297. For the way $w u$ might demote the initial clause in a complex charge, see p. 174 below.

298. I take [159AB] and [158AB] from Takashima 1994a:10-11 ms. and generally follow his translation of the substance of those inscriptions. 
Crack-making on gengyin (day 27), Bin divined: "This season the king will in this case go to attack the Yi."

[158B] 庚宙卜寊具:今珪王步伐夷

Crack-making on gengyin (day 27), Bin divined: "This season the king should not go on foot to attack the Yi." (I. Bin) HJ 6461f = Bingbian 276.3-4; Y507.2)

Such cases were rare. There is no other case of $q i$ being contrasted with wu in Bin-group charge-pairs about settlement building; with the one exception of [157AB], the contrast was always between 作邑 and 勿作邑, not between 其作邑 and 勿作邑.299 Similarly, in the analogous charge-pairs about the king sending men to a particular place (see, e.g., $\lfloor 137 \mathrm{AB}\rfloor)$, the contrast was always between 使 and 勿使 (or, of course, 不其使), never between 其使 and 勿使.300 Similarly, the contrast in $[152 \mathrm{AB}]$ was between 賓 and 勿賓, not between 其賓 and 勿賓.

If one includes imperfect pairs, one can find a few more instances of $q i-w^{\prime} u$ opposition, such as:

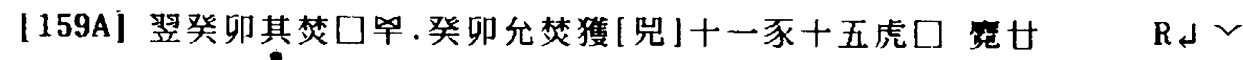
"On the next guimao (day 40), if (we) hunt by fire, ... (we) will catch game." (Verification:) On guimao we really did hunt by fire. (We) caught buffalo, eleven; boar, fifteen; tiger...; fawn, twenty.

[159B] 翌癸卯勿焚

L ᄂ

"On the next guimao we should not hunt by fire." (I. Bin) (HJ $10408 \mathrm{f}=$ Bingbian 102.1-2; Y473.2)

299. Inscription sample at Y117.2-18.1.

300. Inscription sample at Y2.1-3.1. 
[160A] 員:翌乙未其燎

R L ${ }^{2}$

Divined: "On the next yiwei (day 32), (we) should in this case burn-sacrifice."

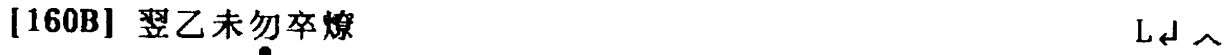

"On the next yiwei we should not end (?)301 the burn-sacrifice."

(I. Bin) ( $H J 152 \mathrm{f}=$ Bingbian 128.9-10; Y721.2, partial.)

[161A]己丑卜爭貞:王其成

$\operatorname{Rd}{ }^{2}$

Crack-making on jichou (day 26), Zheng divined: "The king will in this case sacrifice a prisoner (?)>." 302

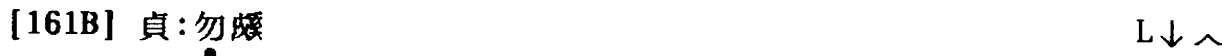

Divined: "(The king) should not sacrifice a prisoner (?)." (1. Bin) $(H J 6016 \mathrm{f}=\text { Bingbian 141.1-2; Y1224.1 })^{303}$

In these cases, the presence of the wu 勿 in the fanwen may explain the presence of the $q i$ 其 in the zhengwen. That is, it is evident for two reasons that the $q i$ of [159A] did not mark the charge as a retest: (1) the inscription unit [159A] is on the right of the shell and is therefore likely to have been divined first (convention no. 2); (2) [159A] is the full form of the inscription, by comparison with its abbreviated charge-mate, [159B], which is on the left (and which more likely to have been the retest; convention no. 3 ). Similarly, $q i$ does not appear to have been resumptive "across the charge-pair" in $[158 \mathrm{~A}]$ or $[160 \mathrm{~A}]$, since those were the charges divined on the right and were, in accordance with convention no. 2 , presumably divined first. I believe, rather, that $q i$ in these complex zhengwen served to demote the

301. On the possible meaning of oracle-bone 卒, see Qiu Xigui 1990 .

302. The meaning of the graph is uncertain. For a brief discussion see Shima 1958:338; Takashima 1973:150. Serruys (1974:33) translates as "make human sacrifice (of a shaman)."

303. For other inscriptions on this plastron, see [142ABC]. 
initial clause, just as the wu served to demote the initial clause in the fanwen.

None of these $q i$-wu charge-pairs persuades me that the deictic, demoting function of $g i$, so well illustrated in the unpaired charges of the Li-group and other diviners, served to express modality. The anaphoric, delimiting explanation is still satisfactory.

Also instructive is the following case:

[162A] 員:贸于筃甲父庚父辛一牛

$R L^{2}$

Divined: "In the offering to Xiang Jia (K17), Father Geng (K18), and Father Xin (K19), (use) 304 one bovid."

[162B] 貞:勿出于霰甲父庚父辛一牛

Divined: "Do not, in the offering to Xiang Jia, Father Geng, and Father Xin, (use) one bovid." (I. Bin) (HJ 6647f = Yibian 7767; Y1329.2)

The 勿 at the start of [162B] served a demoting function (as I have argued that it did in the complex charge, [157B]].

$Q i$ in Prognostications (1): Simple

In summing up this explanation of $g i$, it would be appropriate to see how well the explanation works when applied to Bin-group forecasts. Since charges and prognostications can both be regarded as statements about the future, it is plausible to assume that $q i$ played a similar role in both environments and that, in prognostications, it continued to delimit and demote. As with charges, it is helpful to divide prognostications into the simple and the complex.

304. For the understanding that a co-verb like yong 用 should be inserted in such complex charges, and that the charge itself is complex, see pp. 15 . 
Let us first consider two relatively rare instances of simple-sentence prognostications that employed $q i$ :

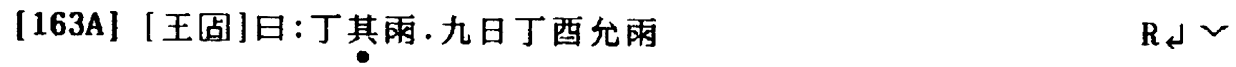

(Prognostication:) [The king read the cracks and] said: "On the ding-day it will in this case rain." (Verification:) On the ninth day, dingyou (day 34 ), it really did rain.305 (I. Bin) (*HJ $12948 \mathrm{f}=$ Bingbian 533.1-2; Y585.1)

[163B] 丁王亦固日:其亦雨.之夕允雨

(Prognostication:) On the ding-day, the king again read the cracks and said: "In this case, it will likewise rain."306

(Verification:) That night (i.e., the night of dingyou) it really

did rain. (I. Bin) $\left({ }^{*} H J 12948 \mathrm{~b}=\right.$ Bingbian 534.2; Y92.2)

[164A] 甲辰卜靔貞:突來白馬.王固日:吉其來

Crack-making on jiachen (day 41), Que divined: " $X \mathrm{i}$ will bring white horses." (Prognostication:) The king read the cracks and said: "Auspicious: he will in this case bring (them)."307

[164B] 甲辰卜靔貞:奚不其來白馬

Crack-making on jiachen, Que divined: "Xi will in this case not bring white horses." (I. Bin) (HJ 9177f = Bingbian 157.11-12;

Y625.1, partial)

305. Zhang Bingquan, in his transcription of Bingbian 533.1, attaches the prognostication [163A] to the charge: [戊]子卜[靔]貞:王令[配]河沈三牛 燎三牛卯五牛, "Crack-making on [wu]zi (day 25), [Que] divined: The king orders (that some officer), in performing the you-cutting sacrifice (to the) River Power, ritually-drown three bovids, burn-sacrifice three bovids, and split open five bovids." "For why I believe the prognostication should be attached to another charge, that had presumably been divined on the upper half of the plastron now missing, see Keightley $1991: 410-11$.

306. We might also treat the prognostications of [163A\&B] as exclamatory: "Ding's raining!"; "Its likewise raining!"; see page 16 above.

307. Takashima (1994a:11 ms) suggests that such prognostications were optative, "Yay ( $\mathrm{Xi}$ ) be going to bring (them)." I do not believe, however, that prognostications played such as role or had such a force; they were forecasts, not wishes. 
Evidently, the forecast of [163A] singled out, through the use of $q i$, that it would, "in this case," i.e., on the ding-day, rain. The $q i$ in the second forecast, [163B], apparently pronounced on that same ding-day, had a similar, specifying function: "in this case," i.e., on this ding-day, it will likewise rain.' 308

On the similar assumption that $[164 \mathrm{~A}]$, on the right and desired, was divined first, then one can see that the $q i$ in the charge of [164B] would have served to individuate and delimit (as $c i$ 此, celui-ci) the retest. That the king repeated the $q i$ in the prognostication of [164A] may have been to emphasize that although the "in this case" of [164B] had been couched in terms of $\mathrm{Xi}$ not bringing white horses, the prognostication in fact was that 'Yes, even in this case for which we have just divined a charge with an inauspicious outcome, the outcome will, precisely in this case, be auspicious.' The repetition of $q i$ in the prognostication might have served, in this view, to 'build on' its earlier appearance in the charge of [164B], using the referential "in this case" of the charge to strengthen the specificity of the prognostication. But such cases, in which $g i$ was used in a simple-sentence prognostication, were rare; there is little to be gained by straining to explain them further.

$Q i$ in Prognostications (2): Time-Specific

No strong pattern links the presence or absence of $q i$ in simple-sentence prognostications to the specificity of the king's prognostications about a particular time, as in ([163A] "On the ding-day it will in this case rain."

308. I do not think that the prognostication of [163B] meant it would rain a second time; it meant, rather, that the cracks had again indicated a ding-day rain: "Its likewise raining!" (see n. 306). 
The king, in such prognostications, sometimes employed the $q i$, as in the case just cited. But on other occasions, also involving uncontrollable phenomena, the king (or his record keepers) omitted the $q i$, even when a particular gan-day was specified (see too [151C] and [168D]:

[165]王固日:己雨

The king read the cracks and said: "On the $j i$-day it will rain."309 (I. Bin) ( $H J 418 \mathrm{~b} ; \mathrm{Y} 837.1)$

[166A] 庚辰卜古貞:翌辛已易日.王固日:睗日 Rムレ

Crack-making on gengchen (day 17), Gu divined: "On the next day, xinsi (day 18), it will be sunny." The king read the cracks and said: "It will be sunny."

[166B] 貞:翌辛已不其易日 L」へ

Divined: "On the next day, xinsi (day 18), it will not, in this case ( $q i)$, be sunny." (I. Bin) (HJ 13220f; Y837.2)

I cannot speculate with any assurance about why the prognostication of $[163 \mathrm{C}]$, divined by Que, was 丁其雨 (with $q i$ ) and the prognostication of $[7 \mathrm{C}]$, for example, also divined by Que, was 庚雨 (without gi); or why the prognostication of $[164 \mathrm{~A}]$ was 其來 rather than *⿻大从木 ; or why the prognostication for [166] was 賜日 rather than *其賜日; or why, for that matter, the prognostication of $[142 \mathrm{C}]$ was 我伐隹丁 rather than *我伐其隹丁. As with so many of the cases considered in this study, I can devise plausible scenarios, but I cannot show that they are correct. All we can conclude with certainty is that in simple prognostications, as in charges, the use of $q i$ was optional.

That the diviners did not employ $q i$ at all in some kinds of prognostications may throw light on these questions about how $q i$ functioned.

309. The charge to which [165] was a response does not appear to have been preserved on the front or back of this plastron. 
It is worth asking, for example, why in the case of harvest prognostications like [83C] (in note 217), the Shang always wrote 王固日:吉受出年 rather than *王固日：吉其受出年. The first formulation meant, "Auspicious. We will receive this harvest." The second formulation, by contrast, would have meant, by analogy with the childbearing prognostications discussed in the second paragraph below, *nAspicious, its receiving this harvest," and thus "Auspicious, the receiving of this harvest," which might not have made sense in a non-contingent context where only one harvest was at issue. If $q i$ served to nominalize the phrases it preceded in prognostications, that would well explain why we never find, for example, prognostications like *王固日:我其受㯟年, *nOur receiving millet harvest." Or if gi served to delimit, there would have been no desire to limit a favorable harvest forecast in this way: *"We will in this case receive millet harvest."

The harvest prognostications also suggest that whereas the you of you nian 4 年, "this harvest," in [83C), and the delimiting gi of fu qi shou shu nian 弗其受㯟年 in $[83 \mathrm{~B}]$, "will not in this case, receive millet harvest," both served a referential function, the you was directly adjectival and inclusive, appropriate for large, indeterminate events like harvests (or calamities; see [169] below), while the $q i$ was adverbial and restrictive, appropriate for specific events, like birth days ([150A]), the bringing of white horses ([164A], the coming of bad news ([169]), or the fall of rain on particular days ([163A]).310 That the scope of reference was larger for you than for $q i$ is well demonstrated by the discussion of [169] below. In this view of the matter, gi (small reference) could follow a you (large reference),

310. See too the distinction proposed on page 108 above, in which you was for intra-charge, $q i$ was for inter-charge, reference. 
thus serving to narrow the discussion; but a you could not follow a $q i$, could not, in other words, expand what had already been narrowed; hence, as already noted, one never finds *王固日:其受出年.

\section{Qi in Prognostications (3): Multi-Part, Contingent}

It is also of interest that, in complex prognostications about childbearing, the formula was always, as in [150A], 其住丁婏堂其住庚婏引吉, "If it be a ding-day childbearing, it will be good; if it be a geng-(day) childbearing, there will be prolonged auspiciousness." We never find a childbearing prognostication of the form, *隹干婏嘉, *"It will be a gan-day childbearing and it will be good." As in [137C] and [150A], the standard form included the $q i$ : 其佳干婏嘉. "This being a gan-day childbearing will be good."311 The avoidance of the formula, *隹干婏嘉, suggests that the role of $q i$ in 其住干婏嘉 did not simply specify "in this case," but altered the structure of the prognostication, making it contingent by nominalizing and demoting the initial sentence, If it be a gan-day childbearing, it will be good.'

Multi-part prognostications about uncontrollable activity, in which all the forecasts were contingent, were not limited to childbearing. The king might be equally cautious about alternative weather-forecasts as in the following detailed prognostication:

[167]王圆日:丁丑其出不吉其隹甲出吉其隹[辛]出整亦不吉

The king read the cracks and said: "On dingchou (day 14), if there be thunder, it will be inauspicious; if it be on a jia-day that there is thunder, it will be auspicious; if it be on [a $x$ in-day]

311. E.g., HJ 376b, 454, 13996, 14001, $14002(=[150 \mathrm{~A}]), 13926 \mathrm{~b}, 14009$, from the sample at Y783.2-84.1; see, too, the sample at S309.2. 
that there is thunder, it will likewise be inauspicious." 312 (I. Bin) (HJ 6485b; Y357.2 = Bingbian 19.9.)

The occurrence of the three $q$ is in the prognostication clearly expressed the king's uncertainty about whether and when there would be thunder as he proposed a series of "in this case" alternatives (其出 ... 其佳甲... 其隹[辛]); given that uncertainty, the prognostication can be read as a sequence of contingent forecasts.

One can find similar "hedging" in the king's rain forecasts, as in [6C]: [6C] 王闾日:吉其雨隹庚其住辛雨引吉

The king read the cracks and said: "Auspicious. This raining will be on a geng-day (i.e., gengxu [day 47]); this being a $x$ in-day raining (i.e., xinhai [day 48]), will be extensively auspicious." (I. Bin) ( $H J 809 \mathrm{~b}=$ Bingbian 524.4)

Thus, when $g i$ 其 preceded we $i$ 隹 in complex prognostications (as in [6C], $[150 \mathrm{~A}, \mathrm{C}],[153 \mathrm{~A}]$, and $[167])$, the $q i$ served to nominalize what followed: '( This being... $=$ ) Its being...' On the other hand when 隹 preceded 其 in a simple prognostication, as in $[168 \mathrm{C})$, the $q i$ played its usual deictic function:

[168A] 己五卜爭:翌乙未雨.王(固)日ロ Crack-making on jichou (day 26), Zheng divined: "On the next yiwei (day 32 ), it will rain." The king (read the cracks and) said....

[168B] $\square[$ 乙]未不雨 R Lへ .... "On (the next [yi]wei, it will not rain." [168C]王固日:雨隹其不延.甲午允雨 Re

312. For a discussion of the kind of charge, which had probably involved ancestral sacrifice, to which this prognostication was a response, see Keightley 1978:87-88. 
The king read the cracks and said: It will rain, only, in this case it will not be prolonged." 313 (Verification:) On jiawu (day $31)$ it really did rain.

[168D] 王固日:】于辛雨

L L

The king read the cracks and said: "... On the xin-day (i.e., $x$ inmao [day 28]), it will rain." (I. Bin) ( $H J 14161 \mathrm{~b}=$ Bingbian $522.1-2,4-5)^{314}$

$Q i$ 其 and You 4

Qi 其 in prognostications also served to nominalize what followed when it preceded you 4 . This is evident in Wu Ding's prognostications about various calamities, recorded as part of "display inscriptions." 315 Typical examples of such display inscriptions (unpaired) are found on the large scapula originally published as Jinghua $2(\mathrm{~S} 307.2)$. I present only one inscription unit here, first using the "in this case" translation:

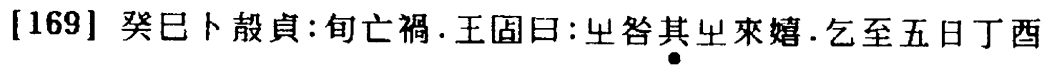

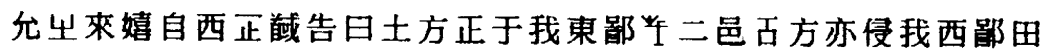
Crack-making on guisi (day 30), Que divined: "In the (next) ten days there will be nothing ominous." (Prognostication:) The king read the cracks and said: "There will be calamities; there will in this case be (someone) bringing alarming news." (Verification:) When it came to the fifth day, dingyou (day 34), there really was (someone) bringing alarming news from the west. Zhi Guo reported and said: "The Tufang have attacked in our eastern borders and have seized two settlements. The Gongfang likewise invaded the fields of our western borders." (I. Bin) (HJ 6057f = Jinghua 2; Y449.1)

313. See the earlier discussion of this charge (as [8C]) at $n, 28$ above.

314. For further discussion of the inscriptions on this plastron, see [8AB].

315. I have defined the characteristics of Wu Ding's display inscriptions as: (1) bold, large calligraphy; (2) a prognostication and verification written as a single, continuous unit that was usually placed immediately next to the charge; (3) a verification, frequently detailed, that confirmed the accuracy of the prognostication (Keightley 1978:46, n.90). 
In four other instances on this scapula the engravers recorded prognostications that were identical in form to that of [169]: 王固日:坐焒其坐來婟, "The king read the cracks and said: 'There will be calamities (in this case): "there will be (someone) bringing alarming news." " It is evident that the meaning would have been much the same if $q i$ is thought of as serving to nominalize what followed: "There will be calamities: '(this [qi] being =) their being the coming of alarming news." "Read in this way, $q i$ in such contexts served as an "i.e.." as a "namely"; the difference from "in this casen $^{n}$ is minimal. It may also be noted that the formula was always 王固日:出煚其出來嬉 (with the gi); we never find *王闾日:出吡出來嬉 (without the $q i) .316$ This makes good sense in terms of the distinction we have attempted to draw earlier (page 179) between you as inclusive and $q i$ as restrictive. The clause that followed the $q i$ was, as "namely," a subset of the larger clause governed by the you.

$Q i$ as Context-Dependent

In closing it is worth reiterating that the function of deictic $q i$ varied with its context, particularly when we compare simple and complex charges. Consider, first, the following two simple charges whose translation presents no problem:

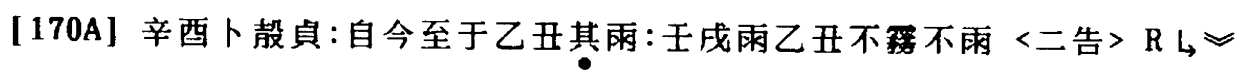
Crack-making on xinyou (day 58), Que divined: "From today down to yichou (day 2), it will in this case rain." (Verification:) On renxu (day 59), it rained; on yichou it was not foggy and it did not rain.

[170B] 辛西卜靔 (貞): 自今至于乙丑不雨 L J $\approx$

316. Sample at Y1076.1-77.2; see, e.g., HJ 1075f, 4518b, 6057f, 6057b, 6063f, $6068 \mathrm{~b}$, etc. 
Crack-making on xinyou, Que (divined): "From today down to yichou (day 2), it will not rain." (I. Bin) (HJ 6943)

It is the next two, related complex charges (already translated as [2AB] above), on the same plastron, whose translation is instructive.317 Because these charges are complex, the $g i$ functioned to demote the head clause:

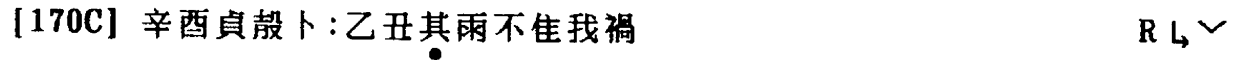

Crack-making on xinyou (day 58), Que divined: "(As to yichou its raining, it will not be ominous for us = The raining on yichou will not be ominous for us $=$ ) If it rain on yichou (day 2), it will not be ominous for us."

[170D]貞:乙丑其雨隹我禍 L」へ

Divined: "If it rain on yichou, it will be ominous for us." (I. Bin) (HJ 6943 = Bingbian 306.6-7; Y829.1)

This means that the way Shang $q i$ worked varied with context. In a simple declarative charge like [170A], the sentence 自今至于乙丑其雨 meant "From today down to yichou, it will in this case rain" (cf. [138AB]). In a complex, contingent charge like $[170 \mathrm{C}]$, the head clause 乙井其雨 meant, by contrast, "the rain on yichou," and, because the clause was demoted, meant "As to the rain on yichou."318 Such variability in function is hardly unknown in Early Chinese; zhi 之, for example, could function in analogous ways, either as a demonstrative pronoun, adjective, or genitive (see the quote from Takashima on page 8 above). There is no reason to think that certain Shang words would not

317. Zhang Bingquan in his commentary to Bingbian 306, places [170CD] before [170AB], as Bingbian 306.6-7 and 306.8-9 respectively. Three factors encourage me to think that [170A\&B] were divined before [170C\&D]: (1) [170A\&B] represent the fuller form (the preface of [170D] is abbreviated); (2) the prognostication was attached to [170A] (convention no. 4); and (3) the content of [170C\&D] appears to refer back to a rainfall that has already been divined.

318. Compare the discussion on p. 10 above, about the way the meaning of the phrase 其告 might vary with context. 
have been equally versatile, particularly when, as in the case of $q i$, that versatility stemmed from the way that deictic reference worked in different contexts.

Similar variation in function can be seen divinations about the Gongfang "going out" on campaign. When the charge was a simple sentence, the $g i$ can best be translated as "in this case," as in:

[171】員: 古方其出

Divined: "The Gongfang will in this case go out." 319 (I. Bin) ( $H J$ 6106; Y274.1)

When the clause containing $g i$ stood at the start of complex sentence, however, then its deictic function served to demote and genitivize, and I would translate 百方其出 differently, as in:

[172] 口五方其出隹 [我禍]

...." (As to the Gongfang's going out, [it will be ominous for us]

$\Rightarrow$ ) If the Gongfang go out, [it will be ominous for us]."320 (I.

Bin) ( $H J 6104 ; Y 274.1)$

The same phrasing in a complex charge, but inscribed without the $q i$ (which, as we have seen, was always optional), would thus be translated in the same way:

[173]丁未卜亘貞:古方出隹我禍

Crack-making on dingwei (day 44), Xuan divined: "(As to the

Gongfang's going out, it will be ominous for us $=$ ) If the Gongfang

319. The same charge appears on $H J$ 6107-6112 (Y274.1), all divined on scapulas. Once again, we may note that if $q i$ served to nominalize the verb that followed, this charge might be read as an exclamatory phrase (see page 16 above), "The Gongfang's going out!" This understanding accords well with the translation of [173] about to be offered below.

320. A similar, fragmentary charge was present on $H J 6105$ (Y274.1), also divined on scapula. 
go out, it will be ominous for us." 321 (I. Bin) (HJ 6091; Y273.2)

Comparison of [172] (with the gi) and [173] (without the gi) suggests, once again, that $q i$ was optional in such contexts. And once again the parallels with Classical Chinese zhi 之, which could also be omitted without affecting the meaning, come to mind. I conclude, in short, that thanks to the presence, real or implied, of the $q i$, we may treat the initial clause in a complex charge as a nominalized and demoted topic phrase, "The Gongfang's going out ...." 322

This understanding helps our understanding of charges in which $g i$, occurring twice, played a nominalizing role in the one case and a deictic role in the second, as in the following inscription. The "in this case" translation results in a clumsy charge, difficult to parse: "The king in this case will go to hunt and in this case it will rain." It seems preferable to take the first $q i$ as nominalizing the first clause, which then becomes the demoted topic:

[174] 貞：王其往田其雨

Divined: "(As to the king's going to hunt $=$ ) If the king goes to hunt, it will in this case rain." (I. Bin) (HJ 13758b; Y319.2) $\square$

321. For similar charges without the $q i$, see too $H J 6086,6093 \mathrm{f}(Y 273.2)$, and $Y C 545 \mathrm{f}$ (Y274.1), all scapulas.

322. See too Herforth as cited in n. 149 and Takashima as quoted on p. 4 above. 


\section{CONCLUSI ONS}

I draw several conclusions from the evidence addressed in this study. First, I conclude that $g i$ served as a deictic marker that focused attention on particular simple charges and on particular phrases in complex charges; its impact varied with the context in which it appeared. In the special usage represented by the Bin-group charge-pairs, the phrase marked by $q i$ in the retest was frequently a quote of the main assertion in the primary charge.

Second, I conclude that the diviners enjoyed considerable freedom of choice in applying the various divinatory conventions proposed above. Part of a diviner's skill, presumably, lay precisely in his ability to shape and place his divinations, and their record, in ways that he thought most efficacious. When we find that $q i$ appeared on the "wrong" side or in the "wrong" charge, for example, it is entirely likely that the diviner was engaging in creative (and possibly ironic) variation, influenced by his sense of intuition--about, for example, the play of spiritual forces, about the luck that he might have had with an unorthodox or idiosyncratic pattern of placement on other occasions, about his sense that certain zones of a particular plastron were more receptive than others to the charges he wished to divine.

Third, patterns of $q i$-usage varied with topic, diviner-group, and period. If we focus attention on the gao charges about ritual-reports, the use of $q i$, particularly in the earlier periods, was entirely optional. The Li-group, in 
divining about this topic, used $g i$ to head a demoted clause more consistently than did the Bin-group (pages 49,51 ). The diviners of period II, like their successors in periods III-IV, used $q 1$ more consistently as a clause marker (pages 52, 53), particularly to demote the initial clause of a complex charge (pages 88, 89). By period $\mathrm{V}, \boldsymbol{g} i$ usage in the hunt charges, although still optional, had virtually ceased (pages 84, 89-90). That the use of the word appears to have declined with the passage of time is understandable; as divinatory formulations became routine, the need for grammatical markers would have declined accordingly.

Fourth, it is evident that despite this flexibility in the way qi might be used, different diviner groups employed $g i$ in characteristic ways. The Bin-diviners, for example, frequently inserted $g i$ in the retest charges of their charge-pairs. The Li-group, by contrast--working with scapulas rather than plastrons, less committed to the use of charge-pairs, and sharing the convention established by the Shi-group and continued by later diviner groups--used $g i$ to demote the head-clause. It is also notable that when a diviner was not recorded, $q i$ was inserted far more liberally in both sides of a charge-pair than when a diviner was present.

These patterns of usage, whatever their precise meaning, lead me to speculate about the reasons that $q i--a$ word whose presence, as we have seen, was generally optional--was included with such evident care in many of the inscriptions. 
The Bone Inscriptions: A Rationale

Building upon an insight of Lothar Von Falkenhausen that the Western Zhou bronze inscriptions were "not primary texts, but secondary versions of the documents stored in the donor's family archives," 323 I would urge that the oracle-bone inscriptions, as incised into the oracle-bone, were also likely to have been secondary rather than primary texts. I envisage the following scenario: (1) The diviner (or king) called out the charge as the bone or shell was cracked. (2) He scrutinized the cracks and arrived at a preliminary judgment. (3) The content of the charge that he had called out, together with his initial evaluations of the cracks, was recorded on perishable material as the preliminary record, the primary text. (4) The crack-numbers and cracknotations (the basis of these initial evaluations) were incised into the bone (presumably so that the preliminary record of the charge's content could be correlated with the appropriate cracks when the inscriptions, the secondary text, were carved). (5) The king made his prognostication, on the basis of the evidence that the diviner presented to him and on the basis of his own intuition. (6) His forecast was then recorded, on perishable material, as an addition to the primary text. (7) After the outcome, if any, had been determined, the verification was also recorded on perishable material. Only after the divinatory scenario had ended was the bone consigned to the engravers, together with a copy of the preliminary account, for the slow and laborious process of carving the inscriptions into the bone next to their related cracks, crack numbers, and crack notations.

If this scenario is correct, it is likely that the inscriptions provide a retrospective, edited record of what had transpired, rather than a verbatim,

323. Von Falkenhausen 1993:163. 
primary transcription. It is also evident that by the time the numerous $q$ is were incised, the divination itself had long been ended. Yet the presence of $g i$ in the inscriptions--optional, and yet when present in Bin-group chargepairs, used in highly-patterned ways--suggests that its recording, at least to the Bin-group engravers, was important. Because the carving of characters demanded considerable energy, the tens of thousands of $g$ is carved into the bones, particularly those of the Bin-diviners, reinforce that sense of importance. In where did the importance lie?

I would suggest as a hypothesis for further study, that, just as we have seen (page 32) that the presence of $q i$ was related to the complexity of the charges, so the presence of $q i$ was related to the complexities of the divination process, frequently, in charge-pairs, marking preferences and retests, primary and ultimate concerns, and even expressing aesthetic concerns. The decision to use $g i$ or not may, particularly in unpaired charges of all groups, also have been linked to the question of intended audience. Could it be that $g i$ was used in some charges and not in others because the engravers had a sense of who might be reading their records? Sophisticated and practiced readers--such as the diviners named in the prefaces, a mature king, the ancestors?--might not have needed the assistance of the $g i$ markers. Inexperienced readers--such as the diviners' staff, a young king, dependents

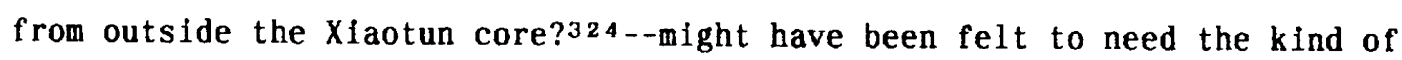
guidance that the use of $q i$ as clause-marker could provide. The liberality with which the divinerless charge-pairs of the Bin-group used $g 1$ (page 163)

324. It may be significant, for example, that $[155 \mathrm{~A}-\mathrm{J}]$, one of the most celebrated cases involving the liberal use of $q 1$, involved a series of charges about Zhi Hua of Cha and the fortunes in battle of various Shang emissaries. 
suggests that, at least in the earlier periods, it was thought a "good thing," when in doubt about who in the official hierarchy might be reading the text, to include $g 1$.

It is no coincidence, I suspect, that the use of $q i$ was most common in the charge-pairs of the Bin-group diviners, a group whose charges were markedly "public"--a characteristic that has led some modern scholars to refer to them as the "court diviners."325 Their charges were thus more likely be recorded for a wider audience, precisely the kind of audience, perhaps, that would have been impressed by the use of the complementary charge-pairs and that would have benefited from the use of $q i$ to mark the passages taken from one charge and "quoted" in another. The dwindling use of $q i$ in the charges of later periods would thus have been a response not just to the abandonment of the Bin-group's charge-pairs, but to the general reduction in the scope of Shang divination as a whole, the diminished role of the diviners, the increasing routinization of royal pyromancy.326 one has a sense that, by period $V$, the audience had shrunk and that the divinatory formulas were being formulated and read by a staff of experts well versed in the tradition; there would have been little need of $q i$ to guide them through records whose forms they knew so well. It may again be no coincidence that the use of $q i$ declined as the size of the engravers' calligraphy shrank; the period $V$ charges being less intended for public display, there would have been less reason to include the $g i$ markers to guide the uninformed reader.

325. Keightley 1978:31; the term was original Kalzuka Shigeki's.

326. See, e.g., Keightley 1978:122; 1983:555; 1988:381-82;1991:315-31. 
For whatever reason, it seems that, when $q i$ was part of the charge as vocalized by the diviner or the $k i n g$, its presence in the record--both perishable and permanent--was important: to the record keepers, to the spirits or humans who may have formed the audience for the inscriptions, to the divinatory process itself. If, as I hope, this study has helped to demonstrate how oracular $g 1$ worked, the reasons for $i$ ts presence and absence in each instance may, upon further study, eventually be revealed.

Postscript: The Origins of Modal $Q i$

I see no obstacle to the argument that modal $q i--$ if it existed at all (see the comments of Herforth cited at note 9 above)--would have developed from deictic $9 i .327$ This is a matter that scholars working with western and Eastern Zhou texts would need to consider in more detail.328 One can well see, however, that the way in which $q i$ demoted a verb-phrase in the Shang divination inscriptions could have led to a modal construal of the phrase so demoted. 329

327. I do note, however, that Takashima (1994a:483) concurs with Pulleyblank (1992:3) that "it is difficult to argue that preverbal modal qi developed into pronominal gi."

328. Cikoski $(1978: 80,114-17)$, who argues that Classical Chinese $q i$ represented two distinct words, provides interesting figures for its modal and pronominal occurrences in Zhou texts, viz.: in genuine sections of Shu 140 modal ( 70 percent), 59 pronominal (30 percent); in Shi modal occurrences fall to only 16 percent; in Zuozhuan the 563 modal occurrences constitute 22.5 percent. By the fourth century $\mathrm{BC}$, "the modal had nearly vanished from the language."

329. Herforth (1994:176) notes, for example, Eastern Zhou cases in which "syntactic demotion is marked by the third-person genitive pronominal $q i$ 其" and which are construed as conditionals. 


\section{APPENDIX A : RETESTS ON SCAPULAS}

The following two sets of rainfall inscriptions throw light on how retests worked on scapulas. They are worth studying with this question in mind because the inscriptions were recorded on the same bone. The placement of the inscriptions in the first example may be studied in fig. 2): 1
[A.1A] 丁聿卜:翌戊宙不雨.允不雨
L J

Crack-making on dingchou (day 14): "On the next day, wuyin (day 15), it will not rain." (Verification:) It did not rain.
[A.1B] 翌戊苖其雨
Lง
"On the next wyin, it will 'rain." "

[A.1C]戊宙卜爭: 翌己卯不雨

$\operatorname{RaV}$

Crack-making on wuyin, Zheng (divined): "On the next day, jimao, it will not rain."
[A.1D] 戊寅卜爭崱:翌己卯其雨
R」へ

1. Fig. 2 demonstrates Zhou Hongxiang's different reconstruction $(1969: 200$, fig. 57) of the divinatory scenario. He proposes that the four charges curved around the top of the scapula, moving up from the left and then down on the right. In the terms of his placement, we may regard [A.1A] as the primary charge, recorded without $q i$; this would then have been followed by the negative charge of the pair, [A.1B], identified as a retest by the presence of the referential $q 1$; another retest, [A.1D], containing $q i$, would have been initiated on the next day, and then a final, negative, charge, [A.1C], would have completed that second pair. It is anomalous, however, to find the referential $q i$ omitted in $[A .1 C]$; one would have expected a back reference to [A.1D]. This problem does not arise in the ordering $I$ give in the main text above. I would also note that my placement of the inscriptions, in which the charges moved up the scapula, accords with the usual treatment of inscriptions on scapulas, on which "the burning of cracks, and thus the recording of associated charges, tended to proceed either from bottom to top or, less frequently, from top to bot tom" (Keightley 1978:52). 
Crack-making on wuyin (day 15), Zheng divined: "On the next day, jimao (day 16), it will 'rain." (I. Bin) (HJ 12974; Y701.2, partial)

In this case, the $q i$ of [A.1D] 翌己卯其雨 can plausibly be understood as a reference back to the primary charge, [A.1C] 翌己卯不雨, divined on the same day, wuyin. It thus seems likely that [A.1C] was divined before [A.1D], so that the two charges on the right moved up the bone, precisely as the two charges on the left, $[A .1 A \& B]$, did. The difficulty with this solution is that the putatitve primary charge, [A.1C], is more abbreviated (lacking the verb zhen 貞 in the preface) than the putative secondary charge, [A.1D], thus violating convention no. 4, namely, that when one member of a charge-pair was abbreviated, it was the fuller-form of the inscription (as in [A.2C\&E]) that, because it was fuller, would have been divined first and that would, representing "new information," have been the more desired of the two.2

In this case, therefore--and to the extent that the omisssion of the one graph, zhen 賁, was significant--it would seem that two conventions would have been in conflict, and that, in this instance at least, the diviner chose to obey the convention (no. 3) in which he first divined the charge without the $q i$, rather than the convention that recorded the primary charge in fuller form. It may be noted that the form of the primary charge, [A.1A], divined without the $g i$ on dingchou, "It will not rain," indicates that this was the diviner's ultimate concern. That the verification appended to the primary charge, [A.1A] 翌戊宙不雨, records 允不雨, "it really did not rain," is another reason for thinking that the Shang had not wanted it to rain. It seems plausible, accordingly, that the diviner would have repeated the main

2. Nivison Source for this??? Cf. Keightley 1978:51, n.124; 52, nn.125, 130; 120 , n. 132 . 
assertion of [A.1A] 不雨, "It will not rain," in another primary charge, [A.IC], divined one day later. In this view of the matter, each of the two primary charges, [A.1A\&C], was followed by a retest, [A.1B\&D], in which the $q I$ played its expected role. The retest theory, acordingly, works well in this case.

A further example of retests on the same bone (see too [140A-D] and [141A-N] may be studied in fig. 3, another scapula fragment in wich the three-charge pairs about rain were separated by boundary lines:

[A.2A] 戊子卜沐: 翌己丑其雨

$\mathrm{RL} \approx$

Crack-making on wuzi (day 25), Mu (divined): 3 "On the next day, jichou (day 26), it will 'rain.'"

[A.2B] 戊子卜沐:翌己丑不雨

L」ล

Crack-making on wuzi, Mu (divined): "On the next day, jichou, it will not rain."
[A.2C] 己丑卜沐:翌庚宙其雨
$\mathrm{R} L \approx$

Crack-making on jichou: "On the next day, gengyin (day 27), it will in this case rain."

[A.2D]已丑卜:翌侇宙不雨

Crack-making on jichou: "On the next day, gengyin it will not rain."

[A.2E] 庚宙卜沐:翌辛卯不雨

R L ${ }^{2}$

Crack-making on gengyin (day 27), Mu (divined): "On the next day, $x$ inmao (day 28 ), it will not rain."
[A.2F] 翌辛卯其雨
LA

"On the next day, xinmao, it will 'rain."

(I. Bin) $(H J$ 12436) $\triangle$

3. The diviner Mu appeared on only two oracle-bones, both scapulas, this one and $H J 6578$. 
As in the previous cases, within each pair it is plausible that we take the charge containing the $q i$ as a retest of the primary charge that lacked the $g i$. If we interpret the inscriptions in this way, however, then it is necessary that we take [A.2B\&D], on the left, as the primary (and desired) charges, so that $[\mathrm{A} .2 \mathrm{~A} \& \mathrm{C}]$, on the right, that contained the $q 1$, may refer back to them. This irregular placement order appears to have been reversed in the case of [A.2E\&F], as the $q i$ changed sides from right (in [A.2A\&C]) to left (in [A.2F]) and the primary charge, $[A .2 E]$, occupled its normal position on the right.

Such an interpretation, however--as in the case of [[A.1CD]--again challenges convention no. 3 , about the priority given in charge-pairs to the fuller form of an inscription. That is, because [A.2C] 已丑卜沐: 翌庚宙其雨 was more complete than $[A .2 D]$, one would expect $[A .2 C]$ to have been the primary charge; but because it contains the referential $q i$, one would expect it to have been the secondary charge. It is entirely plausible, however, if we accept convention no. 4, that the charge of [A.2E] 庚宙卜沐:翌辛卯不雨 would have been primary in its pair, divined before [A.2F] 翌辛卯其雨, because [A.2E] was the more complete record. That $[A .2 F]$ also contained the referential $q i$ that we associate with retests confirm this.

We are thus still led, as in the previous paragraph, to the conclusion that the diviner, Mu, changed his procedures over a three-day period: he started his series of three divination charges at the top left of the scapula with the primary charge, [A.2B] 翌已丑不雨, followed by its pair member [A.2A] 翌已丑其雨 (a retest, with $g i$ ) at the top right. He repeated this procedure by divining another charge-pair on the next day, treating [A.2D] as the primary charge, on the left, and $[A .2 C]$, with $q i$, as the retest on the right. 
But then, on the third day, he reversed his right-left conventions, divining the primary charge, $[A .2 E]$, at the bottom right, before he divined its abbreviated pair, a retest with $q i,[A .2 F]$, at the bottom left. Despite the variations in right-left placement, however, in which the desired and undesired charges might be found on both the right and the left sides of the bone, we observe that Mu consistently divined his preference for 'no rain' as the primary charge $([A, 2 B, D, \& E])$, without the $q i$, regardless of the side of the scapula on which he recorded it.

This switch of the primary charge from left ([A.1A] and [A.2B]) to right ( $([A .1 C]$ and $[A .2 E])$ does not, for a number of reasons, destroy the general validity of the Bin-group conventions proposed in this study. In the first place, these examples occurred on scapulas where practice was likely to be less consistent than on plastrons. In the second place, the switch merely demonstrates that a diviner in a particular situation could apply these conventions flexibly and that he was at liberty to give priority to one convention over another, in this second case, shifting the location of [A.2F], his final retest (less desired), from the right side of the bone (where he had placed his two previous retests) to the left, the side where the two previous primary charges [A.2B\&D] had been placed.

It should be noted that such flexibility is entirely what one would have expected in a divination process in which the reading of the cracks, so far as we can tell, depended upon a mix of subjective and objective criteria. ${ }^{4}$ There is no reason to think that the diviner's placement of the cracks and their inscriptions would have been bound by rigid, mechanical rules. Charge-pairs

4. Keightley $1991: 25-28$. 
were divined in a context of other divinations and it was the diviner's privilege, apparently, to make a series of choices about such matters as the location and form of the primary charge and its retest(s). 


\section{APPEND I X B : \\ $Q I$ AS A MARK OF QUOTATION \\ I N LATER TEXTS}

Since I argue in the body of this study that deictic $q i$ was used to introduce oracle-bone clauses that had previously been proposed, so that $q i$ acted rather like opening single quotes or a colon to highlight a particular repeated phrase or sentence, it is natural to enquire if any traces of this usage can be found in later texts. 5 Some passages in the bronze inscriptions and in the Shangshu do permit us to treat $q i$ as introducing quoted material.

\footnotetext{
[B.1]旦日其作大邑, 其自時配皇天

"You, Dan, had said: '(We) will build a great settlement.' 'We will from it comport with august Heaven." (Shangshu, "Shao Gao," para. 14$)^{6}$
}

In this example, the gi--presumably understood in all these examples as "This:

'...".--introduced a previous utterance of the Duke of Zhou.

5. Dobson has claimed that $q i$ served as a "reduplicative marker," either preposed or post-posted (Dobson 1974:185-86). Unfortunately, his translated examples do not reveal how he thought $q i$ worked, and none of the passages he cites (from Shijing. "Guofeng") appear to support his claim. It appears that Sima Qian used qigi 期期 to indicate a stammerer's duplication of the previous word (Shiji 96:000).\} The passage 臣期期知其不可 would thus be rendered, "Your servant kn-kn-knows his inability." (I am grateful to Christopher Harbsmeier for calling this passage, in another context, to my attention.) According to the Zhengyi, "one had to wait ( $q i$ 期) because the speaker was stammering; therefore (the passage) repeats the word, qigi (期以口吃每言,故重言期期)." I do not know if there is any link to earlier usages of $q i$ 其, to indicate duplication, in the Shang. Dobson (1974:190), of course, also notes that $q i$ 期 served as an anaphoric pronoun in Eastern Zhou and Han texts.

6. Ap. Shaughnessy 1993:62. 


\section{[B.2] 知日其有能格知天命}

"How much the less would I say: 'I have the ability to comprehend and know the commands of Heaven'?" (Shangshu, "Da gao," para. 1) (Karlgren [1950:36]: "how much the less then should I be able to comprehend and know the commands of Heaven?")

I assume that in this case, the young King Cheng was citing some previous document (now lost to us) that defined the qualifications for kingship. The plausibility of this interepretation is strengthened by a similar reference in another chapter of the Shangshu:

\section{[B.3] 我則鳴鳥不聞知日其有能格}

"We are thus (a case of) 'The singing bird is not heard'; how much the less can it be said that "We have the ability to comprehend (the commands of Heaven)." (Shangshu, "Jun Shi," para. 16) (Karlgren [1950:62]: "...to us [Zhou] then no singing bird [sc. of good auguryl will make itself heard; how much the less shall we be able to [arrive $=$ ] succeed.")

I suspect in this case that, like the $q i$, the $z e$ 則 also served to introduce a saying. That the phrase following the $q i$ in [B.3] repeats the first three characters, 其有能, of the phrase in [B.2], supports the view that the speaker was duplicating a known text. I would propose, in fact, that any passage introduced by the phrase shen yue $q i$ 矧日其.... "How much the less can it be said that: '..., ", was probably repeating a text known from another document. Indeed, it is hard to see how the introduction, "How much the less can it be said that," would make sense in any other way.

To cite one more example:

[B.4]在今後呞王, 誕图影于天,知日其有德念于先王勤家

Their successor in our time greatly lacked (clearness $=$ ) a clear understanding of Heaven. Still less can it be said that: 'He was willing to think of how the earlier kings toiled for the house." (Shangshu, "Duo Shi," para. 9) (Karlgren [1950:55]: "... Still less was he willing to think of how....") 
Once again I suspect that the Duke of Zhou, or the king for whom he spoke, was repeating a phrase from some creed of ideal kingship.

The following quote evidently invoked a similar charter of ideal royal behavior:

\section{[B.5] 知日其克從先王之烈}

"How much less can it be said that we are: "Able to follow the brilliant deeds of the former kings." (Shangshu, "Pan Geng," para. 3) (Karlgren [1950:20]: "how much less shall we be able to follow up the brilliant deeds of the former kings!")

As in the case of $[\mathrm{B} .2]$, the "Dagao" passage, I sense that Pan Geng was quoting some standard of behavior that Shang kings were expected to follow. Consider too:

\section{[B.6]亦言其人有德乃言日载采采}

"When we say: 'A man has virtue' then we mean to say he initiates the various works." (Shangshu, "Gaoyao mo," para. 3) (Karlgren [1950:8]: "when [we] say that this man has virtue, [we] [say = ] mean that he initiates the various works.")

It would seem that Gaoyao was evidently explicating a quoted phrase. Qi may also have been used to quote the results of divinations, as in:

\section{[B.7]卜稽日其如台}

"I have cracked and examined, and (the cracks) said: "As it is wished." (Or, "This is as you wish.") (Shangshu. "Pan Geng," para. 2) (Karlgren [1950:20]: "I have taken tortoise oracle and enquired, and [the Spirits] say that it is [in accordance with me $=$ ] as I say"; see Karlgren 1948:172, no. 1405)

Again, the king appears to have been repeating either a prognostication made at the time of divination, or an injunction commonly used by rulers. A passage in the "Jin teng" also links $q i$ to the report of a divination: 


\section{[B.8] 乃ト三雪一習吉....公日艋王其周害}

(The Duke of Zhou) then divined with three turtle shells and all were auspicious.... The Duke said: "According to the configuration (of the cracks?), for the king: "There will be no harm." ("Jin teng," paras. 9, 10) (Karlgren [1950:35]: ".... According to the [configurations $=$ ] content [of the oracles], the king will suffer no harm.")

It hardly needs pointing out that the phrase, wang hai 亡害, "there will be no harm," had been a common apotropaic formula in Shang divination charges. ${ }^{7}$ The appearance of the phrase, after the gi, suggests that the Duke was quoting words that had formed the last part of a charge.

The phrasing, qi ru yi 其如台, quoted in [B.7], occurs elsewhere in Shangshu:

[B.9]民有不者德不㯖罪天既孚命正厥德乃日其如台

"When among the people there are those who do not comply with virtue and do not acknowledge their guilt, Heaven has (always) given its grant of life, (adjusting $\Rightarrow$ ) determining their virtue. And thus it is said: "As it is wished." (Shangshu, "Gao Zong yong ri," para. 4) (Karlgren [1950:26]: ".... And thus I say: it is (in accordance with me $=$ ] as I tell you." )

In other cases, one can again sense that the speaker is appealing to some proverb, as in:

[B.10] 今其有今周後

"Now (it is a case of): 'You have the present but you do not have the future." (Shangshu, "Pan Geng," para. 24) (Karlgren [1950:23]: "Now there is a present, but there is no [afterwards =] future. $"$ )

7. See, e.g., the cult inscriptions at Y685.2-686.1. On the word hai 害 itself, recorded in the bones as 壱, see Qiu Xigui 1983:218. 


\section{[B.11] 今予其数心腹腎腸}

"Now I will: 'Disclose my heart and belly, reins and bowls,' and in all details tell you people my will." (Shangshu, "Pan Geng," para. 37) (Karlgren [1950:24]: "Now I will [spread out, lay open $=$ ] disclose my heart and belly, reins and bowls, and [seriatim] in all details tell you people my will.")

In [B.11], in particular, the striking adoption of the vivid metaphor of the internal organs suggests that Pan Geng was quoting a popular saying.

Similar examples can be found in later texts.8 A series of passages in Zuozhuan that start with the phrase wei $q i$ 罚其 may be understood as introducing passages that were packaged, as it were, for reference. For example, in a long passage of moral exhoration, Ji Liang 季梁, a minister in the state of Sui, explained to his king (and here I take various liberties with Legge), "It is the people who are the Spirits' chief concern. Because of this the sage kings first secured the welfare of their people and (only) subsequently exerted themselves for the Spirits.

[B.12] 故奉性以告日:博碩肥渞, 罚民力之普存也. 㑩其畜之碩大蕃游.

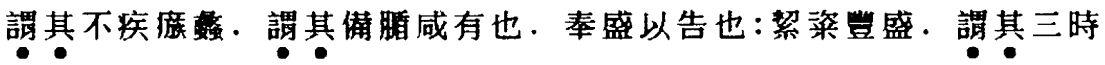

不害而民和年嶄也、奉酒䣯以告日：嘉栗旨酒。謂其上下

皆有嘉德而無違心也。

Thus, when they presented their victims, they made ritual announcement about them, saying 'They are large and fat.' This meant 'the people's strength all preserved.'9 This meant 'the domestic animals large and flourishing.' This meant 'freedom from scab or itch.' This meant 'fully fattened and enjoyed by all.'

8. I am grateful to David Nivison for calling examples [B.12] to [B.16] to my attention.

9. I suspect that, to match the subsequent passages, the text should read 謂其民力之普存也, and I have translated accordingly. As the HarvardYenching Suoyin notes (p. 31, no. 5), one edition places a 於 before the 民, and another writes 名 for 民. Evidently there was some corruption at this point in the text. 
When they presented their vessels of millet, they made ritual announcement about them, 'They are clean and abundant.' This meant 'In the three seasons, no harm' and 'The people harmonious, the harvests abundant.' When they presented their distilled and sweet spirits, they made ritual announcement about them, "They are admirable, strong, and good.' This meant 'Superiors and inferiors all of admirable virtue' and 'None have refractory hearts." (Zuozhuan, Huan 6, suppl. 1; Legge 1872:48-49)

Whether or not Ji Liang was quoting previous aphorisms or ideals, it seems likely that he was highlighting these texts by placing the $q i$ before them.

In a long Zuozhuan passage desribing how Duke Wen of Jin rewarded and punished his supporters after his victory over Chu at the battle of Chengpu, the narrator comments:

\section{[B.13]君子謂文公其能刑矣}

The princely man will declare that Duke Wen excelled in the use of punishments.' (Zuozhuan, Xi 28, para 12, suppl.; Legge $1872: 212$ )

Again, one senses that the junzi was quoting some well-known standard or aphorism.

The junzi makes a similar appearance, being invoked in the body of a long speech by Xiafu Fuji 夏父弗忌, the director of the ancestral temple in the state of Lu, about the correct ordering of the ancestral tablets. After invoking a series of rules and precedents, Xiafu quoted the Shijing (Mao no. $300)$,
春秋匪解
享祀不式
皇皇后帝
皇祖后瑷
In spring and in autumn, without delay,
He presents his offerings without error,
To the great and sovereign $\mathrm{Di}$,
And to his great ancestor Prince Millet. 
He then remarked:

[B.14]君子日:䄇謂其后椤親而先帝也

The princely man says: "For ceremonies, one says: 'Prince Millet is a kin relation, but precedence goes to $\mathrm{Di}$.' (Zuozhuan, Wen 2, para. 6; Legge $1872: 234$ )

Xiafu Fuji then quotes another of the songs (Mao no. 39),

問我諸姑

遂及伯姊

I will ask my aunts,

And then my elder sisters

and again remarked,

\section{[B.14]君子曰:禮謂其姉親而先姑也}

The princely man says: "For ceremonies, one says: 'Elder sisters are kin, but precedence goes to the aunts.'"

In both cases, the junzi was evidently referring back to previous formulations that bore on these issues.

I am struck by the fact that in most, if not all of the cases, cited above, the passage marked by the $q i$ was embedded in another speech. The orality of this referential usage would further accord with oracle-bone practice, in which one assumes that the charges--and the numerous examples of $g i$ they contained--had originally been cried out by the diviner as he cracked the shell.

Two more cases in Mengzi provide more evidence. Wan Zhang asked Mengzi:

[B.15]舜往于田,躆泣于旻天,何謂其號泣也

"When Shun went into the fields, he cried out and wept towards the pitying heavens. Why does it say, "cried out and wept'?" (Mengzi 5.A.1) 
In this case, the deictic function of $q i$ is transparent: "Why does it say this 'cried out and wept'?"

In the second example, Mengzi was expressing his doubts about the "Wu cheng" chapter of Shangshu:

\section{[B.16] 仁人無敵於天下,以至仁伐至不仁,而何其血之流杆也}

The benevolent man has no enemy under heaven. When the most benevolent fights the most unbenevolent, how could the flow of blood float the pestles'? (Mengzi 7.B.3)

Mengzi, of course, was referring to the famous passage in the jinwen chapter, describing the carnage at the battle of Muye: 血流漂杆, "the blood flowed till it floated the pestles about."10 In both of these examples, the gi evidently precedes quoted text.

Unless the original passages or aphorisms can actually be found, the claim that $q i$ served to mark quotations cannot be verified. In some of the passages cited $q i$ could perhaps be construed as a modal particle, serving to indicate future action; and in [B.6] the $g i$ could certainly be explained as a demonstrative adjective ("This man has virtue"). But neither of these explanations work well for [B.2] or [B.10]. The presence of the yue 日 before the $q i$ 其, moreover, in [B.3], [B.4], [B.5], [B.6], [B.7], and [B.9], together with the frequently formulaic ([B.2], [B.3], [B.7], [B.8], [B.9], [B.12], [B.13], [B.14]), aphoristic ([B.10], [B.13]), or metaphorical ([B.11]) nature of the words--special, and worthy of being highlighted--that followed $q i$, lends plausiblity to the hypothesis that these words were repeated from a previous utterance or document. The use of actual quotations after the $q i$ in [B.15] and [B.16] provides further support for this view.

10. Legge $1865: 315$. 
That $q i$ did not serve to introduce quotations in the Western Zhou bronze inscriptions suggests that in official documents its role was limited to the precise kinds of references and emphases suggested in my discussion of the oracle-bone inscriptions in the study above and that the bronzes did not quote the kinds of sayings I discern in the Shangshu passages. The same conclusions may be drawn about the odes in the Shijing; the Shangshu phrase (in [B.2]-[B.5] above) shen yue gi 矧日其..., "How much the less can it be said that: '....," does not appear in the Shijing. 
SYMBOLS USED

A series of symbols, placed in the right margin of each oracle-bone text, convey the following information about the placement and context of the inscription on a shell or bone:

The letters $\mathrm{R}$ and $\mathrm{L}$ indicate that the inscription was incised on the right or left side of the turtle plastron (and, where relevant, the cattle scapula). A series of arrows, $L, \downarrow, \downarrow$, and so on, indicate the direction in which the inscription ran on the oracle bone; $L_{,}$, for example, indicates that the columns are to be read from top to bottom and running from left to right. The letters and arrows are placed in parentheses--(R), (L), ( L), $(\downarrow),(\downarrow)$, and so on--when these indications refer to the back of a bone or shell. In these cases they refer to the right or leftness of the placement, or the direction of the text, when seen from the the back. The parentheses alert us to the fact that, when seen from the front, these designations would be reversed (see the discussion of "rightness" and "leftness" in note 275 above). Thus, an inscription placed on the left side of a plastron when seen from the back would, in fact, lie underneath an inscription placed on the front of the bone when seen from the front. An inscription that ran from left to right, when seen from the back, would have run from right to left when seen from the front. The Shang diviners evidently paid attention to such matters and so should we.

The double chevrons, $\approx$ and $\approx$ indicate that the charge so indicated formed part of a perfect "charge-pair" (modern term, duizhen 韹真) with the charge to which the chevrons point; a charge-pair is "perfect" when the 
preface and content are identical, except for the fact that one charge is couched in the positive and the other in the negative, and that one or both charges may or may not contain a $g i$. The single chevrons, $\checkmark$ and $\wedge$, indicate that the charge so indicated formed part of an imperfect charge pair with the charge to which the chevron points; a charge-pair is "imperfect" when there is variation--in the date, the diviner's name, or the content of the charges beyond the positive and negative nature of the formulation. 
TABLE 1: APPROXIMATE DISTRIBUTION OF QI

IN CHARGE-PAIRS ABOUT RAINFALL

IN BINGBIAN $1-632$

(1) 其雨/不其雨

$63.3-4,5-6,7-8 ; 151.3-4 ; 447.8-9 ; 527.3-4,7-8,9-10$

8 cases $(14.5 \%)$

（2）其雨/不雨

$93.1-2 ; 116.10-11 ; 151.1-2 ; 153.7-8 ; 220.2-3 ; 263.9-10$;

$306.8-9 ; 342.21-22 ; 343.8-9 ; 349.4-546-47 ; 527.11-12$;

$529.1-2,3-4,5-6,7-8,9-10,11-12,13-14,15-16,18-19$;

$622.2-3$

22 cases $(40 \%)$

(3) 雨/不雨

$235.5-6(?) ; 522.1-2$

2 cases (3.6\%)

(4) 雨/不其雨

$149.11-12,21-22 ; 155.5-6,202.9-10,11-12 ; 235.1-2$;

$304.1-2 ; 346.2-3 ; 368.1-2 ; 381.7-8 ; 422.3-4 ; 433.1-2$;

$454.1-2,3-4 ; 519.5-6 ; 523.5-6 ; 527.1-2 \quad 17$ cases $(30.9 \%)$

(5) 雨/其雨

$433.3-4^{a} ; 527.5-6^{a}$

2 cases $(3.6 \%)$

$(6)^{\mathrm{b}}$ 雨/雨

$255.1-2(?)^{\mathrm{c}}$

1 case $(1.8 \%)$

(7) $\mathrm{b}$ 其雨 $/$ 其雨

$166.13-14^{\mathrm{a}} ; 521 \cdot 6-7^{\mathrm{a}} ; 527.5-6^{\mathrm{a}} ; 528 \cdot 1-2^{\mathrm{a}}$

3 cases $(5.4 \%)$

Source: Takashima 1985a:412-19, who does not identify charge-pairs; not all of the cases tabulated, in fact, turn out to be perfect pairs (as defined on page 17 above). In a small number of the cases listed in this table, the verb being qualified (or not qualifed) by the 其 was 令, in the phrase 帝令雨, "(Di) orders rain."

a None of these occurrences are perfect pairs (as defined on page 17 above). Note that if the opposition (5) 雨/其雨 never appears in perfect pairs, this would suggest that $q i$, in perfect pairs, was only used for propositions that were contrastive. 
because no positive/negative formulations are involved none of the charges in (6) and (7) qualify as perfect pairs. This raises the possibility that one charge in the pair was simply a reiteration of the other, thus explaining the presence (or absence) of $q i$ in both elements of the "pair."

cSince the last part of each charge in the pair is missing, it is possible that the opposition was of the form, 雨/不其雨. 


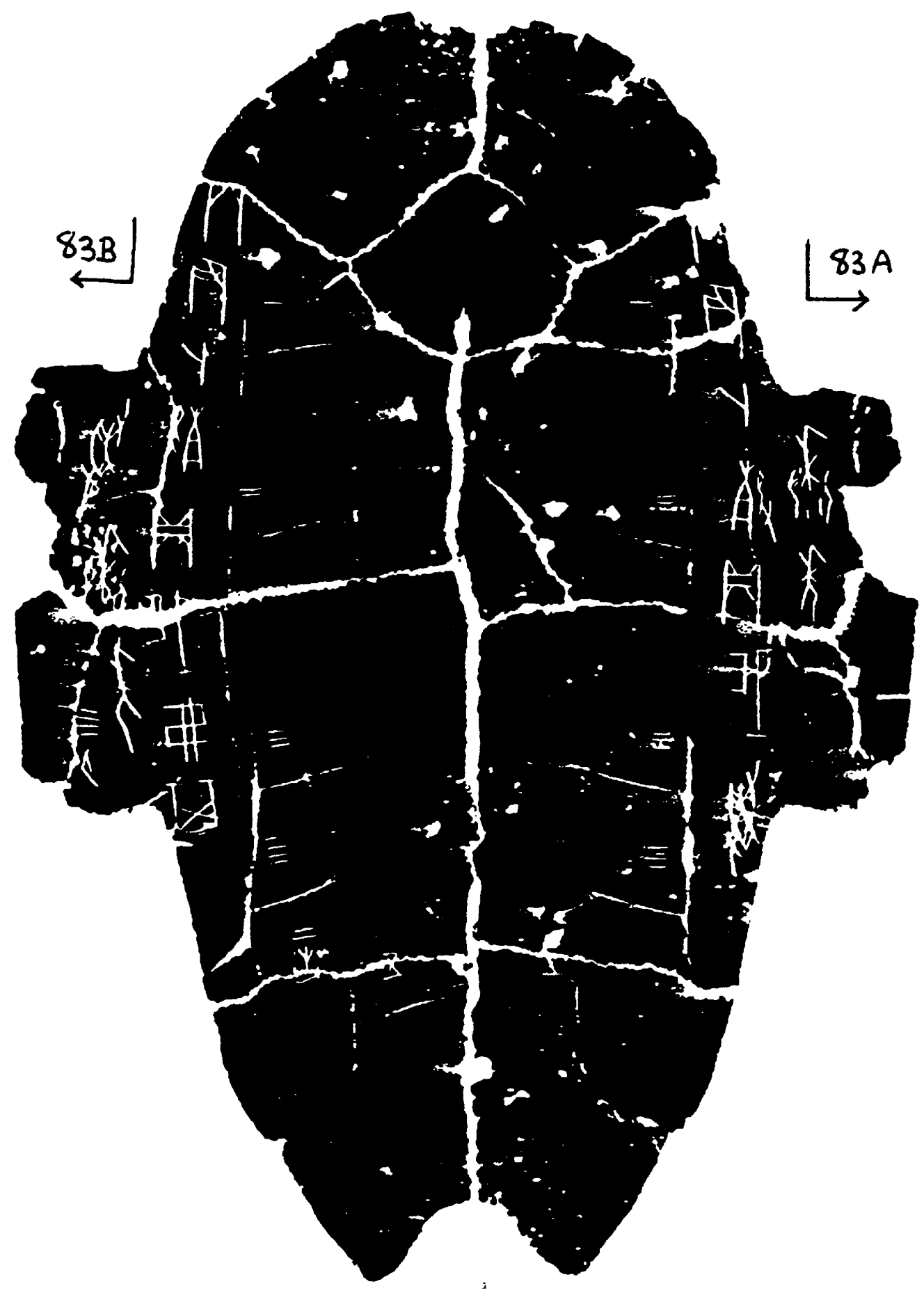

Fig. 1. Bin-group charge-pairs about receiving harvest. See [83AB] on page 59. (HJ 9950f) 


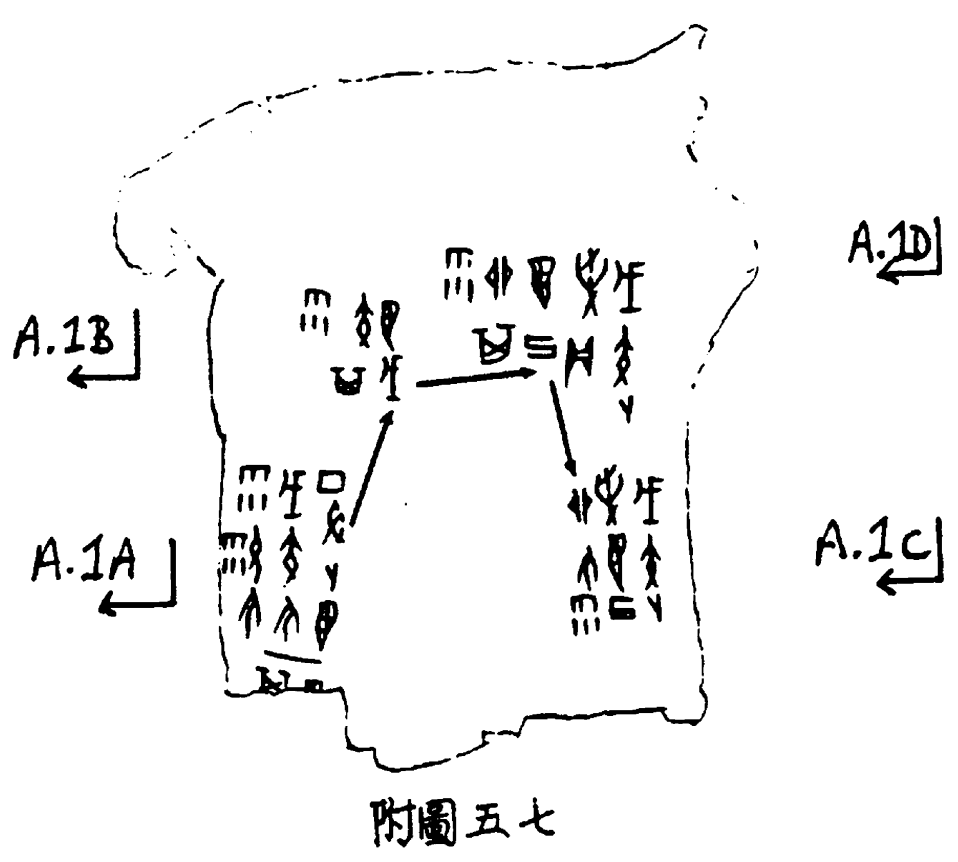

Fig. 2. Charge-pairs on scapulas. See $[A, 1 A B, C D]$ on page 193 and the discussion there at note 1. (Drawing from Zhou Hongxiang 1969:200, fig. 57.) (HJ 12947) 


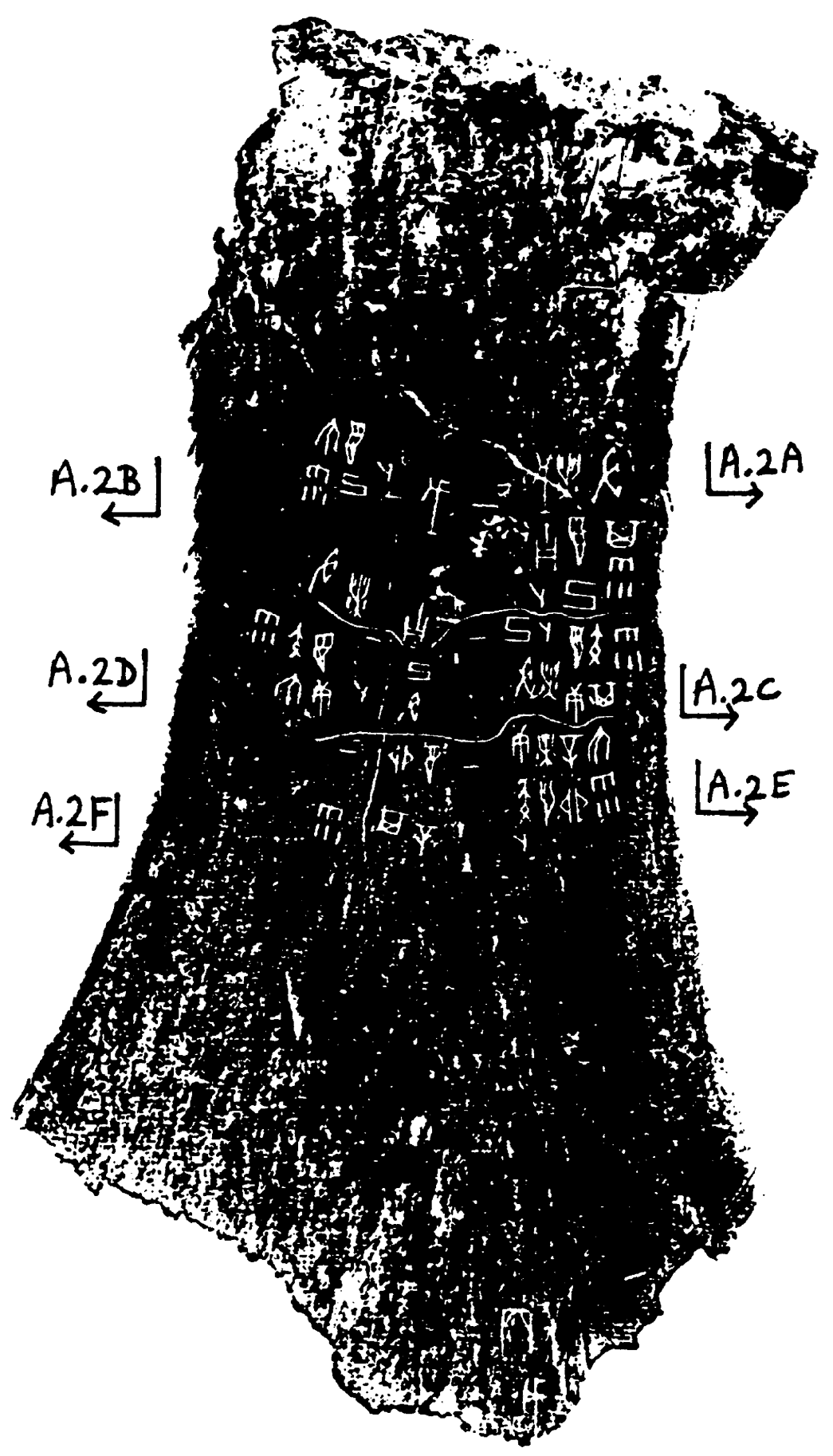

Fig. 3. Charge-pairs on scapulas. See [A.2A-F] on page 195. (HJ 12436) 


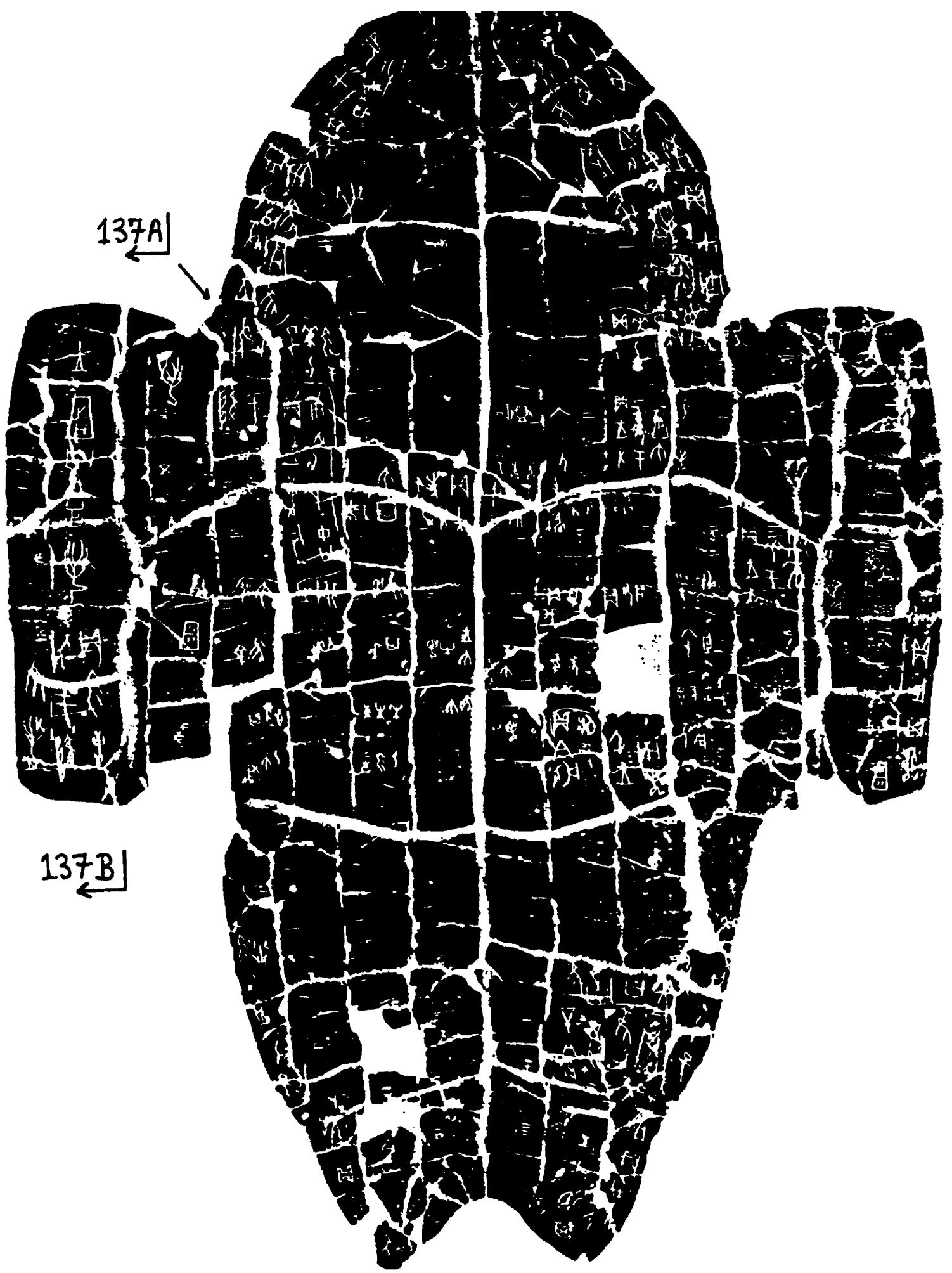

Fig. 4. Right and left placement of charges. See [137AB] on page 114. (HJ $376 \mathrm{f}$ ) 


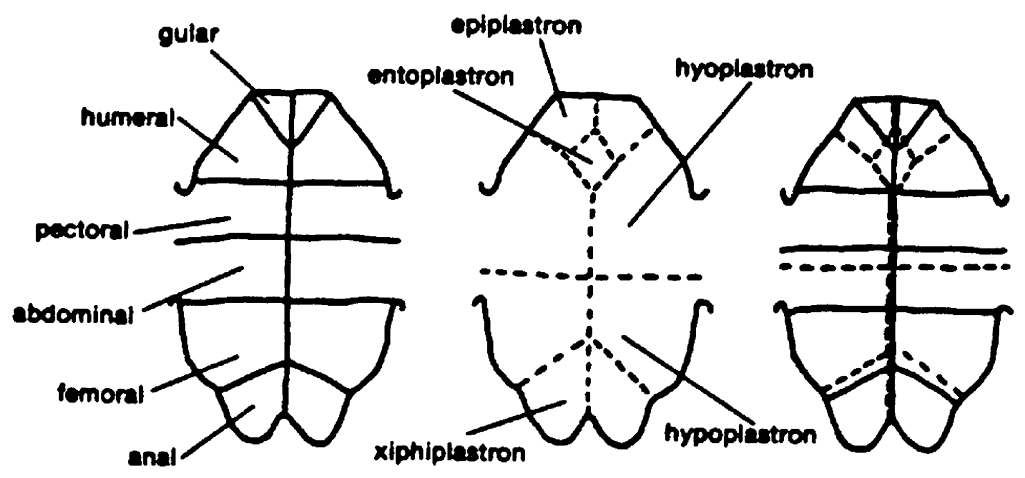

Fig. 5. Technical nomenclature of the turtle plastron (from Keightley 1978, fig. 3). 


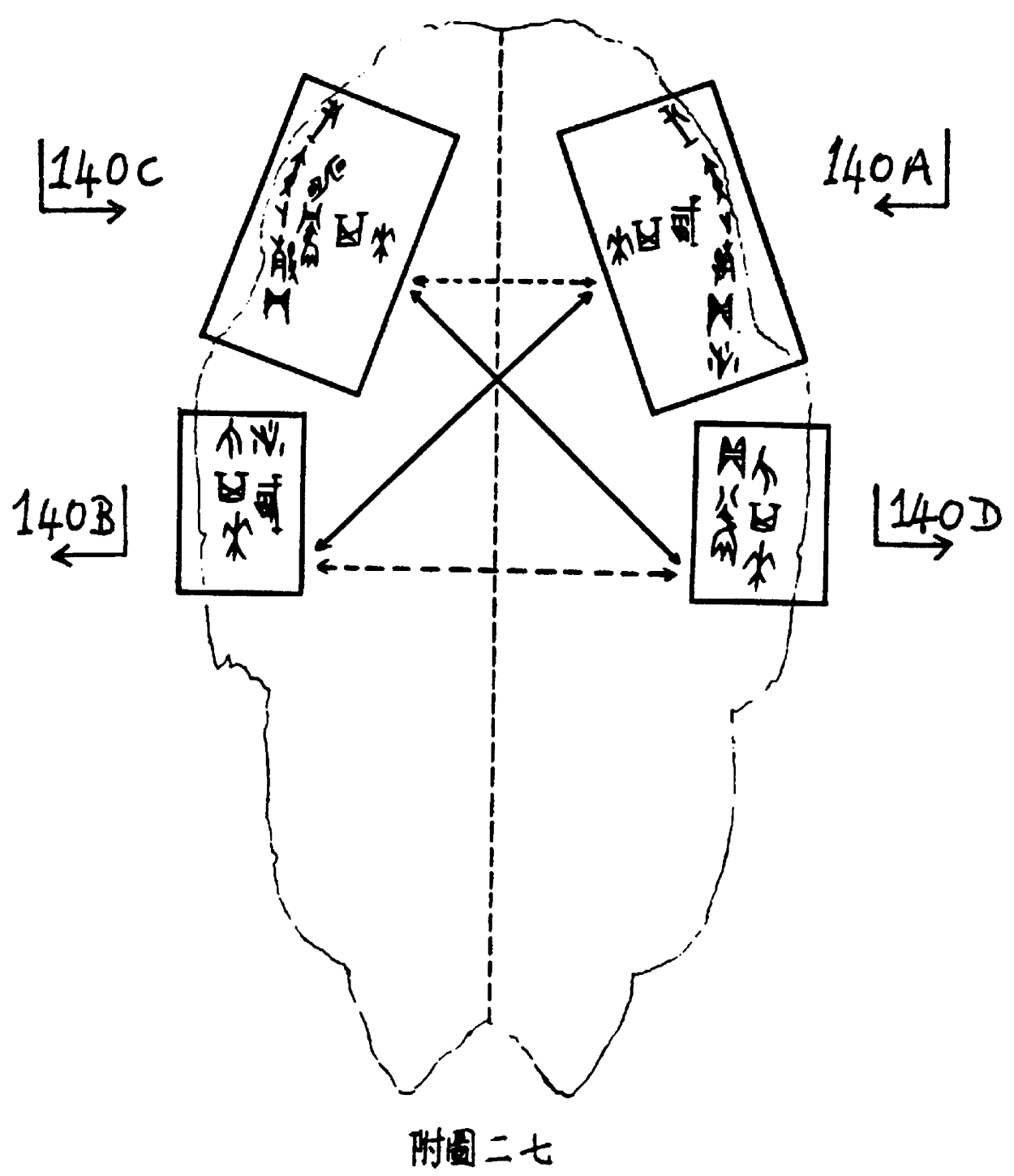

Fig. 6. Criss-cross placement of inscriptions in two charge-pairs. See [140AB and $\mathrm{CD}$ ] on page 122. (Drawing from Zhou Hongxiang 1969:175, fig. 27). ( $H J 3947 \mathrm{f}$ ) 


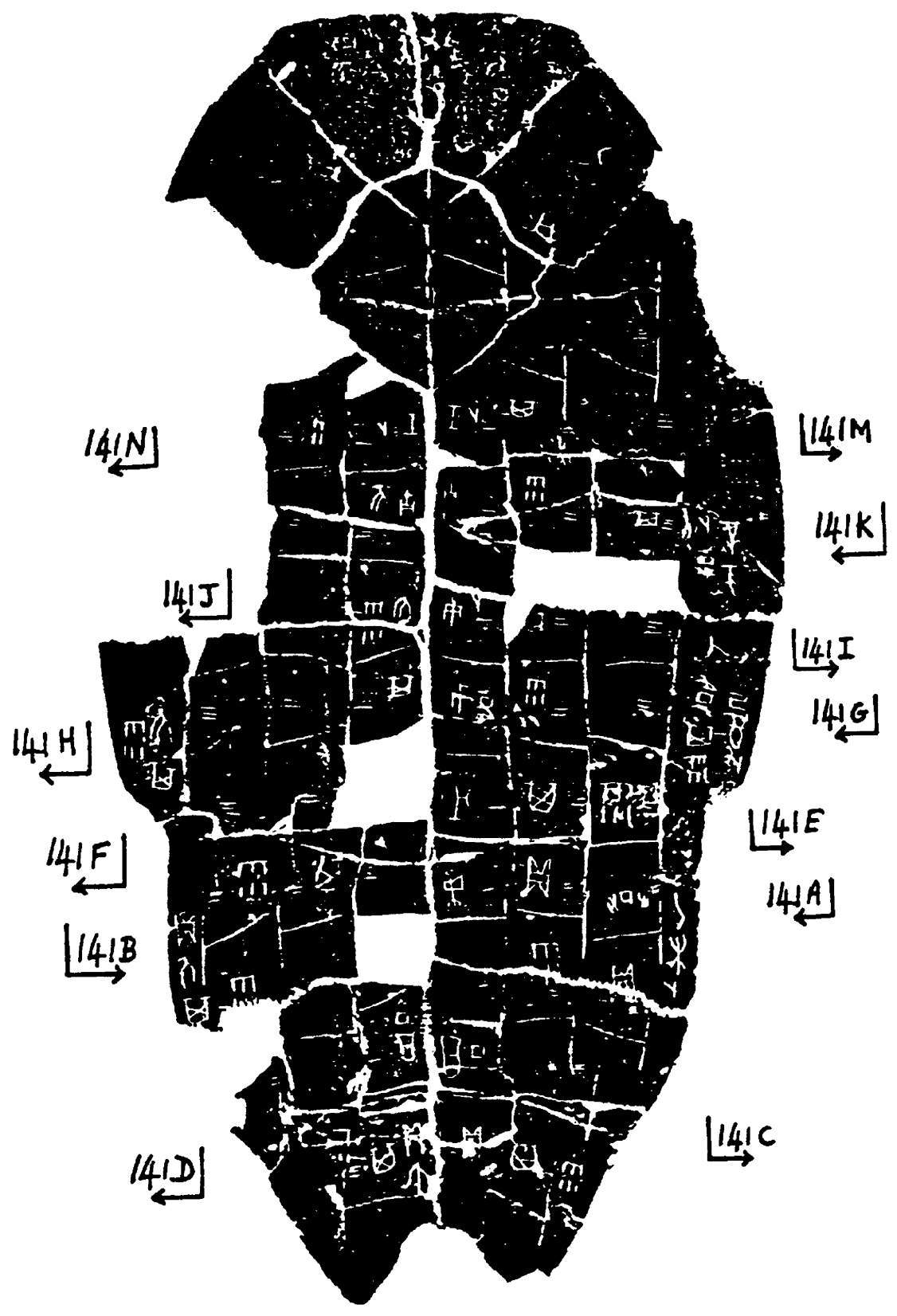

Fig. 7A. An abundance of gis (see too Fig. 7B). See $[141 \mathrm{~A}-\mathrm{N}]$ on page 127. (HJ 11892f) 


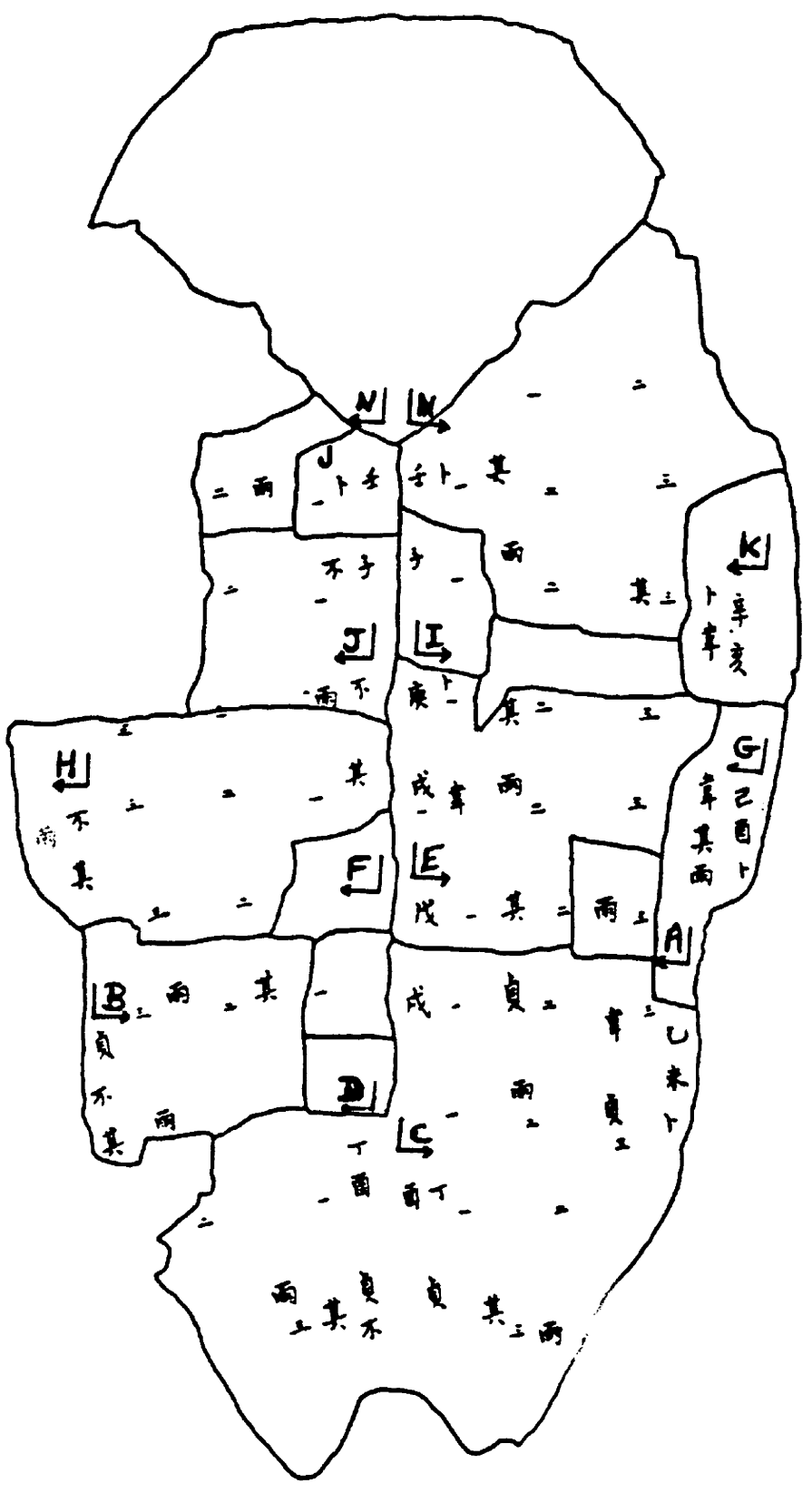

Fig. 7B. The modern graphs for the rubbing of Fig. 7A. (From Zhang Bingquan's tissue overlay to Bingbian 527.) 


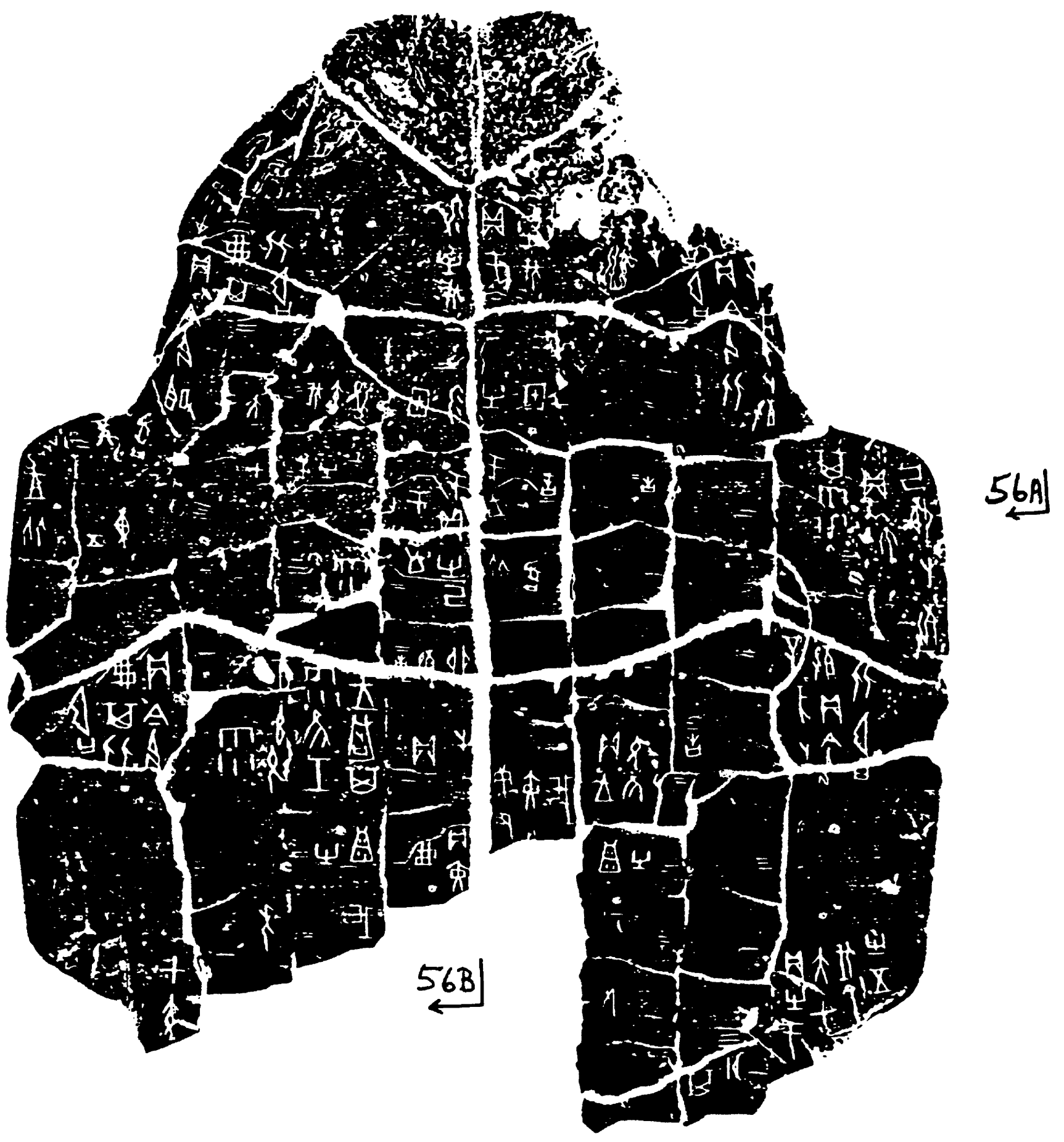

Fig. 8. Unconventional placement: desired charge on the left. See [56AB] on page 137. (HJ902f) 

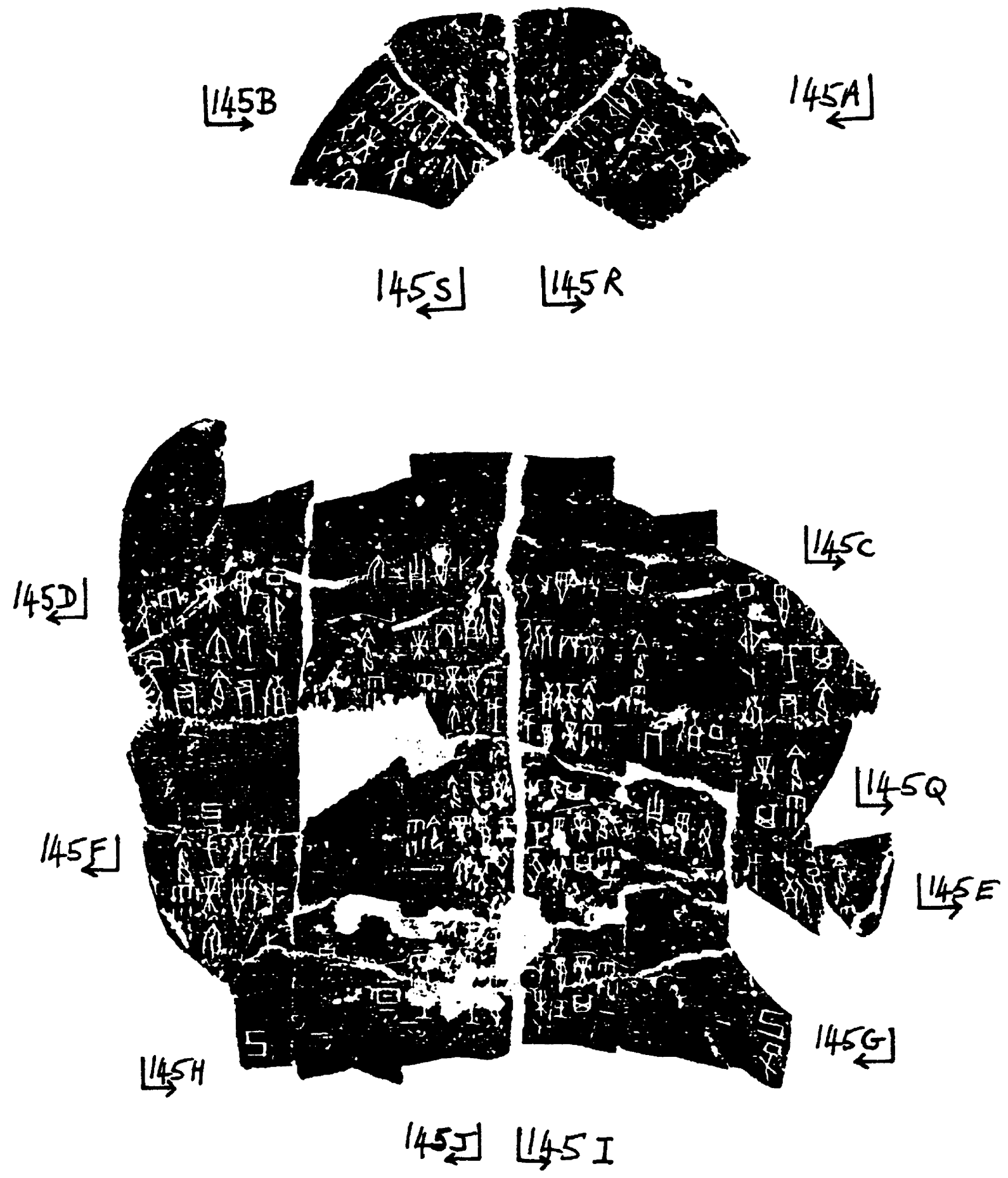

Fig. 9A. Deictic gi consistently placed on the right (see too Fig. 9B). See [145A-U] on page 141. (HJ 14153) 

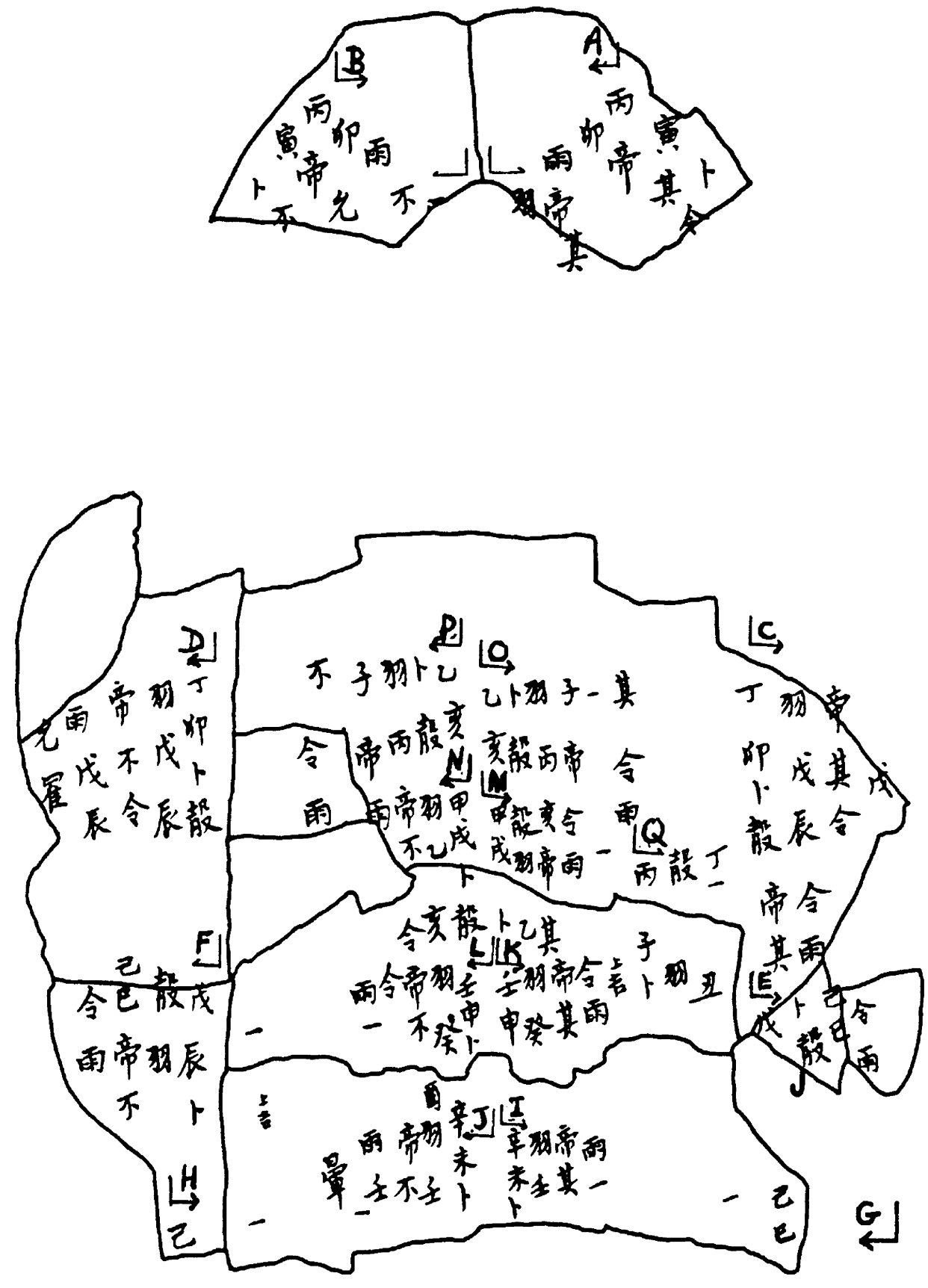

Fig. 9B. The modern graphs for the rubbing of Fig. 9A. (From Zhang Bingquan's tissue overlay to Bingbian 529.) 


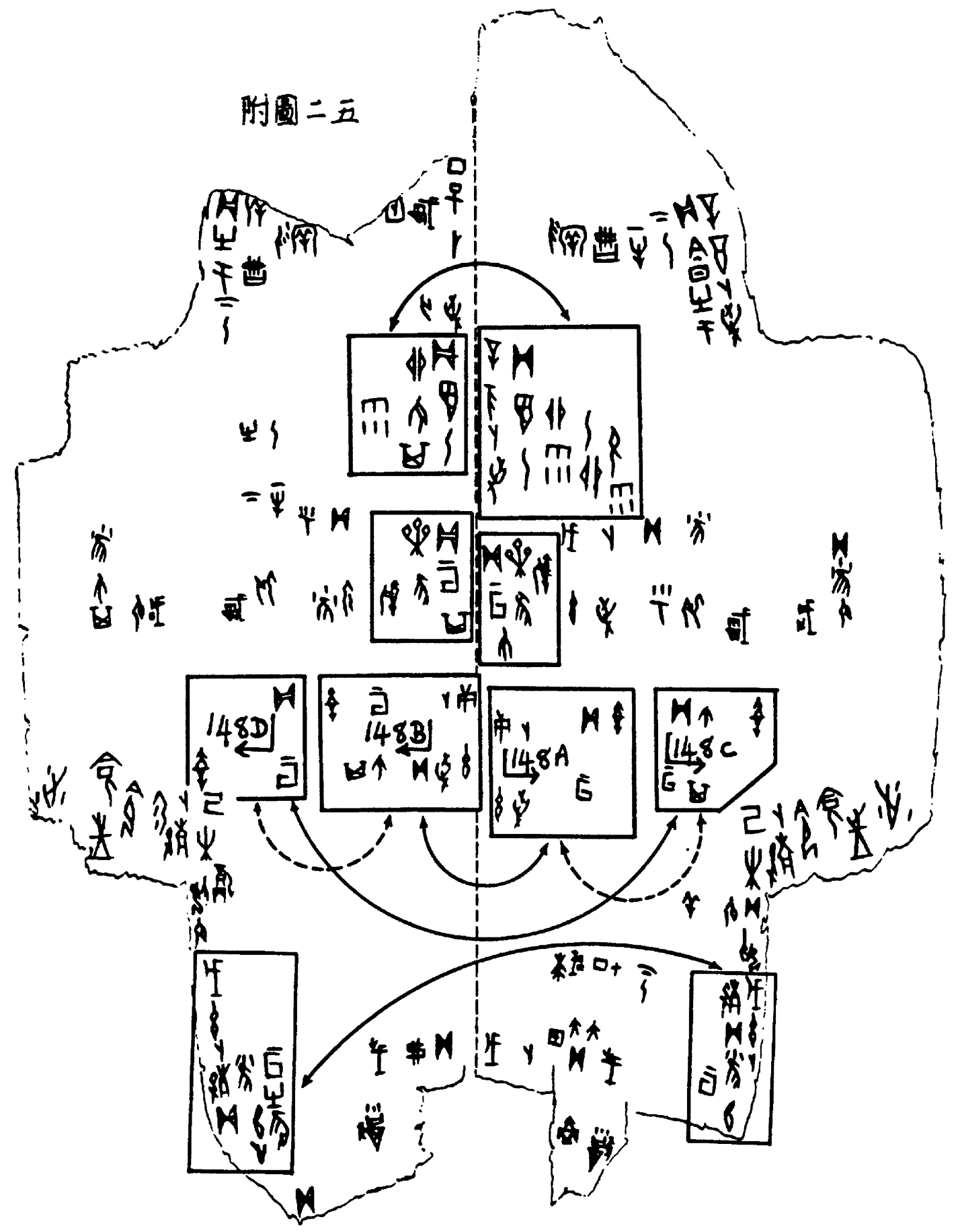

Fig. 10. Inconstancy of right and left placement. See [148A-D] on page 148. (Drawing from Zhou Hongxiang 1969:173, fig. 25.) (HJ 6947f) 

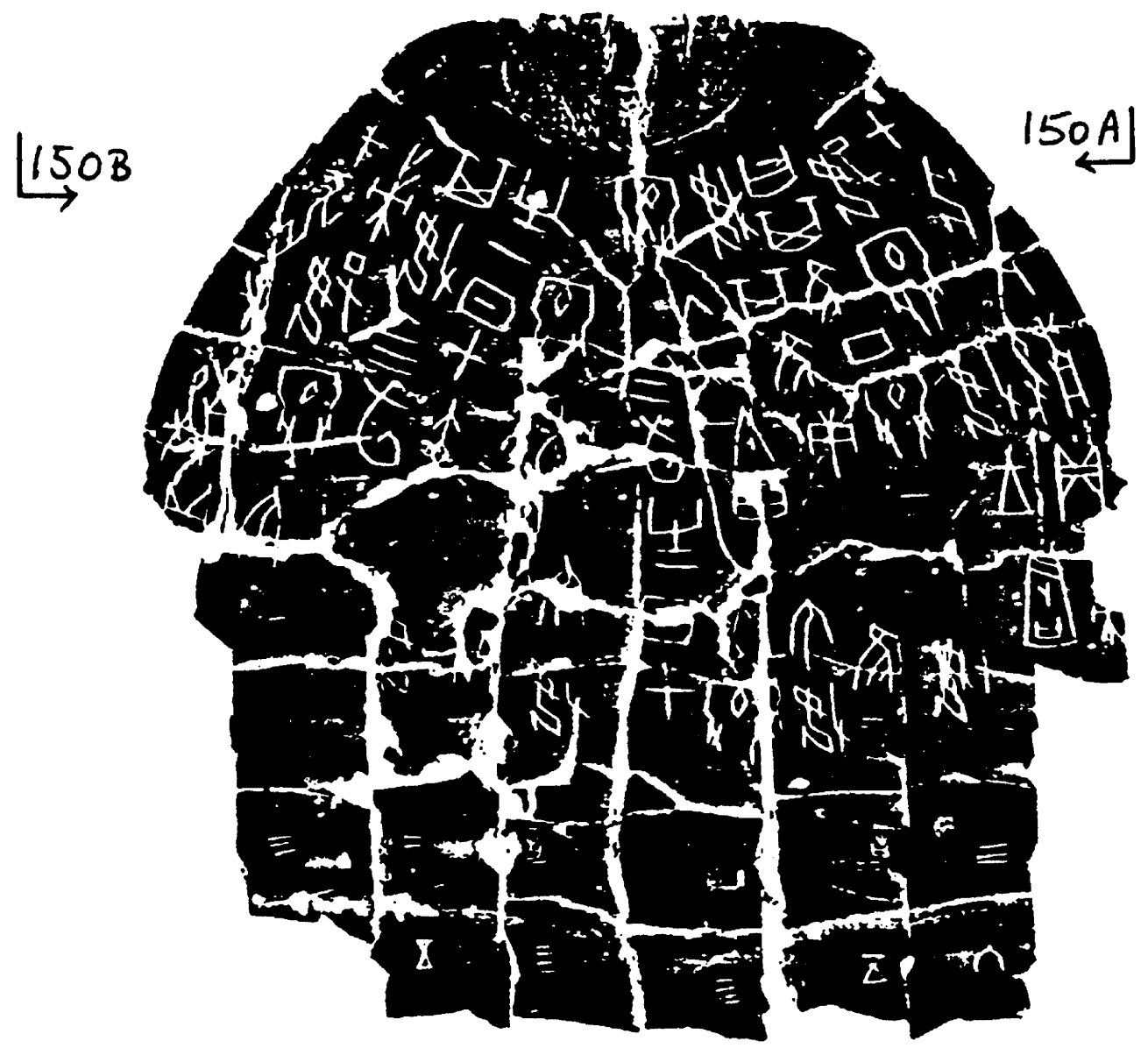

Fig. 11. Placement of prognostications and verifications. See [150AB] on page 156. (HJ 14002f) 


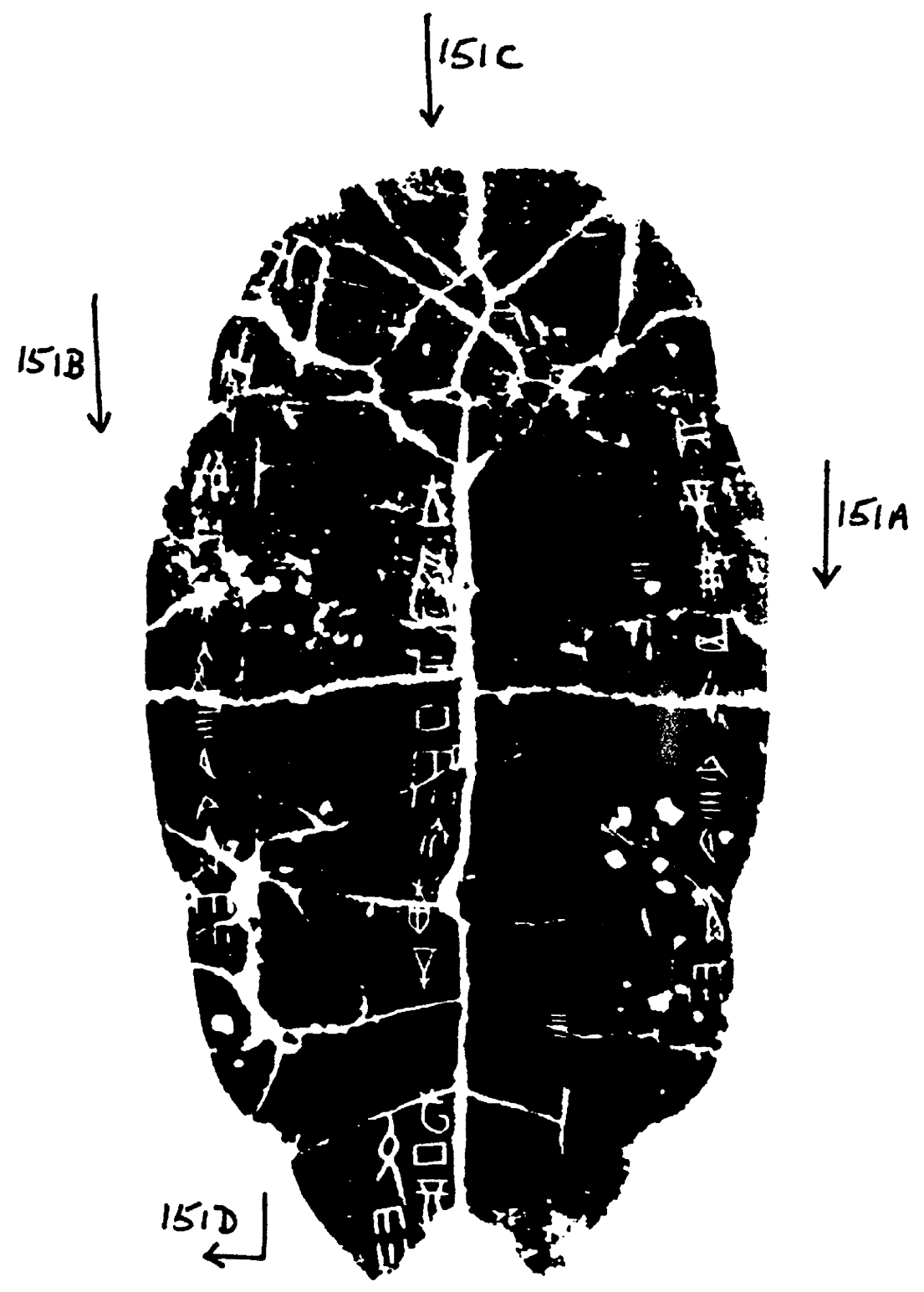

Fig. 12. Immediate fear and final hope. See [151A-D] on page 157 . ( $H J$ 14138) 


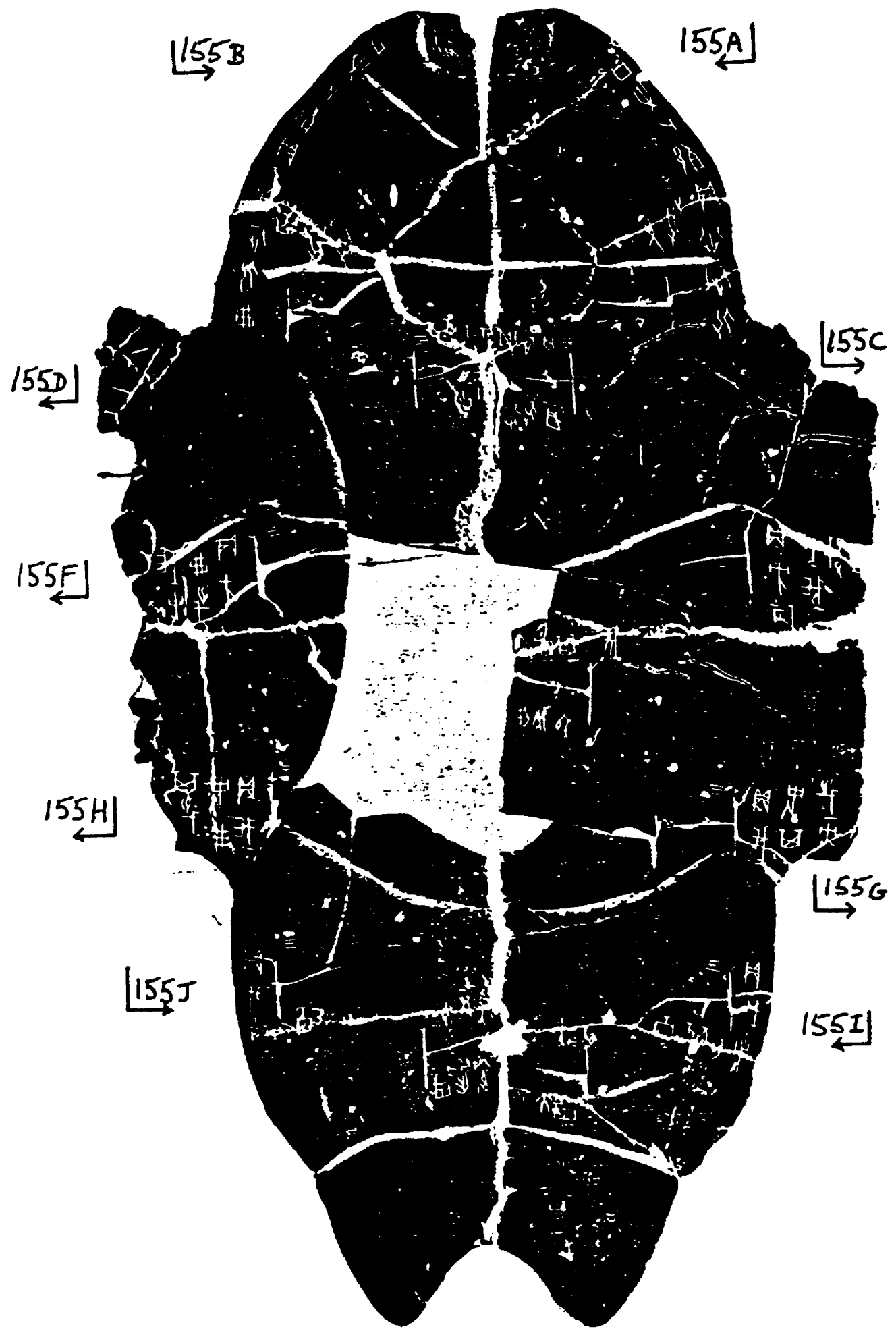

Fig. 13. A test of the divinatory conventions. See $[155 \mathrm{~A}-\mathrm{J}]$ on page 165 . ( $H J$ 9472f) 


\section{WORKS CI TED}

Allan, Sarah

1991

The Shape of the Turtle: Myth, Art, and Cosmos in Early

China. Albany: State University Press of New York.

Boltz, William G.

1994

The Origin and Early Development of the Chinese Writing

System. New Haven, Connecticut: American Oriental

Society. American Oriental Series 78.

Braunmuller, Kurt

1978

"Remarks on the Formation of Conjunctions in Germanic

Languages." Nordic Journal of Linguistics 1: 99-120.

Chen Yengjia 陳夢家

1956

Yinxu buci zongshu殷虚卜踥綜述. Beijing: Kexue.

Chow, Kwok-ching (Zhou Guozheng)

1982

"Aspects of Subordinative Composite Sentences in the Period I Oracle Bone Inscriptions." Ph.D. dissertation, University of British Columbia.

Cikoski, John S. 1978

"The Existence and Function of the so-called Modal chyi in

Classical Chinese--Three Essays on Classical Chinese

Grammar, II." Computational Analyses of Asian \& African

Languages 9:77-129.

Comrie, Bernard

1976

"Conditionals: A Typology." In Elizabeth Traugott, et

al., eds., On Conditionals. Cambridge: Cambridge

University Press. Pp. 77-99.

Djamouri, Redouane. 
"Études des formes syntaxiques dans les écrits oraculaires gravés sur os et écailles de tortue." Ph.D. dissert. Ecoles des hautes études en sciences sociales. Paris.

Dobson W. A. C. H. 1974

A Dictionary of the Chinese Particles with a prolegomenon in which the problems of the particles are considered and they are classified by their grammatical functions. Toronto: University of Toronto Press.

Gao Ming 高明 1980 Guwenzi leibian 古文字類编. Beijing: Zhonghua. Herforth, Derek Dane

1944

"Conditional Sentences in Old Chinese." Ph.D. diss., University of California at Berkeley.

Hopper, Paul, and Elizabeth Closs Traugott

Grammaticalization. Cambridge: Cambridge University Press.

Ikeda Suetoshi 池田末利

Inkyo shokei kôhen shakubun kô. 殷城書契後编釋文稿.

Hiroshima: Hiroshima daigaku bungakubu Chûgoku testsugaku kenkyûshitsu.

Ji Xiaojun 䔬小軍 1991

"Shuo jiagu wenzi zhong biao qiqiu yi de hui zi--Jian tan hui zi zai jinwen cheshi mingcheng ahong de yongfa 說甲骨金文中表祈求義的字-一兼談字在金文車飾名的中的 用法." Hubei daxue xuebao 湖北大學學報 1991.1:35-44.

Keightley, David N.

"The Sources of Shang History." Book ms.

1978

Sources of Shang History: The Oracle-Bone Inscriptions of Bronze Age China. Berkeley: University of California Press. 
1983

1988

1990

1991

1992

1993

1994

$1994 \mathrm{a}$

1995

in press
"The Late Shang State: When, Where, and What?" In Keightley, ed., The Origins of Chinese Civilization. Berkeley: University of California Press. Pp. 523-64. "Shang Divination and Metaphysics." Philosophy East and West $38: 367-97$.

"Sources of Shang History: Two Major Oracle-Bone Collections Published in the People's Republic of China." Journal of the American Oriental Society 110.1: 39-59. "Divination and Kingship in Late Shang China." Book ms. November 1991.

"Shang Charges and Prognostications: The Strong and the Weak?" 25th International Conference on Sino-Tibetan Linguistics, Berkeley. 15 October 1992. Manuscript. "Certainty and Control in Late Shang China: Modal Qi in the Oracle-Bone Inscriptions." 28 July 1993. Manuscript. "Executive $Q i$ in the Shang Oracle-Bone Inscriptions: A New Hypothesis." 30 January 1994. Manuscript.

"In the Bone: Divination, Theology, and Political Culture in Late Shang China." Pre-Modern China Seminar, Fairbank Center, Harvard University, 17 0ctober 1994.

"A Modest Proposal: The Translation of Oracular $Q i$ 其." 2 March 1995. Manuscript.

"Shang Oracle-Bone Inscriptions." In Edward L.

Shaughnessy, ed., New Sources of Early Chinese History: An Introduction to Reading Inscriptions and Manuscripts (Hong Kong: Chinese University of Press). Pp. 15-55.

in preparation (1) "Qi and Divinatory Conventions...."

in preparation (2) "Graphs and Meanings....."

Keightley, David N., and Jean A. Lefeuvre
"Oracle-Bone Periodization: A Tabular Guide to Recent Scholarship." In Keightley 1991, pp. 495-551. 
KJS

Matsumaru Michio 松凡道雄 and Takashima Kenichi 高鳦謙一. Kôkotsumoji Jishaku Sôran 甲需文字字程综䜿. Tokyo: Tokyo University Press, [1993, not for sale] 1994.

Liu Zhao 制釗

1986

"Shi zhe 释8." GWZY 15:229-34.

Matsumaru Michio 松凡道雄

1963

"Inkyo bokujichû) no denryôchi ni tsuite--Indai kokka kôzô kenkyû no tame ni 殷墟卜鿷中の田䰺について." Tôyô bunka kenkyîjo kiyo 洋文化研究所紀要 31:1-163.

Mizuno Hiroshi 水野宏

1960

"Teiji no gengi 禘字の原義." Kokugakuin daigaku kambun gakkaihô 國學院大學漢文字學會報 11：65-79.

Nivison, David S.

$\mathrm{XXXX}$

$1978 \mathrm{f}$

1992

"Grammar and History: A Paper Prepared for the Stanford Workshop on Oracle Bone Inscriptions." 2 January. WHAT YEAR???

"The Grammar and Theology of the King's Crack-Reading:

Supplement." Meeting of the American Oriental Society, Toronto. 12 April 1978.

"Modal Qi: Statement for the Sino-Tibetan Workshop." 25 th International Conference on Sino-Tibetan Linguistics, Berkeley. 15 October 1992. Manuscript.

1994

"Response to K. Takashima, "Towards a New Pronominal Hypothesis of $Q i$ in Shang Chinese'." Chinese Language, Thought and Culture, Essays Dedicated to David S. Nivison. Edited by P.J. Ivanhoe. (La Salle, Ill.: Open Court).. In press.

Pulleyblank, E.G. 1992

"Modal Qi 其--Comments on the Panel." 25th International Conference on Sino-Tibetan Linguistics, Berkeley. 15 October 1992. Manuscript. 
Qiu Xigui 豖錫圭 1982

1988

1989

1981

1986

Serruys, Paul L-M. 1974

"Buci 'yi'zi he Shi, Shu li de 'shi'zi 卜踥'異'字和詩, 書里的“式”字." Zhongguo yuyan xuebao 中國語言學報 1 (1982): 173-188.

"Guanyu Yinxu buci de mingci shi fou wenju de kaocha 開于殷墟卜的命是否問句的考察。” Zhongguo yuwen 中国語文 1988.1:1-20. (For an English version, see Qiu Xigui 1989.)

"An Examination of whether the Charges in Shang OracleBone Inscriptions Are Questions." Translated by Edward L. Shaughnessy. Early China 14:77-114, 165-72.

"The Language of the Shang Oracle Inscriptions." TP $60: 12-120$.

"Towards a Grammar of the Language of the Shang Bone Inscriptions." Zhongyang yanjiuyuan guoji Hanxue huiyi Iunwenji 中央研究院國際漢學會議論文集. Taibei. Pp. 313-64.

"Notes on the Grammar of the Oracular Inscriptions of Shang." Contributions to Sino-Tibetan Studies, eds. John McCoy and Timothy Light. Cornell Linguistic Contributions 5. Leiden: Brill. Pp. 203-57.

Shaughnessy, Edward L.

1993

"The Duke of Zhou's Retirement in the East: Conjectures on the Beginnings of the Ministerialist-Monarchist Debate in Chinese Political Philosophy." Early China 18: 41-72.

Smith, Arthur

1899

Village Life in China: A Study in Sociology. New York: Revell.

Takashima, Ken-ichi 1970

"Amphibolous $C h$ ' $i$ in the Bone Inscriptions of the King Wu Ting Period." Manuscript. October 1970. 
1973

1984

$1984-85$

1985

$1985 a$

$1988-89$

1989

1990

1991

1994

"Negatives in the King wu-ting Bone Inscriptions." Ph.D. dissertation, University of Washington.

"Nominalization and Nominal Derivation With Particular Reference to the Language of the Oracle-Bone Inscriptions." Papers in East Asian Languages 2:25-74.

"Noun Phrases in the Oracle-Bone Inscriptions." Monumenta Serica 36:229-302.

"On the Quantitative Completement in Oracle-Bone Inscriptions." Journal of Chinese Linguistics 13.1 (1985): 44-67.

Yinxu wenzi bingbian tongjian 殷虚文字丙编通檢. (A Concordance to Fascicle Three of Inscriptions from the Yin Ruins). Taibei: Zhongyuan yanjiuyuan lishi yuyan yanjiusuo.

"An Evaluation of the Theories Concerning the Shang Oracle-Bone Inscriptions." The Journal of Intercultural Studies (Kansai University) 15-16:11-54. (Abridged version of Takashima 1989.)

"Indai teiboku gengo no honshitsu 殷代員卜言語の本質." Tôyô bunka kenkyûjo kiyô 東洋文化研究所紀要 110:1-166. "A Study of the Copulas in Shang Chinese." The Memoirs of the Institute of Oriental Culture (University of Tokyo) $112: 1-92$.

"An Emphatic Verb Phrase in the Oracle-Bone Inscriptions." Memorial Volume of the Late Professor honor of Professor Li Fang-kuei Taibei: Institute of History and Philology. Pp. 663-704.

"Towards a New Pronominal Hypothesis of $Q i$ in Shang Chinese." Chinese Language, Thought and Culture, Essays Dedicated to David S. Nivison. Edited by P.J. Ivanhoe. (La Salle, Ill.: Open Court).. In press. I have ms of January 1994 . 
$1994 a$

"The Modal and Aspectual Particle $Q i$ in Shang Chinese."

Papers of the First International Congress on Pre-Qin

Chinese Grammar. Eds. Robert H. Gassman and He Leshi.

Changsha: Yuelu shushe, 1994. Pp. 479-565.

Von Falkenhausen, Lothar

1993

"Issues in Western Zhou Studies: A Review Article." Early

China 18:137-226.

Xie Ji 謝濟

1982

"Shilun Lizu buci di fengi 試論程組卜的分期." In Hu Houxuan et al., Jiagu tan shilu. Beijing: Sanlian. Pp. 87-111.

Yang, Shuda

1986

Ciquan 詞詮. Shanghai: Guji chubanshe. Vol. 3 of Yang Shuda wenj $i$ 楊樹達文集.

Yan Yiping 嚴一萍

1978

Jiaguxue 甲骨學. Taibei: Yiwen. 2 vols.

Yao Xiaosui 姚孝遂

1985

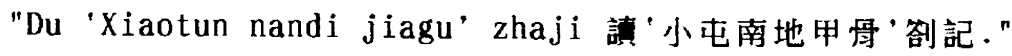

GWZY 12:107-24.

$1985 a$

Xiaotun nandi jiagu kaoshi 小屯南地甲霄考䆁。Beijing：

Zhonghua.

Yu Xingwu 于省吾

1979

"Shi qi 䆄其." In Yu Xingwu Jiaguwen $z i$ shilin

甲骨文字䆁林。Beijing：Zhonghua，Pp.427-31。

Zhao Cheng 趙誡

1988

Jiaguwen jianming cidian: Buci fenlei duben

甲骨文簡明詞典：卜鿷分類謮本。Beijing：Zhonghua。

Zhou Guozheng 周國正

1983

"Buci liangzhong jisi dongci de yufa tezheng $j i$ youguan juzi de yufa fenxi 卜踥兩㮔祭祀的語法特徽及有閵句子的 語法分析." Guwenzixue lunji: Guoji Zhongguo wenzixue 
yantaohui 古文學論集：國際中國古文字學研究會. Hong Kong： Xianggang Zhongwen daxue 香港中文大學. Pp. 00-00.

Zhou Hongxiang 周鸿銿

1969

Buci duizhen shuli 卜踥䍌賁述例. Hongkong.

Zhu Qixiang 朱歧祥

1990

Yinxu buci jufa lungao--duizhen buci juxing bianyi yanjiu

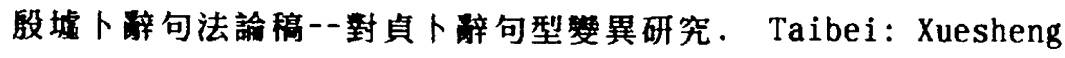
shuju

1994

"Yinxu buci de mingci shi wenju kaobian

殷城卜鲜是問句考辫." Manuscript. 19 pp. 
FINDING LIST OF INSCRIPTIONS CITED

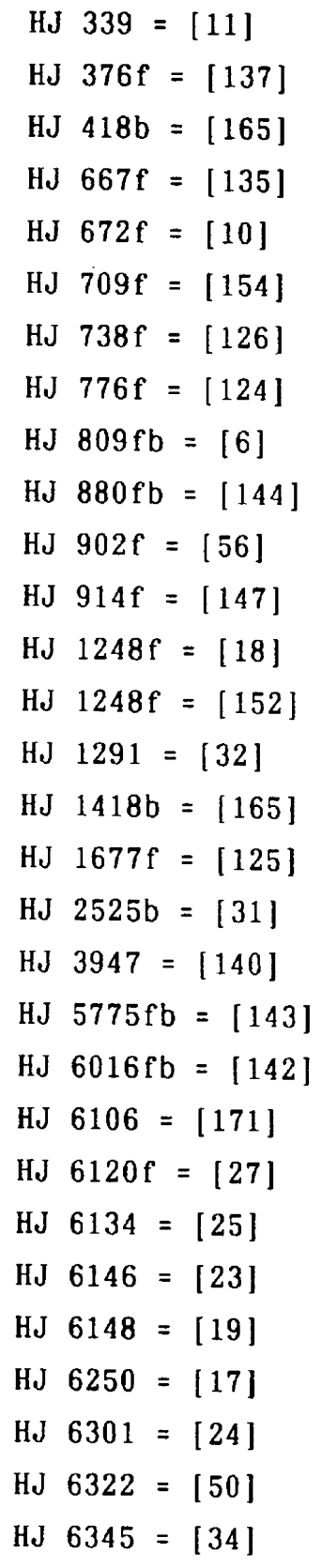
HJ $6347=[35]$
HJ $13626=[21]$
HJ $6349=[36]$
HJ $13646 \mathrm{f}=[20]$
HJ $6385 f=[22]$
HJ $13670=[26]$
HJ $6442=[52]$
HJ $13758 b=[174]$
HJ $6482=[134]$
HJ $14001 \mathrm{f}=[153]$
HJ $6610 \mathrm{f}=[29]$
HJ $14002 \mathrm{fb}=[150]$
HJ $6647 \mathrm{f}=[162]$
HJ $14138=$ [151]
HJ $6657 \mathrm{f}=[53]$
HJ $14153 \mathrm{fb}=[145]$
HJ $6672=[30]$
HJ $14161 b=[8]$
HJ $6771 \mathrm{fb}=[156$ ]
HJ $14161 b=[168]$
HJ $6943=[2]$
HJ $14206 \mathrm{f}=[157]$
HJ $6943=[170]$
HJ $17407 \mathrm{f}=[128]$
HJ $6947=[148]$
HJ $17409 \mathrm{f}=[127]$
HJ $7084=[28]$
HJ $19824=[37]$
HJ $7352=[146]$
HJ $19887=[40]$
HJ $7772 \mathrm{f}=[133]$
HJ $19923=[38]$
HJ $9472 \mathrm{f}=[155]$
HJ $20007=[12]$
HJ $9628=[33]$
HJ $20384=[39]$
HJ $9950 \mathrm{f}=[83]$
HJ $20398=[47]$
HJ $10067=[15]$
HJ $20408=[48]$
HJ $11497=[123]$
HJ $20410=[42]$
$\mathrm{HJ} 11892 \mathrm{f}=[141]$
HJ $20413=[49]$
HJ $12311 \mathrm{fb}=[7]$
HJ $20470=[57]$
HJ $12436=[\mathrm{A} .2]$
HJ $20475=[45]$
$\mathrm{HJ} 12487 \mathrm{f}=[149]$
HJ $20480=[44]$
HJ $12883=[3]$
HJ $20616=[51]$
HJ $12908=[139$ ]
HJ 20706b $=[41]$
$\mathrm{HJ} 12939 \mathrm{f}=[138]$
HJ $20912=[55]$
HJ $12974=[A .1]$
HJ $20923=[59]$
HJ 13220a $=[166]$ 


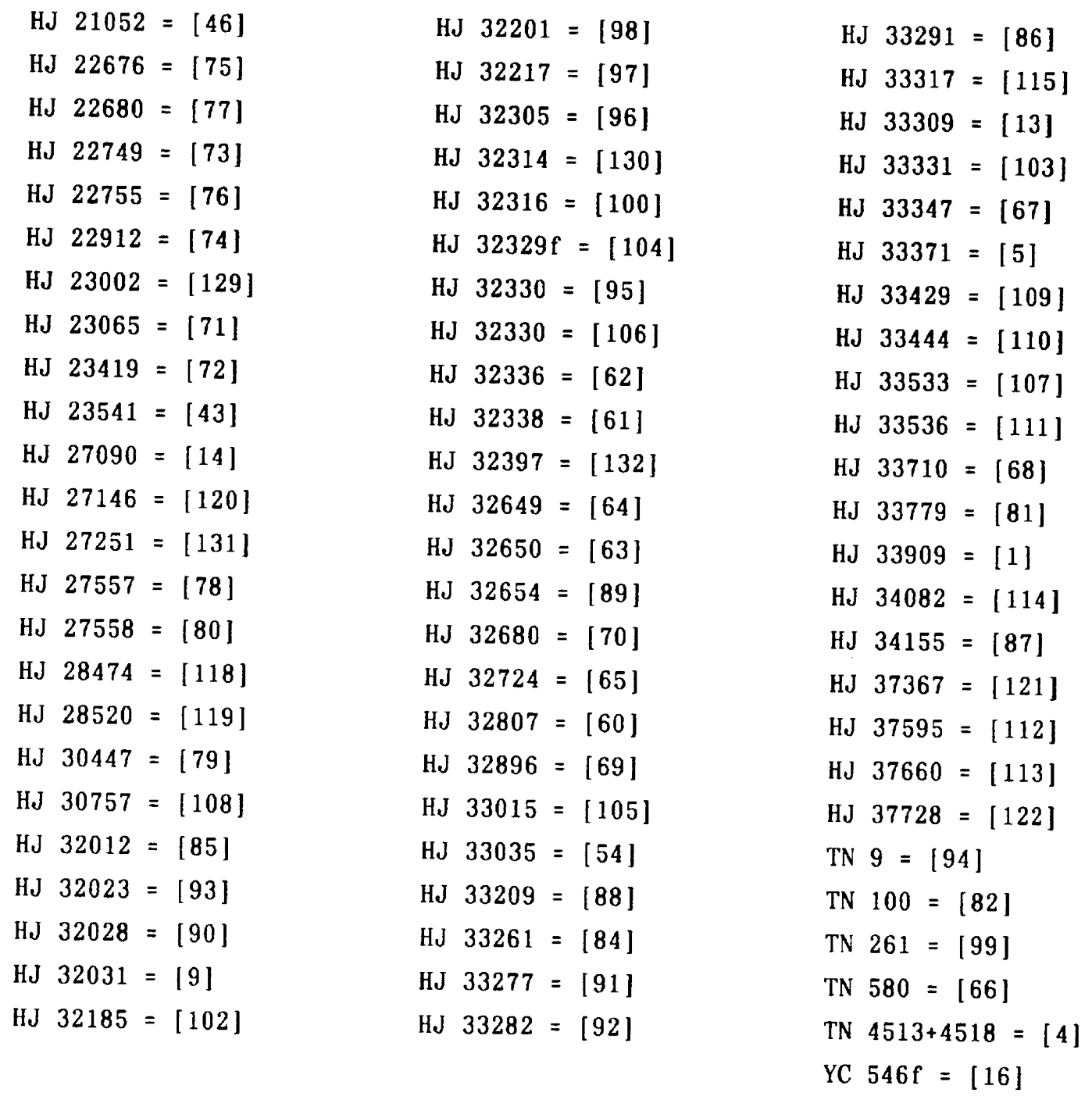

